
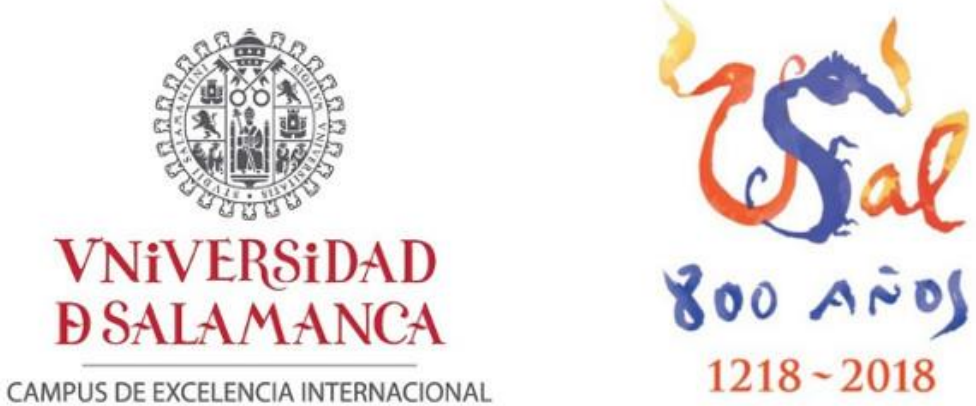

1218 - 2018

\title{
COMPARACIÓN DE LA EFICACIA DE DOS TÉCNICAS DE FISIOTERAPIA EN EL DAÑO CEREBRAL ADQUIRIDO
}

Tesis Doctoral

Ana Domínguez García

Directores de Tesis

Dr. José Ignacio Calvo Arenillas

Dr. Carmelo Antonio Ávila Zarza 


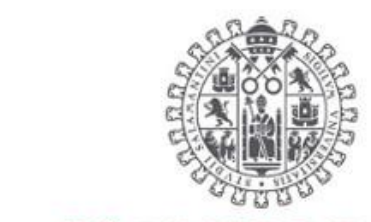

VNIVERSIDAD

BSALAMANCA

CAMPUS DE EXCELENCIA INTERNACIONAL

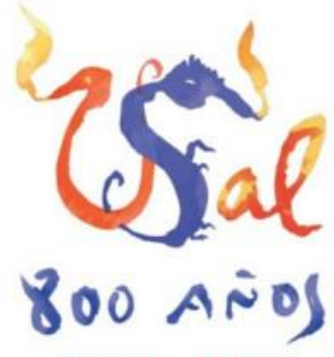

1218 - 2018

Departamento de Medicina

\section{COMPARACIÓN DE LA EFICACIA DE DOS TÉCNICAS DE FISIOTERAPIA EN EL DAÑO CEREBRAL ADQUIRIDO}

Tesis Doctoral

Ana Domínguez García

Directores de Tesis

Dr. José Ignacio Calvo Arenillas

Dr. Carmelo Antonio Ávila Zarza 
Los doctores D. José Ignacio Calvo Arenillas y D. Carmelo Antonio Ávila Zarza, profesores de la Universidad de Salamanca.

\section{CERTIFICAN:}

Que la tesis doctoral titulada "Comparación de la eficacia de dos técnicas de fisioterapia en el Daño Cerebral Adquirido”, realizada por Dña. Ana Domínguez García para optar al grado de Doctor por la Universidad de Salamanca, cumple todos los requisitos necesarios para su presentación y defensa ante el Tribunal que legalmente proceda.

Y para que conste, expedimos el presente certificado en Salamanca a 7 de marzo de 2017.

Fdo. Dr. D. José Ignacio Calvo Arenillas Catedrático de Escuela Universitaria
Fdo. Dr. Carmelo Antonio Ávila Zarza

Profesor Titular de Universidad 
RESUMEN 


\section{AGRADECIMIENTOS}

Gracias en primer lugar y de corazón a mis tutores. A José Ignacio Calvo, Checho, por acompañarme en esta aventura investigadora desde el inicio y no dejar nunca que flaqueasen las fuerzas.

A Carmelo, por su dedicación y esfuerzo durante todo el proceso. Por haberse molestado en entender que la fisioterapia también necesita de los complejos métodos estadísticos para avanzar, y por haber hecho el esfuerzo de acercármelos con su gran talento docente.

Gracias por vuestra infinita paciencia

A los fisioterapeutas que trabajan en el servicio rehabilitador de ASDACE: Jesús Orejuela y Fátima Pérez. Por vuestra disposición y asesoramiento en los aspectos técnicos del estudio. Vuestros consejos e interés han permitido a este proyecto hacerse realidad.

A los compañeros del Hospital Provincial de Salamanca; en especial al fisioterapeuta José Fonseca Velasco que dio luz verde a esta investigación y mostró en todo momento su interés por ella, enviando pacientes candidatos a participar.

A mis compañeros del proyecto de Revitalización Geriátrica y Terapia Ocupacional de la Universidad de Salamanca: José Enrique Artigas, Beatriz Bermejo, Ana María Sánchez, Juan Luis Sánchez, Celia Sánchez y en especial a nuestro coordinador Fausto José Barbero. Gracias por vuestra confianza, ánimo y apoyo en esta causa.

Al Área de Fisioterapia de la Universidad de Salamanca, desde mi etapa como estudiante habéis sido un referente. Gracias por haberme facilitado las cosas y no haberme puesto nunca ningún impedimento en la realización de este trabajo. A todos los que formáis parte de ella, gracias.

A mi familia: papá y mamá; que me inculcaron que el sacrificio y el esfuerzo tienen siempre una recompensa, y la mía ha llegado en el día de hoy. A mi hermano Juan, que siempre me ha enseñado a no tirar la toalla y creer en mí misma. 


\section{RESUMEN}

A mi pareja, Luis. Por aguantar las largas tardes de estudio, reemplazarme en tantas tareas: "vete a estudiar, que yo puedo hacerlo" y en definitiva ser parte indispensable de este trabajo y como no, de mi vida.

A mis amigos de siempre, por el apoyo y los ánimos. Os debo muchas horas de ocio.

Gracias a todos por hacer este proyecto realidad. Ojalá que el tiempo que os he robado sirva para que valoréis que el esfuerzo y la constancia son necesarios para conseguir las metas que nos proponemos en la vida. 
El éxito depende del esfuerzo

Sófocles

A todos

los que me habéis acompañado en el camino

GRACIAS 
RESUMEN 


\section{RESUMEN}

INTRODUCCIÓN: El daño cerebral adquirido es un amplio término en el que se engloban las agresiones que acontecen en el cerebro y que no tienen una etiología congénita o perinatal En España afecta a 420.000 personas de las cuales el 78\% de los casos tuvieron su origen en un ictus. La fisioterapia es el tratamiento rehabilitador de elección para hacer frente al problema, habiendo para ello una gran variedad de abordajes terapéuticos.

OBJETIVO: Determinar la eficacia de la terapia Vojta en el tratamiento de la rigidez del hombro en pacientes adultos con daño cerebral adquirido respecto la fisioterapia convencional.

MATERIAL Y MÉTODOS: Se plantea un estudio de tipo experimental prospectivo mediante un ensayo clínico de grupos en paralelo, con un seguimiento de 9 meses. Los evaluadores del proyecto no formaron parte del equipo terapéutico del mismo.

El estudio se llevó a cabo entre Octubre del 2014 y Junio del 2015 en la Unidad Docente Asistencial de la Universidad de Salamanca y en el Hospital Provincial de Salamanca, España.

Se abordaron 48 pacientes con diagnóstico de daño cerebral adquirido que cumplieron los criterios de inclusión. Doce pertenecieron a la Unidad Docente Asistencial y recibieron terapia Vojta junto con facilitación neuromuscular propioceptiva (Grupo 1) y treinta y seis al Hospital Provincial, (Grupo 2), en el que se realizaron sesiones de fisioterapia con FNP. Todos ellos recibieron 2 sesiones de tratamiento de fisioterapia semanales, en días alternos de 45 minutos de duración. Se realizaron tres evaluaciones; basal, en la mitad del estudio y al finalizar el mismo. Se evaluó el estado de salud percibido por el paciente mediante el cuestionario SF-36, el grado de independencia mediante los cuestionarios MIF e IB así como el balance articular de hombro mediante goniometría. Se comparó estadísticamente el resultado entre los dos grupos mediante test paramétricos.

RESULTADOS: En ambos grupos los pacientes mejoraron significativamente su puntuación inicial en los cuestionarios SF-36, MIF motor e IB y en los resultados de balance articular de hombro.

Dentro del grupo 1, no se observaron diferencias significativas en el balance articular de los individuos atendiendo a su etiología

Comparando un grupo y otro, transcurridos 9 meses del inicio del estudio se establecieron significaciones estadísticas en todos los movimientos analizados: abducción (sig= 0,009), extensión ( $\operatorname{sig} 0,022)$, flexión $(\operatorname{sig}=0,001)$, rotación externa $(\operatorname{sig}=0,002)$ y rotación interna $(\operatorname{sig}=0,000)$.

También se establecieron diferencias significativas entre los grupos en la percepción final de la salud, evaluada con el SF-36. ( sig=0,001) 


\section{RESUMEN}

En el grado de dependencia final la significación fue de 0,02 en el cuestionario MIF y de 0,006 en el IB

Por otro lado se estableció una alta correlación entre la puntuación obtenida con la MIF y el IB de manera general $(\rho=0,948)$ y de manera específica entre los subítems alimentación (MIF) y comer (IB) $(\rho=0,943)$.

$\mathrm{Al}$ analizar mediante técnicas multivariante el cuestionario SF-36; se observa un posicionamiento de los pacientes distinto en función del tratamiento recibido en el plano factorial de dimensión reducida determinado por las dos variables latentes obtenidas en el análisis de correspondencias múltiples.

CONCLUSIONES: El rango articular de hombro aumenta con la fisioterapia aplicada; siendo mayor el conseguido en los pacientes sometidos a terapia Vojta y FNP respecto a los que sólo realizaron FNP. Dicha mejoría es más evidente en los movimientos de flexión y rotación interna. El estado general de salud dentro del estudio de calidad de vida aumentó tras 9 meses de tratamiento en ambos grupos; siendo mayor en el grupo tratado con terapia Vojta. El IB y la MIF son escalas con alta correlación y miden la discapacidad, útiles para valorar los cambios que se han producido y que expresan la mejoría funcional del grupo de terapia con Vojta respecto al grupo que recibió únicamente FNP.

PALABRAS CLAVE: Daño Cerebral Adquirido, Facilitación Neuromuscular Propioceptiva, Terapia Vojta, calidad de vida, hombro. 


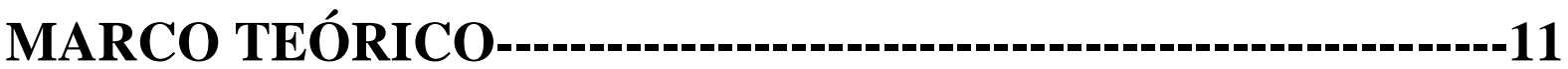

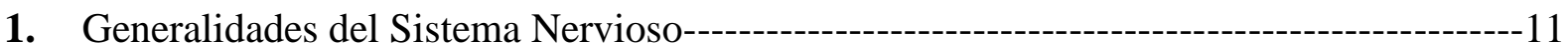

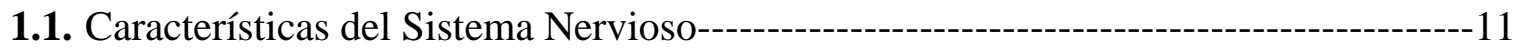

1.1.1.Fisiología del comportamiento motor: centros y vías motoras--------------------11

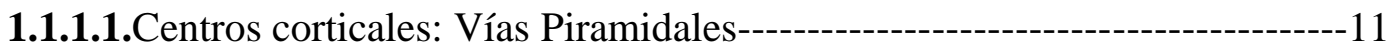

1.1.1.2. Centros subcorticales: Vías Extrapiramidales--------------------------------12

1.1.1.3.Lesiones de los centros y vías motoras------------------------------------13

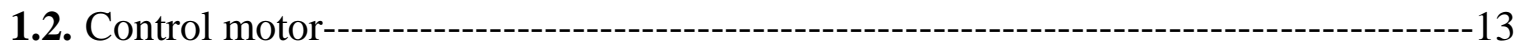

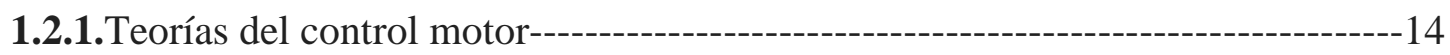

1.2.2.Aprendizaje motor-----------------------------------------------------------17

1.2.2.1.Teorías sobre el aprendizaje motor-----------------------------------------17

1.2.2.2.Fases en la formación del programa motor----------------------------19

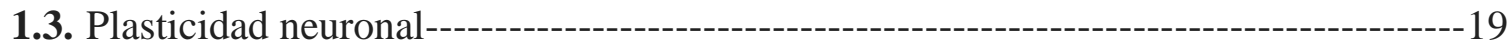

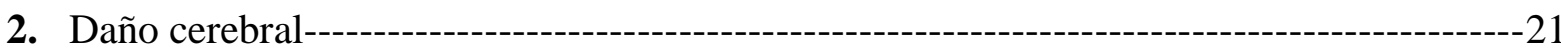

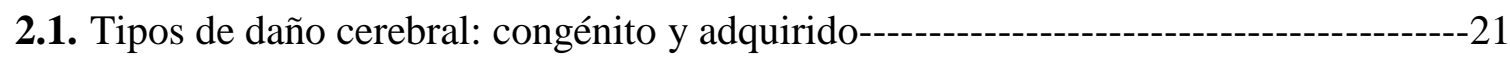

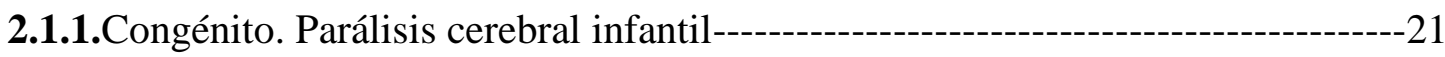

2.1.1.1.Clasificación clínica de la PCI--------------------------------------------------22

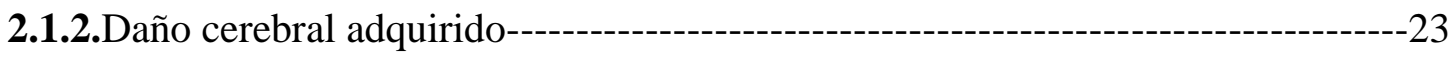

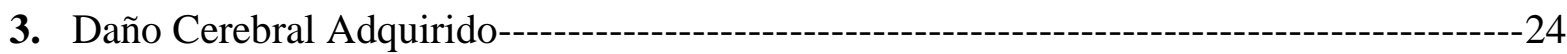

3.1. Clasificación etiológica del Daño Cerebral Adquirido------------------------------24

3.1.1.Accidente Cerebro Vascular---------------------------------------------------------25

3.1.2.Esclerosis Múltiple------------------------------------------------------------------26

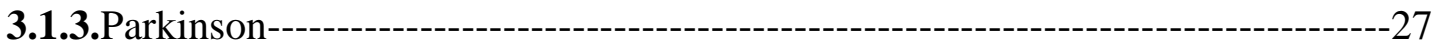

3.1.4.Traumatismo Cráneo-Encefálico, TCE-----------------------------------------------28

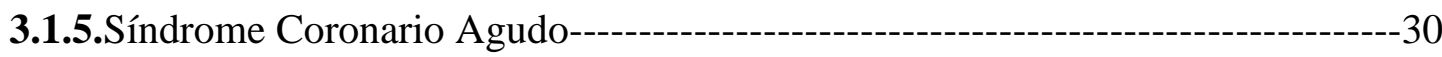

3.2. El Daño Cerebral Adquirido en cifras----

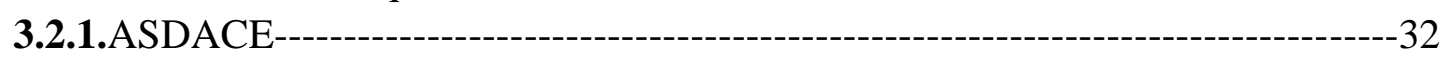

3.3. Características comunes del Daño Cerebral Adquirido. Rigidez de hombro-----------32

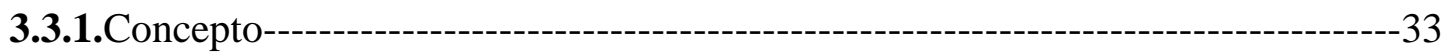

3.3.2.Etiología de la rigidez de hombro en el DCA----------------------------------34

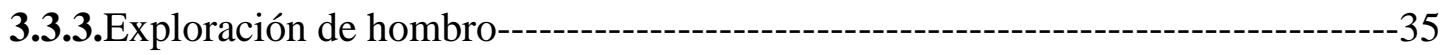

4. Evaluación en fisioterapia del Daño Cerebral Adquirido------------------------------39

4.1. Modelo ICF (Clasificación Internacional del Funcionamiento)-------------------39

4.1.1.Instrumentos de medida según el modelo ICF----------------------------------41

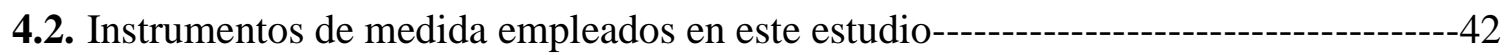

• IB----------------------------------------------------------------------------43

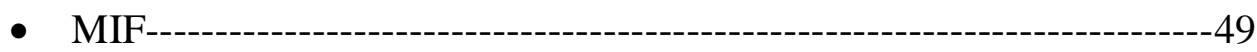

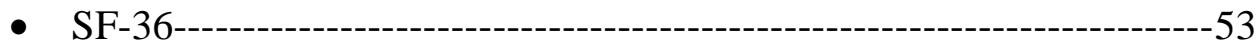


4.3. Evaluación del tono y las reacciones posturales a la movilización en la lesión cerebral adquirida$-57$

4.3.1.Escala de la espasticidad de Ashworth--------------------------------------------58

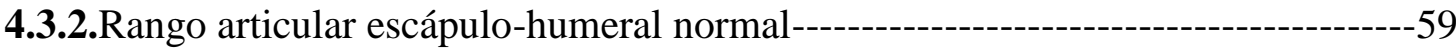

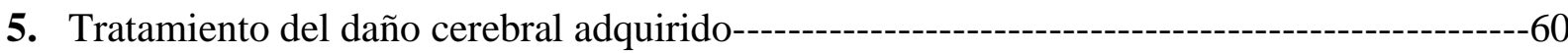

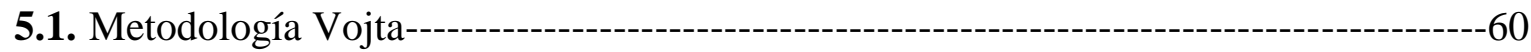

5.1.1.Origen del método-----------------------------------------------------------------------60

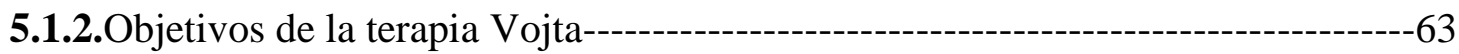

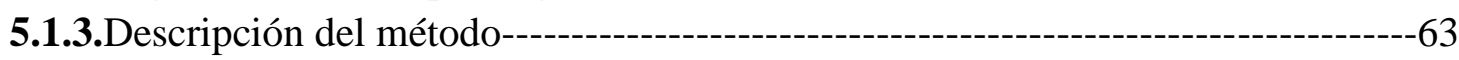

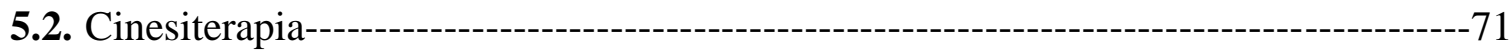

5.2.1.Clasificación de la cinesiterapia---

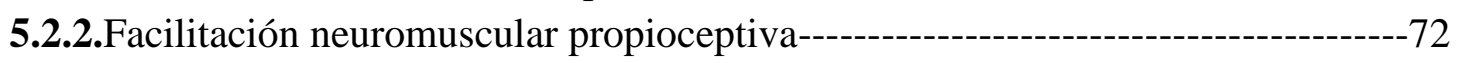

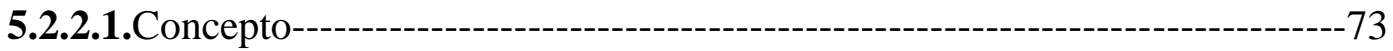

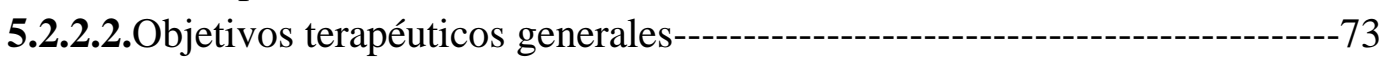

5.2.2.3.Procedimiento general en FNP-----------------------------------73

5.2.2.4.Procedimiento específico en FNP--------------------------------74

5.2.2.5.La estabilización de la articulación del hombro y la zona escapular-------76

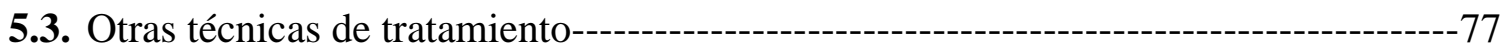

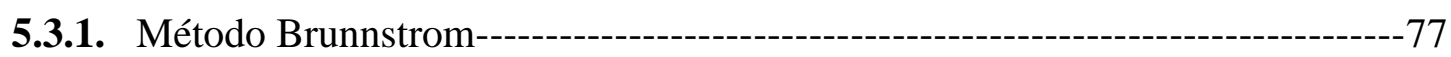

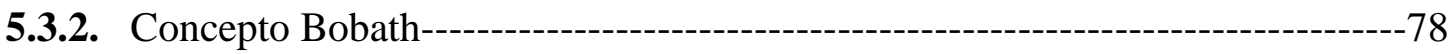

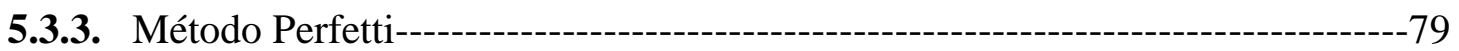

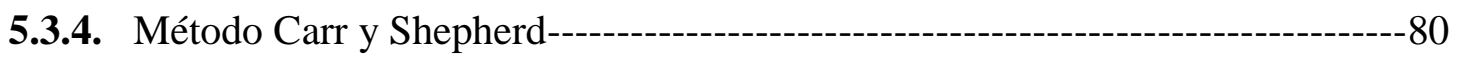

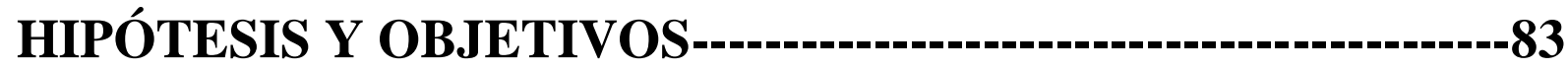

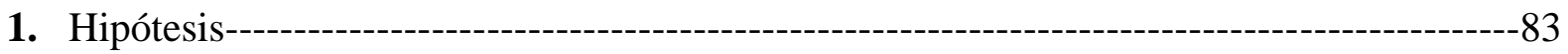

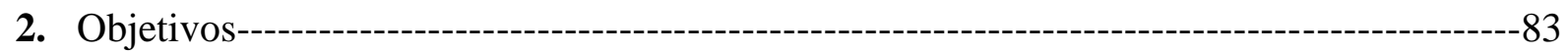

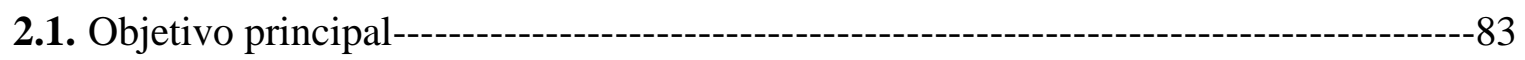

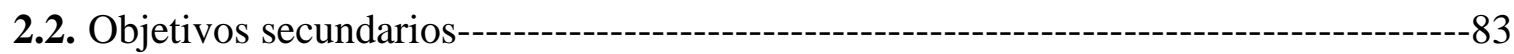




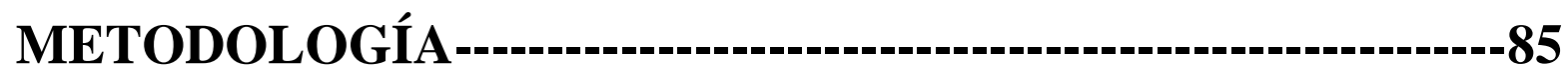

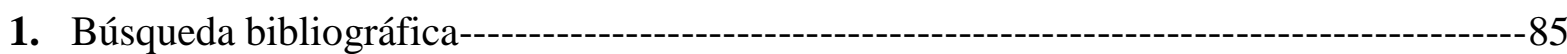

2. Diseño de estudio---------

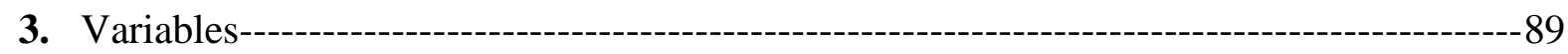

4. Muestra-----------------------------------------------------------------------------------------------91

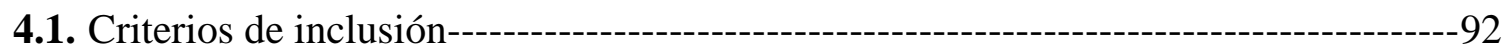

4.2. Criterios de exclusión-----

4.3. Perfil sociodemográfico de los individuos--------------------------------------------92

5. Valoración de los participantes---

5.1. Metodología de valoración del balance articular: Sistema SFTR-----------------------94

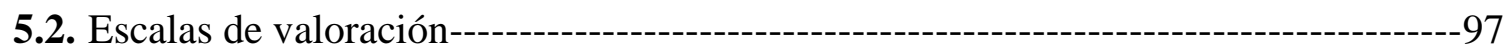

6. Naturaleza de las sesiones realizadas---------------------------------------------------------97

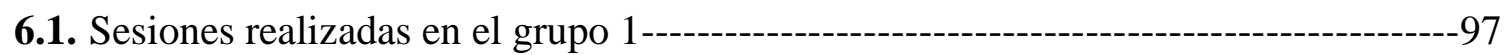

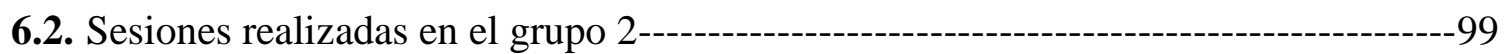

7. Análisis estadístico-------------100

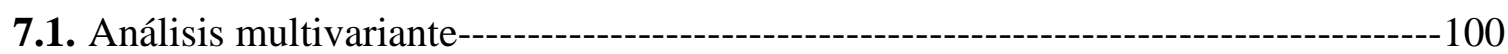

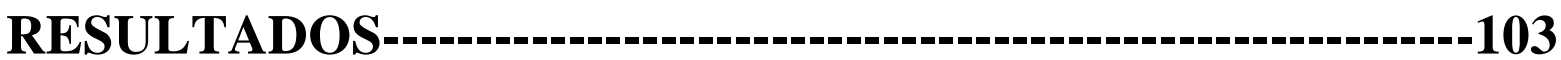

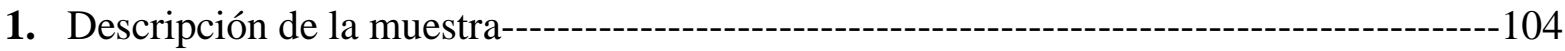

2. Aspectos sociodemográficos grupo 1---------------------------------------------------------104

3. Aspectos sociodemográficos grupo 2---------107

4. Descripción de los resultados en las mediciones de balance articular--------------------109

5. Balance articular de individuos afectados del hemicuerpo izquierdo. Grupo 1---------113

5.1. Resultados del balance articular según etiología--------------------------------116

5.2. Resultados del balance articular según sexo------------------------------117

5.3. Resultados del balance articular según antigüiedad-----------------------------------118

6. Balance articular de individuos afectados del hemicuerpo izquierdo. Grupo 2-----------119

6.1. Resultados del balance articular según etiología-------------------------------122

6.2. Resultados del balance articular según sexo------------------------------------------123

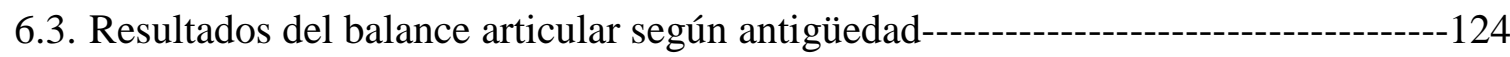

7. Categorización de los individuos afectados del hemicuerpo izquierdo. Grupos 1 y 2---125

8. Balance articular de individuos afectados del hemicuerpo derecho. Grupo 1------------128

8.1. Resultados del balance articular según etiología--------131

8.2. Resultados del balance articular según sexo-------------------------------------132

8.3. Resultados del balance articular según antigüedad---------------------------------133

9. Balance articular de individuos afectados del hemicuerpo derecho. Grupo 2-----------134

9.1. Resultados del balance articular según etiología------------------------------------136

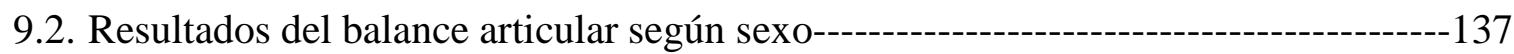

9.3. Resultados del balance articular según antigüedad----------------------138

10. Categorización de los individuos afectados del hemicuerpo derecho. Grupos 1 y 2------139

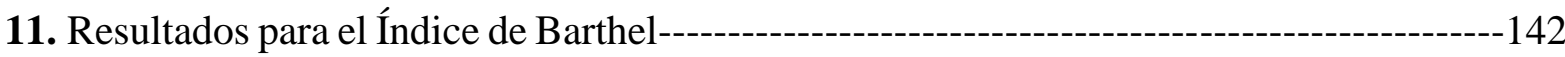


12. Resultados para la Medida de la Independencia Funcional Motora------------------------148

13. Resultados para el cuestionario SF-36--------------------------------------------150

14. Análisis de resultados goniométricos de los individuos afectados del hemicuerpo izquierdo

14.1.Análisis de los individuos del grupo uno con etiología ACV frente a otras etiologías-

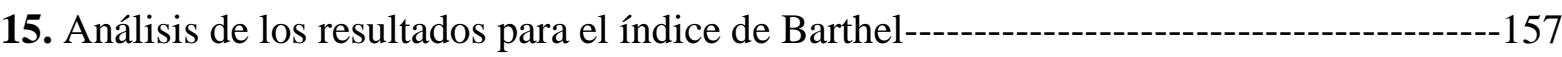

15.1.Comparación de los resultados en el Índice de Barthel. Grupos 1 y 2.------------157

15.2.Comparación de los resultados del Índice de Barthel inicial y final------------------158

16. Análisis de los resultados para la Medida de la Independencia Funcional Motora-------158

16.1.Comparación de los resultados en el Medida de la Independencia Funcional Motora.

Grupos 1 y 2

16.2. Comparación de los resultados en la Medida de la Independencia Funcional Motora inicial y final------------------------------------------------------------------------------159

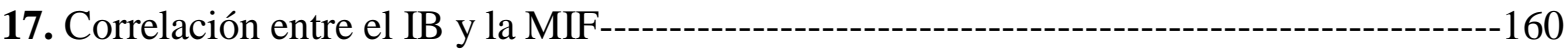

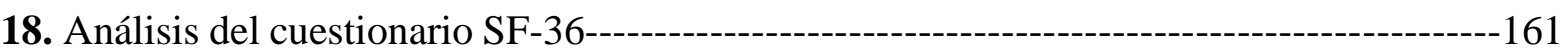

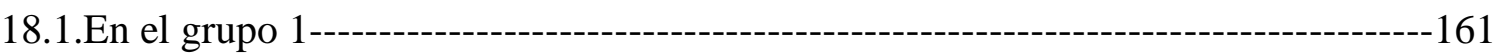

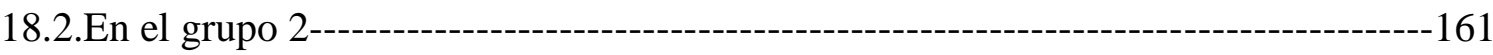

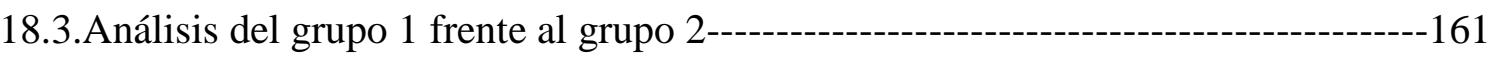

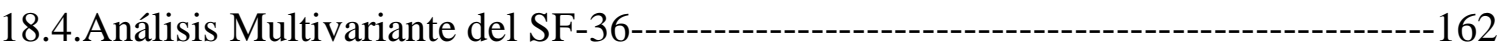

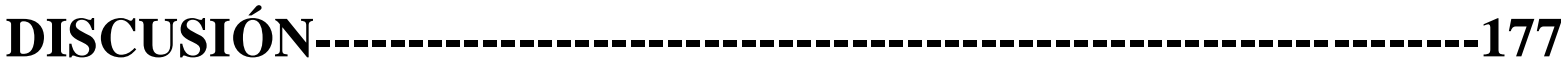

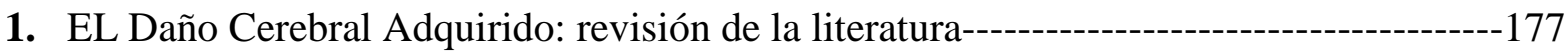

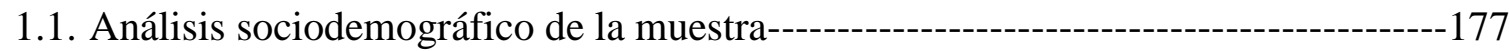

1.2. La subluxación glenohumeral: causa de rigidez de hombro----------------------------178

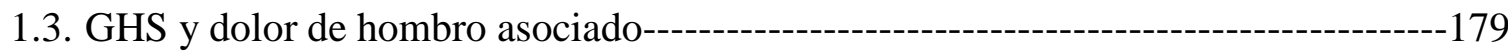

2. La metodología Vojta como tratamiento del hombro afectado por causa neurológica---181

3. La FNP como tratamiento del hombro afectado por causa neurológica--------------------182

4. IB/MIF pronóstico----------------------------------------------------185

5. Resultados goniométricos obtenidos con la terapia Vojta--------------------------------185

6. Limitaciones del estudio----- 
Formulario de registro de pacientes y escalas de valoración ANEXO II

Consentimiento informado

Informe favorable del Comité de Bioética de la Universidad de Salamanca ANEXO IV

Categorización de los individuos afectados del hemicuerpo izquierdo. Grupos 1 y 2 ANEXO V

Categorización de los individuos afectados del hemicuerpo derecho. Grupos 1 y 2 


\section{Abreviaturas empleadas en este trabajo}

- ROT: Reflejos Osteo-Tendinosos

- SN: Sistema Nervioso

- SNC: Sistema Nervioso Central

- SNP: Sistema Nervioso Periférico

- TC: Tronco-Encéfalo

- ME: Médula-Espinal

- CM: Control Motor

- GPC: Generadores de Patrones Centrales

- AM: Aprendizaje Motor

- PC: Parálisis Cerebral

- PCI: Parálisis Cerebral Infantil

- LCA: Lesión Cerebral Aguda

- DCA: Daño Cerebral Agudo

- EM: Esclerosis Múltiple

- SCA: Síndrome Coronario Agudo

- TCE: Traumatismo Cráneo-Encefálico

- ACV: Accidente Cerebrovascular

- AIT: Accidente Isquémico-Transitorio

- MAS: Modified Ashworth Scale

- ABVD: Actividades Básicas de la Vida Diaria

- IB: Índice de Barthel

- MIF: Medida de la Independencia Funcional

- SF-36: Cuestionario de salud modelo 36 abreviado (Short Form 36 health survey)

- SFTR: Sistema Frontal, Transversal, Rotacional o sistema Neutral-Cero

- RR: Reptación Refleja

- VR: Volteo Reflejo

- CV: Columna Vertebral

- T: Terapeuta

- P: Paciente

- FLEX: Flexión

- HC: Hemicuerpo

- FLEX: Flexión de Hombro

- EXT: Extensión de Hombro

- ABD: Abdución de Hombro

- ROTH: Rotación de Hombro

- ROTE: Rotación Externa de Hombro

- ROTI: Rotación Interna de Hombro

- GHS: Subluxación Glenohumeral 
- $\quad \mathbf{N}$ : Total de individuos

- $\boldsymbol{P}:$ Rho de Spearman

- S: Desviación Típica

- $\alpha$ : Nivel de significatividad

- ACM: Análisis de Correspondencias Múltiples 
ÍNDICE 


\section{MARCO TEÓRICO}

\section{GENERALIDADES DEL SISTEMA NERVIOSO}

\subsection{CARACTERÍSTICAS DEL SISTEMA NERVIOSO ${ }^{27}$}

El Sistema Nervioso (SN en lo sucesivo) se divide funcionalmente en dos niveles: somático y vegetativo. El primero comprende los sistemas de comunicación con el exterior y es de tipo consciente. Incluye información de entrada o eferente, de carácter sensorial e información de salida o eferente, de carácter motor. Del sistema vegetativo o autónomo dependen las funciones de regulación e intercomunicación.

Anatómicamente el SN se divide en sistema nervioso central (SNC en lo sucesivo) que comprende el cerebro y la médula espinal y sistema nervioso periférico (SNP) comprende el conjunto de ganglios y nervios.

\subsubsection{Fisiología del comportamiento motor: Centros y vías mo- toras}

Durante mucho tiempo se supuso que la corteza motora cerebral era la responsable directa del impulso motor y considerada como la zona superior jerárquicamente, aunque de hecho se sitúa en niveles relativamente inferiores entre el conjunto de centros implicados en el movimiento ${ }^{27}$.

Se distinguen las vías motoras voluntarias provenientes de la circonvolución precentral de la corteza del cerebro y las vías motoras involuntarias, originadas en diferentes centros nerviosos profundos en relación con la corteza cerebral ${ }^{37}$.

\subsubsection{Centros corticales: Vías Piramidales ${ }^{1.38 .37}$}

Surgen de la circonvolución precentral de la corteza. La corteza motora primaria es la principal fuente de aferencias a esa vía si bien otras áreas como las cortezas premotora y motora suplementaria también contribuyen con algunas fibras. Descienden hasta la médula espinal formando dos contingentes; uno que a la altura del bulbo raquídeo cruza la línea media y se denomina tracto cortico-espinal lateral y otro que no lo hace y se denomina tracto cortico-espinal anterior.

Su denominación se debe a que es el único punto en el que todas las fibras se agrupan sin contaminación por otros haces de fibras se encuentra en las pirámides bulbares del tronco del encéfalo (TE en lo sucesivo). 


\section{MARCO TEÓRICO}

Al igual que otros sistemas motores descendentes, la vía piramidal hace sinapsis con interneuronas de la médula espinal (ME en lo sucesivo). Estas interneuronas conectan a su vez con motoneuronas que inervan el músculo estriado. Sin embargo existen conexiones directas sin necesidad de interneurona que no están presentes al nacer y que se conforman en el individuo a partir de los 2-4 primeros años de vida ${ }^{27}$.

\subsubsection{Centros subcorticales: Vías extrapiramidales ${ }^{1}$}

En algunos casos no obedecen a órdenes voluntarias pero transportan impulsos que provienen de centros situados a lo largo del neuroeje, colaborando así con la vía piramidal. Son los siguientes

- Tracto rubroespinal, proveniente del núcleo rojo.

- Tracto olivoespinal: proveniente de neuronas del núcleo olivar inferior

- Tracto retículoespinal: neuronas provenientes de la sustancia reticular

- Tracto tectoespinal: proveniente del colículo superior

- Tracto vestíbuloespinal: proveniente del núcleo vestibular

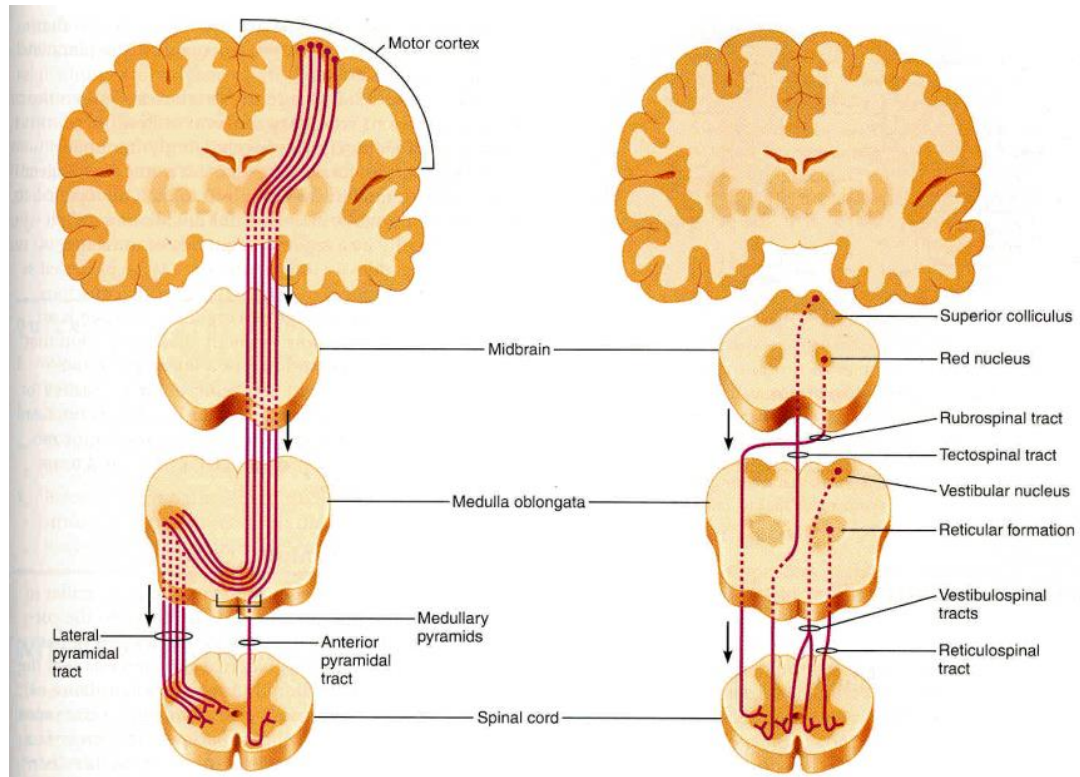

Figura 1: Esquema de las vías piramidales y extrapiramidales en el $S N C^{79}$ 


\section{MARCO TEÓRICO}

\subsubsection{Lesiones de los centros y vías motoras}

En el año 1968 Lawrence y Kuypers ${ }^{1.39}$ así como revisiones posteriores ${ }^{40}$ de este trabajo determinaron que la lesión en las vías extrapiramidales tenía una influencia mucho mayor sobre el tono muscular que si se alteraba la vía piramidal.

Se desarrolló un modelo en el que el sistema reticuloespinal lateral (o tracto bulbo reticular) recibía aferencias excitadoras de la corteza y tenía la capacidad de reducir la excitabilidad de los reflejos de estiramiento y flexión. Este sistema se contrarresta por el sistema retículoespinal medial (o tracto póntico reticular) que carece de aferencias corticales pero excitaba los reflejos de estiramiento e inhibía los de flexión.

Por tanto en la acción de un ictus capsular u otra lesión que afecte a la corteza y produzca lesión cerebral que destruya las aferencias del sistema cortical al sistema lateral, la acción del sistema medial será dominante y por consiguiente los reflejos de estiramiento serán mayores aunque los de flexión sólo se verán afectados levemente ${ }^{2,40}$.

En comparación con esto, ante una sección medular completa se destruirían ambas vías y no habría supresión en los reflejos de flexión por parte del sistema retículoespinal. Sin embargo, los sistemas retículoespinales son complejos y se sabe que juegan un papel importante en el control del tono muscular y los reflejos de flexión en el movimiento normal ${ }^{40}$.

\subsection{CONTROL MOTOR}

El control motor (CM en lo sucesivo) es el resultado de las acciones integradas del SN a través de sus vertientes sensitiva y motora.

No podemos explicar el aprendizaje de un movimiento sin comprender cómo se controla mediante los procesos internos ${ }^{26}$, y esto incluye por ejemplo la compresión de cómo actúan, por ejemplo, la atención o la memoria. También es importante tener en cuenta que estos procesos son de tipo dinámico; es decir que pueden modificarse mediante el aprendizaje. Por tanto control y aprendizaje motor son dos conceptos que se relacionan y fundamentan entre sí $i^{2} 27$.

De hecho, si estudiamos el CM en el laboratorio, en condiciones teóricamente óptimas, se estudia dentro del contexto de adaptación donde los sujetos deben de aprender a compensar perturbaciones:(alteraciones visuales, cargas inerciales, cambios en la dinámica del aparato motor) etc. ${ }^{41}$. Sin embargo, no todo aprendizaje motor es fruto de un comportamiento adaptativo. A menudo el individuo aprende a sintetizar nuevos movimientos incluso cuando no hay perturbaciones que lo provoquen.

En términos generales existen dos mecanismos de control motor ${ }^{41}$. Por un lado existe un sistema basado en mejoras producidas de manera indirecta en el rendimiento motor, guiadas por un modelo interno del entorno que se actualiza en base a los errores 


\section{MARCO TEÓRICO}

de predicción, y un sistema directo, en el que el aprendizaje se produce directamente a nivel del controlador y es impulsado por el refuerzo y las acciones cursadas con éxito. Estos sistemas de aprendizaje distintos son cada uno adaptado a diferentes tareas y como tales son complementarios entre sí.

Sin embargo, conforme avanza la historia de la ciencia se han ido elaborando diversas teorías acerca del control motor y de su aprendizaje. A continuación se hace un resumen de las mismas.

\subsubsection{Teorías del control motor}

\section{Teoría refleja}

Descrita por Serrington, determina que la respuesta de un estímulo es el estímulo de la siguiente respuesta. Describió este comportamiento en función de reflejos compuestos y su combinación sucesiva o encadenamiento ${ }^{42.43 .44}$.

\section{Teoría jerárquica}

Esta teoría sostiene que SNC se organiza de forma jerárquica, en áreas de asociación superiores: corteza motora y niveles espinales de función motora, y cada nivel superior ejerce control sobre el nivel menor, en una estricta jerarquía vertical ${ }^{45}$.

Gesell $^{46}$ y McGraw ${ }^{47}$ desarrollaron la teoría de la neuromaduración del desarrollo. El desarrollo motor normal es atribuido a la creciente corticalización del SNC que produce la aparición de niveles superiores de control sobre los reflejos de nivel inferior, siendo la maduración del SNC el agente primario para el cambio en el desarrollo, minimizando la influencia de otros factores.

Esta teoría, surgida en los años 40, ha evolucionado, y en la actualidad se reconoce que cada nivel del SN puede actuar sobre los otros dependiendo de la actividad, considerándose los reflejos no como único determinante del CM, sino solo uno de los diversos procesos esenciales para la generación y control del movimiento ${ }^{48}$.

\section{Teorías de la programación motora}

Las teorías más actuales acerca del CM abogan por la idea de que sea un sistema basado en la fisiología de las acciones y se alejan de la idea de que sea un sistema fundamentalmente reactivo. Esto es debido a que se puede obtener una respuesta de tipo motor determinada tanto por un estímulo de tipo sensorial como por un proceso generado a nivel central en ausencia de un estímulo o información aferente. 
Esta teoría surgió de estudios en el análisis de la locomoción en animales felinos, gatos, ${ }^{49}$ y sugiere que se debería de hablar de un patrón motor central. Se apoya por tanto en la idea de que es posible el movimiento en ausencia de una acción refleja, de tal manera que las neuronas de la médula espinal podrían producir un ritmo de locomoción sin patrones descendentes del cerebro ni estímulos sensoriales; pudiéndose realizar el movimiento sin biofeedback.

Introduce esta teoría un nuevo concepto: Generadores de patrones centrales: GPC o circuitos neuronales espinales capaces de generar por sí mismos movimientos locomotrices tales como andar o correr y sobre los cuales los estímulos sensoriales ejercerían, eso sí, un importante papel modulador ${ }^{50,51}$.

\section{Teoría del procesamiento de distribución en paralelo}

La teoría del procesamiento de distribución en paralelo (PDP) describe la forma en que el SN procesa la información para actuar. El SN operaría tanto mediante procesos en serie (procesando la información a través de una vía única), como en paralelo, interpretando la información por medio de vías múltiples que la analizarían simultáneamente en diferentes formas ${ }^{63.64}$.

La estrategia ha sido desarrollar modelos matemáticos simplificados de sistemas cerebrales y posteriormente estudiar éstos para comprender la manera en que varios problemas de cálculo pueden ser resueltos por tales mecanismos ${ }^{63,64}$. Los modelos consisten en elementos que están conectados por circuitos. Al igual que las sinapsis neurales, cada elemento puede ser afectado por los otros de forma positiva o negativa en distinta magnitud65. Estos elementos se distribuirían en neuronas sensoriales, interneuronas y motoras. La eficiencia del desempeño dependerá de la cantidad de conexiones de salida y la fortaleza de la conexión ${ }^{63}$.

\section{Teoría de sistemas}

El principio fundamental de esta teoría es afirmar lo siguiente: "los movimientos no son dirigidos ni central ni periféricamente, sino que emergen de la interacción de muchos sistemas $^{52}$. Se considera al cuerpo como un sistema mecánico sujeto a fuerzas externas (gravedad) e internas ${ }^{50}$. Una misma orden central puede ocasionar movimientos muy dispares debido a la interacción entre las fuerzas externas y las variaciones de las condiciones iniciales o bien, el mismo movimiento podría ser originado por comandos distintos. La teoría intenta explicar cómo afectan las condiciones iniciales a las características del movimiento ${ }^{53}$. 


\section{MARCO TEÓRICO}

En realidad predice el comportamiento real mucho mejor que las teorías precedentes al considerar no solo los aportes del SN a la acción, sino también las contribuciones de diferentes sistemas así como las fuerzas de gravedad e inercia.

\section{Teoría de la acción dinámica}

Considerando el principio de autoorganización, afirma que cuando un sistema de partes individuales se une, sus elementos se comportan colectivamente en forma ordenada, no siendo necesario un centro superior que envíe las instrucciones para lograr la acción coordinada ${ }^{54}$. Propone que el movimiento surge como resultado de elementos que interactúan, sin la necesidad de programas motores. Esta acción dinámica trata de encontrar descripciones matemáticas de estos sistemas autoorganizados que seguirían un comportamiento no lineal, situación en la cual, cuando uno de los parámetros se altera y alcanza un valor crítico, el sistema entra en un patrón de comportamiento completamente nuevo. A través de estas formulaciones matemáticas sería posible predecir las formas en que un sistema dado actuará en diferentes situaciones. La perspectiva de la acción dinámica reduce la importancia de las nociones de comandos provenientes del SNC para controlar el movimiento y busca explicaciones físicas que también puedan contribuir a las características del movimiento.

\section{Teoría orientada a la actividad}

Greene ${ }^{62}$ indicó la necesidad de una teoría que explicase cómo los circuitos neuronales operaban para lograr una acción, lo que proporcionaría la base para una imagen más coherente del sistema motor. El método orientado a la actividad se apoya en el reconocimiento de que el objetivo del $\mathrm{CM}$ es el dominio del movimiento para realizar una acción particular, no para efectuar movimientos por el solo hecho de moverse. El control del movimiento se organizaría alrededor de comportamientos funcionales dirigidos a objetivos.

\section{* Teoría ecológica}

Esta teoría fue desarrollada por Gibson en los años setenta. Pretende explorar la forma en que nuestros sistemas motores nos permiten interactuar con el medio ambiente de la manera más efectiva para tener un comportamiento orientado al objetivo ${ }^{61}$.

Su investigación se centró en cómo detectamos la información del entorno y de cómo la utilizamos para controlar nuestros movimientos. El individuo explora el entorno, que a su vez es el sostén de la actividad del individuo, luego las acciones de éste están orientadas al ambiente. 


\section{MARCO TEÓRICO}

\subsubsection{Aprendizaje motor}

El aprendizaje motor (AM en lo sucesivo) se define como el conjunto de procesos internos asociados a la práctica y la experiencia, que producen cambios relativamente permanentes en la capacidad de producir actividades motoras, a través de una habilidad específica. Lo que aprendemos se retiene o almacena en nuestro cerebro y constituye lo que denominamos memoria ${ }^{57}$, no considerándose como aprendizaje las modificaciones a corto plazo $^{58.59}$.

La neurorehabilitación tendrá como objeto el mantenimiento de las habilidades existentes, la readquisición de habilidades perdidas y el aprendizaje de nuevas destrezas. Se considera generalmente que una habilidad es una característica o rasgo relativamente estable, típicamente asociado a un componente genético y que no puede alterarse fácilmente mediante la práctica o la experiencia ${ }^{40}$. Otra manera de entender el concepto de habilidad es distinguiéndolo del de destreza. Al contrario que la primera, la destreza puede ser modificada mediante la práctica o la experiencia, de hecho, y de igual modo, puede ser adquirida a través de estas ${ }^{60}$.

\subsubsection{Teorías sobre el aprendizaje motor}

Una vez explicadas las teorías sobre el CM, es importante conocer cómo se ha explicado por los autores el AM. Existen varios modelos para explicar las teorías del AM, recogeremos en este estudio los más relevantes.

\section{* Modelo de los tres estadios ${ }^{55.56}$}

Fue desarrollado por Fitss y Posner y sugiere que existen tres etapas principales en el AM

I. Etapa cognitiva. En la que el paciente aprende una nueva destreza o reaprende una habilidad antigua. En esta fase necesita realizar la tarea bajo supervisión y guía externa, siendo importante el cometer errores y corregirlos a tiempo así como la práctica con frecuencia.

II. Etapa asociativa. En la que el individuo consigue dirigir su actividad dentro de unas condiciones específicas. En esta fase tendrá menos errores en la ejecución y logrará realizar con menor esfuerzo la tarea.

III. Etapa autónoma. En la que el paciente consigue moverse dentro de una variedad de ambientes, manteniendo el control en todo el programa. El verdadero aprendizaje se consigue cuando consigue mantener la habilidad y generalizarla a múltiples contextos gracias a la automatización de la tarea, puesto que según los autores la práctica en la vida cotidiana es generalmente aleatoria ${ }^{56}$. 


\section{Modelo de sistema de tres fases de Berstein ${ }^{52}$}

Según esta teoría lo importante es controlar los grados de libertad, es decir, el número independiente de movimientos necesarios para completar una acción, como un componente central del aprendizaje de una nueva destreza motora. Este modelo de aprendizaje plantea tres fases.

I. Fase inicial. En la que el individuo simplifica el movimiento reduciendo los grados de libertad

II. Fase avanzada. En la que el sujeto comienza a ganar ciertos grados de libertad, permitiendo el movimiento en mayor número de articulaciones incluidas en la tarea

III. Fase de experto. Aquella en la que el individuo posee todos los grados de libertad necesarios para llevar a cabo la tarea de manera coordinada y efectiva.

\section{Modelo de dos fases de Gentile}

I. Fase Inicial. Comprende la comprensión del objetivo de la tarea, el desarrollo de las estrategias de movimiento apropiadas para conseguir el objetivo, así como la interpretación de las características del entorno para la organización del movimiento

II. En la segunda fase, denominada de fijación o fase de diversificación, el objetivo del sujeto es redefinir el movimiento, ya sea adaptando el movimiento a los cambios pertinentes como desarrollar la tarea de manera eficaz. 


\section{MARCO TEÓRICO}

\subsubsection{Fases en la formación del programa motor}

Diversos investigadores se han planteado qué cambios jerárquicos podrían ocurrir en el control del movimiento cuando los programas motores se unen durante el aprendizaje de una nueva tarea ${ }^{48}$. Los programas motores que rigen una conducta compleja podrían ser creados a través de la combinación de programas motores que controlan unidades más pequeñas de la conducta, hasta completar el control total de ésta como una sola unidad ${ }^{48}$.

\subsection{PLASTICIDAD NEURONAL}

Tradicionalmente se ha considerado al SNC de los mamíferos como una estructura sin capacidad de renovación tras el nacimiento. Sin embargo, ya con los trabajos de Altman $\left(1962^{29}, 1969^{30}\right)$, se demostró la existencia de células madre y se pasó de una concepción totalmente estática de este sistema a otra más plástica, en la que se acepta la generación de nuevos elementos. Así pues, se consideró la renovación y cambio de ciertos circuitos y estructuras, y la existencia de cierta renovación tisular en el SNC ${ }^{29,32}$, 33 .

Hasta la fecha se ha demostrado la presencia de neurogénesis -formación de nuevos elementos neurales a partir de células madre o progenitoras- en el SNC adulto de todos los grandes grupos de vertebrados: peces, anfibios, reptiles, aves y mamífe$\operatorname{ros}^{34,35}$. Consecuentemente, este proceso no se trata de un fenómeno aislado, sino de un mecanismo conservado en la evolución.

El fenómeno de la plasticidad neuronal demuestra que la experiencia deja una huella en la red neuronal, al tiempo que modifica la eficacia de la transferencia de información a nivel de los elementos más finos del sistema (Morris R.G.M et al.2003) ${ }^{66}$. Es decir que más allá de lo innato y de cualquier dato de partida, lo que es adquirido por medio de la experiencia deja una huella que transforma lo anterior ${ }^{71}$.

La experiencia modifica permanentemente las conexiones entre las neuronas, y los cambios son tanto de orden estructural como funcional ${ }^{67}$. El cerebro es considerado, entonces, como un órgano extremadamente dinámico en permanente relación con el medio ambiente, por un lado, y con los hechos psíquicos o los actos del sujeto, por otro $^{68,71}$.

La plasticidad introduce una nueva visión del cerebro, al considerar que la red neuronal permanece abierta al cambio y a la contingencia; modulada por el acontecimiento y la experiencia, que pueden modificar el estado previo de dicha red. 
Así, a través de una suma de experiencias el individuo se vuelve único e imprevisible, más allá de las determinaciones que genéticamente le son atribuidas ${ }^{69,70,71}$.

Integrando el concepto de plasticidad se pueden agrupar dos ideas heterogéneas. Por un lado el genotipo y por otro la experiencia, quedando así ambas en un mismo nivel lógico ${ }^{69,70}$. 


\section{DAÑO CEREBRAL}

La parálisis cerebral (PC en lo sucesivo) se define como un trastorno del movimiento y de la postura debido a un defecto o lesión del cerebro inmaduro (Bax, $1964)^{74}$.

La característica esencial de esta definición de PC es que la lesión afecta al cerebro inmaduro, interfiriendo la maduración del SNC, lo cual tiene consecuencias específicas en términos del tipo de PC que se desarrolla, de su diagnóstico, evaluación y tratamiento $^{76}$.

\subsection{TIPOS DE DAÑO CEREBRAL: CONGÉNITO Y AD- QUIRIDO}

El daño cerebral puede presentarse en las circunstancias que rodean al periodo pre o perinatal (congénito) o bien a lo largo de la vida (adquirido).

\subsubsection{Congénito. Parálisis cerebral infantil (PCI en lo sucesivo)}

Si bien es cierto que en lo que compete a este estudio, los sujetos presentan una lesión cerebral adquirida. La otra gran entidad dentro del daño cerebral son las lesiones que acaecen durante el periodo pre o perinatal $^{72}$.

En relación a estos últimos diremos que postura y movimiento son elementos inseparables de la función motora, la cual actúa sobre el cuerpo como un todo. De hecho, aunque la lesión puede afectar a múltiples áreas cerebrales de pendiendo de su magnitud, es la alteración motora lo que define la PCI.

Por tanto en la PCI lo que se altera es la capacidad del SNC de coordinar y elaborar respuestas motoras adecuadas a los estímulos del entorno y a las necesidades mentales del niño. Al ocurrir en el periodo perinatal o en los primeros días de vida, altera el proceso del desarrollo motor, aquel que va a dirigir:

- El enderezamiento del tronco frente a la gravedad.

- El control del equilibrio.

- El ajuste y la coordinación de los movimientos diferenciados y propositivos (p.ej. el lenguaje).

Se asocia, además con otras alteraciones de tipo sensitivo, cognitivo, de conducta, comunicación etc. que condicionan de manera importante el pronóstico individual de cada paciente ${ }^{78}$.

El desarrollo de la función motora humana se manifiesta a lo largo del primer año de vida, en una secuencia ordenada de etapas como resultado de la capacidad del 


\section{MARCO TEÓRICO}

cerebro de organizar y controlar en movimiento del cuerpo. Dicho de otro modo, cada etapa supone un determinado nivel de organización neurológica en el control de la postura del enderezamiento y de la movilidad fásica en la relación del niño con su entorno ${ }^{77}$. Es lo que se conoce como "maduración psicomotriz" $" 73.74 \mathrm{del}$ niño.

Etapa tras etapa, los logros iniciales se modifican, se perfeccionan y se adaptan para integrarse en patrones de movilidad y destreza más finos y más selectivos; y aunque el proceso se prolongue a lo largo de la vida, los cambios más significativos ocurren en los primeros 18 meses de vida ${ }^{75.77 .78}$.

\subsubsection{Clasificación clínica de la PCI $\mathbf{P}^{78.76 .74 .75}$}

Aunque no es el objeto de este trabajo, es importante recordar cómo clasificamos estos pacientes, ya que en el daño cerebral adquirido hay determinados aspectos de la semiología que son idénticos. De manera esquemática se pueden agrupar del siguiente modo.

\begin{tabular}{|c|c|c|c|}
\hline \multicolumn{4}{|c|}{ CLASIFICACIÓN TOPOGRÁFICA } \\
\hline \multicolumn{2}{|c|}{ Unilateral } & & \begin{tabular}{cc}
\multicolumn{2}{l}{ Bilateral } \\
$\circ$ & Diparesia \\
$\circ$ & Triparesia \\
$\circ$ & Tetraparesia
\end{tabular} \\
\hline \multicolumn{4}{|c|}{ CLASIFICACIÓN EN FUNCIÓN DEL TRASTORNO MOTOR PREDOMINANTE } \\
\hline Tipo & $F(\%)$ & Causa & Clínica más frecuente \\
\hline Espástica & $70-80$ & $\begin{array}{l}\text { Lesión del sistema pi- } \\
\text { ramidal }\end{array}$ & $\begin{array}{l}\text { O + de los ROT, de los reflejos patológi- } \\
\text { cos, clonus y cocontracciones } \\
\text { - de la coordinación y el equilibrio, } \\
\text { debilidad muscular, fatiga, dispraxia }\end{array}$ \\
\hline $\begin{array}{l}\text { Dis- } \\
\text { cinética }\end{array}$ & $10-20$ & $\begin{array}{l}\text { Asfixia o isquemia } \\
\text { grave perinatal. Le- } \\
\text { sión de la vía extrapi- } \\
\text { ramidal (ganglios ba- } \\
\text { sales). }\end{array}$ & $\begin{array}{l}\text { Movimientos involuntarios y alteraciones del } \\
\text { tono y de la postura, con imposibilidad para } \\
\text { ejecutar adecuadamente los movimientos. } \\
\text { De forma hiperkinética o distónica }\end{array}$ \\
\hline Atáxica & $5-10$ & $\begin{array}{l}\text { Afectación del cere- } \\
\text { belo o vías pontocere- } \\
\text { belosas }\end{array}$ & $\begin{array}{l}\text { Hipotonía, hiperextensibilidad articular y baja } \\
\text { estabilidad en una postura con pérdida de } \\
\text { fuerza. }\end{array}$ \\
\hline
\end{tabular}

Tabla 1: Clasificación de la PCI

En la PCI se alteran algunos de los circuitos de regulación motora del SNC que aún no han entrado prácticamente en funcionamiento y que se encuentran en proceso de ma- 
duración. Si el cerebro no consigue una reorganización de forma espontánea o mediante un tratamiento adecuado, la alteración motora se estructura de forma permanente ${ }^{78}$.

\subsubsection{Daño cerebral adquirido}

Aquel que sucede por circunstancias no relacionadas con el embarazo, el parto o el puerperio, y del que se hablará a continuación. 


\section{DAÑO CEREBRAL ADQUIRIDO}

La lesión cerebral adquirida (LCA) es un amplio término en el que se engloban las agresiones que acaecen en el cerebro y que no tienen una etiología congénita o perinatal ${ }^{1}$.Normalmente se emplea para describir el resultado de una lesión traumática clara o de una patología producida por un solo fenómeno. La causa más frecuente de la LCA es el traumatismo cráneo encefálico (TCE en lo sucesivo). El ictus es otra importante entidad relacionada con este aspecto.

Sin embargo existen múltiples etiologías que pueden ocasionar una LCA y que no necesariamente ocurren en un episodio único y abrupto, tales como las enfermedades degenerativas (Esclerosis Múltiple, Párkinson etc.) y que englobamos en este concepto puesto que se adquieren a lo largo de la vida.

Otro tipo de lesiones que pueden cursar con DCA son los tumores cerebrales, ya sean de origen primario o metastásico.

\subsection{CLASIFICACIÓN ETIOLÓGICA DEL DCA}

Por su frecuencia en la sociedad actual y por su influencia en el presente estudio explicaremos brevemente en qué consisten aquellas LCA que han formado parte del mismo: Párkinson, Ictus, Esclerosis Múltiple (EM en lo sucesivo), Traumatismo Cráneo-Encefálico, (TCE en lo sucesivo). Así mismo, incluiremos el Síndrome Coronario Agudo (SCA en lo sucesivo) aunque sea una enfermedad coronaria, pero si se prolonga en el tiempo puede tener consecuencias neurológicas (LCA) severas.

Los pacientes con Daño Cerebral Adquirido (DCA) son entidades clínicas complejas, puesto que cada individuo presenta alteraciones propias en función de su etiología, nivel de afectación, progresión en el tratamiento etc. así como en función de múltiples criterios tales como su edad, sexo, condición física e incluso implicación emocional con la enfermedad y el tratamiento ${ }^{2}$.

A continuación se ofrece una pequeña descripción de cada una de las enfermedades por separado. Se entiende que son entidades clínicas complejas, y cada una de ellas forma parte de una especialidad médica concreta. El objetivo de este estudio no es determinar un tratamiento para cada una de ellas en concreto, si no buscar alteraciones comunes en los pacientes que las sufren. 


\section{MARCO TEÓRICO}

\subsubsection{Accidente Cerebro Vascular ${ }^{82,1,2,3}$}

El Accidente Cerebro Vascular (ACV) o ictus es la interrupción real del aporte sanguíneo a una parte del cerebro ${ }^{3}$, dando lugar a la isquemia y posterior muerte tisular de esa parte y a las consiguientes deficiencias neurológicas. Suele ocurrir de manera repentina provocando déficits neurológicos que pueden ser más o menos graves en función de su localización y extensión en el cerebro.

\section{Clasificación del ACV}

De manera general se clasifican en isquémicos y hemorrágicos.

Isquémicos: oclusión de una arteria cerebral por causas tromboembólicas y reducción del aporte sanguíneo.

Hemorrágicos: Rotura de un vaso sanguíneo por hemorragias intracerebrales o subaracnoideas.

\section{Clínica}

La clínica de los ACV se clasifica en función de la evolución sin tener en cuenta la etiología ni la fisiopatología de éste.

Accidente isquémico transitorio (AIT): Episodio isquémico localizado que producirá deficiencias en función de la zona del cerebro afectada. Al resolverse el episodio (en minutos, horas o 24 horas máximo) se reestablece la normalidad neurológica

Déficit neurológico isquémico reversible: Es similar al AIT pero persiste más de 24 horas. La recuperación funcional es casi completa pero hay un mayor riesgo de infartos posteriores

Ictus en evolución. También llamado ictus en progresión, produce un cuadro de déficit neurológico creciente que evoluciona durante horas o días. Hay un empeoramiento clínico durante los siete días siguientes al comienzo de los síntomas.

Ictus completo. Es la estabilización del estado del paciente con persistencia del déficit neurológico. Se distinguen entre ACV derechos e izquierdos según sea la localización de la lesión en el hemisferio derecho o izquierdo del cerebro. Su semiología dependerá de la localización y de la extensión de la lesión. (Foto móvil III). 


\section{MARCO TEÓRICO}

\section{Semiología}

- Cefalea intensa de comienzo brusco, náuseas, vómitos, rigidez nucal.

- Alteraciones en el nivel de consciencia (desde el estupor al coma)

- Signos de irritación meníngea, alteraciones sensitivas y motoras así como de los nervios craneales.

\subsubsection{Esclerosis Múltiple ${ }^{2,3.82,83}$}

La Esclerosis Múltiple (EM) es una enfermedad desmielinizante del sistema nervioso central. Es la enfermedad neurológica crónica más frecuente en adultos jóvenes de raza blanca y una de las principales causas de invalidez neurológica en este grupo de edad13. Aunque clásicamente se la ha denominado así haciendo referencia a las placas o lesiones que produce la enfermedad en el cerebro y la médula espinal, lo cierto es que en la actualidad se desconoce su etiología y no existen formas de tratamiento efectivas.

Por tanto la esclerosis múltiple se puede definir como una enfermedad inflamatoria, desmielinizante y neurodegenerativa del SNC. Se define por la aparición sucesiva, en cualquier localización de la sustancia blanca del SNC de focos de inflamación autolimitados que pueden dejar como secuela la desmielinización definitiva de esa zona.

\section{Fisiopatología 82}

Destrucción de la mielina con una total o relativa preservación de las neuronas y sus prolongaciones. La desmielinización se presenta a lo largo de todo el SNC pero más frecuentemente alrededor de los ventrículos, el nervio y el quiasma óptico, el troncoencéfalo, los pedúnculos cerebelosos y la médula espinal.

En función de la fase en la que se encuentre la enfermedad distinguimos una lesión aguda (en la que predominan fenómenos inflamatorios) y una crónica con signos evidentes de degeneración axonal, desmielinización severa y gliosis.

\section{Clínica $^{83}$}

Puesto que lo que se produce es una desmielinización del SNC, la clínica variará en función del lugar de aparición de la placa. Se encontrarán signos y síntomas motores, sensitivos, oculares, alteraciones de la coordinación, esfínteres, pares craneales etc.

Una de las complicaciones frecuentes de la EM es la espasticidad que no responde a tratamiento farmacológico, y que a la larga produce mayor parálisis del individuo. 


\subsubsection{Parkinson ${ }^{82}$}

La enfermedad de Parkinson fue descrita por primera vez en el año 1817 por J. Parkinson como una patología neurodegenerativa crónica que afecta al área encargada de coordinar la actividad, el tono muscular y los movimientos.

\section{Fisiopatología ${ }^{84}$}

Es la manifestación de la lesión de los ganglios basales causada por la degeneración de las neuronas dopaminérgicas de la parte compacta de la sustancia negra, lo que provoca una reducción del contenido de dopamina del cuerpo estriado. Esto hace que disminuyan los movimientos voluntarios. A su vez, se aumentan los niveles de Acetilcolina.

\section{Clínica $^{85}$}

Lo más habitual en la enfermedad de Parkinson es lo que se conoce como la tríada parkinsoniana:

- Rigidez muscular e incapacidad para relajar la musculatura (no hay un impulso dopaminérgico inhibidor para la acción).

- Temblor en reposo: ocasionado por la actividad de los músculos antagonistas, que desaparece al efectuar movimientos con un objetivo definido.

- Bradicinesia o acinesia, con movimientos asociados muy escasos y desaparición de la expresión de la mímica de cara y manos.

Derivado de esto presentan otros síntomas como trastornos posturales, de la marcha, sensitivos, del sueño... 


\subsubsection{Traumatismo Cráneo-Encefálico, $T C E^{2,12}$}

Consiste en el deterioro funcional del contenido craneal debido a un intercambio brusco de energía mecánica. Esta definición (San Diego, EE UU) incluye causas externas que pueden provocar conmoción, contusión, hemorragia o laceración del cerebro o el tronco del encéfalo hasta la primera vértebra cervical.

Sin embargo hay quien sigue empleando una clasificación anterior (criterios de Jennett12) por su simplicidad, que incluyen como casos de TCE aquéllos que presenten alguna de las siguientes circunstancias:

- Historia documentada de golpe en la cabeza.

- Laceración del cuello cabelludo o de la frente.

- Alteración de la consciencia, independientemente de su duración.

\section{Epidemiología}

Aunque existen diferencias según los países; sí que es cierto que hay una relación varón mujer de 3:1 y que se presenta sobre todo en los adolescentes y varones jóvenes entre 15 y 29 años.

Los accidentes de tráfico son la causa externa más importante, seguida de las caídas.

\section{Clínica}

Disminución del grado de consciencia. Para objetivarlo se emplea la escala de coma de Glasgow12, 86 .

En esta escala, el nivel de conciencia pleno se registra con la máxima puntuación en cada uno de los niveles (15 puntos en total). El mínimo (ausencia de respuesta a estímulos motores, oculares y verbales) son 3 puntos. 


\begin{tabular}{|c|}
\hline Escala de coma de Glasgow \\
\hline Apertura ocular \\
Espontánea: 4 puntos \\
A la orden: 3 puntos \\
Ante un estímulo doloroso: 2 puntos \\
Ausencia de apertura ocular: 1 punto \\
Respuesta motora \\
Obedece órdenes correctamente: 6 puntos \\
Localiza estímulos dolorosos (p. ej. presión sobre el lecho ungeal): 5 puntos \\
Evita estímulos dolorosos retirando el segmento corporal explorado: 4 puntos \\
Respuesta con flexión anormal de los miembros: 3 puntos \\
Respuesta con extensión anormal de los miembros: 2 puntos \\
Ausencia de respuesta motora: 1 punto \\
Respuesta verbal \\
Orientado correctamente: 5 puntos \\
Paciente confuso: 4 puntos \\
Lenguaje inapropiado (p.ej. interjecciones): 3 puntos \\
Carencia de actividad verbal: 1 punto \\
\hline
\end{tabular}

Tabla 2: Escala de coma de Glasgow

- Manifestaciones de fracturas: estas son variadas en función de su localización. Existe con frecuencia hundimiento craneal, hipoacusia (lesión del VIII par craneal), parálisis facial...

- Manifestaciones de los nervios del $\mathrm{TE}^{85}$. Especialmente de los pares oculomotores. El que más frecuentemente se ve afectado es el III par craneal y en cuyo caso el paciente presentaría visión doble. Otro par craneal que resulta afectado con frecuencia es el nervio facial (VII par) cuya lesión cursa con desviación de la boca hacia el lado sano.

- Otras manifestaciones: Los TCE además pueden tener otras manifestaciones muy severas: por ejemplo vértigos ${ }^{85}$ (Afectación de VIII par craneal). 


\subsubsection{Síndrome Coronario Agudo ${ }^{80.87 .88 .89}$}

\section{Concepto}

Los Síndromes Coronarios Agudos ${ }^{14}$ se agrupan en dos categorías bien definidas que van a tener una actitud terapéutica específica. Por una parte los SCA con elevación del ST en los que se produce una oclusión total de una arteria coronaria que es la responsable de la isquemia. Por otro lado existen los SCA sin elevación del ST en los que no existe una obstrucción completa de la arteria coronaria. En el primer caso el tratamiento será de reperfusión (abrir la arteria obstruida) y en el segundo se tomarán medidas antitromóticas y antiisquémicas.

\section{Fisiopatología}

Sea cual sea el tipo de SCA, la fisiopatología de éste es un déficit de oxígeno y nutrientes, ya sea por aumento de necesidades de los mismos como por disminución en el aporte de oxígeno.

\section{Etiología y patogenia del SCA}

Existen múltiples causas que pueden llevar a un desequilibrio entre la demanda y el aporte de oxígeno suministrado a las arterias coronarias. Citando algunas de las más frecuentes:

○ Trombo no oclusivo sobre placa aterosclerótica preexistente

- Inflamación o infección del organismo

- Obstrucciones progresivas de las arterias coronarias sin necesidad de formación de trombos asociados.

○ Anginas inestables secundarias a otras enfermedades

\section{Clínica}

La angina de pecho típica se define como dolor torácico de perfil opresivo, de localización precordial con irradiación posible a miembros superiores, mandíbula, espalda, que se desencadena con el esfuerzo y/o estrés emocional y alivia con el reposo o nitroglicerina. Además no se modifica con los movimientos respiratorios ni cambios posturales ni la palpación. Pero existen otras manifestaciones como disnea, síncope etc.

\section{Tratamiento}

En lo que se refiere a este estudio, no vamos a precisar en el tratamiento farmacológico y las medidas llevadas a cabo por el personal médico y de enfermería para restablecer la función miocárdica, puesto que no es el objetivo del mismo. 


\subsection{EL DCA EN CIFRAS ${ }^{143,144}$}

De acuerdo con el informe que realizado por FEDACE (Federación Española de DCA) con la colaboración del Real Patronato sobre Discapacidad durante el año 2015; en España viven 420.000 personas con Daño Cerebral Adquirido. El 78\% de los casos tuvieron su origen en un ictus y el $22 \%$ restante en traumatismos craneoencefálicos y otras causas. Cada año se dan 104.071 nuevos casos de Daño Cerebral Adquirido: 99.284 por accidentes cerebrovasculares, 4.937 por TCEs y 481 por anoxias.

El 65,03 \% de las personas con DCA son mayores de 65 años, dato que se relaciona con la alta incidencia del ictus en un colectivo en el que la mayor parte del mismo (el $52 \%)$ son mujeres.

A continuación se muestran los recursos disponibles en nuestro país para este colectivo.

\begin{tabular}{|c|c|c|c|c|c|}
\hline Tipo de recurso & $\begin{array}{c}\mathbf{N}^{\mathbf{0}} \mathbf{d e} \\
\text { recursos }\end{array}$ & Plazas Totales & Pu. & Co. & Pr. \\
\hline Totales & $\mathbf{9 1}$ & $\mathbf{4 . 2 5 9}$ & $\mathbf{7 3 3}$ & $\mathbf{1 . 2 6 5}$ & $\mathbf{2 . 2 6 1}$ \\
\hline Centro de Día & $\mathbf{2 1}$ & 734 & 86 & 470 & 178 \\
\hline Centro Especial de Empleo & $\mathbf{1}$ & 0 & 0 & 0 & 0 \\
\hline Centro Ocupacional & $\mathbf{0}$ & 0 & 0 & 0 & 0 \\
\hline Piso Tutelado & $\mathbf{2}$ & 11 & 0 & 11 & 0 \\
\hline $\begin{array}{c}\text { Residencia } \\
\text { ción }\end{array}$ & $\mathbf{4}$ & 91 & 0 & 25 & 66 \\
\hline $\begin{array}{c}\text { Unidad Ambulatoria de Rehabilita- } \\
\text { de Hospital de Día }\end{array}$ & $\mathbf{1 9}$ & 1.407 & 170 & 0 & 1.237 \\
\hline $\begin{array}{c}\text { Unidad de Rehabilitación en régimen } \\
\text { ción }\end{array}$ & $\mathbf{2 4}$ & 946 & 178 & 268 & 500 \\
\hline Ud. Hospitalaria de Neurorehabilita- & $\mathbf{7}$ & 146 & 40 & 106 & 0 \\
\hline Pu.=Plazas públicas; Co.= Plazas concertadas; Pr. $=$ Plazas privadas & & \\
\hline
\end{tabular}

Tabla 3: Disponibilidad en España de plazas en centros públicos, concertados y privados para este colectivo. Año 2015. 


\subsubsection{ASDACE ${ }^{144}$}

Esta Asociación surge desde la inquietud de personas afectadas, sus familiares y un grupo de profesionales en Febrero de 2002.

Ante la grave problemática que presentan las personas con Daño Cerebral Adquirido y la magnitud de secuelas que comporta esta discapacidad, así como la falta de servicios, se crea una asociación que trabaja por mantener y mejorar las habilidades físicas, emocionales e intelectuales de estas personas y así mejorar su calidad de vida.

ASDACE extiende su actividad a todo el territorio de la provincia de Salamanca, no obstante puede colaborar y en estos momentos, está ofreciendo sus servicios, a personas de la provincia de Zamora y Ávila.

A través de un convenio docente asistencial, la Universidad de Salamanca presta sus servicios a los pacientes de la asociación en las instalaciones de la E.U. de Enfermería y Fisioterapia.

\subsection{CARACTERÍSTICAS COMUNES DEL DCA. Rigidez de hombro}

Como se ha descrito, la etiología de la lesión cerebral adquirida es diversa. A través de múltiples enfermedades, algunas sin causa neurológica primaria podemos llegar a tener una lesión cerebral fruto de complicaciones secundarias y que son de gran complejidad.

Sin embargo sí que es cierto que estos pacientes presentan una serie de características comunes que podemos observar en la práctica clínica diaria, y que son más o menos significativas en función del paciente82.

En lo que a rehabilitación y fisioterapia se refiere estos enfermos presentan problemas severos en diferentes áreas (motoras y sensoriales) así como experimentan una pérdida de independencia funcional, con las consiguientes repercusiones sobre la vida diaria, laboral, social y económica, tanto para ellos mismos como para sus familias21. Estudios previos consideran que factores tales como la gravedad de la lesión, características del individuo (edad, sexo, nivel educativo y personalidad pre-mórbida) y el contexto en el que se desenvuelve (apoyo familiar e integración laboral) ayudan a establecer un pronóstico más certero sobre los posibles cambios evolutivos y el nivel de discapacidad futuro22.

Con todo, hay ciertos problemas que suelen ser comunes, independientemente de la causa de la lesión, en casi todas las personas afectadas. Dentro del ámbito psicosocial, Lezak $(1988)^{23}$ propuso una serie de alteraciones comunes a los pacientes que sufrían DCA: problemas de percepción y conciencia social, falta de auto-control, in- 
capacidad para aprender de la experiencia, dependencia (física o emocional) y alteraciones emocionales específicas (apatía, insensatez, reacciones exageradas, irritabilidad, ansiedad, ideas paranoicas y depresión).

En lo que se refiere al aparato locomotor, los problemas músculo-esqueléticos son importantes en la recuperación de estos pacientes, bien sea por su afectación inicial debido a la enfermedad o por las secuelas del tratamiento (encamamiento, pérdida de movilidad etc.).

En este estudio se recoge un problema relacionado con el aparato locomotor que resulta frecuente en pacientes con una LCA, la rigidez de hombro derivada de la luxación glenohumeral ${ }^{166.167 .168 .169 .170 .174}$ (GHS en lo sucesivo) que se origina en los pacientes con algún tipo de daño cerebral.

Se estima que después de un accidente cerebrovascular. Del 16\% al 72\% de los pacientes con ictus desarrollan problemas de movilidad en el hombro ${ }^{175}$. Aunque puede ocurrir hasta en un $80 \%$ de los pacientes con ictus que tienen poco o ningún movimiento voluntario del miembro superior afectado ${ }^{176}$.

Otros autores estiman que la prevalencia de esta secuela aumenta con el grado de deterioro motor situándose hasta en el $83 \%$ en sujetos con baja función motora, siendo el resultado de déficits sensoriales y motores, subluxación articular y rango de movimiento pasivo limitado ${ }^{160}$.

\subsubsection{Concepto}

El hombro congelado (rígido) es una patología muy común que afecta a uno de cada cuatro adultos en algún momento de la vida ${ }^{10}$, por lo que es necesario conocer cómo abordar de forma correcta el diagnóstico de estos pacientes. Conviene descartar lo que son síndromes del hombro propiamente dichos de lo que son dolores deferidos o irradiados desde otras estructuras, lo cual se realizará con una anamnesis cuidadosa que descarte otros procesos patológicos. 


\subsubsection{Etiología de la rigidez de hombro en el DCA}

Las etiologías consideradas más frecuentes son la subluxación ${ }^{166.170 .171 .172 .173, ~}$ asociada en ocasiones a espasticidad de la musculatura periarticular ${ }^{177}$ y de forma menos común la distrofia simpáticorefleja ${ }^{146.177}$, si bien es cierto que en general el dolor se suele deber a trastornos combinados ${ }^{146}$. Estas causas provocan a menudo dolor en el paciente lo que ocasiona una rigidez en el complejo articular del hombro que pueden llegar a sufrir hasta el $74 \%$ de los pacientes con LCA $^{146}$. En el presente estudio, se han excluido aquellos sujetos que presentaban un dolor exagerado a la movilización así como los que tenían una espasticidad igual o superior a 1 en la escala de espasticidad de Ashworth.

Matteo Paci, PT et al. En $2002^{178}$ hacen una revisión de la literatura existente en la que se citan las una serie de causas y teorías para explicar la luxación glenohumeral (GHS) y la rigidez de hombro derivada. En ella se recoge lo siguiente:

En 1959, Basmajian y Bazant ofrecieron una teoría para explicar el desarrollo de complicaciones glenohumerales post-ACV ${ }^{165}$. Su propuesta fue que, durante la fase flácida, el tronco tiende a inclinarse o acortarse hacia el lado hemipléjico o afectado, lo que hace que la escápula descienda de su nivel horizontal normal. El trapecio y el serrato anterior también se vuelven flácidos, haciendo que la escápula también descienda y rote hacia abajo. Sin tono normal, el manguito rotador ya no puede mantener la integridad del complejo articular del hombro. El conjunto de estas condiciones contribuyen a una subluxación de la articulación glenohumeral. Durante la fase espástica, los músculos pectoral mayor y menor, romboides, elevador de la escápula y dorsal ancho pueden encontrarse hipertónicos, lo que se suma a la rotación de la escápula hacia abajo, y produce $\mathrm{GHS}^{179 .}$

Actualmente hay poca evidencia de que la orientación de la escápula interfiera en el desarrollo de GHS. ${ }^{166.167 .168}$. Prevost et al. Evaluaron a 5 pacientes con ACV sin encontrar ninguna asociación entre el SGA y una orientación hacia debajo de la escápula ${ }^{166}$. Ikai et al. informan de la presencia de SGA en tan sólo 1 de los 52 pacientes evaluados que tenían rotación escapular hacia abajo ${ }^{167}$ Culhan et al. ${ }^{168}$ obtuvo resultados similares en una muestra de 34 pacientes. y Price et al. En una de 30 pacientes todos ellos con ACV ${ }^{169}$. Recientemente, Zorowitz encontró reducciones espontáneas del SGA en pacientes con recuperación motora significativa ${ }^{170}$. Chang et al. consideran el deterioro sensorial un factor precipitante para el desarrollo del SGA ${ }^{171}$; Por el contrario, Daviet et al. no encontraron correlación significativa entre el deterioro sensorial y el SGA ${ }^{172}$. Varios autores ${ }^{173.174}$ sugieren que otros factores que contribuyen a la subluxación incluyen la colocación inadecuada, la falta de apoyo en la posición vertical, y tirar del brazo hemipléjico cuando el paciente es transferido. 


\section{MARCO TEÓRICO}

\subsubsection{Exploración del hombro ${ }^{10.90 .91 .92}$}

De manera sistemática, podemos establecer la siguiente exploración de hombro para todos los pacientes, hayan sufrido o no, una LCA.

Antes de comenzar con la exploración postural, debemos de asegurarnos que no presenta otras patologías de tipo neurológico o enfermedades sistémicas mayores que puedan enmascararse en una posible rigidez del complejo articular del hombro. Por ello antes de comenzar la exploración en sí, se deben descartar las siguientes entidades y/o patologías.

I. Descartar otros síndromes asociados ${ }^{10.90}$ : En primer lugar debemos de constatar que el paciente no presenta afecciones cardiorrespiratorias que refieran dolor en hombro y miembro superior. No obstante, suele venir acompañado de antecedentes familiares y/o personales de enfermedades cardiopulmonares así como de otras manifestaciones clínicas.

II. Descartar también cervicobraquialgias de origen radicular ${ }^{10.91 .92}$ que puedan irradiar dolor al hombro. Existen varios test traumatológicos (de tracción, distracción, Test de Jackson etc.) para su diagnóstico diferencial.

III. Exploración de los dermatomas y los reflejos osteotendinosos (ROT) si se presenta disminución o ausencia de los mismos, hay que sospechar de patología neurológica ${ }^{10.90}$

IV. Descartar el Síndrome del Desfiladero Torácico: produce dolor irradiado al hombro y miembro superior, provocado por la compresión del paquete vascular subclavio y plexo braquial. Existen también pruebas para su diagnóstico diferencial (Test de Adson ${ }^{16}$, $\operatorname{Roos}^{17}$, Wright ${ }^{15}$ etc.).

V. Síndrome del Nervio Supraescapular: compresión de este en el orificio coracoideo por engrosamiento del ligamento que lo recubre ${ }^{10}$.

\subsubsection{Exploración postural ${ }^{10}$}

Una vez que se ha comprobado que el problema es únicamente mecánico y del complejo articular del hombro, podemos evaluar la postura del individuo en si; esto es, sus curvaturas en los diferentes planos, la relación de sus hombros con las mismas, así como el patrón de postura global que adopta en el espacio.

\subsubsection{Exploración de la musculatura ${ }^{10}$}

Nos fijaremos fundamentalmente en el deltoides. En los casos de lesión que provoque inmovilización o falta de activación significativa del miembro (como es el caso del presente estudio, la musculatura tiende a atrofiarse, y si la pérdida de masa muscular es importante, la recuperación se dificulta en gran medida. 


\section{MARCO TEÓRICO}

Relacionado con esto, es importante tener en cuenta la posición que adopta la escápula respecto a la parrilla costal. El hallazgo de asimetría en la disposición de ambas escápulas puede deberse a una alteración del cinturón escapular (en función de qué músculos se encuentren hipo o hipertónicos) o bien a una disfunción en la articulación escápulotorácica.

\subsubsection{Exploración ósea ${ }^{91}$}

Además de la escápula, se tendrá en cuenta la posición de la clavícula y del muñón del hombro (a nivel de la cabeza humeral y del troquín).

\subsubsection{Exploración física del hombro (palpación de estructuras) ${ }^{91}$}

Deberán de palparse la piel, el tejido celular subcutáneo (TCS), las estructuras óseas (ya comentadas). El tejido capsuloligamentoso y muscular.

\subsubsection{Valoración del movimiento activo ${ }^{91}$}

En la valoración del movimiento activo del hombro se evalúa la actuación en conjunto de todas las articulaciones integrantes del complejo articular.

Se han de observar tanto la cantidad del movimiento (amplitud total) como la capacidad de contracción muscular de los músculos implicados (agonistas) en cada movimiento.

Se deben de valorar de forma analítica cada uno de los movimientos que se realizan en el hombro (flexión, extensión, abducción, aducción, rotaciones externa e interna). Si el movimiento activo está limitado, puede ser por lo siguiente:

I. Insuficiencia Muscular: el movimiento activo no estaría limitado

II. Dolor que impide el movimiento e inhibe la contracción muscular: el movimiento pasivo no está limitado a no ser que el dolor desencadene espasmo reflejo.

III. Acortamiento muscular o de estructuras capsuloligamentosas que impiden el movimiento que provoca su estiramiento: el movimiento pasivo está también limitado.

IV. Insuficiencia mecánica por alteración articular: el movimiento pasivo también está limitado. 


\section{MARCO TEÓRICO}

Para realizar una valoración rápida se pueden realizar dos pruebas:

I. Que el paciente lleve la mano al borde superior de la escápula contraria por detrás de la cabeza (testando anteversión, abducción y rotación externa máximas).

II. Que el paciente leve la mano al ángulo inferior de la escápula contraria por detrás de la espalda (testando retroversión, aducción y rotación interna máximas).

\subsubsection{Examen de la movilidad pasiva ${ }^{10}$}

Es esta valoración la que más nos interesa en el estudio. Aquí se emplea la fuerza del terapeuta que sustituye a la contracción muscular activa del paciente para efectuar los movimientos. Se valorarán por tanto:

I. La amplitud del movimiento pasivo. Si éste estuviera limitado estaría provocado por alteraciones articulares o retracción de estructuras capsuloligamentosas y musculares. En este punto hay que señalar que el dolor y la inseguridad del paciente pueden desencadenar un espasmo muscular reflejo que fije la articulación e impida su extensibilidad, por lo que el paciente debe estar muy relajado al realizar la prueba y ésta debe efectuarse con suavidad.

II. La existencia de arcos dolorosos provocados por la lesión de estructuras no contráctiles.

III. El tope o sensación final del movimiento.

Cuando existe imitación en el movimiento pasivo es importante observar el tope final para poder conocer la procedencia de esa restricción. La pericia y experiencia del examinador permiten que éste perciba diferentes tipos de sensaciones al final de distintas alteraciones en el movimiento pasivo articular. Según Cyriax estos topes son:

I. Tope duro, resultante del choque entre estructuras óseas.

II. Freno brusco, provocado por un espasmo muscular periarticular.

III. Tope elástico, asociado al acortamiento de partes blandas, que en el caso de que sean musculares se acompañará de una sensación de rebote.

IV. Aproximación de partes blandas o interposición de éstas entre segmentos óseos, que impiden que sea mayor la extensión articular.

En el caso de los pacientes del estudio, éstos tendrán un tope elástico asociado al acortamiento de las partes blandas (cápsula y ligamentos) así como de los músculos adyacentes). 


\section{MARCO TEÓRICO}

\subsubsection{Signos de pinzamiento subacromial ${ }^{136}$}

Aparecen en la elevación activa del brazo entre los $60^{\circ}$ y $\operatorname{los} 120^{\circ}$. Son sensaciones de dolor que pueden volver a ser percibidas al descender o volver el brazo a su posición original.

Otras maniobras que indican este mismo conflicto son las de $\mathrm{Neer}^{19}$, Hawkins $^{20}$, Yocum, Jobe, Patte, Gerber o Speed ${ }^{18}$. Todas ellas ponen en tensión de una u otra manera el espacio subacromial ${ }^{10}$. 


\section{EVALUACIÓN EN FISIOTERAPIA DEL DAÑO CE- REBRAL ADQUIRIDO}

En fisioterapia es fundamental la rehabilitación, recuperación y adaptación de los pacientes con Daño Cerebral Adquirido2.

Determinar los efectos que un trastorno neurológico produce en una persona y los resultados obtenidos tras el tratamiento sólo es posible si la exploración neurológica se realiza mediante recursos validados y contrastados, para que esta resulte estandarizada. Desde la década de 1950 en fisioterapia se aboga por este concepto que busca el registro estadístico basado en la evidencia científica más allá de lo meramente empírico.

Dicho registro debe ser objetivo, sistemático y secuencial, para ello, se emplean diferentes escalas de valoración neurológica.

Basándonos en un modelo multidisciplinar de evaluación del DCA, es necesario atender a los siguientes aspectos, que son comunes a todos los pacientes en mayor o menor medida36.

- Problemas sensitivo-motores

- Evaluación de las alteraciones perceptivas

- Evaluación de los trastornos cognitivos y afectivos

- Evaluación de los problemas psicosociales

- Evaluación funcional y ocupacional

Será esta última evaluación la que tenga objeto de análisis en el presente estudio, por estar relacionada de manera directa con la rehabilitación física y la fisioterapia.

\subsection{MODELO ICF}

Conceptualmente, la fisioterapia (entendida como ciencia holística) se basa en el modelo llamado Clasificación Internacional del Funcionamiento, de la Discapacidad y de la Salud (International Classification of Functioning, Disability and Health, ICF) elaborado en el 2001 por la Organización Mundial de la Salud (OMS). Este documento es a su vez una revisión de uno anterior (1980) denominado Clasificación Internacional de Deficiencias, Discapacidades y Minusvalías (CIDDM) también estructurado por la $\mathrm{OMS}^{6}$.

De manera esquemática, podemos entender este modelo de la siguiente manera: 


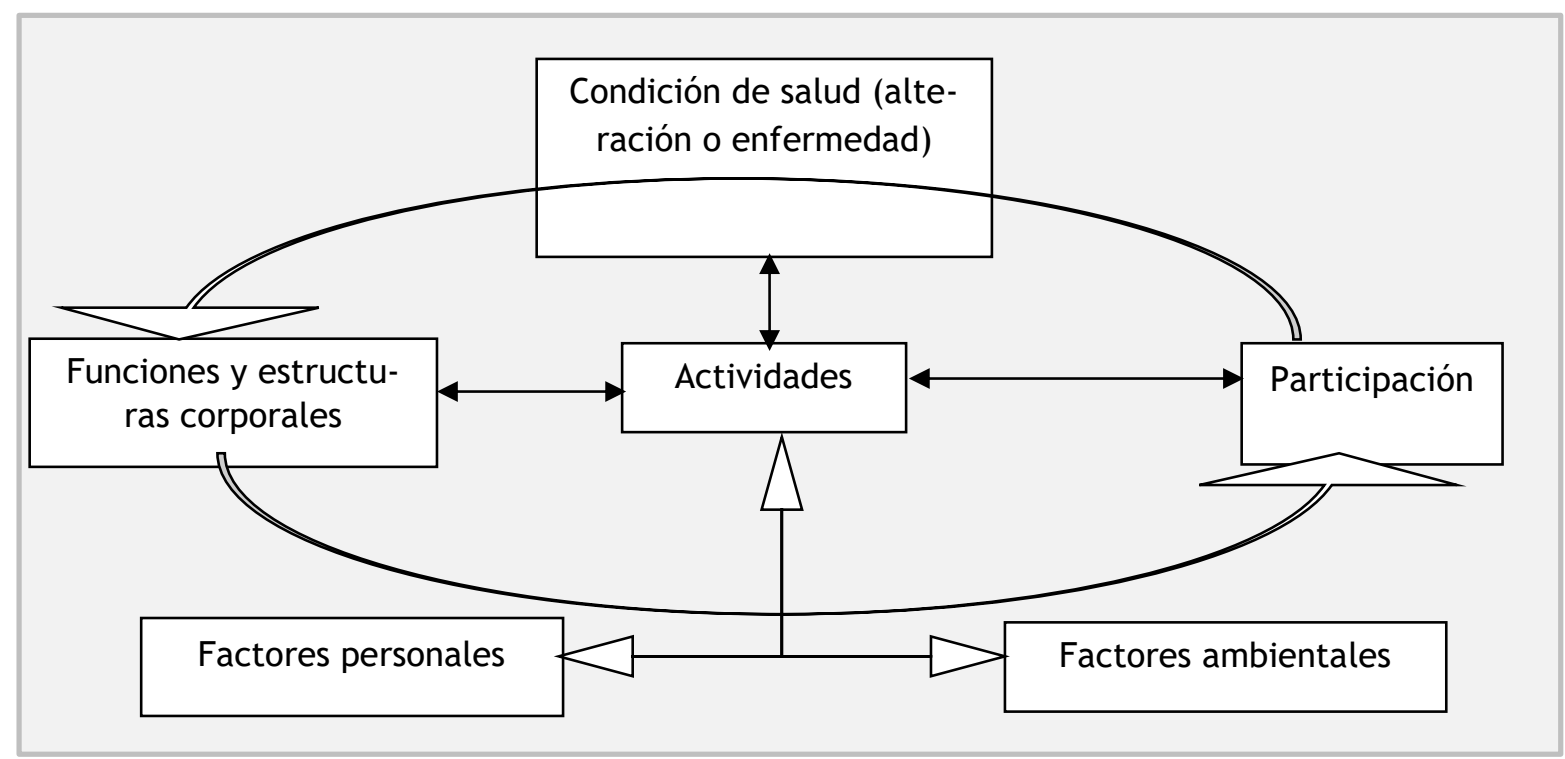

Figura 2: Modelo de la Clasificación Internacional del Funcionamiento según la OMS

Así, el funcionamiento y la discapacidad del individuo se conciben como una interacción dinámica entre los estados de salud y os factores contextuales, ya sean personales y/o ambientales ${ }^{2}$. 


\subsubsection{Instrumentos de medida según el modelo ICF}

\begin{tabular}{|c|c|c|}
\hline Parámetro & Instrumento de medida & $\begin{array}{l}\text { Referencia biblio- } \\
\text { gráfica }\end{array}$ \\
\hline \multicolumn{3}{|c|}{ Déficit } \\
\hline Hipertonía & $\begin{array}{l}\text { Escala modificada de Ashworth (Mo- } \\
\text { dified Ashworth Scale, MAS) }\end{array}$ & $\begin{array}{l}\text { Bohannon y Smith, } \\
1987^{93}\end{array}$ \\
\hline Fatigabilidad & $\begin{array}{l}\text { Escala modificada del Impacto de la } \\
\text { Fatiga (Modified Fatigue Impact Scale, } \\
\text { MFIS) }\end{array}$ & Fisk et al.; $1994^{96}$ \\
\hline \multicolumn{3}{|c|}{ Nivel de actividad } \\
\hline \multirow[t]{2}{*}{$\begin{array}{l}\text { De forma gené- } \\
\text { rica }\end{array}$} & Índice de Barthel & $\begin{array}{l}\text { Mahoney \& Barthel, } \\
1965^{97}\end{array}$ \\
\hline & $\begin{array}{l}\text { Medida de la Independencia Funcional } \\
\text { (Functional Independence Measure, } \\
\text { FIM) }\end{array}$ & $\begin{array}{l}\text { Granger et al., } \\
1993^{98}\end{array}$ \\
\hline \multirow{3}{*}{$\begin{array}{l}\text { De forma especí- } \\
\text { fica } \\
\text { Marcha } \\
\text { Equilibrio }\end{array}$} & Motor Assessment Scale para AVC & Carr et al., $1985^{99}$ \\
\hline & Ten Metres Walking Test & Wade, $1992^{100}$ \\
\hline & Time Get up and Go Test & $\begin{array}{l}\text { Podsialo y Richard- } \\
\text { son, } 1991^{101}\end{array}$ \\
\hline \multicolumn{3}{|c|}{ Nivel de participación } \\
\hline Calidad de vida & $\begin{array}{l}\text { Cuestionario de Salud SF-36 } \\
\text { Escala de Discapacidad de Londres } \\
\text { (London Handicap Scale, LHS) }\end{array}$ & $\begin{array}{l}\text { Ware et al., } 1993^{102} \\
\text { Hardwood et al., } \\
1994^{103}\end{array}$ \\
\hline
\end{tabular}

Tabla 4: Instrumentos de medida que recoge la CIF

En el presente estudio se han utilizado el Índice de Barthel (IB en lo sucesivo) y la Medida de la Independencia Funcional como indicador del nivel de actividad, el Cuesionario de Salud SF-36 como medida del nivel de participación y calidad de vida y la Escala Modificada de Ashworh (Modified Ashworth Scale, MAS) como indicador de una posible hipertonía, y por tanto criterio de exclusión del estudio, como más adelante veremos. 


\title{
4.2. INSTRUMENTOS DE MEDIDA EMPLEADOS EN ESTE ESTUDIO
}

En este estudio se han empleado una serie de escalas de medida en base a cuantificar las deficiencias en salud del individuo. Todas ellas están validadas y pertenecen a la tabla anterior.

\author{
Índice de Barthel \\ Cuestionario de Salud SF-36 \\ MIF
}

(Ver ANEXO I)

Además se ha empleado la goniometría para medir el balance articular de hombro mediante el sistema SFTR

A continuación se ofrece una explicación de cada uno de estos instrumentos de medición. 


\subsection{1. ÍNDICE DE BARTHEL}

\subsubsection{Origen}

Fue creado en 1965 por Mahoney y Barthel para la valoración de pacientes con $\mathrm{ACV}$, sin embargo ha demostrado su utilidad en la valoración de cualquier paciente anciano y/o dependiente ${ }^{108}$. Es el instrumento recomendado por la British Geriatrics Society para la evaluación de las AVBD ${ }^{106}$.

El IB fue uno de los primeros intentos de cuantificar la discapacidad, sumado a los resultados que obtenían los profesionales de rehabilitación en los programas de mejora de los niveles de dependencia de los pacientes ${ }^{106}$.

La elección de las actividades que componen el IB fue empírica, a partir de las opiniones de fisioterapeutas, enfermeros y médicos. Por tanto no está basado en un modelo previo que justifique la elección de determinadas actividades de la vida diaria o la exclusión de otras ${ }^{107.108 .106 .}$.

\subsubsection{La escala: recogida de datos e interpretación ${ }^{105.108}$}

La escala se divide en 10 ítems correspondientes a las AVDB, incluyendo capacidad para bañarse, asearse, subir escaleras, deambular, desplazarse de la cama al sillón, usar el retrete, vestirse, alimentarse y continencia de esfínteres. A cada uno de ellos se les asigna un valor en función de si la persona es independiente para esa actividad, semiindependiente o dependiente. La suma de todos los valores obtenidos variará entre el 0 , totalmente dependiente y 100 , totalmente independiente ${ }^{108}$.

Para la asignación de la puntuación de cada ítem se deben preguntar al paciente o al cuidador si es capaz de realizar la actividad propuesta o bien observar al enfermo, aunque la comprobación directa no es necesaria.

Las categorías medias implican que el paciente puede aportar el 50\% del esfuerzo para realizar la actividad. Se debe tener en cuenta que lo que se mide es lo que el paciente hace en la vida diaria, no lo que podría llegar a hacer. Si el paciente precisa supervisión no se le puede considerar independiente, y si utiliza ayudas técnicas sin supervisión, ni ayuda, sí se le considera independiente.

El rango de valores posibles del IB oscila entre 0 y 100 , con intervalos de 5 puntos si tomamos como referencia la versión original siendo 0 el mayor grado de dependencia y 100 la independencia absoluta ${ }^{106.108}$.

Algunos autores han propuesto puntuaciones de referencia para facilitar la interpretación del IB. Por ejemplo, se ha observado que una puntuación inicial de más de 60 se relaciona con una menor duración de la estancia hospitalaria y una mayor 


\section{MARCO TEÓRICO}

probabilidad de reintegrarse a vivir en la comunidad después de recibir el alta. Esta puntuación parece representar un límite: con más de 60 casi todas las personas son independientes en las habilidades básicas para el desempeño de las ABVD ${ }^{111.113}$.

La interpretación sugerida por Shah et al. ${ }^{114}$ sobre la puntuación del IB es:
○ 0-20: Dependencia total
o 21-60: Dependencia severa
- 61-90: Dependencia moderada
- 91-99: Dependencia escasa
- 100: Independencia

Por otra parte también se ha intentado jerarquizar las actividades incluidas en el IB según la frecuencia con que se observa independencia en su realización. Según los resultados de Granger et al. ${ }^{114}$ el orden es el siguiente:

1. Comer

2. Aseo

3. Control de heces

4. Control de orina

5. Baño

6. Vestirse

7. Usar el retrete

8. Traslado cama/silla

9. Desplazarse

10. Subir/bajar escaleras

Comer es la actividad en la que se observa independencia con más frecuencia. Wade y Hewer observaron que la recuperación de las diferentes actividades ocurría en un orden jerárquico bien definido. Bañarse sin ayuda fue la actividad que se recuperaba más tarde, siendo la incontinencia ocasional de heces la primera en recuperarse ${ }^{113}$. 


\subsubsection{Molestias para el paciente. Aceptabilidad}

Las molestias que puede ocasionar el IB al paciente son escasas (únicamente hay que observarle/preguntarle).

Para los encargados de puntuar el IB la molestia es también escasa. Collin et al. informan que realizar la evaluación mediante preguntas a cuidadores o a familiares se realiza en 2-5 minutos ${ }^{110}$. La versión de autovaloración de la discapacidad, en pacientes que saben leer y escribir, requiere aproximadamente 10 minutos ${ }^{115}$.

El IB resulta un instrumento sencillo, fácil de aprender y de interpretar y que puede ser repetido periódicamente. Se ha sugerido que el intervalo mínimo entre la administración consecutiva de la escala en centros de rehabilitación es de dos semanas $^{114}$.

Este índice ha sido aplicado tanto por profesionales sanitarios como por entrevistadores no sanitarios entrenados ${ }^{113}$. Se requiere una sesión única de aproximadamente una hora para aprender a puntuar el $\mathrm{IB}^{113}$.

\subsubsection{Adaptación linguiística y cultural}

El IB no requiere una adaptación lingüística propiamente dicha ya que se basa en la observación de actividades muy específicas o en la consulta a cuidadores o próximos. Sólo es necesario realizar una traducción simple de las actividades y categorías de puntuación.

El IB es utilizado en múltiples países. La traducción al español de la puntuación se realizó por los autores Baztán et al ${ }^{116}$.

\subsubsection{Estudios que han empleado el Índice de Barthel}

El IB ha sido utilizado en diferentes poblaciones y con propósitos diversos. A continuación se presenta una selección de las principales aplicaciones de este índice.

○ Originalmente el IB se aplicó en centros de rehabilitación física para evaluar la capacidad funcional de pacientes con discapacidades y especialmente de pacientes con ACVA ${ }^{106,107-112,114}$.

- En la atención domiciliaria, para organizar y protocolarizar la atención de los servicios sanitarios de ayuda a domicilio ${ }^{117}$. 


\section{MARCO TEÓRICO}

- En residencias de ancianos y unidades geriátricas para valorar y pautar protocolos de actuación ${ }^{118,119}$.

- A nivel investigador, en ensayos clínicos randomizados ${ }^{120}$.

- Como referencia para estudiar las características de nuevas escalas. ${ }^{121}$

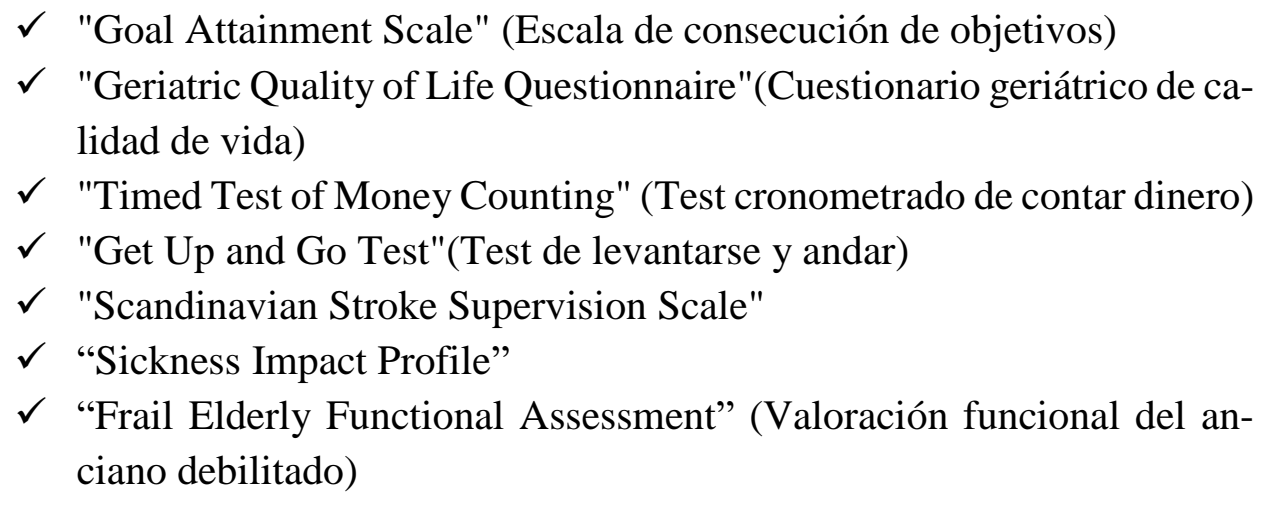

\subsubsection{Ventajas e inconvenientes ${ }^{106.107 .108}$}

Las ventajas que aporta el IB vienen derivadas de contemplar más medidas de movilidad que otros índices de similares características. El índice de Katz por ejemplo, es menos completo ya que no aborda la deambulación o la subida de escaleras. Esto d mayor poder discriminativo. Es un instrumento cuya validez, fiabilidad y sensibilidad a los cambios le hacen muy útil para describir la situación funcional y los cambios a lo largo del tiempo. Además, resulta bastante rápido evaluar a los pacientes con él.

La principal crítica que ha recibido es el hecho que su sensibilidad para detectar pequeños cambios es excesiva. Por otro lado, tiene un alto efecto techo (imposibilidad de medir la incapacidad dado un determinado umbral). ${ }^{104}$

\subsubsection{Propiedades psicométricas}

\section{Fiabilidad}

La fiabilidad (o capacidad de una prueba para obtener los mismos resultados bajo las mismas condiciones) del IB no fue determinada cuando se desarrolló originariamente. Loewen y Anderson ${ }^{109}$ se atribuyen haber realizado el primer estudio de fiabilidad del IB en su versión original comprobando la fiabilidad mediante pruebas de concordancia inter e intra observador.

Para ello entrenaron a catorce terapeutas que, usando grabaciones de vídeo de pacientes, puntuaron la realización de las actividades. De los resultados de este estudio se deduce una buena fiabilidad interobservador, con índices de Kappa entre 0,47 y 


\section{MARCO TEÓRICO}

1,00. Con respecto a la fiabilidad intraobservador se obtuvieron índices de Kappa entre 0,84 y $0,97^{109,110}$.

En cuanto a la evaluación de la consistencia interna, se ha observado un alpha de Cronbach de 0,86-0,92 para la versión original (empleada en este estudio).

\section{Validez}

A la hora de considerar la validez del IB (capacidad de un instrumento para medir lo que tiene que medir) hay que tener en cuenta que este índice se ha elaborado sobre bases empíricas, lo cual limita la posibilidad de llevar a cabo una evaluación exhaustiva de este criterio.

Se han realizado estudios de validez de constructo o validez de concepto, comparándose el IB con otras medidas con las que hipotéticamente guarda relación. En este sentido se ha observado que el IB inicial es un buen predictor de la mortalidad $^{106.107}$. Es presumible que esta asociación se deba a la habilidad del IB para medir discapacidad, cualidad que también presenta una asociación fuerte y consistente con una mayor mortalidad. También se ha observado que entre los pacientes con ACVA los más jóvenes presentan grados menores de discapacidad ${ }^{106}$.

Se ha observado también una relación consistente entre la puntuación del IB y la evaluación realizada por el clínico al alta ${ }^{106,107 .}$

Wade y Hewer ${ }^{113}$ realizaron una evaluación de la validez del IB en 572 pacientes con ACV agudo mediante la comparación con un índice de motricidad, obteniendo correlaciones significativas entre 0,73 y 0,77 . Por otra parte, se ha observado que los pacientes con esta misma patología que reciben tratamiento precoz presentan una mejora más rápida del IB que los que lo reciben más tardíamente ${ }^{106}$.'

\section{Sensibilidad y capacidad para detectar cambios}

Uno de los motivos por los que se creó el IB fue para valorar la evolución de los pacientes. La evidencia empírica ha probado que el IB es capaz de detectar un progreso o deterioro en ciertos niveles del estado funcional ${ }^{108}$, aunque su capacidad para detectar cambios en situaciones extremas es limitada ${ }^{111.112}$. Por ejemplo, si una persona con una puntuación de 0 cae en una situación de inconsciencia y por tanto en un mayor nivel de dependencia, el IB no cambia. Así mismo, en la parte alta de la escala, un joven atleta profesional y un anciano independiente obtendrían la misma puntuación. Esto es lo que se conoce como flooreffect y ceilingeffect (efecto suelo y efecto techo, respectivamente $)^{108}$. Estos inconvenientes no son especialmente problemáticos en la práctica clínica, mientras que en el ámbito de la investigación conviene 
tenerlos en cuenta. Sin embargo para aquellas personas con puntuaciones intermedias los cambios son fácilmente detectados.

Cabe señalar que la versión del IB con 5 niveles de puntuación se desarrolló precisamente para incrementar la sensibilidad de la escala a pequeños cambios ${ }^{114}$. 


\subsubsection{MEDIDA DE LA INDEPENDENCIA FUNCIONAL}

\subsubsection{Origen}

La FIM ${ }^{122}$ es el instrumento más ampliamente aceptado como medida de funcionalidad en el ámbito de la rehabilitación. Se desarrolló ante la falta de una medida uniforme de la discapacidad y de los resultados tras el tratamiento rehabilitador. Fue un índice desarrollado en los años ochenta por un consorcio del Congreso Americano de Rehabilitación y la Academia Americana de Medicina Física y Rehabilitación ${ }^{123}$.

Este primer borrador se creó con la idea de crear un índice de medida global de incapacidad, similar al Barthel, pero con mayor sensibilidad y que tuviera en cuenta las alteraciones cognitivas y psicosociales que el IB no incluía. Es de gran aceptación y uso en los Estados Unidos.

\subsubsection{La escala: recogida de datos e interpretación}

Es un instrumento para determinar la capacidad funcional entre pacientes ingresados en rehabilitación. Discrimina pacientes según edad, comorbilidad y destino al alta. Distingue diferentes grados de gravedad entre pacientes con lesión medular y enfermedad vascular cerebral.

Cada una de las 18 áreas que comprenden el FIM (13 motoras y 5 cognitivas) tienen un máximo de puntuación de siete y la puntuación más baja es de uno. Con un máximo total de 126 como máxima independencia funcional ${ }^{123}$.

Valora la cantidad de ayuda que requiere una persona para realizar las ABVD con seguridad y efectividad, y para valorar la cantidad de ayuda que requerirá una persona discapacitada en su medio. Mide lo que realmente la persona puede hacer independientemente del diagnóstico y de las capacidades potenciales. Todos los ítems deben ser completados, no se considera que un ítem no pueda ser respondido.

Esta escala se divide en dos subescalas: una motora y otra cognitiva. La subescala motora comprende las áreas del autocuidado, el control de esfínteres, la movilidad y la ambulación. La cognitiva se encarga de la comunicación y el conocimiento social.

Cada uno de los apartados motores comprende los siguientes aspectos: 


\section{MARCO TEÓRICO}

○ Autocuidado

I. Alimentación

II. Arreglo personal

III. Baño

IV. Vestido hemicuerpo superior

V. Vestido hemicuerpo inferior

VI. Aseo perineal

- Control de esfínteres

I. Control de la vejiga

II. Control del intestino

○ Movilidad

I. Traslado de la cama a silla o silla de ruedas

II. Traslado en baño

III. Traslado en bañera o ducha

- Ambulación

I. Caminar/desplazarse en silla de ruedas

II. Subir y bajar escaleras

Por su parte las áreas cognitivas engloban los siguientes aspectos

- Comunicación

I. Compresión

II. Expresión

○ Conocimiento social

I. Interacción social

II. Solución de problemas

III. Memoria 
Cada ítem se puntúa con un valor del 1 al 7 siendo 1 la máxima dependencia y 7 la independencia completa. Atendiendo a este sistema se establece el siguiente criterio.

○ Independencia

- Independencia Completa: 7 puntos

- Independencia con cierta limitación: 6 puntos

- Dependencia moderada

- Supervisión: 5 puntos

- Mínima asistencia (realiza por sí mismo el 75\% de la actividad o más): 4 puntos

- Moderada asistencia (realiza por sí mismo el 50\% de la actividad o más): 3 puntos

○ Dependencia completa

- Asistencia máxima (realiza por sí mismo el $25 \%$ de la actividad más): 2 puntos

- Total asistencia (no realiza por sí mismo el 75\% de la actividad): 1 punto

\subsubsection{Molestias para el paciente. Aceptabilidad}

La escala MIF es un cuestionario incómodo de pasar ${ }^{122}$ debido a la necesidad de ser realizado dentro de un equipo multidisciplinar que estaría compuesto por logopeda, personal de enfermería, médico rehabilitador, fisioterapeuta, terapeuta ocupacional, etc.

Sin embargo, de cara al paciente, no supone perturbación añadida.

La recogida de los datos debe ser de lo que el paciente realiza de forma habitual y no de lo que el paciente es capaz de hacer o ha realizado de forma ocasional. Si hay funciones que el paciente es solo capaz de realizarlas en determinados ambientes o en determinadas horas del día, se debe recoger la puntuación más baja.

\subsubsection{Propiedades psicométricas}

\section{Fiabilidad}

En la evaluación de las pruebas psicométricas en numerosos artículos ha demostrado validez, fiabilidad y sensibilidad ${ }^{124,125}$.

El principal medio de evaluar la fiabilidad de la FIM es el acuerdo entre los distintos evaluadores, teniendo en cuenta que la variedad de profesionales que va a emplear esta escala es amplia: (médicos, enfermeros, fisioterapeutas y terapeutas ocupacionales). 


\section{MARCO TEÓRICO}

Se ha demostrado la fiabilidad intraobservador de los ítems motores en la FIM en el hospital y en el domicilio, pero falla la fiabilidad interobservador en los ítems de transferencias, locomoción, interacción social y los que se engloban en el FIM cognitivo ${ }^{126}$. Además la escala cognitiva FIM muestra un efecto techo notable en pacientes con EM, lo cual limita su utilidad en la medición de resultados en este proceso ${ }^{127}$. Además la valoración en rehabilitación neurológica de los déficits motores es sobre todo cualitativa y carece de estandarización ${ }^{124}$.

\section{Validez}

La validez de construcción de la FIM está demostrada, tiene gran fiabilidad test-retest y puede ser un instrumento muy útil en la valoración funcional de personas de 80 o más años de edad ${ }^{128}$.

La FIM puede utilizarse para objetivar cambios durante la rehabilitación del paciente ingresado y para comparar diferentes unidades de rehabilitación. De hecho, ya en 1996 Grimby estableció una fuerte correlación entre la puntuación FIM en admisión y al alta. En pacientes con ACV los ítems físicos influencian más del $50 \%$ de la duración de la estancia ${ }^{129}$.

\section{Sensibilidad y capacidad para detectar cambios}

Algunos autores la critican por ser insensible para detectar cambios clínicos, inadecuada para los niveles de asistencia ambulatoria y exigir un importante entrenamiento para lograr su correcta aplicación ${ }^{124}$. 


\section{MARCO TEÓRICO}

\subsubsection{CUESTIONARIO DE SALUD SF-36}

\subsubsection{Origen e historia ${ }^{134}$}

El cuestionario de salud SF-36 se desarrolló a principios de los años noventa en Estados Unidos para su uso en el Estudio de los Resultados Médicos (Medical Outcomes Study, MOS $)^{131}$. Es una escala genérica que proporciona un perfil del estado de salud y es aplicable tanto a la población general como a los pacientes.

Ha resultado útil para evaluar la calidad de vida relacionada con la salud (CVRS) en la población general y en subgrupos específicos. Además ha servido como instrumento para detectar los beneficios que producen en la salud determinados tratamientos, valorar el estado de salud de pacientes a título individual así como comparar diversas enfermedades y la carga que representan en una población.

\subsubsection{La escala: recogida de datos e interpretación ${ }^{136}$}

El Cuestionario de Salud SF-36 está compuesto por 36 preguntas o ítems que valoran los estados tanto positivos como negativos de la salud. Se desarrolló a partir de una extensa batería de cuestionarios empleados en el MOS, que incluían 40 conceptos relacionados con la salud ${ }^{132}$. El cuestionario abarca 8 niveles, que representan los conceptos de salud empleados con más frecuencia en los principales cuestionarios de salud, así como los aspectos más relacionados con la enfermedad y el tratamiento ${ }^{132}$.

Los 36 ítems del instrumento cubren las siguientes escalas: función física, rol físico, dolor corporal, salud general, vitalidad, función social, rol emocional y salud mental. Adicionalmente, el SF-36 incluye un ítem de transición que pregunta sobre el cambio en el estado de salud general respecto al año anterior. Este ítem no se utiliza para el cálculo de ninguna de las escalas pero proporciona información útil sobre el cambio percibido en el estado de salud durante el año previo a la administración del SF-36. Las escalas del SF-36 están ordenadas de forma que a mayor puntuación mejor es el estado de salud.

Hay dos versiones del cuestionario en cuanto al período recordatorio: la «estándar» (4 semanas) y la «aguda» (1 semana). En este estudio se ha empleado la versión estándar que recoge la información respecto al último mes. (ANEXO I). 


\section{MARCO TEÓRICO}

\subsubsection{Propiedades métricas de los componentes sumarios de SF-36 ${ }^{130}$.}

La evaluación de esta escala, al no ser tipo Likert como las anteriores se realiza de manera diferente.

La evaluación de la validez de contenido de los componentes sumarios del SF-36 se beneficia de la ya realizada sobre sus dimensiones dado que el contenido de los ítems es el mismo y únicamente varían los cálculos para la obtención de las puntuaciones.

La validez de criterio (el grado en que las medidas obtenidas con un instrumento se asemejan a las obtenidas con el método estándar o de referencia) se evaluó mediante el coeficiente $\mathrm{R}^{2}$ obtenido en los modelos de regresión construidos para predecir las puntuaciones sumario del SF-36 a partir de los ítems del SF-12 (versión simple de este cuestionario).

Para la evaluación de la validez de constructo se emplearon los coeficientes de validez relativa obtenidos de la versión española del SF-36, que estiman la interrelación entre conceptos afines al objeto de la medición.

Finalmente, la fiabilidad de los componentes sumarios (grado en que están libres de error aleatorio) se evaluó en términos de consistencia interna (homogeneidad). Dado que los componentes sumarios del SF-36 son una combinación lineal de las 8 dimensiones que miden diferentes constructos de salud, para la estimación de la consistencia interna del CSF y el CSM se tuvieron en cuenta la fiabilidad de cada una de las 8 dimensiones y las covariancias entre ellas.

\subsubsection{Molestias para el paciente. Aceptabilidad ${ }^{133}$}

El cuestionario está dirigido a personas de $\geq 14$ años de edad y preferentemente debe ser autoadministrado, aunque también es aceptable la administración mediante entrevista personal y telefónica. La consistencia interna no presentó diferencias entre los cuestionarios autoadministrados y los administrados mediante entrevista.

\subsubsection{Propiedades psicométricas}

\section{Fiabilidad}

En la mayoría de los estudios, el coeficiente de consistencia interna $\alpha$ de Cronbach superó el valor mínimo recomendado para las comparaciones de grupos ( $\alpha$ de Cronbach $=0,7$ ) en todas las escalas, excepto en la escala función social. Las escalas rol físico, función física y rol emocional obtuvieron los mejores resultados de fiabilidad y en la mayoría de ocasiones superaron el valor de 0,90, límite recomendado para las comparaciones individuales. 
Con el fin de obtener una estimación conjunta del coeficiente $\alpha$ de Cronbach de cada escala a partir de todos los estudios, se llevó a cabo un metaanálisis para cada una de las escalas utilizando siempre el modelo de efectos aleatorios, dado que se observó heterogeneidad entre los estudios en todos los casos. Las estimaciones conjuntas obtenidas a partir del metaanálisis de los coeficientes $\alpha$ de Cronbach fueron $\geq 0,9$ para las escalas función física, rol físico y rol emocional. Las estimaciones conjuntas del resto de las escalas superaron el valor de 0,7 .

\section{Sensibilidad y capacidad para detectar cambios}

El efecto suelo del cuestionario fue inferior al $15 \%$ para todas las escalas en la mayoría de los estudios, excepto en las escalas de rol físico y rol emocional de la muestra de pacientes con EPOC ${ }^{134}$ y la de pacientes con una posible cardiopatía isquémica $^{135}$, donde fueron superiores al 17,5\%. El valor máximo observado fue del 33,0\%. El efecto techo fue inferior al $15 \%$ para las escalas de función física, salud general, vitalidad y salud mental en la mayoría de estudios. Sin embargo, se mantuvo elevado en el resto de las escalas, en especial para las escalas rol físico y rol emocional.

\section{Validez}

El SF-36 ha demostrado validez predictiva tras intervenciones de cirugía coronaria, diálisis renal crónica, diabetes, evolución de la EPOC ${ }^{134}$ etc.

En cuanto a la validez de constructo, la escala ha mostrado utilidad en la valoración de la CVRS en pacientes con Cardiopatía ${ }^{135}$, asma' EPOC ${ }^{134}$ y otras enfermedades de larga evolución. 


\section{MARCO TEÓRICO}

\subsubsection{SISTEMA SFTR ${ }^{122.123 .124}$}

El sistema SFTR combina el método de 0 a 180 para anotar las medidas del grado de movilidad con una disposición sistemática de las reglas para registrar dichas mediciones. Las reglas son las siguientes:

○ Los movimientos de las articulaciones se miden desde la posición anatómica.

- Todos los movimientos y posiciones de las articulaciones de registran en los tres planos básicos del espacio: frontal, transversal y rotacional.

- Los movimientos de rotación interna y rotación externa se registran como rotaciones únicamente.

- Todos los movimientos se registran mediante tres números. Los que alejan a la articulación del cuerpo se registran en primer lugar y los que la acercan los últimos. La posición inicial se registra en el medio y normalmente es el 0.

- En las rotaciones e inclinaciones de columna, está estipulado que primero se registren hacia el lado izquierdo. (En el resto de rotaciones articulares, las que alejen al cuerpo más de la articulación se anotarán en primer lugar).

- Cada plano del espacio se registra mediante una letra:

$$
\begin{array}{ll}
\checkmark & \text { F : Plano frontal } \\
\checkmark & \text { T: Plano transversal } \\
\checkmark & \text { R: Plano rotacional }
\end{array}
$$

Particularizando en el aspecto del rango articular, también evaluado en este estudio, ${ }^{5}$ hemos de precisar que el concepto de rango articular en las articulaciones individuales (en este caso el complejo articular del hombro) se basa en la idea de que los movimientos pasivos de cualquier articulación en todo su rango proporcionarán información confiable sobre la capacidad del paciente para utilizar activamente los rangos realizados de manera pasiva, siempre que sus músculos sean lo bastante fuertes como para realizar el movimiento.

Este tipo de evaluación suele efectuarse en asociación con la evaluación funcional, pero no se relaciona con ella. Además, en pacientes con LCA no tiene en cuenta el efecto de la espasticidad sobre el rango articular, lo cual puede ser determinante. 


\subsection{EVALUACIÓN DEL TONO Y LAS REACCIONES POSTURALES A LA MOVILIZACIÓN EN LA LE- SIÓN CEREBRAL ADQUIRIDA}

En relación con lo dicho anteriormente en torno a la espasticidad, y siguiendo con la doctrina de B. Bobath ${ }^{5}$; si comparamos las reacciones de una persona normal cuando se le moviliza una articulación con las de un paciente con hemiplejia, éstas serán bien distintas. Una persona con un sistema nervioso central normal (coordinación y tono no alterados) conseguirá que sus músculos se adapten activa y automáticamente a cualquier cambio de postura o movimiento. La adaptación automática es protectora contra las lesiones, o la pérdida del equilibrio.

Sin embargo el paciente que presenta alteraciones del tono y de la coordinación no se adapta a los cambios de postura ${ }^{7,9}$. En presencia de espasticidad existe una excesiva resistencia a la movilización en contra de los patrones de espasticidad y una excesiva asistencia al movimiento a favor del patrón espástico. Este paciente ha perdido también las reacciones posturales normales contra la gravedad. Un ejemplo de esto es que al inclinarse hacia delante al sentarse se contraen los flexores del tronco sin que haya contracción de los músculos espinales, por lo que el paciente tiende a caerse hacia delante.

En el caso de los miembros, y particularizando en el caso de la cintura escapular que es lo que nos atañe, el paciente que presente LCA con espasticidad perderá también de manera general la adaptación normal de los músculos contra la gravedad durante los movimientos de sus miembros ${ }^{7}$. La contracción espástica de los flexores y depresores de la cintura escapular suprime la actividad postural normal de sus antagonistas. En lugar de relajarse en un movimiento hacia abajo a favor de la gravedad, esta contracción espástica aumenta incluso al final del movimiento, es decir que se hace más fuerte cuanto más se moviliza el miembro a favor de la gravedad. Finalmente desemboca en una inhibición completa de los antagonistas que deberían de elevar el brazo en contra de la gravedad.

Es necesario recordar que tono y movimiento son inseparables y que se pueden examinar mejor simultáneamente.

Los pacientes de este estudio no presentaron un nivel superior a 1 en la escala de Ashworth, por lo que la espasticidad, problema de muchas lesiones cerebrales no será la causa de la rigidez articular de hombro de los pacientes. 


\subsubsection{Escala de la espasticidad de Ashworth ${ }^{7.93 .94 .95}$}

La escala de espasticidad de Ashworth, en su versión modificada, es el método más empleado para medir de manera directa la espasticidad.

A favor de la misma diremos que es fácil de emplear; sirve para prácticamente todas las articulaciones (a excepción de la cadera, articulación para la que hay que tomar particularidades a la hora de evaluar los aductores, pero puesto que no tienen consideración en el presente estudio, no serán importantes) está ampliamente difundida y posee una elevada fiabilidad interoservador. En contra está que es poco sensible y discriminativa.

\begin{tabular}{|l|l|}
\hline 0 & No incremento de tono, normal \\
\hline 1 & $\begin{array}{l}\text { Ligero incremento en tono (aumento de la respuesta del músculo al movi- } \\
\text { miento de flexión o extensión), con resistencia mínimadurante parte del } \\
\text { movimiento articular. } \\
\text { Es visible con la palpación o la relajación o sólo existe mínima resistencia } \\
\text { al final del arco del movimiento. }\end{array}$ \\
\hline $1^{+}$ & $\begin{array}{l}\text { Ligero aumento de la respuesta de músculo al movimiento de flexión o ex- } \\
\text { tensión seguido de una mínima resistencia en todo el resto del arco de reco- } \\
\text { rrido (menos de la mitad). }\end{array}$ \\
\hline 2 & $\begin{array}{l}\text { Incremento en la resistencia del músculo durante la mayor parte del arco } \\
\text { del movimiento articular, pero la articulación puede moverse fácilmente. }\end{array}$ \\
\hline 3 & $\begin{array}{l}\text { Incremento marcado, difícil de completar el arco de movimiento. El movi- } \\
\text { miento pasivo es difícil. }\end{array}$ \\
\hline 4 & Contractura fija cuando se mueve pasivamente. \\
\hline
\end{tabular}

Tabla 5: Escala de espasticidad de Ashworth 


\subsubsection{Rango articular escápulo-humeral normal}

En personas sanas, (sin DCA) los valores normales de rango articular son los siguientes, tanto en el hemicuerpo derecho como en el hemicuerpo izquierdo.

Sin entrar en particularidades anatomo-fisiológicas de la articulación del hombro (ver para ello capítulo 1 Tomo 1 libro Kapandji ${ }^{8}$ )

Los valores mostrados a continuación están tomados de los esquemas de A.I. Kapandji ${ }^{8}$.

Partiendo de la posición anatómica del individuo; esto es en bipedestación, pies ligeramente separados, miembros superiores a lo largo del cuerpo en supinación y mirada al frente.

\begin{tabular}{|c|c|}
\hline Flexión & $180^{\circ}$ \\
\hline Extensión & $45-50^{\circ}$ \\
\hline Aducción & $\begin{array}{l}\text { Desde la posición anatómica no es factible, ha de asociarse a una extensión, y } \\
\text { se produce una aducción leve; o bien a una flexión, y se produce una aducción } \\
\text { entre } 3 \mathbf{3 0}^{\mathbf{o}} \text { y } \mathbf{4 5}^{\mathbf{0}} \text {. } \\
\text { En el presente estudio este valor no se ha tenido en cuenta a la hora de evaluar } \\
\text { a los sujetos. }\end{array}$ \\
\hline Abducción & $\begin{array}{l}180^{\circ} . \text { No obstante este movimiento se realizará de manera secuencial en las di- } \\
\text { ferentes articulaciones del complejo articular del hombro. } \\
\cdot 0-60^{\circ} \text { Se produce el movimiento únicamente en la articulación glenohumeral. } \\
\cdot 60^{\circ}-120^{\circ} \text { Participa la articulación escápulotorácica } \\
\cdot 120^{\circ}-180^{\circ} \text { Participa además de las articulaciones del hombro, la inclinación } \\
\text { heterolateral del tronco. }\end{array}$ \\
\hline $\begin{array}{l}\text { Rotación } \\
\text { Externa }\end{array}$ & $\begin{array}{l}\text { Medida con el codo flexionado a } 90^{\circ} \text { de forma que el antebrazo está entonces } \\
\text { en el plano sagital, así no se añade la pronosupinación del antebrazo. } \\
\text { Los valores normales no llegan a } \mathbf{9 0 ^ { \circ }}\end{array}$ \\
\hline $\begin{array}{l}\text { Rotación In- } \\
\text { terna }\end{array}$ & Medida de igual manera que la rotación externa, su amplitud es de 100-110. \\
\hline
\end{tabular}

Tabla 6: Valores normales en gonometría de hombro ${ }^{8}$ 


\section{TRATAMIENTO DEL DAÑO CEREBRAL ADQUI- RIDO ${ }^{149.150}$}

Las técnicas de tratamiento del DCA forman parte de la amplia esfera que conforma la fisioterapia neurológica. Estas técnicas comenzaron a desarrollarse en la primera parte del siglo XX y en la actualidad algunos de esos métodos continúan evolucionando gracias a las aportaciones que se hacen desde el campo de la neurociencia y al trabajo diario con los pacientes.

El tratamiento de fisioterapia en el paciente con DCA se engloba como una disciplina más junto al del resto del equipo transdisciplinar ${ }^{149}$ (medicina rehabilitadora, logopedia, enfermería, terapia ocupacional, trabajo social, neuropsicología y neuropsiquatría).

La evolución en las últimas décadas ha hecho que los tratamientos sean cada vez más eficaces y de mayor rigor científico aumentando así la calidad de vida y funcionalidad de los pacientes con DCA ${ }^{149}$.

Desde entonces hasta hoy, se pueden mencionar algunos relevantes como Bobath $^{151.152}$, Brunnstrom ${ }^{151.152}$, Perfetti ${ }^{151}$, Kabat ${ }^{138.139}$, Vojta ${ }^{4.9}$ o Carr y Shep$\operatorname{herd}^{154.155 .156}$.

Por su importancia en el presente estudio se recogerán a continuación los principios teóricos de tratamiento de la metodología Vojta así como de la facilitación neuromuscular propioceptiva en la que se recoge el método Kabat.

\subsection{METODOLOGÍA VOJTA}

\subsubsection{Origen del método ${ }^{4}$}

El método Vojta basa su terapia en el concepto de Ontogénesis Motora ${ }^{4}$ (Vojta 1978). Según el autor, los patrones de la ontogénesis motora del primer año de vida o de la ontogénesis de enderezamiento (Vojta, 1988) están determinados genéticamente.

A partir del nacimiento, el contenido cinesiológico de esos parámetros está estrechamente relacionado con el contenido cinesiológico de la postura erguida y la locomoción. Estos patrones, se consideran ideales porque son innatos, y es lo que constituye la cinesiología del desarrollo.

El método, usado tanto en diagnóstico como en el tratamiento tiene dos bases fundamentales. Por un lado realiza un análisis cinesiológico de la motricidad espontánea del individuo y por otro realiza un estudio la ontogénesis postural de éste.

El método se empezó a aplicar en niños con diversos cuadros de parálisis cerebral. El objetivo primero no fue construir un método de tratamiento si no algo que estimulase su movilidad empleando los medios disponibles. Para ello se utilizó la técnica de estímulo-respuesta. 
Con este sistema se pudo documentar que al poner resistencia a determinados movimientos del tronco y de las extremidades activados mediante una orden, se provoca no sólo una lateralidad de segmentos medulares muy distantes, sino que desaparecía la estereotipia de los patrones motores de la parálisis cerebral infantil (PCI) y se activaban algunos juegos musculares ausentes, es decir, se hacían presentes unidades cinesiológicas fisiológicas. Y los patrones aparecían con regularidad al repetir de forma sistemática el procedimiento. A finales de 1959 se analizó y registró el contenido de los patrones parciales que aparecían de forma regular.

Vojta llegó por tanto a la conclusión de que se pueden desencadenar reacciones motoras repetidas (patrones de locomoción refleja) en el tronco y en las extremidades a partir de estímulos definidos y partiendo de unas posturas determinadas. Al poder provocarlo en recién nacidos sanos y luego en adultos, pensó que se trataba de patrones motores innatos.

Los complejos de locomoción de la reptación refleja ${ }^{4.9}$ (RR en lo sucesivo) y del volteo reflejo ${ }^{4.9}$ (VR en lo sucesivo) son los empleados en este estudio con los pacientes son patrones globales, porque con ellos se activa la musculatura estriada de todo el cuerpo en una determinada coordinación. En ello participa todo el SNC, desde los circuitos de sus niveles más bajos a los más altos. Se pueden desencadenar desde diferentes posturas (decúbito dorsal, ventral y lateral). Ante esto, surge la idea de que estos dos patrones son patrones globales de locomoción.

La locomoción refleja es la base de la terapia, y se puede activar, estando tumbado, a partir de tres posiciones básicas: sobre el vientre, de lado y de espalda. Los patrones motores se pueden desencadenar desde diez zonas del cuerpo - descritas por Vojta - y localizadas en el tronco, en los brazos y en las piernas. Combinando varias zonas y cambiando la intensidad y dirección de la presión se pueden activar los patrones motores de la reptación refleja y del volteo reflejo. Juega también un papel relevante la posición angular en que se colocan las extremidades y la resistencia que se ejerce. 


\section{MARCO TEÓRICO}

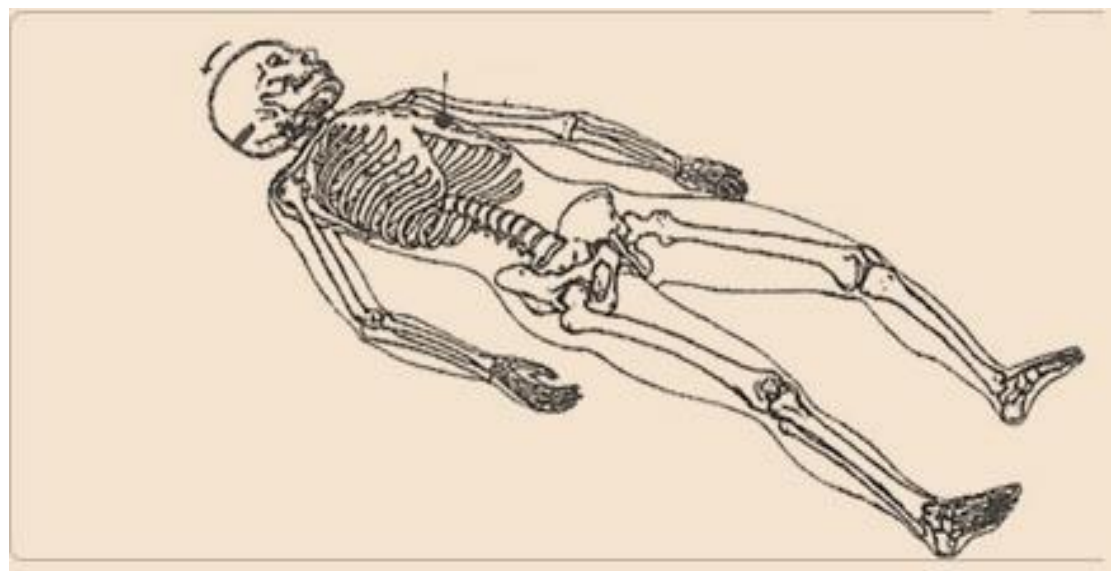

Figura 3: Posición de partida para el volteo reflejo, en la que se observa el punto de estimulación de la zona pectoral, (que se describe posteriormente) ${ }^{141}$.

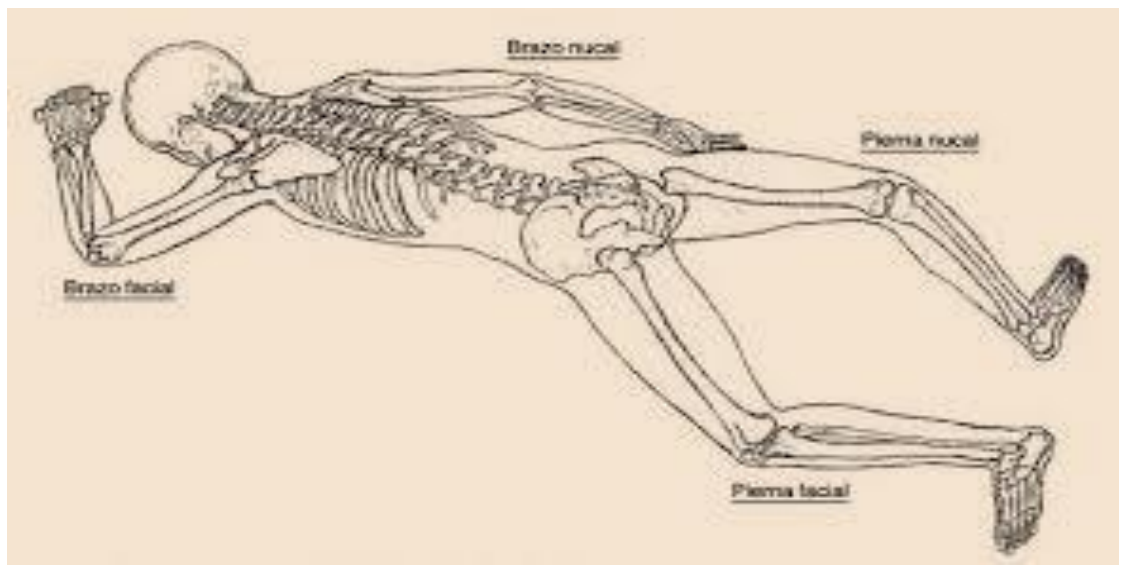

Figura 4: Posición de partida para la reptación refleja, en la que se indican las posiciones de cada una de las extremidades en referencia a la cabeza y la nuca ${ }^{141}$ 


\subsubsection{Objetivos de la terapia Vojta ${ }^{4}$}

Los objetivos que se persiguen con este método de tratamiento es emplear los patrones de locomoción de la reptación refleja y el volteo reflejo como base de tratamiento en los pacientes para así activar y mejorar los mecanismos motores y posturales automáticos necesarios para la realización de la función motora humana que son:

I. La locomoción bípeda

II. La prensión radial manual

$\mathrm{Al}$ activarse áreas motoras cerebrales que influyen sobre el enderezamiento se consigue el enderezamiento del cuerpo, el equilibrio y los movimientos intencionales.

Estos elementos están presentes en las patologías neuromotoras, y su grado de mejoría dependerá de cuánto se pueda llevar a cabo la "reorganización" cerebral en función de la gravedad de la lesión.

\subsubsection{Descripción del método ${ }^{4}$}

El método emplea de base las posturas de volteo reflejo y reptación refleja, si bien es cierto que éstas presentan variantes en su ejecución.

Sin embargo, en lo que atañe al presente estudio, se han utilizado únicamente estas dos y por tanto son las que se describen a continuación.

\section{Volteo reflejo (volteo en primera fase)}

\section{Introducción al volteo reflejo ${ }^{4}$}

El volteo reflejo es un patrón global cuyo objetivo final es el gateo. El patrón global del volteo reflejo empieza en decúbito dorsal, con un movimiento dirigido en sentido ventral (primera fase del volteo), pasando por el decúbito lateral (volteo en segunda fase).

En el VR intervendrán los mismos grupos musculares que en la reptación refleja pero en funciones diferentes. Una buena coordinación de un grupo muscular en el patrón de la reptación refleja no es lo mismo que en el patrón del volteo reflejo.

Las diferencias más importantes que vamos a encontrar al ubicar al individuo en una u otra postura son: ${ }^{9}$ 


\begin{tabular}{|c|c|}
\hline Reptación refleja & Volteo reflejo \\
\hline -Función de prensión de las extremida- & -Función de apoyo de las extremidades \\
des & -Separación del metacarpo y metatarso \\
-Separación del metacarpo y metatarso & -Extensión de los dedos y flexión dorsal \\
-Flexión dedos de la mano y del pie & de muñeca \\
\hline
\end{tabular}

Tabla 7: diferencias en la respuesta del cuerpo ante la $R R$ y el VR

En lo que se refiere a este estudio, sólo se ha empleado la primera fase del volteo reflejo, por lo que a partir de ahora, nos referiremos a ella en exclusiva.

\section{$>$ Posición de partida ${ }^{4}$}

Se parte de decúbito dorsal, que es una posición asimétrica tanto en el recién nacido como en el adulto con LCA.

La cabeza está girada hacia un lado en un ángulo de $30^{\circ}$. Cada uno de los lados del cuerpo se denominan lado facial y lado nucal, dependiendo de la posición de la cabeza. Las extremidades se mantienen relajadas sobre la base de apoyo, dependiendo de la edad y del status neurológico, el decúbito dorsal es más o menos asimétrico con la posición de la cabeza, del tronco y de las extremidades.

\section{Zonas de estimulación ${ }^{4}$}

En el volteo reflejo, el proceso del giro se desencadena al estimular la zona pectoral en el recién nacido, y también en el adulto.

El terapeuta desencadena el estímulo en la zona pectoral del lado hacia el que está girada la cabeza (lado facial). El proceso del volteo reflejo se realiza, por tanto, en contra de la postura de predilección fisiológica. La zona pectoral de estimulación se localiza en el punto de intersección de la línea mamilar con el diagrama. Está a nivel de la $6^{\mathrm{a}}$ costilla, ya sea entre la $5^{\mathrm{a}}$ y la $6^{\mathrm{a}}$ o la $6^{\mathrm{o}}$ y la $7^{\mathrm{a}}$.

\section{Dirección del estímulo ${ }^{4}$}

Dorsal, medial, craneal (oblicuo hacia la CV).

\section{Efectos directos del estímulo ${ }^{4}$}

Según el propio Vojta, se pueden enumerar los siguientes:

I. Estiramiento directo de la musculatura intercostal, alrededor de la $6^{\mathrm{a}}$ costilla, en el lado facial. 
II. Una repercusión directa, a través de las costillas y articulaciones costovertebrales sobre la musculatura autóctona, en este caso los músculos rotadores cortos y largos de la columna vertebral.

III. Distensión directa de la inserción del diafragma del lado facial.

IV. Strech directo de la musculatura intercostal y del músculo abdominal externo del lado facial.

V. Distensión indirecta de la inserción del diagrama del lado nucal.

VI. Compresión indirecta del pulmón, con desplazamiento del mediastino.

VII. Strech trasferido del cuadradolumbar del lado facial.

VIII. Estimulación interoceptiva de la pleura y el mediastino.

Por tanto el estímulo es múltiple y se extiende de forma radiada sobre muchos segmentos medulares. La zona pectoral es un lugar con amplia irradiación en abanico sobre la zona lumbar torácica y cervical de la médula hasta la zona del bulbo raquídeo. 


\section{Reptación refleja ${ }^{4}$}

\section{$>$ Introducción a la reptación refleja ${ }^{4}$}

La reptación refleja contiene el enderezamiento y transporte del tronco en dirección a las extremidades de apoyo.

La condición para que se produzca el enderezamiento del tronco es que haya una extensión libre de la columna vertebral en cada uno de los segmentos. De otro modo no son posibles las rotaciones a nivel del órgano axial (cabeza y tronco).

El tronco se eleva del plano de apoyo, siendo su tendencia locomotriz hacia el codo apoyado. El brazo está flexionado $120-135^{\circ}$ en el hombro y en una abducción de unos $30^{\circ}$. Con ello el punto de apoyo del codo está localizado lateral y cranealmente con respecto al tronco.

Los segmentos proximales de las extremidades del lado facial (brazo y muslo) y del talón del lado nucal se convertirán alternativamente en puntos de apoyo).

Durante la función de enderezamiento (fase de apoyo del paso) la superficie articular se desliza girando sobre las cabezas del húmero y del fémur. En el movimiento fásico (movimiento de balanceo del paso), la cabeza del húmero y del fémur se deslizan girando en la superficie articular.

\section{$>$ Posiciones de partida ${ }^{4}$}

La cabeza se coloca pasivamente provocando una extensión del cuello y girándola unos $30^{\circ}$, de modo que apoye la prominencia frontal en la superficie de apoyo. Se corrige así la lordosis de la columna cervical.

Brazo facial: Está flexionado en el hombro algo más de $120^{\circ}$, pero menos de $135^{\circ}$ y en abducción de $30^{\circ}$. El epicóndilo medial del húmero se encuentra así apoyado sobre la superficie de apoyo. Con ello la mano está alineada con el hombro y la cadera. (Tomando como referencia inicial la posición anatómica bípeda del individuo).

El antebrazo se mantiene apoyado sobre la cara palmar.

Brazo nucal: El brazo del lado opuesto a la cara está con el hombro y el codo en posición articular del $0^{\circ}$, y se encuentra a lo largo del cuerpo. Las articulaciones de la mano y de los dedos se mantienen libres. 


\section{MARCO TEÓRICO}

\section{Zonas principales de desencadenamiento ${ }^{4}$}

Son zonas situadas sobre periostio y situadas sobre las extremidades

Existen zonas secundarias que están en la cintura escapular y pélvica y el estímulo perióstico se combina con un strech sobre determinados grupos musculares. A excepción de la zona del tronco, que se emplea para estimular la musculatura autóctona. De manera esquemática son las siguientes

I. Talón: borde externo del talón, en el calcáneo en el origen del músculo abductor del quinto dedo, en la tuberosidad lateral del calcáneo.

A. Dirección de la presión: ventral, craneal y medial con relación a la pierna

B. Tipo de estímulo: fundamentalmente tiene un carácter propioceptivo.

C. Con respecto a la participación de los receptores de la piel (táctiles y álgicos) no podemos dar ninguna información.

\section{Epicóndilo medial del fémur.}

A. Dirección de la presión: dorsal medial craneal

B. Tipo de estímulo: perióstico, es decir, propioceptivo, además de presión de la cabeza femoral en la cavidad articular de la cadera y stretch de los aductores del muslo.

III. Brazo nucal: a un cm de la apófisis estiloides del radio, en la cara medioventral del radio

A. Dirección de la presión: dorsal, lateral y craneal

B. Perióstico

\section{Brazo facial: Epitróclea}

A. Dirección: dorsal, caudal, medial

B. Tipo de estímulo: perióstico, además de la presión de la cabeza humeral en la cavidad articular del hombro.

Utilizando una determinada posición de partida y unas mismas zonas de estimulación, se activa el SNC tanto en el niño de meses como en el adulto. Se abordan programas innatos del SNC sólo realizables de forma refleja.

En el caso de los sujetos adultos con lesión cerebral adquirida, los pacientes se encuentran no sólo en una situación de "bloqueo de la ontogénesis postural" (Vojta 1962, 1964) sino que en ellos los patrones normales ideales han sido reemplazados por patrones sustitutorios (Vojta 1981). La posibilidad de anular estos patrones sustitutorios con un tratamiento iniciado después del decimosegundo mes de vida, y dar primacía a los juegos musculares ideales activados, es bastante limitada debido al conflicto que existe entre la ontogénesis del enderezamiento y la motricidad fásica propositiva. Para poder aplicar este sistema de activación en niños mayores o adultos, tienen que 


\section{MARCO TEÓRICO}

poder colocarse en la posición de partida activada como en el lactante, o al menos lo más parecida a ella.

Las zonas de estimulación son las mismas que en el niño pequeño. En los adultos se puede trabajar con una orden verbal, aunque no es necesario. Mejor que una orden directa es la orden inespecífica. Con ello el paciente se centra en el estímulo de presión. Sin embargo al niño con PCI (parálisis cerebral infantil) no se le debe dar ninguna orden de movimiento concreto, porque no puede realizarlo con un patrón normal. El niño vivencia el patrón sustitutorio como normal, puesto que ha crecido con él.

Puesto que en este estudio se pretende valorar la eficacia de esta terapia frente a la fisioterapia convencional evaluando el caso particular de la articulación del hombro, explicaremos en este punto cómo actúa la terapia de la locomoción refleja a nivel de la cintura escapular y el complejo articular del hombro, según el propio autor de la metodología.

\section{> Movimientos del brazo facial y de la cintura escapular ${ }^{4}$ :}

- El brazo facial juega un papel determinante en esta posición, asume junto con la cintura escapular la función de apoyo para el tronco.

- La cintura escapular es enderezada sobre ese hombro en contra de la gravedad.

- La cabeza y el tronco se impulsan hacia adelante sobre el hombro, en dirección al brazo facial, en sentido lateral y craneal.

El punto de apoyo es el codo. Y cuando aparece este apoyo, vemos un movimiento de prensión del objeto colocado en la mano, con extensión dorsal de la muñeca e inclinación radial. Los metacarpianos se abducen al flexionarse las articulaciones interfalángicas. Durante la reptación refleja, esta mano cerrada en un puño permanece descargada.

El hombro cobra aquí una especial significación, porque sobre él se produce todo el mecanismo de la reptación refleja. En el movimiento hacia adelante, todo el peso del cuerpo descarga sobre esa articulación. Cuando, durante la reptación refleja, aparecen posturas compensatorias anormales, el resto del cuerpo no tiene posibilidad de iniciar la función de enderezamiento del patrón global. En vez de ello aparecen movimientos compensatorios en el hombro, que se transfieren, a través del tronco y de toda la columna, hasta las zonas periféricas de las extremidades. 


\section{$>$ Relaciones musculares en el hombro ${ }^{4.24}$}

Como se ha visto, el hombro juega un papel determinante en la reptación refleja, y en ello tienen especial importancia las relaciones musculares que se establecen.

En este estudio se ha propuesto determinar el grado de mejoría en el balance articular de hombro de los pacientes, por tanto haremos hincapié en las relaciones musculares que se establecen en el complejo articular del hombro al posicionar al individuo en esta postural.

Los músculos del hombro mueven el órgano axial sobre la articulación del hombro, tanto en la reptación refleja como en la ontogénesis locomotriz. Por ello, esa articulación tiene un papel clave en la diferenciación de la función muscular. Los músculos que participan en la extensión del hombro, al contraerse hacia el punctum fixum (punto fijo) del codo, en el lado facial, provocan un movimiento de avance del tronco. A ellos pertenece también el músculo dorsal ancho que transporta el tórax y la cintura pélvica hacia el brazo de apoyo. A la musculatura dorsal del hombro pertenecen además las porciones espinal y acromial del deltoides y la porción larga del tríceps braquial; así como los dos redondos (mayor y menor).

Particularizando en cada uno de los músculos, podemos decir lo siguiente:

Respecto al deltoides del brazo facial; si la contracción muscular del músculo se dirige hacia el punto de apoyo en el codo (como en el caso de la reptación refleja de modo que tira del acromion, de la espina de la escápula hacia delante de manera craneal, ventral, lateral). Debido a esto, tiene un efecto antigravitatorio sobre el tórax, produciéndose una elevación del ángulo inferior de la escápula con respecto al tórax lo que desencadena una contracción por distensión de la musculatura dorsal de la escápula.

El tríceps facial por su parte se contrae hacia el punto fijo en el codo y tira de la fosa glenoidea en dirección ventral, lateral y craneal.

La porción larga del bíceps actúa de manera sinérgica con el tríceps bracial para tirar de la apófisis coracoides de la escápula para girar el omóplato sobre la cabeza hummeral (tirando de la escápula en sentido lateral, ventral y craneal).

Los rotadores de hombro internos (Pectoral mayor, Dorsal Ancho, subescapular Redondo menor) son mucho más potentes que los externos (infraespinoso, supraespinoso redondo mayor). Esta relación es la que provoca tan fácilmente la posición patológica del brazo en rotación interna. Sin embargo al activarse la reptación refleja no prevalece la mayor potencia de los rotadores internos. 


\section{MARCO TEÓRICO}

La terapia Vojta se ha empleado en numerosas ocasiones como alternativa de tratamiento en pacientes con DCA. Así, estudios previos demuestran su eficacia en la mejora de pacientes con daño cerebral instaurado en fase tardía.

En pacientes con LCA y alteraciones de la marcha se observaron mejoras en el ciclo completo del paso de la marcha ${ }^{24,25}$ : aumento de la velocidad de éste de manera global, tanto en fase de oscilación como de apoyo. 


\section{MARCO TEÓRICO}

\subsection{CINESITERAPIA}

La cinesiterapia es una técnica ampliamente utilizada en fisioterapia que consiste en la aplicación, o no, del movimiento con fines curativos mediante movimientos activos, activoasistidos, pasivos y/o resistidos.

Los principios que van a seguir el modelo de cinesiterapia aplicada al paciente neurológico son los que ya se han descrito en anteriores apartados: el control motor del individuo y la plasticidad neuronal ${ }^{1}$.

\subsubsection{CLASIFICACIÓN DE LA CINESITERAPIA}

Atendiendo al grado de implicación del paciente se pueden determinar, de manera general, tres tipos de cinesiterapia ${ }^{140}$.

\section{$\circ$ Cinesiterapia pasiva}

Todo movimiento producido dentro de los rangos de movilidad articular sin restricción de un segmento que se produce por completo por la acción de una fuerza externa. No hay contracción muscular voluntaria. La fuerza externa puede proceder de la gravedad de una máquina, de otra persona y otra parte del propio cuerpo de la persona.

$\checkmark$ Indicaciones

- Mantener la integridad de la articulación y los tejidos periarticulares

- Reducir al mínimo la aparición de hipertonías musculares

- Mantener la elasticidad muscular

- Ayudar a la circulación dinámica vascular

- Mejorar el movimiento sinovial para la nutrición de los cartílagos y la difusión de materiales en la articulación

- Reducir o inhibir, si es posible, el dolor

- Ayudar al proceso de curación después de una lesión o cirugía

- Ayudar a mantener la conciencia de movimiento al paciente 


\section{MARCO TEÓRICO}

○ Cinesiterapia activa

Movimiento dentro de los límites de la movilidad sin restricción de un segmento que se produce por la acción de una contracción activa de los músculos que cruzan esa articulación

$\checkmark$ Indicaciones

- Cumplirá los mismos objetivos que la movilidad pasiva añadiendo a ésta los de la contracción muscular

- Aumentará la fuerza o resistencia física

- Ayudará a mejorar la circulación en el grado en que lo hace la contracción activa de un músculo voluntario.

\section{○ Cinesiterapia activo-asistida}

Un tipo de movilidad activa donde existe una fuerza externa que proporciona ayuda mecánica o manual dado que el/los grupos musculares implicados necesitan asistencia para completar el movimiento.

Dentro de este tratamiento de neurocinesiterapia se engloba como parte fundamental del tratamiento la Facilitación Neuromuscular Propioceptiva (FNP), pudiéndose considerar ésta como fisioterapia activo asistida (atendiendo a sus principios y procedimientos generales, como veremos posteriormente), ya que el paciente ha de mostrarse dinámico en la consecución de las tareas y la implicación del fisioterapeuta resulta fundamental.

\subsubsection{FACILITACIÓN NEUROMUSCULAR PROPIOCEPTIVA}

La FNP 138.139 es una filosofía y método de tratamiento iniciado en el año 1940 por H. Kabat. En sus inicios se empleó como tratamiento en pacientes poliomielíticos, pero la experiencia dejó claro que el enfoque de tratamiento era efectivo para pacientes con muy diversos diagnósticos. Se trata de un método muy laborioso de tratamiento en el cual el fisioterapeuta facilita la realización de patrones de movimiento específicos por parte del paciente con uso especial de las manos del terapeuta. 


\subsubsection{Concepto}

Atendiendo a los términos que le dan nombre podemos decir lo siguiente.

- Facilitación: hacerlo más sencillo

- Neuromuscular: engloba a músculos y nervios

- Propioceptiva: relacionado con los receptores sensoriales que dan la información concerniente al movimiento y a la posición corporal.

Partiendo de lo anterior se pueden destacar los siguientes aspectos conceptuales de la metodología:

- Metodología integral: entendiendo el cuerpo como un conjunto y no un problema específico o segmento corporal aislado.

- Enfoque positivo: se refuerza lo que el paciente puede hacer, tanto a nivel físico como psicológico.

- Meta principal: alcanzar el nivel de funcionalidad más alto.

\subsubsection{Objetivos terapéuticos generales}

- Aumentar la capacidad del paciente para moverse o quedarse estable.

- Guiar el movimiento mediante las presas correctas y la resistencia apropiada.

- Ayudar al paciente a lograr un movimiento coordinado a través del sincronismo.

- Aumentar la resistencia del paciente y evitar la fatiga.

\subsubsection{Procedimiento general en FNP}

Aunque en este estudio se han hecho valoraciones y tratamientos correspondientes únicamente al complejo articular del hombro, Adler et al. (2008) describieron 10 procedimientos básicos para realizar la técnica 1.138 .139 que son aplicables en cualquier región corporal. Combinados entre sí se obtienen una respuesta máxima por parte del paciente.

- Resistencia. La aplicación de resistencia manual ha sido una de las características más importantes de la FNP. Se ha dejado de emplear la resistencia máxima para emplear la adecuada según las necesidades del paciente. Se emplea para ayudar a la contracción muscular y al control motor, aumentar la fuerza y ayudar al aprendizaje motor.

- Irradiación y refuerzo: empleo del desbordamiento de la respuesta para estimular

- Contacto manual: para guiar el movimiento aumentar la fuerza con la presa manual y la presión

- Posición y mecánica corporal: para dirigir y controlar el movimiento o la estabilidad que se pretende. 


\section{MARCO TEÓRICO}

○ Órdenes verbales: palabras y volumen de voz apropiados para poder dirigir al paciente.

- Visión: para guiar el movimiento y aumentar la fuerza.

- Tracción y aproximación: elongación o compresión de los miembros y el tronco para facilitar el movimiento o la estabilidad.

- Estiramiento: el empleo de la elongación muscular y del reflejo de estiramiento para facilitar la contracción y disminuir la fatiga muscular.

- Programación temporal: el sincronismo estimula la contracción muscular a través del "sincronismo para el énfasis"; esto es, cambiar la secuencia normal de los movimientos para insistir en la el trabajo de un músculo concreto o una actividad deseada.

- Patrones de movimiento: en movimientos sinérgicos en masa, los componentes del movimiento funcionan normal.

\subsubsection{Procedimiento específico en FNP: articulación del hombro y zona es- capular}

\section{I: Procedimientos y técnicas ${ }^{138.139}$}

En este estudio los sujetos muestran una amplitud articular pasiva disminuida al realizar un balance articular de hombro. Existen múltiples técnicas y procedimientos que se emplean en la FNP atendiendo a las necesidades de cada paciente. Sin embargo, atendiendo al problema esencial que nos atañe (rigidez articular), la intervención se llevará a cabo de la siguiente manera:

\begin{tabular}{|c|c|c|}
\hline Procedimientos & Técnicas & Combinaciones \\
\hline $\begin{array}{c}\text { Sincronismo para el énfa- } \\
\text { sis }\end{array}$ & Contracción relajación & $\begin{array}{c}\text { Contracción relajación + } \\
\text { isotónicos de nueva am- } \\
\text { plitud }\end{array}$ \\
\hline Tracción & $\begin{array}{c}\text { Inversión de estabiliza- } \\
\text { ción de antagonistas }\end{array}$ & $\begin{array}{c}\text { Contracción relajación + } \\
\text { inversiones lentas, co- } \\
\text { menzando el movimiento } \\
\text { en la nueva amplitud }\end{array}$ \\
\hline Resistencia apropiada & Estabilización rítmica & $\begin{array}{c}\text { Estabilización rítmica + } \\
\text { inversión dinámica de an- } \\
\text { tagonistas }\end{array}$ \\
\hline
\end{tabular}

Tabla 8: Síntesis de los procedimientos y técnicas de FNP

Los procedimientos empleados ya se han descrito previamente. Por su importancia en este estudio, se describen a continuación las técnicas citadas anteriormente: 


\section{MARCO TEÓRICO}

Contracción-relajación

- Concepto: Contracción isotónica resistida de los músculos que limitan (antagonistas) seguida de la relajación y aumento de la amplitud del movimiento.

- Objetivo e indicaciones: Aumentar la amplitud articular pasiva

- Procedimiento: El terapeuta (T en lo sucesivo) o el paciente (P)desplazarán la articulación hasta el final de la amplitud articular pasiva. A continuación $\mathrm{T}$ solicitará una contracción fuerte del músculo antagonista de 5 a 8 segundos y el T permitirá el movimiento suficiente para que todos los músculos necesarios se contraigan. Pasado ese tiempo se pide relajación al P.

Inversión en la estabilización de antagonistas

- Concepto: Alternar contracciones isotónicas opuestas con una resistencia suficiente como para impedir el movimiento. La consigna es una orden dinámica y el T permite únicamente un pequeño movimiento.

- Objetivos e indicaciones: Aumentar la estabilidad, el equilibrio, la fuerza muscular y la coordinación agonista antagonista.

- Procedimiento: El T aplica resistencia manual al paciente mientras pide al paciente que se oponga a la fuerza. Se permite un movimiento muy pequeño. Cuando el $\mathrm{P}$ contrarreste completamente la fuerza, el T cambiará una mano y comenzará a aplicar resistencia en sentido opuesto. Una vez que el p responda a la nueva resistencia, el T cambiará la otra mano para oponerse al nuevo sentido del movimiento.

\section{Estabilización rítmica}

- Concepto: Alternar contracciones isométricas contra resistencia, no existe ninguna intención de movimiento.

- Objetivos e indicaciones: Aumentar la amplitud articular, la fuerza, la estabilidad y el equilibrio. Reducir el dolor.

- Procedimiento: El T resistirá una contracción muscular del grupo muscular agonista y el $\mathrm{P}$ mantendrá la posición sin intentar moverse. La resistencia irá aumentando conforme el paciente desarrolle fuerza. Cuando el $\mathrm{P}$ responda por completo, el T cambiará una mano para comenzar a resistir el movimiento antagonista en la parte distal. Ni el fisioterapeuta ni el paciente se relajarán cuando se invierta la resistencia. La nueva resistencia irá aumentando despacio. Cando el paciente responda, el T moverá la otra mano para resistir también el movimiento antagonista. 


\section{II: Patrones de movimiento}

Los patrones de miembro superior se utilizan para tratar problemas neurológicos, desórdenes musculares y/o restricciones articulares, empleándose también para ejercitar el tronco. Como se ha descrito anteriormente, la resistencia aplicada a los grupos musculares fuertes irradia contracción a los más debilitados en otra parte del cuerpo.

En el miembro superior se emplean dos diagonales de movimiento

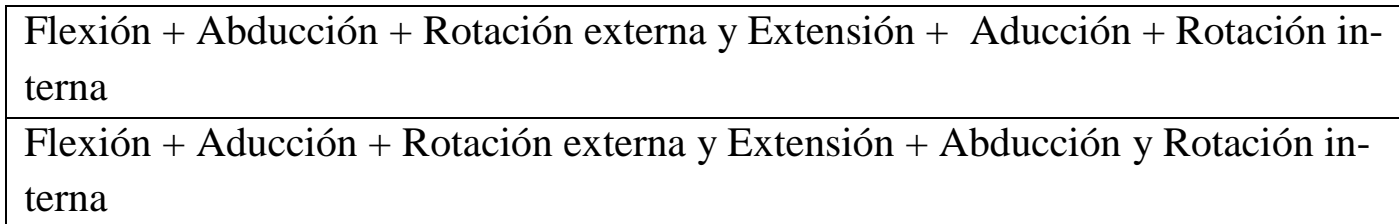

Tabla 9: Diagonales de FNP en las EESS

De manera genera se puede determinar que el hombro y el complejo muñeca mano se relacionarán juntos en la sinergia del patrón. El codo quedará libre para moverse hacia la flexión, la extensión o bien quedarse inmóvil. No hay que permitir que la extremidad se mueva fuera de su diagonal.

Cada una de estas diagonales de movimiento se describe atendiendo a los procedimientos generales y en ellas se pueden aplicar cualquiera de las técnicas descritas con anterioridad así como el resto que están descritas en la metodología. (Para una descripción detallada consultar Adler S.S. et Cols. El miembro superior En: La Facilitación Neuromuscular Propioceptiva en la práctica. Guía ilustrada).

El movimiento escapular forma parte integrante de cada patrón y no puede separarse de ellos. No obstante, presenta patrones de movimiento propios que si bien es cierto no pueden dejarse a un lado, no son de uso imprescindible en los sujetos de este estudio.

\subsubsection{La estabilización de la articulación el hombro y la zona escapular. ${ }^{137}$}

La importancia en la estabilización y los ejercicios de la zona escapular que tiene el mecanismo complicado es la función muscular que relaciona recíprocamiente las articulaciones glenohumeral, la clavícula, el hueso del hombro y la existencia de la escápula. Cuando en los seres humanos se cambió de una posición cuadrúpeda a una bípeda, los brazos se liberaron de sostener su peso y se reconvirtieron principalmente para el uso de las tareas laborales. El omóplato se encuentra también en los animales que caminan a cuatro patas.

La recuperación de las extremidades superiores e inferiores del paciente hemipléjico conserva en muchos casos movimientos cooperativos. Sin embargo, aunque las extremidades inferiores en muchos casos se pueden corregir con la ayuda de aparatos 
o de bastón, para conseguir la marcha, las extremidades superiores del cuerpo requieren funciones de nivel más complejo y en muchos casos se induce el llamado síndrome del brazo en desuso. O bien en ocasiones se manifiesta dolor o rigidez a través del síndrome del hombro, que produce la semiluxación de las articulaciones escapulares y el impedimento de la circulación periférica.

\subsection{OTROS MÉTODOS DE TRATAMIENTO ${ }^{151}$}

Existen otros métodos de tratamiento en el DCA: Brunnstrom, Perfetti, Phelps, Kabat, Brunnstrom, Bobath, Vojta, Rood, Phelps, Plum, Le Mètayer etc. Por su relevancia actual se recogen a continuación los principios generales de algunos de ellos.

\subsubsection{BRUNNSTROM ${ }^{151.152}$}

El método debe su nombre a Signe Brunnstrom, fisioterapeuta de origen sueco que en los años 50, estando afincada en Nueva York desarrolló su propio método de tratamiento para pacientes con afectación neurológica, en su mayoría hemipléjicos.

Según esta metodología los estímulos aferentes e interoceptivos provocan cambios en la respuesta motora del paciente con hemiparesia espástica. Por ello propuso utilizar estímulos aferentes para iniciar movimientos que el paciente, a priori, es incapaz de realizar por sí mismo de manera voluntaria.

Con ello se consigue el movimiento del paciente dentro de la sinergia de la extremidad (superior o inferior). Una vez conseguido esto podrán introducirse modificaciones y combinaciones de movimientos derivados de esas sinergias.

Según la autora, las sinergias y su adquisición son la antesala de la recuperación del movimiento normal, y por tanto provocarlas constituye una fase intermedia necesaria para la recuperación del movimiento normal. Dicho movimiento normal se obtendrá, si llega el caso, avanzando en las diferentes fases, de modo ordenado, sin omitir ninguna. La progresión no obstante puede detenerse en cualquiera de las fases del método.

El método Brunnstrom por tanto se caracteriza por:

- Las sesiones de tratamiento se planifican solicitando sólo tareas que el paciente pueda llegar a realizar, dependiendo de la fase en la que se encuentre.

- La selección del estímulo aferente depende de la fase de recuperación.

- En las fases iniciales se utilizan los reflejos tónicos, laberínticos, la estimulación propioceptiva o la resistencia a los movimientos para provocar las sinergias.

- Posteriormente se intenta facilitar el control voluntario de las sinergias mezclando componentes de diferentes patrones de movimiento e introduciendo actividades cada vez más complejas. 


\section{MARCO TEÓRICO}

\subsubsection{BOBATH ${ }^{151.152 .153}$}

El método Bobath surge a partir del concepto de que el aumento del tono muscular y de la actividad refleja aparecen por una falta de inhibición de un mecanismo reflejo postural dañado. El paciente espástico sólo podría llegar a tener una función motora normal si se le normaliza el tono muscular y se elimina la actividad muscular no deseada.

Berta Bobath, fisoterapeuta, junto a su esposo Karl, neurofisiólogo, diseñaron de manera empírica técnicas para influir sobre las alteraciones en el tono muscular de los pacientes con PC y hemiplejia.

B. Bobath observó que podría influir sobre el tono muscular modificando la posición y el movimiento de las articulaciones proximales del cuerpo. Los tres pilares básicos del tratamiento serían:

- Disminuir la espasticidad, las sinergias y los patrones anormales de movimiento utilizando técnicas de inhibición.

- Desarrollar patrones normales de postura y movimiento mediante técnicas de facilitación.

- Incorporar el lado hemipléjico en todas las actividades terapéuticas, desde las fases más iniciales, para evitar su olvido, restablecer la simetría e integrarlo en movimientos funcionales.

El papel del terapeuta en este método es el de contactar de manera manual en los "puntos clave de control" para mejorar la calidad del movimiento de paciente. Sin embargo no se incluyen en el método ejercicios específicos para fortalecer la musculatura puesto que según la autora, al disminuir la espasticidad los músculos aparentemente débiles podían contraerse eficazmente. 


\subsubsection{PERFETTI ${ }^{151}$}

El Ejercicio Terapéutico Cognoscitivo, más conocido como "Método Perfetti", es un método de neurorehabilitación que nace en Italia a principios de los años 70. Forma parte del grupo de las numerosas técnicas propuestas para la recuperación de un paciente con problemas en el plano sensitivo-motor provocados por un Daño Cerebral.

El concepto Perfetti se basa en el aprendizaje progresivo de una motricidad más evolucionada. Aunque el método nació como una forma de trabajar la mano parética, ha ido evolucionando hasta convertirse en un método de tratamiento que incluye todos los segmentos corporales y que se adapta al estadío en el que se encuentra el paciente, evolucionando con él.

El método fue desarrollado por el neurólogo italiano Carlo Perfetti, quien considera la espasticidad como una suma de síntomas del paciente o complejo sintomático.

Su método engloba los componentes de la espasticidad bajo el término de "específico motor" y son los siguientes

- Reacción desmesurada al estiramiento.

- Irradiación patológica.

- Esquemas elementales (motilidad grosera del paciente, con componentes sinérgicos y más apreciables en la raíz de los miembros).

- Déficit de reclutamiento motor: dificultad para activar un número adecuado de unidades motoras suficiente para la ejecución de tareas motoras evolucionadas.

Cada componente individualizado puede ser tratado de forma específica por medio de ejercicios, los cuales aumentan en progresión de dificultad:

- Ejercicios de primer grado: El paciente aprende a relajar. No se solicita al paciente contracción muscular. Son ejercicios para controlar la respuesta exagerada al estiramiento.

- Ejercicios de segundo grado: El paciente empieza a reclutar unidades motoras de forma progresiva y guiada, con lo que ya hay actividad muscular y el movimiento no se desarrolla pasivamente. Son ejercicios para el control de las irradiaciones y los esquemas elementales.

- Ejercicios de tercer grado: El paciente realiza de manera aún más activa los ejercicios.

Una vez realizado el movimiento comparamos el resultado con el que habíamos esperado, lo que nos da la posibilidad de aprender de los errores.

La limitación más importante de este método la encontramos en pacientes con anestesia total o dificultades de comprensión. 


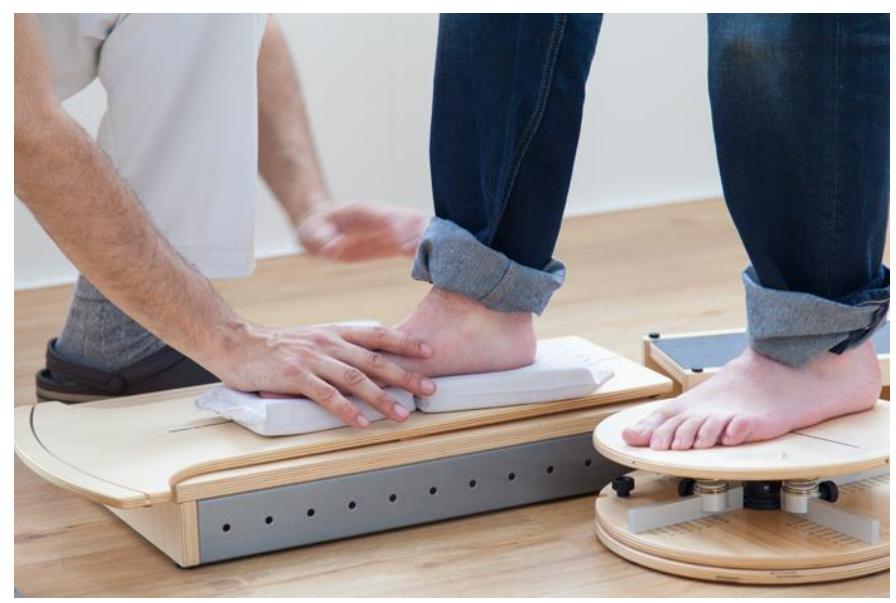

Figura 5: método Perfetti ${ }^{184}$

\subsubsection{CARR Y SHEPHERD ${ }^{151.154 .155 .156}$}

El método de Carr y Shepherd o el reaprendizaje motor orientado a tareas surgió en 1984 de la mano de dos fisioterapeutas australianas, Janet Carr y Roberta Shepherd, basándose en los avances producidos en la ciencia del movimiento, la neurofisiología y la teoría del aprendizaje.

Según Carr y Shepherd el objetivo del tratamiento debe ser un reaprendizaje orientado a tareas específicas, es decir, enseñar al paciente estrategias eficaces para conseguir realizar un movimiento útil funcionalmente. Consideran al paciente un participante activo en su recuperación. En vez de tratar al paciente, el objetivo es entrenarlo. Recomiendan forzar la utilización del lado parético evitando el desarrollo de estrategias compensadoras inadecuadas.

El programa de reaprendizaje motor utiliza cinco estrategias para enseñar y motivar al paciente que el terapeuta combinará de la forma más apropiada adaptándose a las necesidades individuales del paciente. Las estrategias son ${ }^{154}$ :

- Instrucciones verbales simples y claras asociadas, si es necesario, a comunicación no verbal.

- Demostraciones visuales de cómo realizar la tarea.

- Guía manual, pero evitando ayudas innecesarias y disminuyendo progresivamente el nivel de supervisión, hasta lograr la práctica independiente.

- Refuerzo y feedback positivo cuando la acción se realiza correctamente.

- Práctica repetitiva. Para conseguir mejorar el rendimiento motor el paciente debe, además, practicar a lo largo del día según las instrucciones del terapeuta.

Para Carr y Shepherd algunos principios básicos en el tratamiento del ictus serían $^{155}$ :

- Iniciar la terapia lo más precozmente posible. 
- Anticipar y prevenir la contractura de los tejidos blandos por medios activos y, si es necesario, pasivos.

- Identificar los músculos esenciales para la actividad a reeducar y mejorar sus propiedades. Carr y Shepherd analizan en profundidad el reentrenamiento de las actividades más importantes: incorporarse, sentarse, caminar, alcanzar y manipular objetos...

- Modificar el ambiente, si es necesario, para que el paciente pueda entrenar la tarea (elevar el asiento para incorporarse, suspender parcialmente el peso del cuerpo para caminar...).

- Crear las condiciones para que el paciente se implique activamente en la reeducación: colocación de aparatos que faciliten la actividad, órdenes y consignas etc.

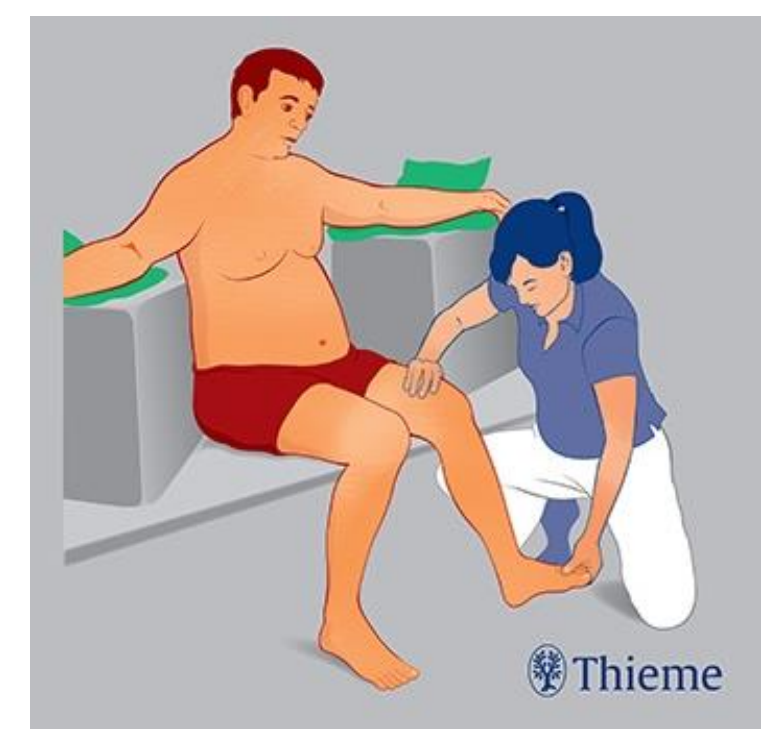

Figura 6: Concepto Bobath en adultos ${ }^{185}$ 
MARCO TEÓRICO 


\section{HIPÓTESIS Y OBJETIVOS}

\section{HIPÓTESIS}

Los pacientes con daño cerebral adquirido sometidos a tratamiento con fisioterapia convencional presentan una evolución diferente que los pacientes con daño cerebral adquirido sometidos a terapia con el método Vojta.

\section{OBJETIVOS}

\subsection{OBJETIVO PRINCIPAL}

- Determinar la eficacia de la terapia Vojta en el tratamiento de la rigidez del hombro en pacientes adultos con daño cerebral adquirido respecto la fisioterapia convencional.

\subsection{OBJETIVOS SECUNDARIOS}

- Cuantificar el rango articular de los pacientes con daño cerebral pre y post tratamiento.

- Valorar el grado de dependencia de los pacientes con daño cerebral pre y post tratamiento.

- Determinar el estado de salud general y la calidad de vida de los pacientes con daño cerebral pre y post tratamiento. 
HIPÓTESIS Y OBJETIVOS 


\section{METODOLOGÍA}

\section{BÚSQUEDA BIBLIOGRÁFICA}

Al realizar una búsqueda bibliográfica en pubmed a fecha 24/01/2016 con los siguientes términos descriptores "shoulder stiffness" AND "neurology" se han encontrado 15 resultados bibliográficos. De los cuales 10 están íntegramente en la red y 5 son de dominio público.

Tan sólo 7 de ellos han sido publicados en los últimos 10 años, y más concretamente 6 de ellos en los últimos 5 .

Los de la última década son los siguientes. 


\begin{tabular}{|c|c|c|}
\hline TÍTULO & AUTORES & PUBLICACIÓN \\
\hline $\begin{array}{l}\text { Prediagnostic presenta- } \\
\text { tions of Parkinson's dis- } \\
\text { ease in primary care: a } \\
\text { case-control study. }\end{array}$ & $\begin{array}{l}\text { Schrag A, Horsfall L, } \\
\text { Walters K, Noyce A, Pe- } \\
\text { tersen I. }\end{array}$ & $\begin{array}{c}\text { Lancet Neurol. 2015 } \\
\text { Jan;14(1):57-64. doi: } \\
\text { 10.1016/S1474- } \\
\text { 4422(14)70287-X. Epub } \\
\text { 2014 Nov 27. }\end{array}$ \\
\hline $\begin{array}{l}\text { Patterns of acute whip- } \\
\text { lash-associated disorder } \\
\text { in the Lithuanian popu- } \\
\text { lation after road traffic } \\
\text { accidents. }\end{array}$ & $\begin{array}{c}\text { Pajediene E, Janusaus- } \\
\text { kaite J, Samusyte G, Sta- } \\
\text { saitis K, Petrikonis K, } \\
\text { Bileviciute-Ljungar I. }\end{array}$ & $\begin{array}{c}\text { J Rehabil Med. } 2015 \\
\text { Jan;47(1):52-7. doi: } \\
\text { 10.2340/16501977-1892. }\end{array}$ \\
\hline $\begin{array}{l}\text { Effectiveness of Anma } \\
\text { massage therapy in alle- } \\
\text { viating physical symp- } \\
\text { toms in outpatients with } \\
\text { Parkinson's disease: a } \\
\text { before-after study. }\end{array}$ & $\begin{array}{c}\text { Donoyama N, Suoh S, } \\
\text { Ohkoshi N. }\end{array}$ & $\begin{array}{c}\text { Complement Ther Clin } \\
\text { Pract. } 2014 \text { Nov;20(4):251- } \\
\text { 61. doi: } \\
\text { 10.1016/j.ctcp.2014.07.010. } \\
\text { Epub } 2014 \text { Aug } 20\end{array}$ \\
\hline $\begin{array}{l}\text { Baraitser-Winter cere- } \\
\text { brofrontofacial syn- } \\
\text { drome: delineation of the } \\
\text { spectrum in } 42 \text { cases. }\end{array}$ & $\begin{array}{l}\text { Verloes A, Di Donato N, } \\
\text { Masliah-Planchon J, } \\
\text { Jongmans M, Abdul-Ra- } \\
\text { man OA., et als. }\end{array}$ & $\begin{array}{l}\text { Eur J Hum Genet. } 2015 \\
\text { Mar;23(3):292-301. doi: } \\
\text { 10.1038/ejhg.2014.95. } \\
\text { Epub 2014 Jul } 23 .\end{array}$ \\
\hline $\begin{array}{l}\text { Anterior uveitis as an in- } \\
\text { itial manifestation of } \\
\text { polymyalgia rheumatica. }\end{array}$ & $\begin{array}{l}\text { Tsuda } \mathrm{H} \text {, Tanaka } \mathrm{K}, \mathrm{Ki}- \\
\text { shida } \mathrm{S} .\end{array}$ & $\begin{array}{c}\text { Case Rep Med. } \\
\text { 2011;2011:621241. doi: } \\
\text { 10.1155/2011/621241. } \\
\text { Epub 2011 May } 10 .\end{array}$ \\
\hline $\begin{array}{l}\text { Asian patients with limb } \\
\text { girdle muscular dystro- } \\
\text { phy 2I (LGMD2I) }\end{array}$ & $\begin{array}{c}\text { Hong D, Zhang W, } \\
\text { Wang W, Wang Z, Yuan } \\
\text { Y }\end{array}$ & $\begin{array}{c}\text { J Clin Neurosci. } 2011 \\
\text { Apr;18(4):494-9. doi: } \\
\text { 10.1016/j.jocn.2010.08.010. } \\
\text { Epub 2011 Feb 5. }\end{array}$ \\
\hline $\begin{array}{l}\text { Whiplash in individuals } \\
\text { with known pre-acci- } \\
\text { dent, clinical neck status. }\end{array}$ & $\begin{array}{c}\text { Sjaastad O, Fredriksen } \\
\text { TA, Båtnes J, Petersen } \\
\text { HC, Bakketeig LS }\end{array}$ & $\begin{array}{c}\text { J Headache Pain. } 2006 \\
\text { Feb;7(1):9-20. Epub } 2006 \\
\text { Feb } 20 .\end{array}$ \\
\hline
\end{tabular}

Tabla 10: Artículos encontrado en la revisión bibliográfica inicial publicados en la última década 
Si realizamos una búsqueda bibliográfica con los siguientes términos "shoulder stiffness" AND “neurological pain" encontramos un total de 154 artículos de los cuales 10 están completos y 5 se encuentran a disposición íntegra del usuario.

Tan sólo 5 de ellos han sido publicados en la última década, y más concretamente 2 de ellos en los últimos 5 años.

\begin{tabular}{|c|c|c|}
\hline TÍTULO & AUTOR & PUBLICACIÓN \\
\hline $\begin{array}{l}\text { Long-term outcomes of } \\
\text { intradural cervical dorsal } \\
\text { root rhizotomy for refrac- } \\
\text { tory occipital neuralgia. }\end{array}$ & $\begin{array}{l}\text { Gande AV, Chivukula S, } \\
\text { Moossy JJ, Rothfus W, } \\
\text { Agarwal V, Horowitz } \\
\text { MB, Gardner PA. }\end{array}$ & $\begin{array}{l}\text { J Neurosurg. } 2015 \text { Dec } \\
18: 1-9 . \text { [Epub ahead of } \\
\text { print] }\end{array}$ \\
\hline $\begin{array}{l}\text { Patterns of acute whip- } \\
\text { lash-associated disorder } \\
\text { in the Lithuanian popula- } \\
\text { tion after road traffic acci- } \\
\text { dents. }\end{array}$ & $\begin{array}{l}\text { Pajediene E, Janusaus- } \\
\text { kaite J, Samusyte G, Sta- } \\
\text { saitis K, Petrikonis K, } \\
\text { Bileviciute-Ljungar I. }\end{array}$ & $\begin{array}{l}\text { J Rehabil Med. } 2015 \\
\text { Jan;47(1):52-7. } \\
\text { 10.2340/16501977-1892. }\end{array}$ \\
\hline $\begin{array}{l}\text { The crowned dens syn- } \\
\text { drome as a cause of } \\
\text { neck pain: clinical and } \\
\text { computed tomography } \\
\text { study in patients with cal- } \\
\text { cium pyrophosphate dihy- } \\
\text { drate deposition disease. }\end{array}$ & $\begin{array}{l}\text { Salaffi F, Carotti M, Gug- } \\
\text { lielmi G, Passarini G, } \\
\text { Grassi W. }\end{array}$ & $\begin{array}{l}\text { Clin Exp Rheumatol. } 2008 \\
\text { Nov-Dec;26(6):1040-6. }\end{array}$ \\
\hline $\begin{array}{l}\text { Investigation of axial } \\
\text { symptoms after cervical } \\
\text { laminoplasty, using ques- } \\
\text { tionnaire survey. }\end{array}$ & $\begin{array}{l}\text { Ohnari H, Sasai K, Akagi } \\
\text { S, Iida H, Takanori S, } \\
\text { Kato I. }\end{array}$ & $\begin{array}{l}\text { Spine J. } 2006 \text { May- } \\
\text { Jun;6(3):221-7. }\end{array}$ \\
\hline $\begin{array}{l}\text { Whiplash in individuals } \\
\text { with known pre-accident, } \\
\text { clinical neck status. }\end{array}$ & $\begin{array}{l}\text { Sjaastad O, Fredriksen } \\
\text { TA, Båtnes J, Petersen } \\
\text { HC, Bakketeig LS. }\end{array}$ & $\begin{array}{l}\text { J Headache Pain. } 2006 \\
\text { Feb;7(1):9-20. Epub } 2006 \\
\text { Feb 20. }\end{array}$ \\
\hline
\end{tabular}

Tabla 11: Artículos encontrados en la revisión bibliográfica inicial publicadas en los últimos cinco años.

Si realizamos una búsqueda con los siguientes términos descriptores "shoulder stiffness" AND “neurological pain" AND "rehabilitation" encontramos tan sólo 1 artículo en pubmed, que es de acceso libre, pero que es de hace tres décadas. 


\begin{tabular}{|l|l|l|}
\hline TíTULO & AUTOR & PUBLICACIÓN \\
\hline $\begin{array}{l}\text { Hemiplegic shoulder } \\
\text { pain. }\end{array}$ & Griffin JW. & $\begin{array}{l}\text { Phys Ther. 1986 } \\
\text { Dec;66(12):1884-93. }\end{array}$ \\
\hline
\end{tabular}

Tabla 12: Artículos encontrados en la revisión bibliográfica inicial cuyo acceso es libre

Por otro lado la búsqueda "shoulder stiffness" AND "neurological pain" AND "physiotherapy" no produce ningún resultado en este buscador.

Dada la escasa afluencia de publicaciones al respecto, se plantea el siguiente estudio. 


\section{DISEÑO DE ESTUDIO}

Se establece un estudio de tipo experimental mediante un ensayo clínico con grupos en paralelo. El estudio fue diseñado atendiendo a los siguientes criterios.

Por su finalidad, es de tipo analítico ya que se pretende averiguar la relación causa-efecto entre las variables.

En cuanto a su secuencia temporal, es longitudinal y prospectivo puesto que se pretenden analizar los cambios a través del tiempo, en este caso, los nueve meses siguientes desde el inicio del proyecto de investigación, el 1 de Octubre del 2014.

El examinador principal del estudio, que será quién recoge los datos de cada participante y posteriormente realizará su análisis, no intervendrá en los procesos de tratamiento de los pacientes en ninguno de los grupos actuando por tanto como evaluador ciego. Así se asegura la fiabilidad y validez de los datos obtenidos, evitando que los pacientes se sientan obligados a responder algo en concreto y evitando el posible condicionamiento previo en la evaluación de los resultados por parte de quién realizó el tratamiento.

\section{VARIABLES}

Se han considerado las siguientes variables:

Como variables independientes se han considerado los valores articulares en la movilidad pasiva de hombro, en los siguientes movimientos analíticos:

○ Flexión hombro

- Extensión de hombro

- Abducción o separación de hombro

- Rotación interna de hombro

○ Rotación externa de hombro

Los valores han sido medidos con un inclinómetro modelo isomed unilevel $95 \AA$ 157 tal y como detalla el manual del mismo. Esto es, poniendo el instrumento sobre la diáfisis humeral en la parte más proximal de ésta para la flexión y extensión en su parte anterior.

Para la abducción se coloca en la diáfisis humeral en la parte más proximal y lateral posible.

Las rotaciones se han medido con el codo adosado al tronco, en flexión previa de $90^{\circ}$ y antebrazo pronado para conseguir que la medición fuese una rotación de hombro lo más pura posible, sin que el antebrazo interviniese. El inclinómetro se situó a la altura de la articulación radio cubital superior por su parte posterior (dorso del antebrazo). 


\section{METODOLOGÍA}

Como movimientos clave en la recuperación de la movilidad se han considerado la separación de hombro y la rotación interna, al ser dos de los movimientos que más tardan en recuperar los pacientes con lesiones cerebrales y con peor calidad de movimiento.

Además se han recogido las siguientes variables sociodemográficas:

○ Edad

- Sexo

- Etiología o causa de aparición del daño cerebral

- Año de aparición del daño cerebral

- Institucionalización o no del paciente: es decir, si el paciente reside en su domicilio habitual o está interno en una institución sanitaria

- Tratamiento rehabilitador que sigue el paciente: bien realiza cinesiterapia manual o bien cinesiterapia manual y terapia Vojta.

Se han registrado también aspectos relacionados con la dependencia, para ello se han usado las siguientes escalas:

- Medida de la independencia Funcional: MIF

En este estudio la vertiente motora del cuestionario es la que se evalúa como susceptible de cambio respecto al tratamiento.

La vertiente cognitiva de la escala se emplea como criterio de inclusión ya que los sujetos han de obtener al menos 25 puntos en dicha subescala.

○ Índice de Barthel: IB

Se han comparado los valores previos y post tratamiento generales, así como el valor en el tiempo medio de tratamiento de una y otra escala (FIM motor e IB) y de manera particular, se ha hecho una comparación específica entre los subítems de alimentación (recogido en la MIF) y comer (del IB) así como de las subescalas vestido del hemicuerpo superior (establecido en la escala MIF), y vestirse y desvestirse (del IB) ya que son dos actividades en las que el complejo articular del hombro interviene de manera esencial.

Lo relacionado con el estado de salud general del individuo se ha cuantificado mediante el cuestionario de salud SF-36, cuyo valor inicial y final se ha comparado. 


\section{MUESTRA}

Se dispone de una muestra de 50 pacientes procedentes de la Asociación de Daño Cerebral Adquirido de Salamanca (en lo sucesivo ASDACE) y del complejo asistencial del Hospital Provincial de Salamanca (en lo sucesivo HP).

Se establece un grupo de tratamiento con terapia Vojta y un grupo de tratamiento con cinesiterapia activo asistida

GRUPO 1: Realiza sesiones de cinesiterapia activoasistida + Terapia Vojta.

Realizada dos días por semana durante 45 minutos. Siempre a días alternos

GRUPO 2: Realiza sesiones de cinesiterapia activoasistida.

Realizada dos días a la semana durante 45 minutos. Siempre a días alternos.

Todos los pacientes son informados del propósito de estudio y su intención de participar en el mismo se recoge mediante un consentimiento informado, de manera oral y escrita. Además, aquellos sujetos cuya imagen ha sido incluida en este trabajo fueron informados también mediante otro consentimiento informado, de manera oral y escrita. (Ambos se encuentran en el ANEXO II).

El estudio cuenta con el informe favorable por parte del comité de bioética de la Universidad de Salamanca. (Ver Informe favorable en el ANEXO III)

Al inicio del tratamiento se recogerá información en una hoja de valoración preestablecida de cada uno de los pacientes que tendrá carácter individual (Ver ficha Anexo 1) y anónimo. En dicho documento se recogen datos sociodemográficos de cada paciente así como valores de rango articular, dependencia y salud general pre y post tratamiento.

El estudio concluyó con 48 de los 50 pacientes que empezaron el mismo, puesto que en los 9 meses de duración dos de ellos fallecieron. Los dos individuos correspondían al grupo 2. Es por ello que los resultados se basan en una muestra total de 48 individuos.

Los pacientes son valorados al inicio del tratamiento, a los cuatro meses y medio y a los nueve meses, siendo ésta la fecha de finalización del estudio. 


\subsection{CRITERIOS DE INCLUSIÓN}

Los pacientes debían de cumplir los siguientes requisitos

- Pacientes adultos con daño cerebral adquirido.

- Déficit de movimiento en el complejo escápulo-humeral en alguno de estos movimientos: flexoextensión, rotación interna o externa, abducción.

- Puntuación inicial en la escala MIF, en su vertiente cognitiva, igual o superior a 25 puntos.

- Origen del déficit de movimiento no provocado por síndromes simpático-reflejos u otras alteraciones neurológicas de origen central.

\subsection{CRITERIOS DE EXCLUSIÓN}

No pudieron participar en el estudio aquellos que cumplieran en el momento inicial al menos uno de estos requisitos:

- Rechazo a la movilización pasiva de hombro.

- Dolor exagerado del complejo escápulo-humeral, considerando el máximo soportable para participar en el estudio de 6 en una escala visual analógica, EVA, a criterio de los investigadores. La escala estaba puntuada del 0 al 10 y se mostraba en horizontal siendo el 0 la ausencia de dolor, situado a la izquierda y el 10 el máximo dolor soportable, situado a la derecha.

- Puntuación igual o superior a 1 en la escala de espasticidad de Ashworth.

\subsection{PERFIL SOCIODEMOGRÁFICO DE LOS INDIVI- DUOS}

De los 50 individuos participantes en el estudio 38 (76\%) pertenecen al GRUPO 1 mientras que el resto 12 (24\%) pertenecen al GRUPO 2.

Atendiendo a los dos grupos por igual 30 sujetos son hombres $(60 \%)$ y 20 son mujeres $(40 \%)$ de los cuales están institucionalizados el $76 \%$ del total de los individuos y el otro $24 \%$ viven de manera ambulatoria. Por sexos, el 60,10 \% de los varones frente al 48,5\% de las mujeres no están institucionalizados.

La media de edad oscila entre los 32 y los 99 años, siendo la media de 74,20 para el conjunto. Por sexos la media es de 72, 53 para hombres (edad mínima 32 y 93 máxima) y de 76,70 para las mujeres (39 y 99 edades mínima y máxima respectivamente).

Atendiendo a si están institucionalizados, la edad media de los individuos es de 58,17 años (error estándar 3,404) para el grupo 1 y de 79,26 años para el Grupo 2 (error 1,620 estándar). 
De los 30 varones participantes en el estudio, 20 pertenecen al grupo $2(66,7 \%$ de los varones) y 10 pertenecen al grupo 1 (33,3\% de los varones). En cuanto a las mujeres, $18(90 \%)$ pertenecen al grupo 2 y $2(10 \%)$ al grupo 1.

En cuanto al año de aparición del daño cerebral, en los hombres oscila entre 1999 y el 2014 y en mujeres entre el 2004 y el 2014 como se observa en las siguientes tablas.

\begin{tabular}{|c|c|c|c|c|c|}
\hline \multicolumn{3}{|c|}{ VARONES } & \multicolumn{3}{c|}{ MUJERES } \\
\hline Año de aparición & Frecuencia & Porcentaje & Año de aparición & Frecuencia & Porcentaje \\
\hline 1999 & 1 & 3,3 & 2004 & 2 & 10,0 \\
\hline 2000 & 1 & 3,3 & 2007 & 1 & 5,0 \\
\hline 2001 & 1 & 3,3 & 2008 & 4 & 20,0 \\
\hline 2005 & 1 & 3,3 & 2009 & 1 & 5,0 \\
\hline 2006 & 1 & 3,3 & 2010 & 1 & 5,0 \\
\hline 2007 & 5 & 16,7 & 2012 & 3 & 15,0 \\
\hline 2009 & 2 & 6,7 & 2013 & 6 & 30,0 \\
\hline 2011 & 1 & 3,3 & 2014 & 2 & 10,0 \\
\hline 2012 & 8 & 26,7 & & & \\
\hline 2013 & 5 & 16,7 & & & \\
\hline 2014 & 4 & 13,3 & & $\mathbf{2 0}$ & $\mathbf{1 0 0 , 0}$ \\
\hline Total & $\mathbf{3 0}$ & $\mathbf{1 0 0 , 0}$ & Total & & \\
\hline
\end{tabular}

Tabla 13: Frecuencia de aparición del DCA por sexos en el presente estudio

Respecto a la etiología o causa del daño cerebral se observa lo siguiente

\begin{tabular}{|c|c|c|c|c|c|}
\hline \multicolumn{3}{|c|}{ VARONES } & \multicolumn{3}{c|}{ MUJERES } \\
\hline Etiología & Frecuencia & Porcentaje & Etiología & Frecuencia & Porcentaje \\
\hline ACV izquierdo & 9 & 30,0 & ACV izquierdo & 4 & 20,0 \\
\hline ACV derecho & 11 & 36,7 & ACV derecho & 9 & 45,0 \\
\hline TCE & 4 & 13,3 & TCE & 3 & 15,0 \\
\hline IAM & 2 & 6,7 & IAM & 0 & 0 \\
\hline Párkinson & 2 & 6,7 & Párkinson & 4 & 20,0 \\
\hline EM & 2 & 6,7 & EM & 0 & 0 \\
\hline Total & $\mathbf{3 0}$ & $\mathbf{1 0 0 , 0}$ & Total & $\mathbf{2 0}$ & $\mathbf{1 0 0 , 0}$ \\
\hline
\end{tabular}

Tabla 14: Etiología del DCA por sexos en el presente estudio

Así, en cuanto a los varones la etiología mayor se concentra en accidentes cerebro vasculares $(66,7 \%)$ del total de la etiología siendo los del lado derecho de mayor incidencia. En cuanto al sexo femenino la etiología más frecuente es de nuevo el accidente cerebro vascular siendo el lado derecho el predominante de nuevo. 


\section{VALORACIÓN DE LOS PARTICIPANTES}

Previo al inicio del estudio cada participante de manera individual es informado del propósito del estudio de manera oral y escrita mediante un consentimiento informado, el cual tiene una copia que se le entrega y otra que queda recogida por el grupo investigador como parte del estudio. Con este consentimiento se advierten los riesgos y beneficios de la participación en el proyecto, el cual cuenta con el informe favorable del Comité de Bioética de la Universidad de Salamanca (Incluido en el anexo I).

Cada paciente será sometido a una valoración inicial individual que se recogerá en su correspondiente hoja de valoración, la cual estará codificada con un código de control para asegurar la confidencialidad de los participantes. Se recogen el nombre y apellidos del sujeto, la edad de éste, el sexo, la etiología de la lesión cerebral y el año en el que sucedió.

La valoración inicial así como las establecidas en la mitad del tratamiento (4,5 meses transcurridos desde el inicio del estudio) y al finalizar el mismo son idénticas en los dos grupos de tratamiento. En ellas se establecieron los valores iniciales de goniometría del complejo articular del hombro para los valores de flexión, extensión, abducción, rotación externa y rotación interna así como las puntuaciones iniciales en los cuestionarios MIF, IB y SF-36. También se recogió la valoración inicial en la EVA, ya que si ésta era superior a 6 puntos el paciente era excluido del estudio.

\subsection{METODOLOGÍA DE VALORACIÓN DEL BA- LANCE ARTICULAR ${ }^{8,148}$}

La goniometría, como se ha mencionado anteriormente se cuantificó mediante un inclinómetro modelo Isomed $95 \AA^{157}$. Durante las valoraciones goniométricas hubo al menos dos sujetos con pleno conocimiento del aparataje realizando las mediciones. A continuación se describen las posiciones de los pacientes y examinadores para llevar a cabo las mediciones del balance articular del hombro en cada una de las tres mediciones que se llevaron a cabo.

Posición de partida: paciente en bipedestación. 


\section{METODOLOGÍA}

- Medición plano $S^{148}$

En él ocurren los movimientos de flexión y extensión. Para ello el terapeuta fija con una mano la posición inicial sobre el hombro del paciente y su otra mano se dispone en el tercio distal del brazo, colocando el inclinómetro en la cara anterior del húmero.
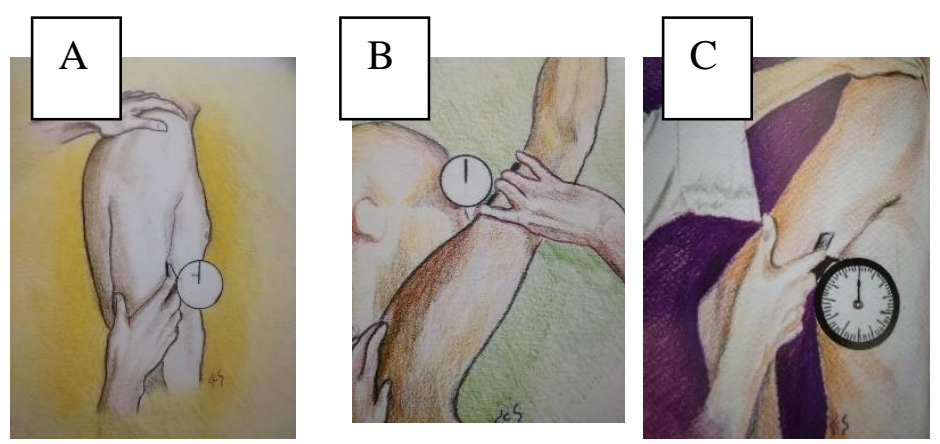

Figura 7: Imágenes medición plano S: A) posición inicial; B) flexión C) extensión ${ }^{148}$

- Medición plano $\mathbf{F}^{148}$

En él ocurren los movimientos de abducción y aducción. En este estudio sólo se ha considerado la abducción o separación de brazo, como ya se ha explicado anteriormente. En este caso la posición inicial consistirá en el terapeuta colocando una de sus manos sobre el hombro del paciente mientras que la otra se dispondrá con el inclinómetro en el tercio distal del brazo, esta vez disponiéndolo en la cara lateral del húmero.
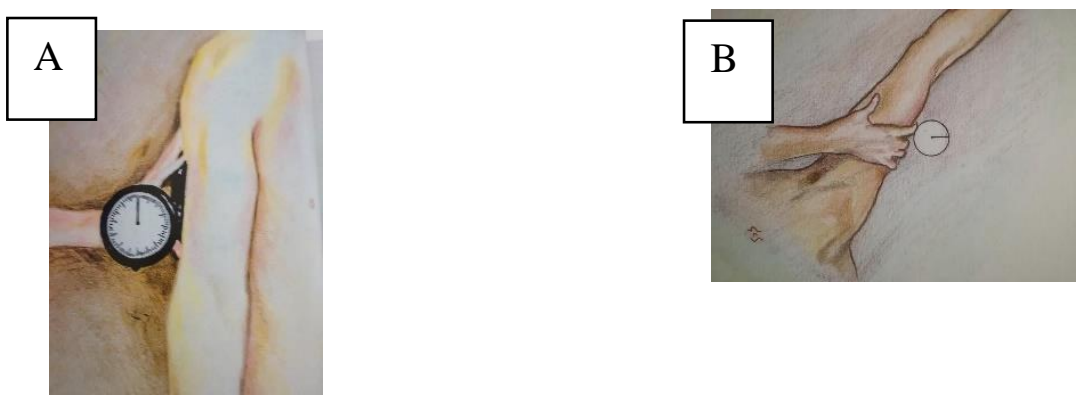

Figura 8: Imágenes medición plano F: A) posición inicial; B) abducción ${ }^{148}$ 


\section{METODOLOGÍA}

\section{- Medición plano $\mathbf{R}^{148}$}

En él ocurren los movimientos de rotación interna y externa. La posición del terapeuta será la misma que en las dos ocasiones anteriores pero esta vez el inclinómetro se dispondrá en la cara posterior del tercio distal del húmero. El movimiento de rotación del hombro se medirá asociado a la flexión de hombro de $90^{\circ}$, como se observa en las imágenes.
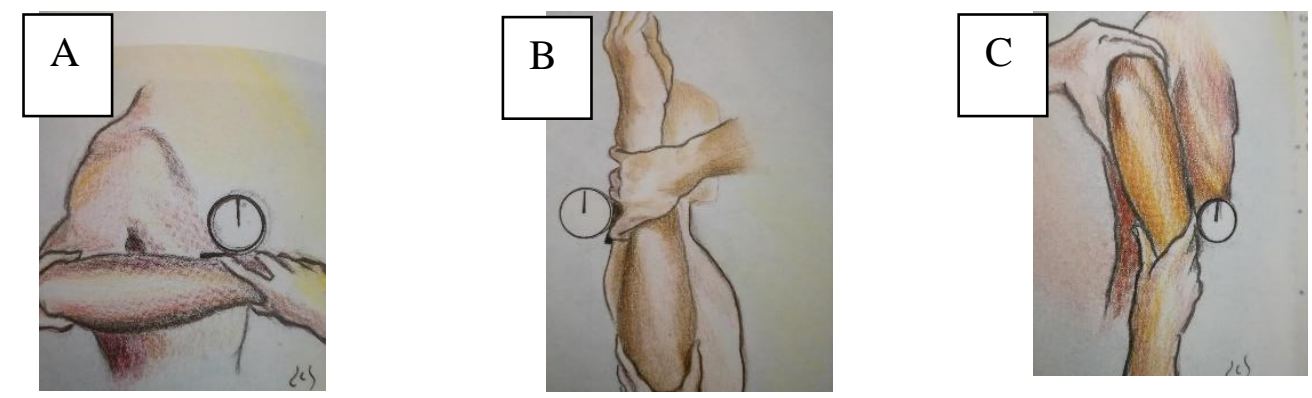

Figura 9: Imágenes medición plano $R$. A): posición inicial; B) rotación externa; C) rotación interna $^{148}$

\section{- Ejemplos de medición con sistema SFTR ${ }^{148}$}

A continuación se muestran algunos ejemplos de escritura del balance articular mediante este sistema, que en este caso corresponden a la articulación del hombro, pero que en función de los grados de movimiento de cada articulación, son aplicables a todas ellas.

- $\quad 5: 10-0-90$

Significado: Extensión del brazo de $10^{\circ}$, posición neutra anatómica, flexión del hombro de $90^{\circ}$.

- $F: 40-10-0$

Significado: Paciente que sólo hace $40^{\circ}$ de abducción desde la posición de $10^{\circ}$ de abducción no teniendo ningún grado de adducción.

- $\quad$ R 70-0-88

Significado: El paciente tiene una movilidad de $70^{\circ}$ de rotación externa y $88^{\circ}$ de rotación interna desde la posición anatómica. 


\subsection{ESCALAS DE VALORACIÓN}

Las escalas de valoración que se han empleado en el estudio han sido el IB y la MIF como indicadores del grado de independencia del individuo y el cuestionario SF36 como indicador subjetivo del estado de percepción de su salud de cada individuo.

El IB y la MIF se determinaron en cada paciente al inicio del tratamiento, en la mitad del mismo y al finalizar el periodo. El SF-36 se cuantificó al inicio y al final el estudio.

El IB y la MIF se recogieron por parte de los investigadores de manera escrita. Siempre hubo al menos dos investigadores para contrastar el resultado de la prueba.

El SF-36 por su parte fue contestado de manera autoadministrable por cada sujeto de manera personal y por escrito, sin intervención de los investigadores, a menos que existieran problemas en la lectura de algunas de las preguntas, en cuyo caso los examinadores procedieron a su aclaración, pero la respuesta otorgada a cada ítem fue dada de manera voluntaria por el sujeto.

\section{NATURALEZA DE LAS SESIONES REALIZADAS}

Como ya se ha mencionado anteriormente el grupo 1 recibió sesiones de fisioterapia consistentes en 45 minutos de tratamiento con metodología Vojta además de cinesiterapia activo asistida consistente en ejercicios basados en la facilitación neuromuscular propioceptiva. En el Grupo 2, las sesiones incluían únicamente FNP. Ambos grupos realizaron el mismo número de sesiones, (2 semanales) a días alternos que bien podían establecerse los lunes y los miércoles o los martes y los jueves, siempre y cuando no coincidiesen con periodos festivos marcados por el calendario laboral de la Universidad de Salamanca del curso 2014-2015, que puede consultarse de manera pública en la página web de dicha institución (www.usal.es). El tiempo total de tratamiento evaluado fue desde el 1 Octubre de 2014 al 30 de Junio del 2016.

\subsection{SESIONES REALIZADAS EN EL GRUPO 1}

El grupo 1 realizó las sesiones de tratamiento en la Escuela Universitaria de Enfermería y Fisioterapia de la Universidad de Salamanca, en una de las aulas que tiene destinadas a la actividad docente asistencial ubicada en el cuarto piso del edificio.

El tratamiento consistió en aplicar la facilitación neuromuscular propioceptiva, como una modalidad de cinesiterapia activo-asistida en el miembro superior así como el tratamiento con la metodología Vojta.

La FNP consistió en emplear las diagonales disponibles en la extremidad superior (ver tabla 10) con aplicando en ellas las técnicas descritas en el apartado 5.2.2.4 Procedimiento específico en FNP: articulación del hombro y zona escapular del marco teórico del presente estudio.

La metodología Vojta ${ }^{4,9,24}$ consistió en aplicar el volteo en primera fase y la reptación refleja básica en ambos hemicuerpos el mismo número de veces con el fin de 


\section{METODOLOGÍA}

desencadenar las respuestas de prensión manual y separación del metacarpo (RR) así como separación del metacarpo, extensión de los dedos, flexión dorsal de muñeca y apoyo de las extremidades (VR).

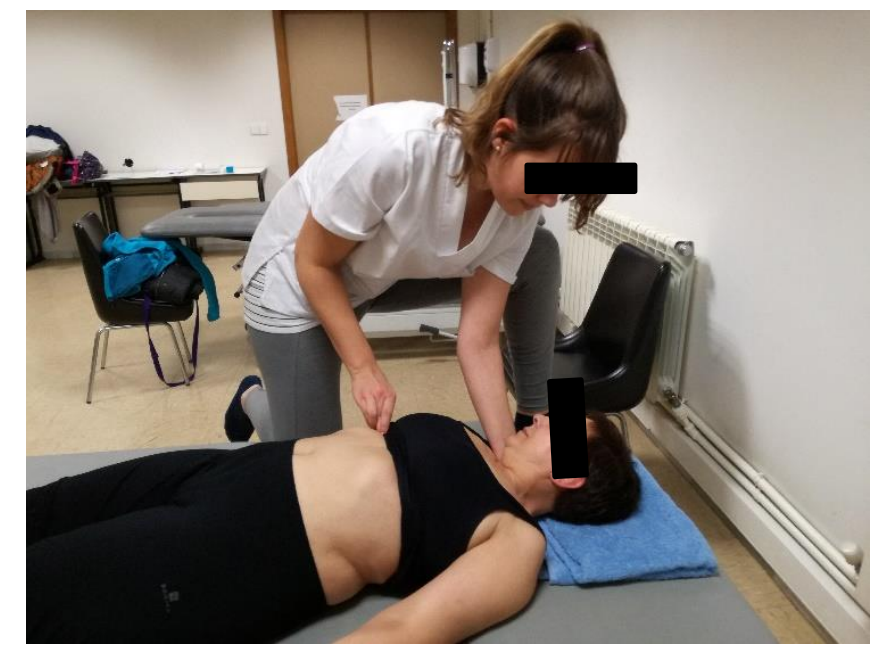

Figura 10: Posición de partida del VR

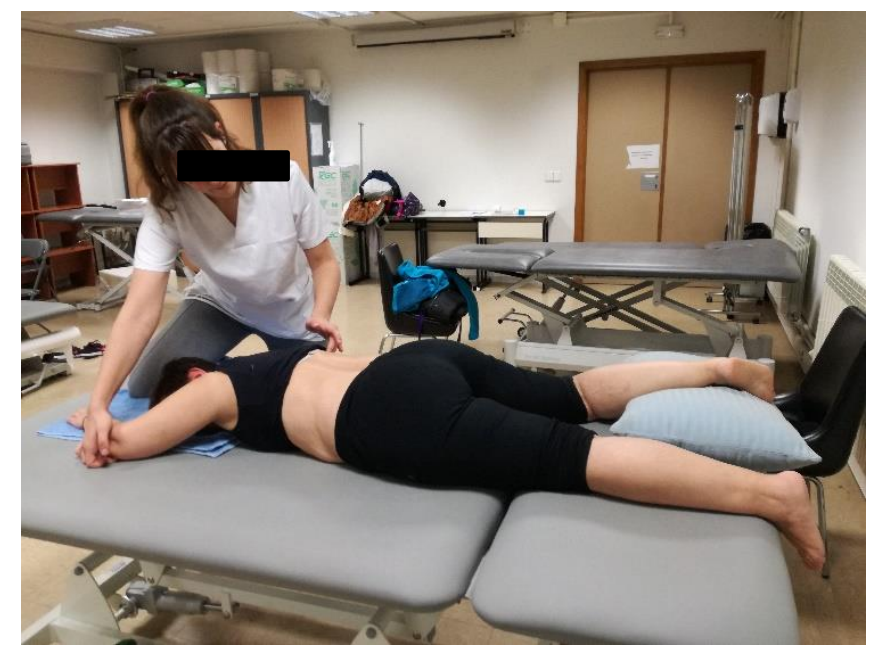

Figura 11: Posición de partida para la RR básica en adultos 


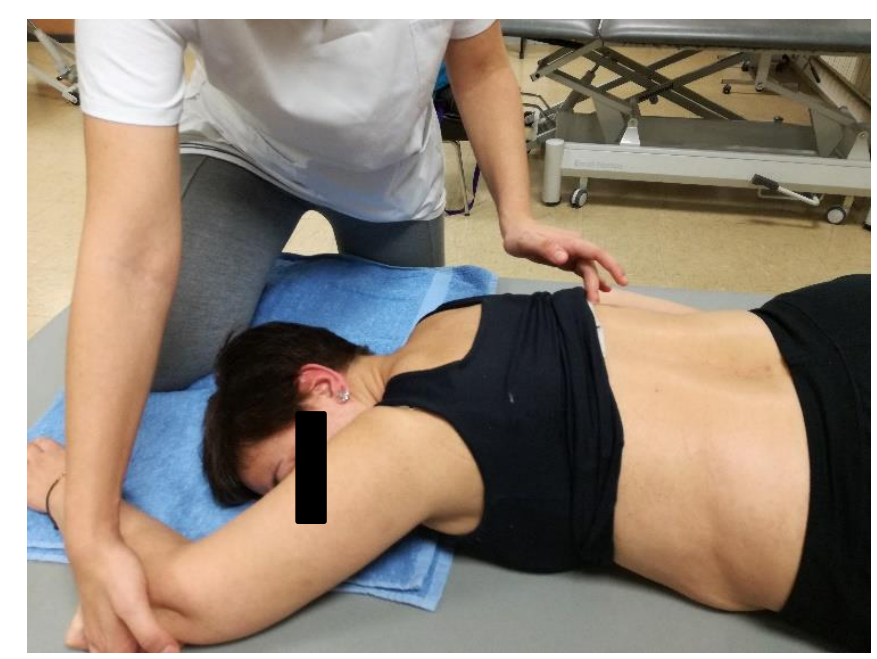

Figura 12: Detalle de la zona del MS en la RR. Estimulación en los puntos de la epitróclea y de los músculos espinales

Este grupo contó siempre con dos terapeutas expertos en las técnicas así como con el apoyo continuo de estudiantes del grado en fisioterapia de tercer y cuarto curso.

\subsection{SESIONES REALIZADAS EN EL GRUPO 2}

El grupo 2 realizó su tratamiento en el Hospital Provincial de Salamanca, situado en la calle García Tejado 28.

En este caso el tratamiento consistió en aplicar la FNP como parte de la fisioterapia activo-asistida por parte del fisioterapeuta responsable del complejo, empleando para ello las técnicas descritas previamente.

En este grupo la presencia de los estudiantes de Fisioterapia de la Universidad de Salamanca se produjo únicamente entre febrero y junio del 2015. 


\section{ANÁLISIS ESTADÍSTICO}

En primer lugar se ha realizado un análisis descriptivo de las variables incluidas en el estudio:

- Variables nominales: frecuencias absolutas y frecuencias relativas (en porcentajes).

- Variables intervalares o de escala: medidas de tendencia central (media) y de dispersión (S)

Para realizar el contraste de las hipótesis planteadas en el estudio, se ha procedido a realizar diferentes análisis en función de las variables empleadas en cada una de las hipótesis.

Para contrastar el efecto de un tratamiento respecto a otro así como la efectividad de uno y otro por separado se han empleado pruebas paramétricas ${ }^{189.190}$ ya que en el estudio las variables implicadas son cuantitativas, la distribución es normal y el total de la muestra es de al menos 25 sujetos.

En grupos de análisis con muestras más reducidas se emplearon pruebas no paramétricas.

Para la aceptación o rechazo de la hipótesis nula ${ }^{190}$ (o la no existencia de diferencias o relación entre las variables analizadas) se ha decidido asumir la recomendación establecida por consenso y considerar un $95 \%$ de fiabilidad para la prueba. Si el nivel de significación, $\alpha$, es de un 0,05 o menor se rechazará la hipótesis nula. Si por el contrario el valor de significación es mayor de 0,05 se procederá a aceptar la hipótesis nula y por tanto, la no existencia de diferencias o relación entre las variables contrastadas.

El Análisis de los datos se ha realizado utilizando el software estadístico SPSS (Statistical Products and Service Solutions), en su versión $22^{197}$ (IBM, 2013).

\subsection{ANÁLISIS MULTIVARIANTE}

Para el análisis estadístico multivariante se ha utilizado el Análisis de Correspondencias Múltiples ${ }^{195.196}$, que considera los datos categóricos mediante la asignación de valores numéricos a las categorías de cada variable.

El Análisis de Correspondencias Múltiples (ACM en lo sucesivo) o HOMALS (del inglés HOMogeneity Analysis by Means of Alternating Least Squares; Análisis de Homogeneidad mediante mínimos cuadrados alternados), es una técnica de Análisis Multivariante no lineal que permite analizar la estructura dimensional de un conjunto de datos cuando el objetivo es investigar las interrelaciones entre un gran número de variables categóricas, particularmente entre todas las categorías simultáneamente. (Tomalá, 2002 ${ }^{198}$ ). 
El ACM es un procedimiento híbrido entre el Análisis Factorial y el Análisis de Correspondencias que permite reducir la dimensionalidad de la información cuando las variables son de tipo nominal ${ }^{195.196}$. De este último incorpora la reducción de la información recogida por muchas variables en una serie de factores que en HOMALS se denominan dimensiones y que permiten la representación gráfica de las relaciones de las variables así como el posicionamiento de los individuos en el plano factorial resultante. Del Análisis de Correspondencias asimila la posibilidad de trabajar con variables categóricas, si bien es capaz de trabajar con más de dos variables; es decir, HOMALS es una generalización del Análisis de Correspondencias.

Se trata de un procedimiento estadístico adecuado para datos cualitativos, como las preguntas que conforman el cuestionario SF-36, cuyo objetivo es describir las relaciones entre variables nominales en un espacio de dimensión reducida, que contiene las categorías de las variables así como los individuos con valores en dichas categorías. Mediante esta técnica, los individuos pertenecientes a la misma categoría se representan cerca los unos de los otros, mientras que los individuos de categorías distintas se representan alejados unos de los otros. El Análisis de Correspondencias Múltiples es una técnica que nos posibilita una interpretación gráfica de baja dimensionalidad con la menor pérdida posible de información ${ }^{195.196}$.

El Análisis de los datos se ha realizado utilizando el software estadístico SPSS (Statistical Products and Service Solutions ${ }^{197}$ ), en su versión 22 y que implementa los tres procedimientos de ESCALAMIENTO ÓPTIMO, que han sido formulados por los miembros del departamento de Teoría de Datos de la Facultad de Ciencias Sociales de la Universidad de Leiden ${ }^{194}$ (sistema GIFI).

Los miembros del departamento de Teoría de Datos de la Facultad de Ciencias Sociales de la Universidad de Leiden, publicaron en 1990 el libro Nonlinear Multivariate Analysis ${ }^{194}$ (Gifi, 1990), en el que se recogían y presentaban los diversos procedimientos de escalamiento óptimo de datos, que configuran lo que se conoce como el Sistema Gifi del Análisis Multivariante No Lineal. Dicho escalamiento óptimo tiene como idea asignar puntuaciones numéricas a las categorías de cada variable. Esta cuantificación óptima se obtiene por el procedimiento de los Mínimos Cuadrados Alternados y permite con posterioridad realizar análisis multivariantes. El objetivo es conseguir cuantificaciones óptimas de las categorías de las variables de manera que dichas categorías estén separadas entre las distintas dimensiones estudiadas tanto como sea posible y además dentro de cada dimensión los individuos estén lo más próximos unos de otros, con la finalidad de obtener una homogeneidad máxima. 
METODOLOGÍA 


\section{RESULTADOS}

\section{DESCRIPCIÓN DE LA MUESTRA}

El estudio se realiza a partir de una muestra inicial de 50 pacientes procedentes de la Asociación de Daño Cerebral Adquirido de Salamanca (ASDACE) y del complejo asistencial del Hospital Provincial de Salamanca (HP).

Se establece un grupo de tratamiento con terapia Vojta y cinesiterapia activo asistida (Pacientes pertenecientes a la asociación de Daño Cerebral Adquirido de Salamanca, ASDACE) que se denominará GRUPO 1 y un grupo de tratamiento con cinesiterapia activo asistida únicamente (Pacientes del complejo hospitalario Hospital Provincial, HP) que se denominará GRUPO 2.

GRUPO 1: Cinesiterapia activo asistida + Terapia Vojta.

Realizada dos días por semana durante 45 minutos. Siempre a días alternos.

\section{GRUPO 2: Cinesiterapia activo asistida.}

Realizada dos días a la semana durante 45 minutos. Siempre a días alternos.

El número total de individuos que componen el grupo 1 es de 12 y el grupo 2 es de 36.2 de los sujetos fallecieron durante el transcurso del presente estudio (ambos pertenecientes al grupo 2) por lo que el total de individuos que finalmente forman parte de la muestra es de 48.

Los 12 individuos del grupo 1 son el total de personas que a fecha 1 de Octubre del 2014 asistían a tratamiento en la Universidad de Salamanca a través del convenio docente-asistencial de esta institución con la Asociación ASDACE y por tanto, eran portadores de un DCA. Los individuos que conforman el segundo grupo son todos aquellos que presentan un DCA y se encontraban en esa misma fecha institucionalizados en el HP de Salamanca.

A continuación se realiza un análisis descriptivo de cada uno de los dos grupos de tratamiento que conformaron el estudio. Se realizará el mismo por separado para cada uno de ellos debido a que los individuos de cada grupo presentan un tratamiento fisioterapéutico diferente, y la base de este análisis es hacer una comparación entre ambas terapias. 


\section{ASPECTOS SOCIODEMOGRÁFICOS GRUPO 1}

El grupo 1 presenta las siguientes características epidemiológicas.

El $83,3 \%$ son varones $(n=10)$ y el $16,7 \%$ son mujeres $(n=2)$ y ninguno de ellos se encuentra institucionalizado, es decir, que el $100 \%$ de los individuos reside en el domicilio.

La edad del grupo oscila entre 32 y 72 años siendo la media de 52,17 (desviación estándar 11,792).

\section{GRUPO 1 CUADRO RESUMEN}

Se muestran en la siguiente tabla las características del grupo 1

\begin{tabular}{|c|c|c|c|c|c|c|c|}
\hline EDAD & & SEXO & & ANTIGÜEDAD & & ETIOLOGÍA & \\
\hline Mínima & 32 & $\begin{array}{l}\text { Mascu- } \\
\text { lino }\end{array}$ & $\begin{array}{c}10 \\
(83,3 \%)\end{array}$ & Antiguo & $\begin{array}{c}4 \\
(33,3 \\
\%)\end{array}$ & $\begin{array}{c}\text { ACV } \\
\text { izquierdo }\end{array}$ & $\begin{array}{c}5 \\
(41,7 \% \\
)\end{array}$ \\
\hline Máxima & 72 & Femenino & $\begin{array}{c}2 \\
(16,7 \%)\end{array}$ & Reciente & $\begin{array}{c}8 \\
(66,7 \\
\%)\end{array}$ & $\begin{array}{c}\text { ACV } \\
\text { derecho }\end{array}$ & $\begin{array}{c}2 \\
(16,7 \% \\
)\end{array}$ \\
\hline Media & $\begin{array}{c}52,17 \\
S(11,792)\end{array}$ & & & & & $\begin{array}{l}\text { Otras } \\
\text { etiologías }\end{array}$ & $\begin{array}{c}5 \\
(41,7 \% \\
)\end{array}$ \\
\hline
\end{tabular}

Tabla 15: resumen de las características de los individuos del grupo 1

\begin{tabular}{|c|c|c|c|}
\hline \multicolumn{4}{|c|}{ SEXO-ANTIGÜEDAD } \\
\hline & Masculino & Femenino & Total \\
\hline Reciente & 6 & 2 & 8 \\
$(<2$ años $)$ & $50,0 \%$ & $16,7 \%$ & $66,7 \%$ \\
\hline Antiguo & 4 & 0 & 4 \\
$(>2$ años $)$ & $33,3 \%$ & $0 \%$ & $33,3 \%$ \\
\hline
\end{tabular}

Tabla 16: clasificación de los individuos por sexo y antigüedad. Grupo 1

En cuanto a la antigüedad de aparición del DC, el 66,7 \% son de instauración reciente (se produjeron en el mismo año 2014 o en los dos inmediatamente anteriores) y el 33,3\% fueron antiguos. Atendiendo por sexos podemos trazar la siguiente tabla y el siguiente gráfico.

Donde el $50 \%$ de los hombres y el $16 \%$ de las mujeres de este grupo sufrieron recientemente el DCA mientras que en años anteriores lo sufrieron el 33,3\% de los varones y ninguna mujer. 
Podemos describirlo gráficamente así:

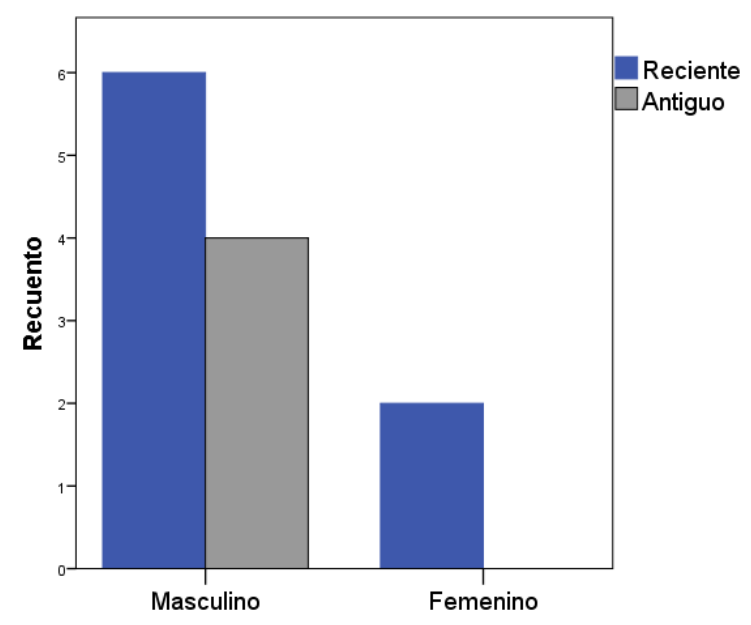

Figura 13: Distribución de los individuos por sexo y antigüedad. Grupo 1

Respecto a la etiología del daño cerebral, 5 de los individuos (41,7\%) sufrieron un ACV de afectación predominante de hemicuerpo izquierdo, 1 único individuo sufrió un ACV de afectación predominante de hemicuerpo derecho (representa el 8,3\% del total) y otras etiologías: EM, TCE, IAM (todas ellas de afectación bilateral) representan el 50,0\% y son 6 individuos en total.

Haciendo una distinción por sexos podemos representarlo de la siguiente manera:

\begin{tabular}{|c|c|c|c|}
\hline \multicolumn{4}{|c|}{ SEXO-ETIOLOGÍA } \\
\hline & Masculino & Femenino & Total \\
\hline $\begin{array}{l}\text { ACV iz- } \\
\text { quierdo }\end{array}$ & 4 & 1 & $\begin{array}{c}5 \\
(41,7 \%)\end{array}$ \\
\hline $\begin{array}{l}\text { ACV de- } \\
\text { recho }\end{array}$ & 2 & 0 & $\begin{array}{c}2 \\
(16,7 \%)\end{array}$ \\
\hline $\begin{array}{c}\text { OTRAS } \\
\text { etiologías }\end{array}$ & 4 & 1 & $\begin{array}{c}5 \\
(41,7 \%)\end{array}$ \\
\hline
\end{tabular}

Tabla 17: clasificación de los individuos por sexo y etiología. Grupo 1 


\section{RESULTADOS}

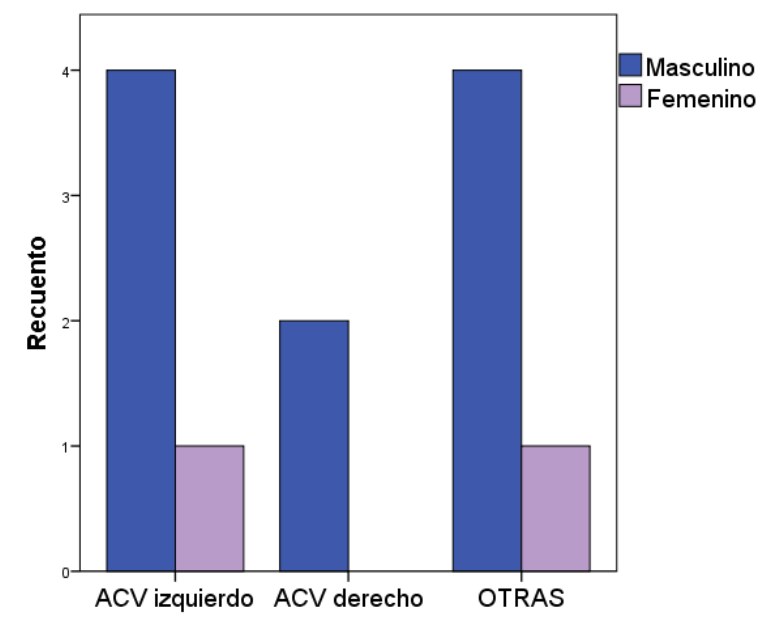

Figura 14: Distribución de los individuos por sexo y etiología. Grupo 1

Recordaremos en este punto que a nivel nacional, el Ictus representa la etiología predominante del $\mathrm{DCA}^{143}$, siendo la primera causa del DCA con el $78 \%$ de los casos. Otras causas como el TCE representan el $22 \%$ restante. Dada la importancia de los accidentes cerebro vasculares en la sociedad actual y en el presente estudio, se les ha catalogado como entidades propias (tanto al ACV derecho como al izquierdo) distinguiéndolos del resto de etiologías del DCA. 


\section{ASPECTOS SOCIODEMOGRÁFICOS GRUPO 2}

El grupo 2 presenta las siguientes características epidemiológicas. Hay 18 hombres y 18 mujeres, $50 \%$ en cada caso. La edad media de los participantes en este grupo es de 78,72 años (s 9,987) siendo la mínima de 49 y el máximo de 99.

Por etiología el 19,4\% presentan un ACV izquierdo ( $n=7)$, el 47,2 \% presenta un ACV derecho $(n=17)$ y el 33,3\% restante pertenecen a otras etiologías de afectación bilateral $(n=12)$.

En cuanto a la antiguiedad del DCA 19 son antiguos y 17 son de instauración reciente, lo que supone un porcentaje de 52,8 y $47,2 \%$ respectivamente.

\section{GRUPO 2 CUADRO RESUMEN}

\begin{tabular}{|c|c|c|c|c|c|c|c|}
\hline EDAD & & SEXO & & ANTIGÜEDAD & & ETIOLOGÍA & \\
\hline Mínima & 49 & Masculino & $\begin{array}{l}18 \\
50,0 \%\end{array}$ & Antiguo & $\begin{array}{l}19 \\
52,8 \%\end{array}$ & $\begin{array}{l}\text { ACV } \\
\text { izquierdo }\end{array}$ & $\begin{array}{l}7 \\
19,4 \%\end{array}$ \\
\hline Máxima & 99 & Femenino & $\begin{array}{l}18 \\
50,0 \%\end{array}$ & Reciente & $\begin{array}{l}17 \\
47,2 \%\end{array}$ & $\begin{array}{l}\text { ACV } \\
\text { derecho }\end{array}$ & $\begin{array}{l}17 \\
47,2 \%\end{array}$ \\
\hline Media & $\begin{array}{l}78,72 \\
S(9,987)\end{array}$ & & & & & $\begin{array}{l}\text { Otras } \\
\text { etiologías }\end{array}$ & $\begin{array}{l}12 \\
33,3 \%\end{array}$ \\
\hline
\end{tabular}

Tabla 18: resumen de las características de los individuos del grupo 2

Atendiendo por sexos podemos trazar la siguiente tabla y el siguiente gráfico:

Tabla 19:

\begin{tabular}{|c|r|r|r|}
\hline \multicolumn{4}{|c|}{ SEXO-ANTIGÜEDAD } \\
\hline & Masculino & \multicolumn{1}{|c|}{ Femenino } & \multicolumn{1}{|c|}{ Total } \\
\hline Reciente & 10 & 9 & 19 \\
& $27,8 \%$ & $25,0 \%$ & $52,8 \%$ \\
\hline Antiguo & 8 & 9 & 17 \\
& $22,2 \%$ & $25,0 \%$ & $47,2 \%$ \\
\hline \hline Total & 18 & 18 & 36 \\
& $50,0 \%$ & $50,0 \%$ & $100,0 \%$ \\
\hline
\end{tabular}

clasificación de los individuos por sexo y antigüedad. Grupo 2 


\section{RESULTADOS}

De manera gráfica se objetiva de la siguiente manera:

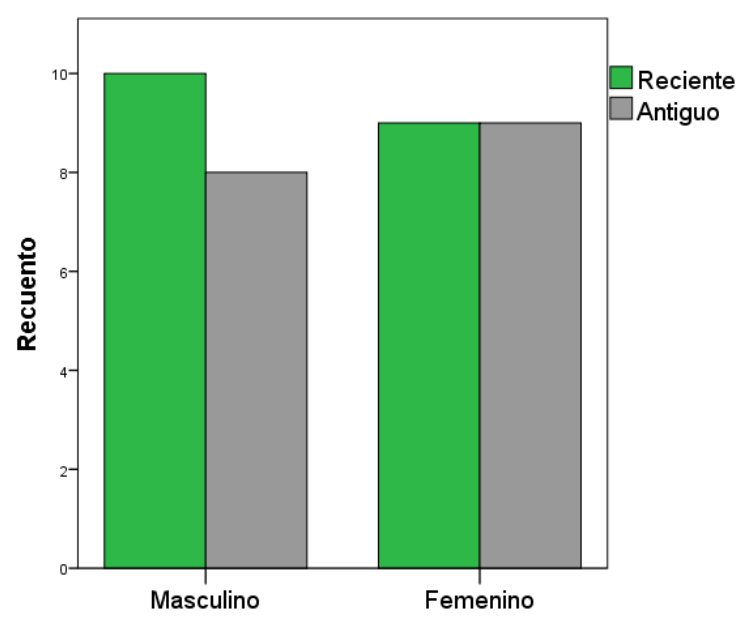

Figura 15: distribución de los individuos por sexo y antigüedad. Grupo 2

Respecto a la etiología del DCA, si establecemos la distinción por sexos, observamos que el $11,1 \%$ de los individuos $(n=4)$ son varones que sufrieron un ACV izquierdo y el 8,3\% fueron mujeres $(n=3)$ que sufrieron esta misma etiología.

El ACV de afectación predominante derecha lo sufrieron el 22,2 \% de los varones y el $25 \%$ de las mueres. Otras etiologías se repartieron equitativamente por sexos representando en hombres y en mujeres el 16,7\%.

Tabla 20:

\begin{tabular}{|c|r|r|r|}
\hline \multicolumn{4}{|c|}{ SEXO-ETIOLOGÍA } \\
\hline & \multicolumn{1}{|c|}{ Masculino } & \multicolumn{1}{|c|}{ Femenino } & \multicolumn{1}{c|}{ Total } \\
\hline ACV iz- \\
quierdo & 4 & 3 & 7 \\
& $11,1 \%$ & $8,3 \%$ & $19,4 \%$ \\
\hline ACV derecho & 8 & 9 & 17 \\
& $22,2 \%$ & $25,0 \%$ & $47,2 \%$ \\
\hline $\begin{array}{c}\text { OTRAS etio- } \\
\text { logías }\end{array}$ & $16,7 \%$ & 6 & 12 \\
\hline TOTAL & 18 & $16,7 \%$ & $33,3 \%$ \\
\hline
\end{tabular}

clasificación de los individuos por sexo y etiología. Grupo 2. 


\section{RESULTADOS}

Esquemáticamente podemos representarlo de la siguiente manera

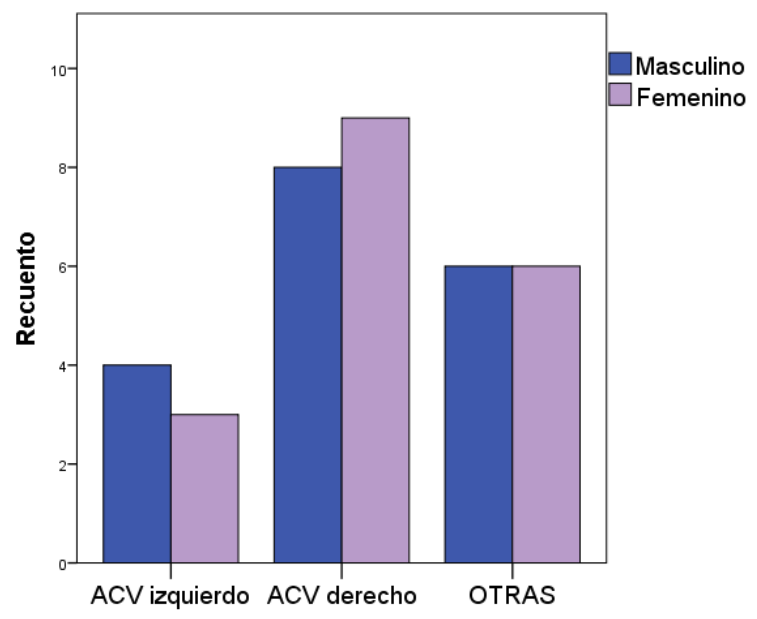

Figura 16: distribución de los individuos por sexo y etiología. Grupo 2

\section{DESCRIPCIÓN DE LOS RESULTADOS EN LAS MEDICIONES DE BALANCE ARTICULAR}

Tal y como se explicó en el apartado de metodología, la goniometría o balance articular del hombro se registró empleando un goniómetro ISOMED unilevel 95 ®. El sistema de notación usado en este estudio, como ya se ha mencionado ha sido el sistema FTR donde en una misma notación se registran los valores para los movimientos en el plano frontal $(\mathrm{F})$, transversal $(\mathrm{T})$ y rotacional $(\mathrm{R})$.

Los movimientos del complejo articular del hombro en cada uno de sus grados de movilidad se han realizado de respetando la fisiología articular y las amplitudes máximas de movimiento 8 .

Los valores mostrados a continuación están tomados de los esquemas de fisiología articular A.I. Kapandji; partiendo de la posición anatómica del individuo; esto es en bipedestación, pies ligeramente separados, miembros superiores a lo largo del cuerpo en supinación y mirada al frente 145. (Kapandji, 20068). 


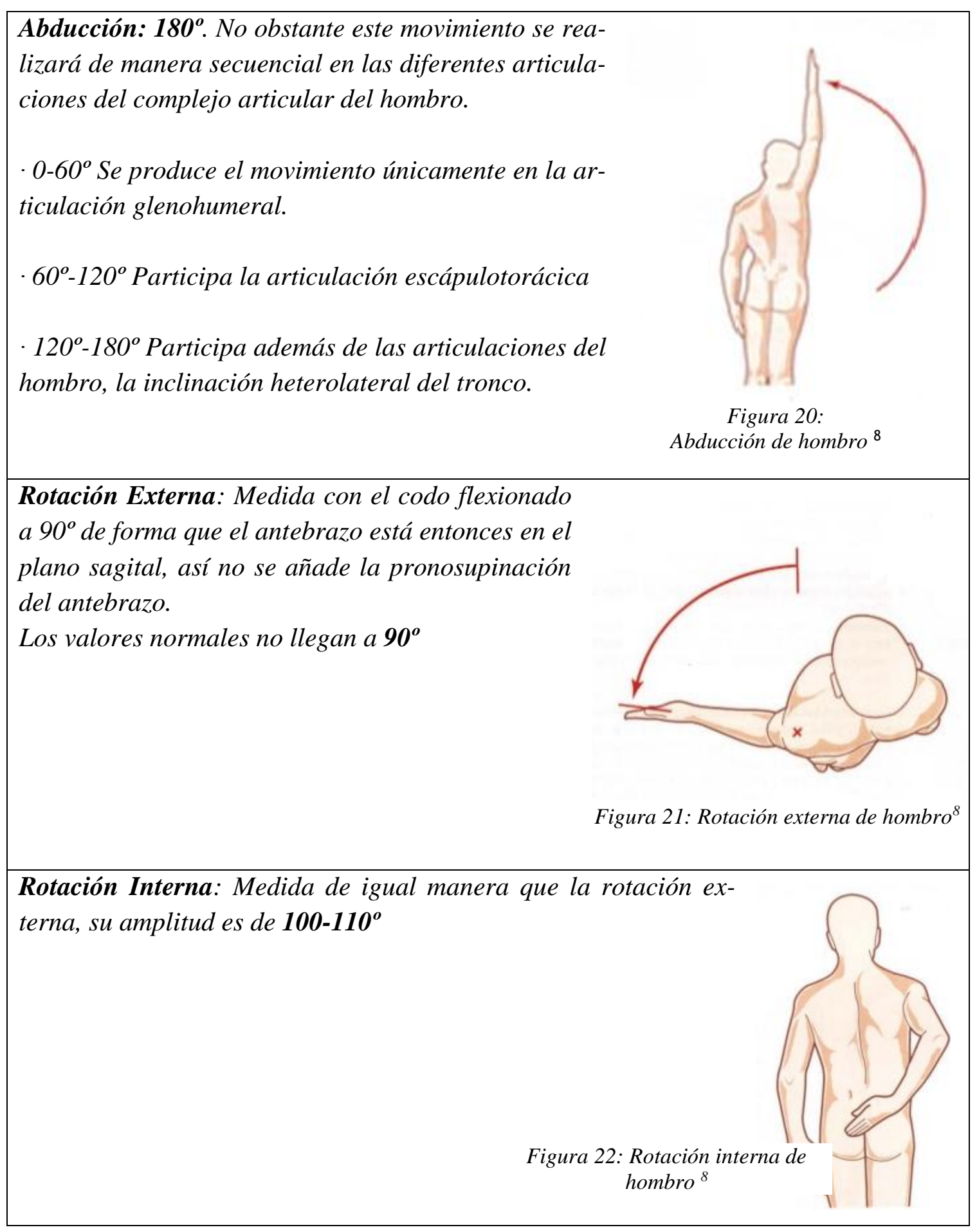

Para analizar los resultados de las pruebas de goniometría8 conviene explicar en este punto cómo se han tomado las valoraciones y posteriormente se han categorizado las mismas.

Para cada una de las mediciones goniométricas extraídas en el estudio (flexión, extensión, abducción, rotación externa y rotación interna) se ha registrado el valor que 


\section{RESULTADOS}

presentaba cada individuo al inicio (tiempo 1), en el tiempo medio de tratamiento (tiempo 2) y al finalizar el mismo (tiempo 3 o tiempo total).

Lo que se ha estudiado es la diferencia entre las valoraciones que presentaban los individuos; es decir se ha procedido a realizar el siguiente cálculo:

- DIF_1: resultado de la diferencia entre el tiempo 2 y el tiempo 1; esto es entre la valoración media y la inicial.

- DIF_2: resultado de la diferencia entre el tiempo 3 y el tiempo 2; esto es entre la valoración final y la intermedia.

- DIF_TOT: resultado de la diferencia entre el tiempo 3 y el tiempo 1; esto es entre la valoración final y la inicial.

Así, con la diferencia de puntuaciones obtenida para cada una de las mediciones (flexión, abducción, extensión, rotación interna, rotación externa) de uno y otro miembro superior se agrupó a los individuos en cinco categorías según fuera la evolución de los mismos para cada una de las mediciones tomadas. Las categorías descritas y el rango articular que abarcan son las siguiente.

\begin{tabular}{|l||l|l|l|l|}
\hline \multicolumn{1}{|l||}{ Categoría } & \multicolumn{3}{|c|}{ Movimiento } \\
\hline & ABD & FLEX & ROTH (derecha e izquierda) & EXT \\
\hline Mucho peor (1) & $-60-30^{\circ}$ & $-75-30^{\circ}$ & $-42-15^{\circ}$ & $-30-15^{\circ}$ \\
\hline Peor (2) & $-29-5^{\circ}$ & $-29-5^{\circ}$ & $-14-5^{\circ}$ & $-14-5^{\circ}$ \\
\hline lgual (3) & $-4+10^{\circ}$ & $-4+10^{\circ}$ & $-4+10^{\circ}$ & $-4+10^{\circ}$ \\
\hline Mejor (4) & $+11+30^{\circ}$ & $+11+30^{\circ}$ & $+11+30^{\circ}$ & $+11+30^{\circ}$ \\
\hline Mucho mejor (5) & $+31+60^{\circ}$ & $+31^{\circ}+75^{\circ}$ & $+31+68^{\circ}$ & $+31+45^{\circ}$ \\
\hline
\end{tabular}

Tabla 21: Categorías establecidas para cada movimiento articular testado y rango articular que comprenden

Para cada una de las variables se categorizó a los individuos en función de cuánto hubieran ganado-o disminuido- en cada movimiento de la goniometría articular del hombro respecto a la valoración anterior o en el conjunto del tratamiento. 


\section{BALANCE ARTICULAR DE INDIVIDUOS AFECTA- DOS DEL HEMICUERPO IZQUIERDO. GRUPO 1.}

Esto comprende tanto a aquellos individuos que han sufrido un ACV de afectación predominante del hemicuerpo izquierdo (HC izq.) como a aquellos cuya etiología es de afectación bilateral (TCE, EM, IAM etc.) englobados todos ellos en "otras etiologías". El total de individuos del grupo 1 que cumple estas condiciones es de 10, lo que supone el $83,3 \% \%$ del total del grupo.

De estos 10 , en cuanto a etiología 5 son de afectación bilateral y 5 individuos sufrieron un ACV de afectación predominante izquierda. Haciendo la distinción por sexos, 8 son varones y 2 son mujeres y en cuanto a la antigüedad 8 son recientes y 3 son antiguos.

\begin{tabular}{|l|l|r||l|r|r||l|r|r|}
\hline Antigüedad & $\mathrm{N}$ & \multicolumn{1}{l|}{$\%$} & Etiología & $\mathrm{N}$ & \multicolumn{1}{l}{$\%$} & Sexo & $\mathrm{N}$ & $\%$ \\
\hline Reciente & 8 & 80,0 & $\begin{array}{l}\text { ACV iz- } \\
\text { quierdo }\end{array}$ & 5 & 50,0 & Masculino & 8 & 80,0 \\
\hline Antiguo & 2 & 20,0 & $\begin{array}{l}\text { Otras etiolo- } \\
\text { gías }\end{array}$ & 5 & 50,0 & Femenino & 2 & 20,0 \\
\hline \hline Total & 10 & 100,0 & Total & 10 & 100,0 & Total & 10 & 100,0 \\
\hline
\end{tabular}

Tabla 22: Clasificación de los individuos por antigüedad, sexo y etiología. HC izq. Grupo 1

A continuación se muestran los resultados medios obtenidos para cada una de las pruebas goniométricas medidas en el hombro; esto es flexión, extensión, abducción, rotación interna y externa del conjunto de los individuos con afectación izquierda en cada uno de los 3 tiempos de medición. 


\section{RESULTADOS}

\begin{tabular}{|c|c|c|c|}
\hline Movimiento & Media & N & S \\
\hline ABD inicial hombro izquierdo & 98,00 & 10 & 34,173 \\
\hline ABD intermedia hombro izquierdo & 108,30 & 10 & 30,291 \\
\hline ABD final hombro izquierdo & 117,40 & 10 & 28,543 \\
\hline EXT inicial hombro izquierdo & 27,60 & 10 & 14,864 \\
\hline EXT intermedia hombro izquierdo & 28,50 & 10 & 14,669 \\
\hline EXT final hombro izquierdo & 34,50 & 10 & 12,021 \\
\hline FLEX inicial hombro izquierdo & 117,00 & 10 & 39,172 \\
\hline FLEX intermedia hombro izquierdo & 124,00 & 10 & 29,094 \\
\hline FLEX final hombro izquierdo & 131,80 & 10 & 28,600 \\
\hline ROTE inicial hombro izquierdo & 42,00 & 10 & 17,512 \\
\hline ROTE intermedia hombro izquierdo & 54,10 & 10 & 19,399 \\
\hline ROTE final hombro izquierdo & 71,90 & 10 & 12,556 \\
\hline ROTI inicial hombro izquierdo & 37,50 & 10 & 26,167 \\
\hline ROTI intermedia hombro izquierdo & 53,50 & 10 & 17,765 \\
\hline ROTI final hombro izquierdo & 64,70 & 10 & 17,205 \\
\hline
\end{tabular}

Tabla 23: Media, $N$ y s de cada uno de los movimientos estudiados para los individuos del grupo 1 afectados del HC izquierdo

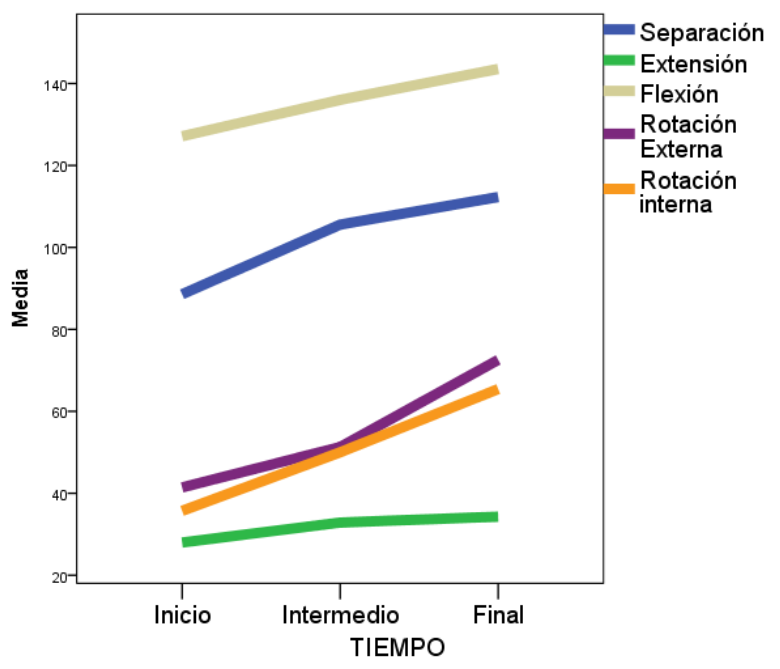

Figura 23: individuos afectados del HC izquierdo. Grupo 1 
Se observa aquí que todas las mediciones incrementan su valor final respecto al inicial. Cabe destacar que la flexión de hombro izquierdo en individuos afectados, aunque aumenta, lo hace de manera muy sutil. La rotación interna y la flexión de hombro aumentan de manera progresiva mientras que la separación y la rotación externa aumentan de manera diferente entre el primer periodo del estudio y el segundo.

Se procederá ahora a estudiar qué ocurre en este grupo de afectación predominante del hemicuerpo izquierdo en el caso de distinguir a los individuos según su etiología (ACV izquierdo u otras) así como por sexo o instauración antigua o reciente del DCA. 


\subsection{RESULTADOS DEL BALANCE ARTICULAR SE- GÚN ETIOLOGÍA}

Observamos que 5 individuos del total del grupo 1 tenían ACV izquierdo y 5 Otras etiologías. Este es el comportamiento de los individuos en cada medición goniométrica a lo largo del tiempo según la causa que originó su DCA.
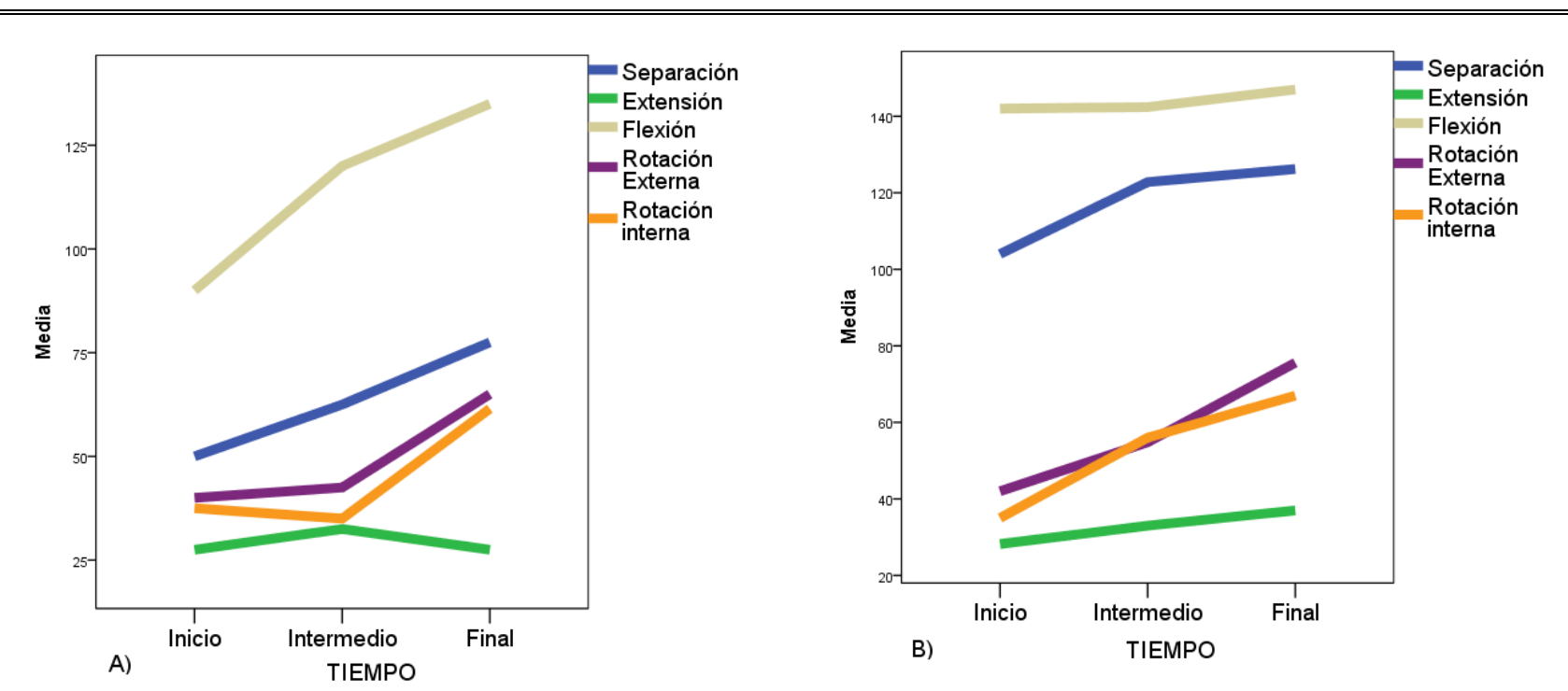

Figura 24: individuos afectados del HC izquierdo. Grupo 1

A) Etiología ACV

B) Otras etiologías de afectación bilateral

De esta manera observamos que los individuos que padecen un ACV izquierdo aumentan de manera muy notable la flexión de hombro izquierdo mientras que no lo hacen de igual modo los que padecen otras etiologías, cuyo incremento es mucho más moderado.

Es destacable también que la extensión de hombro aumenta muy ligeramente en los individuos de afectación bilateral (otras etiologías) e incluso acaba disminuyendo en los que presentan un ACV izquierdo. El resto de valores aumentan para ambos grupos etiológicos. 


\section{RESULTADOS}

\subsection{RESULTADOS DEL BALANCE ARTICULAR SE- GÚN SEXO}

Para este supuesto, 8 varones y 2 mujeres sufrieron un DCA de afectación de hemicuerpo izquierdo, estas son las gráficas que se registraron al tomarles las mediciones goniométricas en los 3 tiempos de medición.
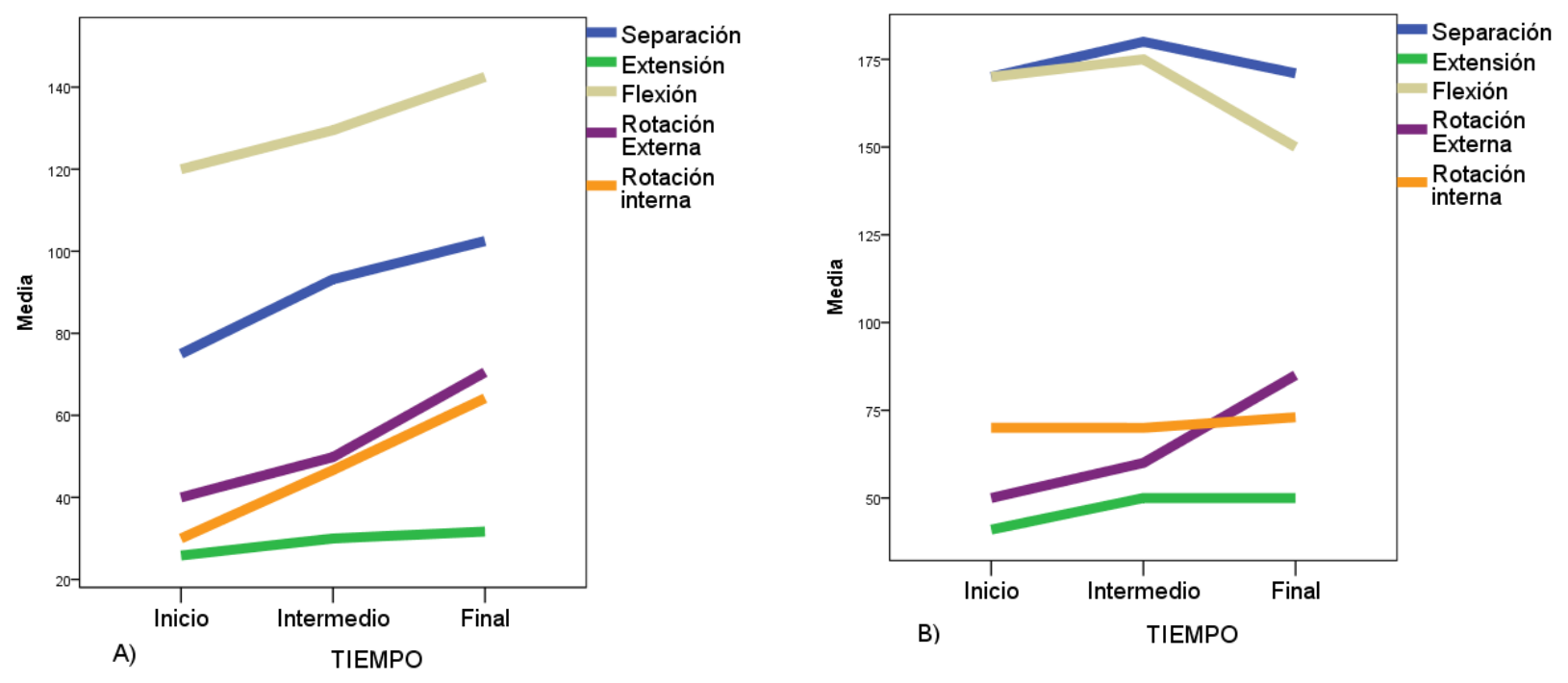

Figura 25: Individuos afectados del HC izquierdo. Grupo 1

13A) Varones

13B) Mujeres

En el caso de los varones se aumenta en todas las mediciones de manera notable a excepción de la extensión de hombro, que permanece prácticamente igual.

Para las mujeres, hay que destacar el retroceso en la separación y flexión de hombro izquierdo así como el mantenimiento en la rotación interna de hombro.. Pero al tratarse de dos únicos sujetos de estudio, resulta complicado extrapolar los datos al conjunto de la muestra. 


\subsection{RESULTADOS DEL BALANCE ARTICULAR SE- GÚN ANTIGÜEDAD}

En este caso 2 individuos sufrieron el episodio con antigüedad y 8 de manera reciente

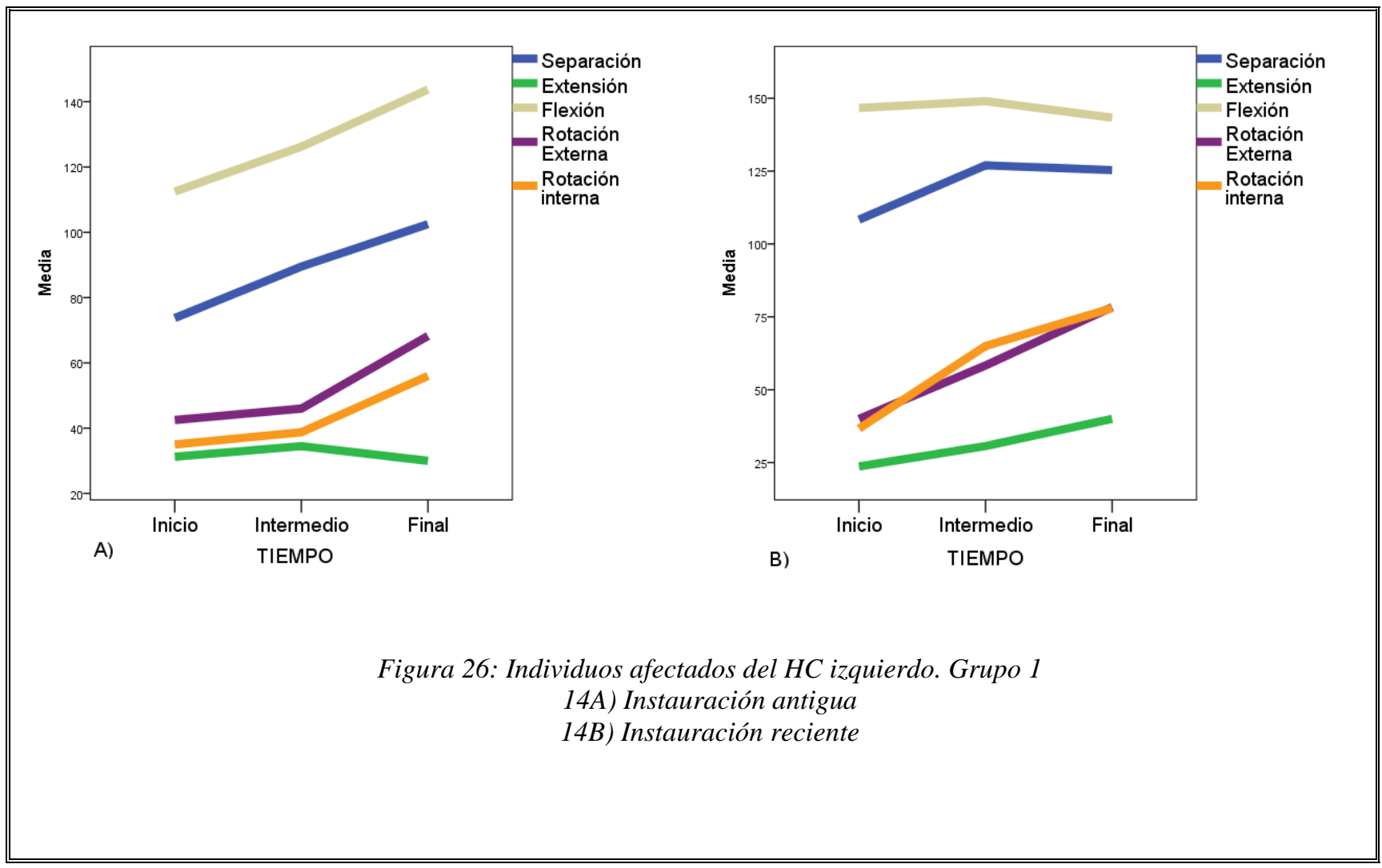

En este caso, los individuos de instauración antigua aumentan su balance articular a lo largo del tratamiento, a excepción de la extensión de hombro que retrocede ligeramente al final del mismo. Los de instauración reciente, aumentan significativamente sus goniometrías en rotación externa e interna de hombro pero se estancan en separación e incluso retroceden ligeramente al final del tratamiento en flexión. La extensión de hombro en sujetos de afectación reciente en este grupo apenas incrementa su valor. 


\section{RESULTADOS DEL BALANCE ARTICULAR DE IN- DIVIDUOS AFECTADOS DEL HEMICUERPO IZ- QUIERDO. GRUPO 2}

El total de individuos afectados en el grupo 2 del hemicuerpo izquierdo es de 19. Por sexos, 10 son varones $(52,6 \%)$ y 9 son mujeres $(47,4 \%)$. El ACV izquierdo supone el $36,8 \%$ de los casos $(n=7)$ y otras etiologías de afectación bilateral son el 63,7 $\%$ restante $(\mathrm{n}=12)$.

En cuanto a la antigüedad en la aparición del episodio. 9 individuos lo sufrieron con anterioridad al inicio del estudio mayor a dos años y 10 en los dos años inmediatamente anteriores o el mismo año incluso de inicio del estudio, lo que supone el 47,7 $\%$ u $52,6 \%$ respectivamente del total de individuos afectados del hemicuerpo izquierdo en este segundo grupo.

Esquemáticamente, podemos trazar la siguiente tabla:

\begin{tabular}{|c|c|c|c|c|c||c|c|c|}
\hline Antigüedad & $\mathbf{N}$ & $\%$ & Etiología & $\mathbf{N}$ & $\%$ & Sexo & $\mathbf{N}$ & $\%$ \\
\hline Reciente & 9 & 47,4 & $\begin{array}{c}\text { ACV } \\
\text { izquierdo }\end{array}$ & 7 & 36,8 & Masculino & 10 & 52,6 \\
\hline Antiguo & 10 & 52,6 & Otras & 12 & 63,2 & Femenino & 9 & 47,4 \\
\hline Total & 19 & 100,0 & & 19 & 100,0 & & 19 & 100,0 \\
\hline
\end{tabular}

Tabla 24: Clasificación de los individuos por antigüedad, sexo y etiología. HC izq. Grupo 2 


\section{RESULTADOS}

\begin{tabular}{|c|c|c|c|}
\hline Movimiento & Media & N & S \\
\hline ABD inicial hombro izquierdo & 76,84 & 19 & 34,165 \\
\hline ABD intermedia hombro izquierdo & 80,58 & 19 & 32,231 \\
\hline ABD final hombro izquierdo & 83,53 & 19 & 33,424 \\
\hline EXT inicial hombro izquierdo & 17,63 & 19 & 15,844 \\
\hline EXT intermedia hombro izquierdo & 17,16 & 19 & 15,334 \\
\hline EXT final hombro izquierdo & 23,16 & 19 & 10,243 \\
\hline FLEX inicial hombro izquierdo & 74,58 & 19 & 34,440 \\
\hline FLEX intermedia hombro izquierdo & 76,84 & 19 & 33,799 \\
\hline FLEX final hombro izquierdo & 86,32 & 19 & 31,965 \\
\hline ROTE inicial hombro izquierdo & 35,00 & 19 & 18,634 \\
\hline ROTE intermedia hombro izquierdo & 38,47 & 19 & 14,045 \\
\hline ROTE final hombro izquierdo & 51,32 & 19 & 19,137 \\
\hline ROTI inicial hombro izquierdo & 20,79 & 19 & 12,164 \\
\hline ROTI intermedia hombro izquierdo & 25,58 & 19 & 13,120 \\
\hline ROTI final hombro izquierdo & 35,32 & 19 & 13,825 \\
\hline
\end{tabular}

Tabla 25: Media, $N$ y $S$ de cada uno de los movimientos estudiados para los individuos del grupo 1 afectados del HC izquierdo

Los resultados de los individuos del grupo 2 afectados del hemicuerpo izquierdo en su conjunto son los siguientes en los 3 tiempos de medición para cada una de mediciones tomadas.

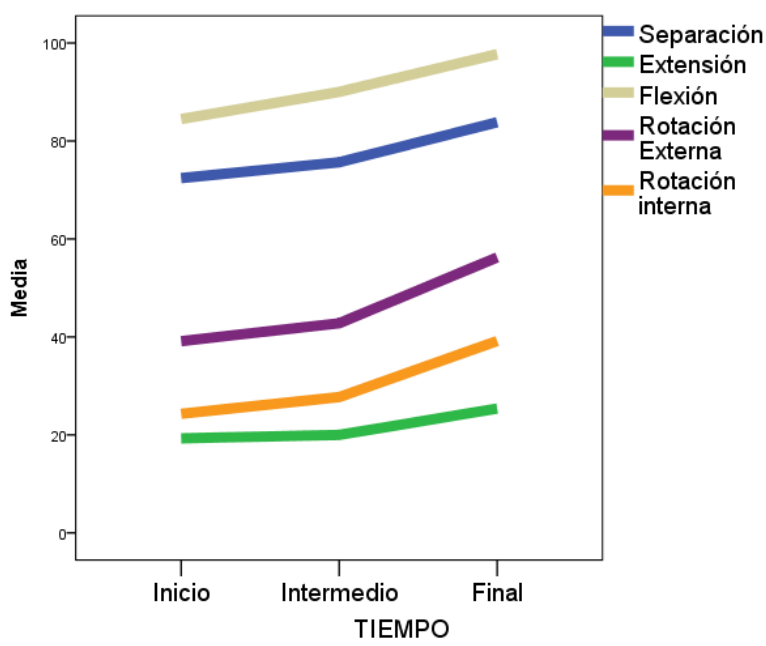

Figura 27: individuos afectados del HC izquierdo. Grupo 
Donde se observa que todas las mediciones tienden a incrementar su valor respecto al inicio. Además, el tiempo medio resulta un punto de inflexión donde la pendiente se vuelve más pronunciada, a excepción de la flexión del hombro izquierdo donde la ganancia es constante a lo largo de los 9 meses de intervención.

Estudiaremos ahora qué ocurre, al igual que en el grupo 1, si observamos al grupo en cuanto al sexo, o a la antigüedad de aparición del DCA. 


\subsection{RESULTADOS DEL BALANCE ARTICULAR SE- GÚN ETIOLOGÍA}

En este grupo hubo 9 sujetos ACV izquierdos y 12 individuos que sufrieron otras etiologías de afectación bilateral.

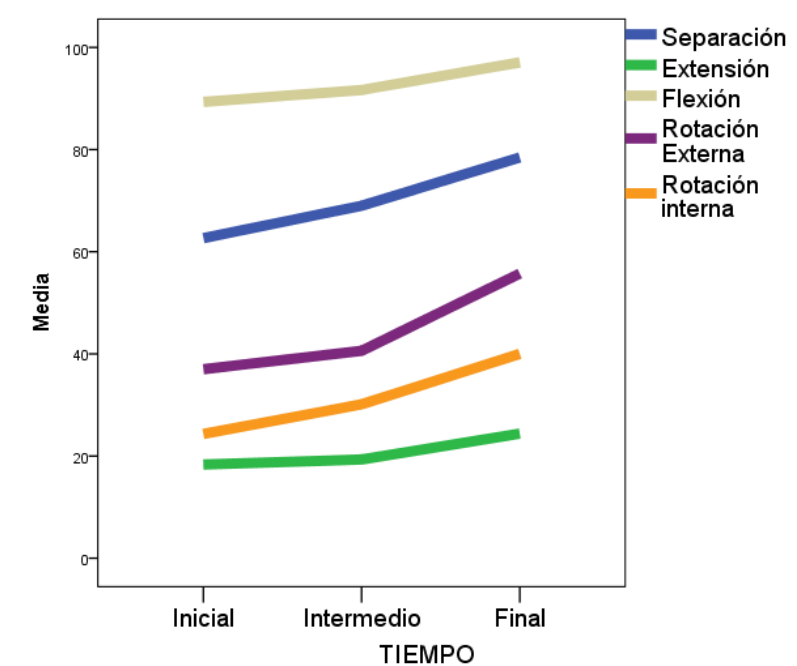

A)

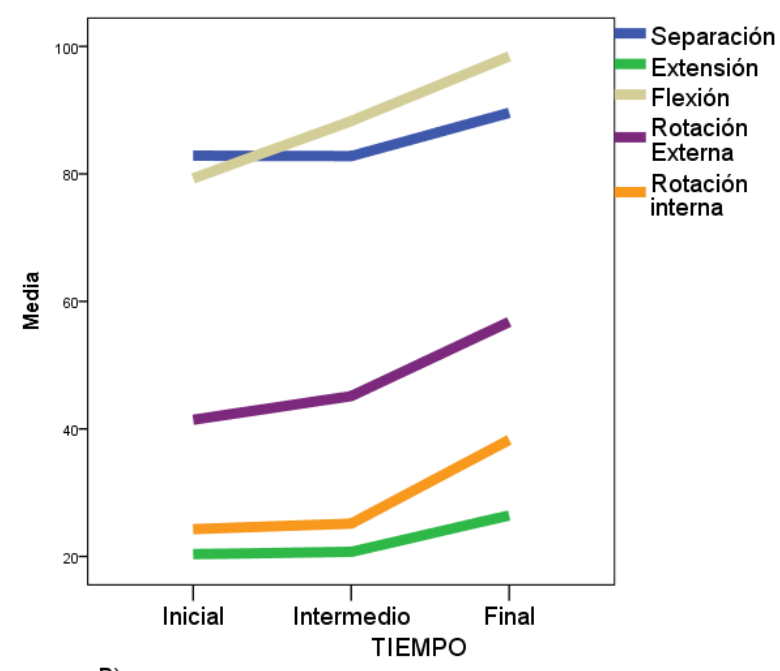

Figura 28: Individuos afectados del HC izquierdo. Grupo 2

A) Etiología ACV

B) Otras etiologías de afectación bilateral

Los individuos con ACV izquierdo experimentan en este grupo 2 una ganancia más lineal o constante a lo largo del tiempo (a excepción de la rotación externa de hombro izquierdo) donde el incremento a partir del tiempo medio es mayor). Mientras que aquellos cuya etiología es de afectación bilateral sufren un incremento en la mejoría a partir del tiempo medio de la intervención (a excepción de la flexión de hombro izquierda que se mantiene lineal a lo largo de los 9 meses de estudio). Los valores finales que se obtienen en cada medición son similares para ambos grupos etiológicos. 


\section{RESULTADOS}

\subsection{RESULTADOS DEL BALANCE ARTICULAR SE- GÚN SEXO}

El número total de hombres fue de 10 y el de mujeres de 9.

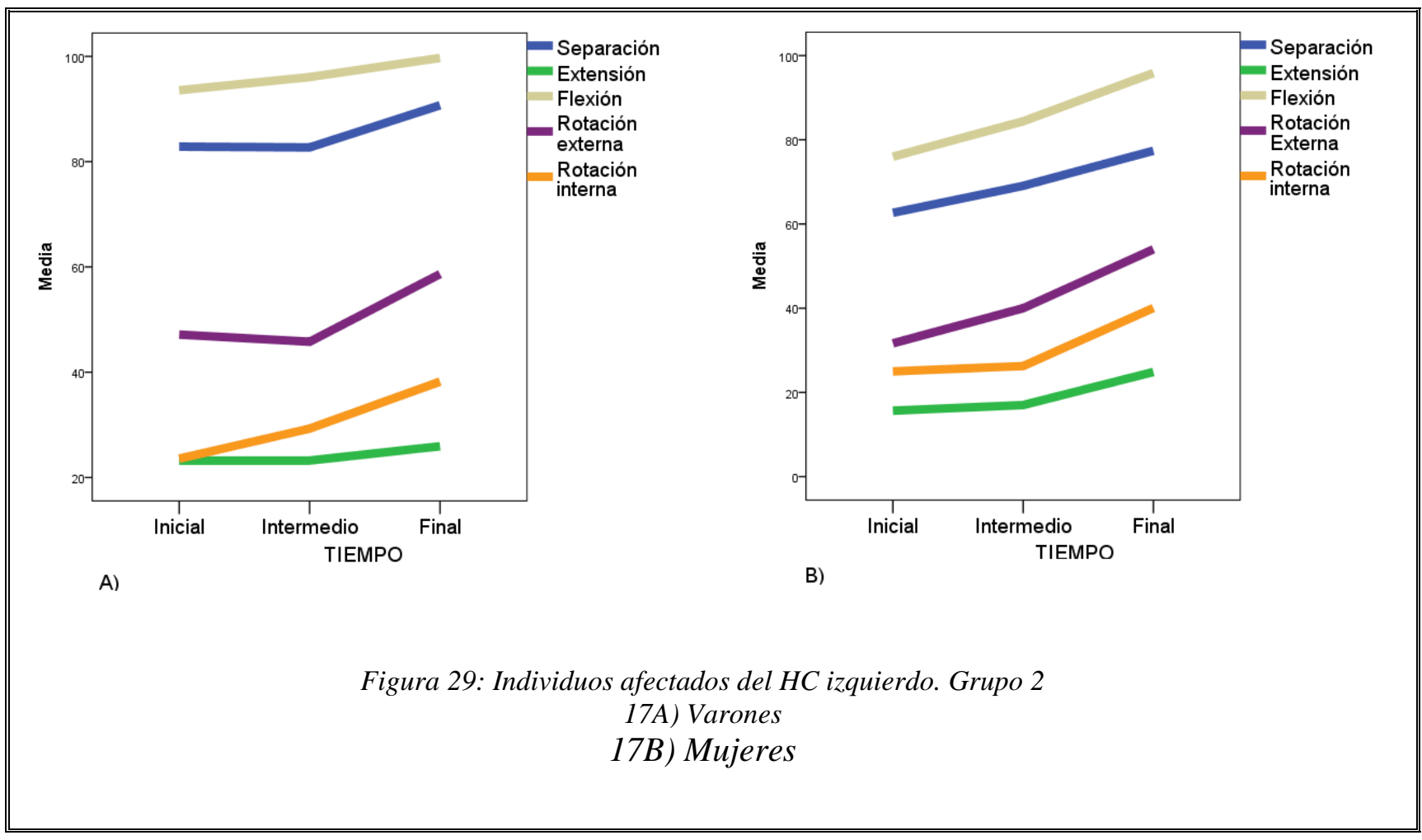

En cuanto a la distinción por sexos, observamos que los valores medios, en general son más altos en el grupo de los varones, y además en la separación de hombro y en la rotación externa se observa un aumento importante entre el tiempo medio y el final. 


\subsection{RESULTADOS DEL BALANCE ARTICULAR SE- GÚN ANTIGÜEDAD}

Hubo 9 individuos de afectación reciente y 10 de afectación antigua.

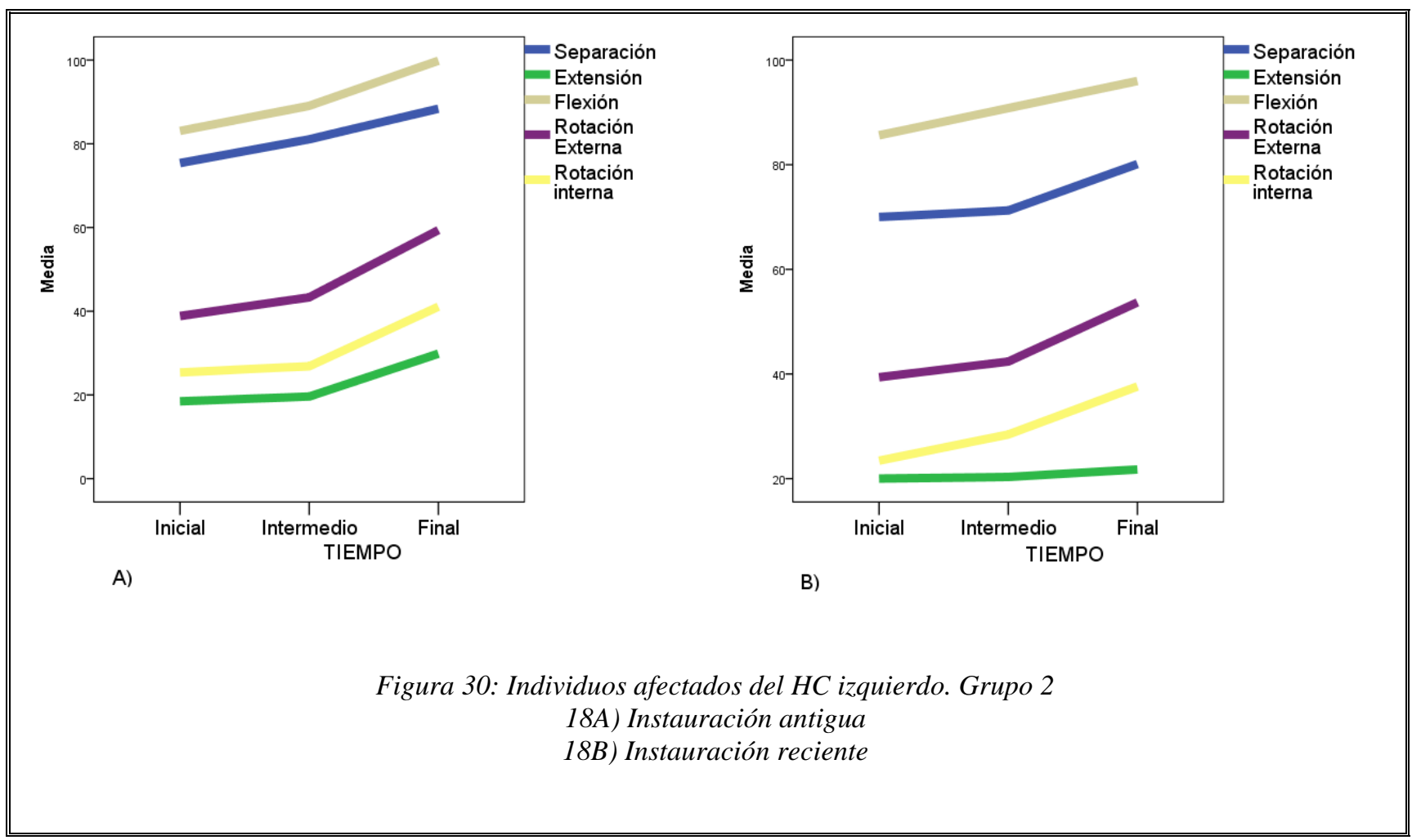

Con respecto a la antigüedad los valores registrados para cada medición son similares en ambos grupos (tanto en el de instauración antigua como reciente). Así mismo cabe destacar que la extensión de hombro izquierdo apenas varía en el grupo de individuos con afectación reciente. 


\section{CATEGORIZACIÓN DE LOS INDIVIDUOS AFECTA- DOS DEL HEMICUERPO IZQUIERDO. GRUPOS 1 Y 2.}

A continuación se describe qué ocurre con los individuos en función de las categorías descritas anteriormente (mucho peor, peor, igual, mejor y mucho mejor) en cada una de las mediciones goniométricas.

Se establece así la diferencia entre el valor obtenido en el tiempo final y el tiempo inicial (DIF_TOT) en cada medición para el total de los individuos afectados del hemicuerpo izquierdo. Es decir trataremos de describir cuántos sujetos se encontraban en cada categoría al finalizar el tratamiento.

Para ello se construye l tabla 52 recogida en el ANEXO IV. Los resultados obtenidos describen lo siguiente:

Respecto a la abducción (tabla 52-A) los individuos del primer grupo encuentran mejor en su mayoría, y ninguno de ellos se encontraba en el estadío más bajo de la clasificación mientras que los del segundo grupo se distribuyen a lo largo de todos los niveles de la tabla.

La extensión del primer grupo (tabla 52-B) registra el mayor número de individuos en las categorías tercera y cuarta descritas, al igual que lo hacen los del segundo grupo. En ninguno de los dos grupos encontramos sujetos en el nivel más alto.

Así en el grupo 1 en flexión (tabla 52-C) la mayoría de los sujetos se encontraban en los niveles más altos (mejor y mucho mejor) mientras que en el grupo 2 la mayoría de los sujetos se hallaron entre el nivel tercero y cuarto habiendo un único individuo en la categoría máxima.

Los individuos del primer grupo se sitúan respecto la rotación externa (tabla 52-D) en las categorías igual y mejor en su mayoría. Por su parte los del segundo grupo presentan a más de la mitad de sus miembros en la categoría de mejor e incluso uno de ellos alcanza el nivel más alto.

En cuanto a la rotación interna, (tabla 52-E), los sujetos del primer grupo se encuentran únicamente en los niveles superiores (tercero, cuarto y quinto). El segundo grupo alberga la mayoría de sus individuos en los niveles igual y mejor teniendo además un sujeto en categorías inferiores y únicamente dos participantes en el nivel más alto.

Si particularizamos en función del sexo, o la antigüedad del DCA al establecer la DIF_TOT (resultado de la diferencia entre la última medición y la inicial) vemos que las categorías quedan de la siguiente manera en función de estas características para los individuos del grupo 1 y del grupo 2 con afectación del hemicuerpo izquierdo. 


\section{RESULTADOS}

(Ver figuras 58-67 en el ANEXO IV)

En este punto resulta complicado describir qué ocurre con los individuos del grupo 1 en cuanto al sexo o la aparición reciente o antigua del DCA debido a que hay tan sólo dos mujeres en este subgrupo y tres individuos de afectación antigua.

Atendiendo a estos gráficos podemos decir que los individuos varones del grupo 1 se comportan de la siguiente manera:

Respecto a la flexión (figura 62-A) la mayoría se encuentran en la categoría mucho mejor. En cuanto a la abducción (figura 58-A) la mayoría de los individuos siguen igual o peor aunque otros estén mejor y mucho mejor.

En extensión (figura 60-A) la mayoría están mejor pero ninguno alcanza la categoría mucho mejor.

En rotación externa (figura 64-A) se reparten entre la categoría mejor y mucho mejor mientras que en la rotación interna (figura 66-A) la mayoría están al final del tratamiento mucho mejor.

Mientras que los varones del grupo 2 en flexión (figura 62-B) la mayoría se encuentran mejor pero ninguno alcanza la categoría mucho mejor. En cuanto a la abducción (figura 58-B) la mayoría están igual si bien es cierto que hay individuos en las categorías de la primera a la cuarta.

En extensión (figura 60-B) la mayoría se encuentran igual y ninguno alcanza la máxima categoría.

Con respecto a las rotaciones la externa (figura 64-B) alberga individuos en las categorías de la segunda a la cuarta de manera equitativa y un pequeño porcentaje en la máxima categoría y la interna (figura 66-B) concentra a la mayoría de sus individuos en la categoría de mejor; no habiendo ninguno en la máxima categoría.

Por su parte las mujeres del grupo 2 se encuentran entre los estratos segundo al cuarto en cuanto a la abducción (figura 58-A) mientras que en la extensión (figura 60-A) se encuentran en su mayoría en el cuarto (mejor) y ninguna de ellas se encuentra en los estratos extremos de la clasificación. La flexión (figura 62-A) alberga a todas las mujeres de este grupo en las posiciones altas de la tabla, en su mayoría en las categorías igual y mejor.

En cuanto a la rotación externa (figura 64-A) la mayoría de ellas se encuentran en el estadío mejor y ninguna está en el peor de todos. La rotación interna (figura 66A) contiene a la mayoría de las mujeres del grupo en el estadío tercero (igual) y ninguna de ellas en el más bajo.

Si analizamos los resultados en función de la antiguiedad de aparición del episodio de DCA se observa que: 
En cuanto a la abducción los individuos del grupo 1 de afectación reciente (figura 59-A) se encontraban en su mayoría igual y nadie se encontraba mucho peor. En el segundo grupo aquellos con afectación reciente se encontraban fundamentalmente en la categoría peor y no hubo individuos en la categoría mucho mejor (figura 64-B).

Los individuos de afectación antigua del grupo 2 (figura 59-B) se encontraban en esencia mejor y no hubo ninguno que alcanzase la máxima categoría.

En cuanto a la extensión (figura 61) los individuos de afectación reciente del primer grupo se encontraban en su mayoría igual y mejor y ninguno se encontró mucho mejor mientras que en el segundo grupo la mayoría se encontraron mejor y tampoco hubo ninguno que alcanzase el máximo nivel.

Respecto a aquellos afectados de manera antigua en el segundo grupo (figura 61-B) se encontraron sobretodo en la categoría igual y ninguno alcanzó el estadío mucho mejor.

La flexión de hombro (figura 63) para los individuos de afectación reciente del grupo 1 categorizó a la mayoría de los individuos en mejor y mucho mejor si bien es cierto que hubo sujetos en todas las categorías (figura 68-A); mientras que los del grupo 2 estuvieron en esencia mejor (figura 68-B). Nadie en este segundo grupo alcanzó la máxima categoría para esta medición. Los de afectación tardía del segundo grupo estuvieron en su mayoría en las categorías igual y mejor (figura 68-B).

La rotación externa de los individuos del grupo 1 (figura 65-A) con afectación reciente fue mucho mejor para la mayoría de los sujetos al finalizar el tratamiento mientras que en el segundo grupo ningún individuo alcanzó esta categoría (figura 65B); la mayoría se quedaron en el estrato mejor. Aquellos con afectación antigua del segundo grupo (figura 65-B) se encontraron en esencia mejor.

$Y$ en cuanto a la rotación interna los individuos del primer grupo con afectación reciente (figura 67-A) se situaron en su mayoría en niveles igual y mejor mientras que los del segundo grupo (figura 67-B) se situaron en su mayoría en el estrato mejor aunque hubo sujetos en todas las categorías a excepción de la inferior.

El grupo 2 con afectación antigua se encontró fundamentalmente igual al finalizar el tratamiento (figura 67-B). 


\section{RESULTADOS DEL BALANCE ARTICULAR DE IN- DIVIDUOS AFECTADOS DEL HEMICUERPO DERE- CHO. GRUPO 1}

Esto comprende tanto a aquellos individuos que han sufrido un ACV de afectación predominante del hemicuerpo derecho como a aquellos cuya etiología es de afectación bilateral (TCE, EM, IAM etc.) englobados todos ellos en "otras etiologías". El total de individuos del grupo 1 que cumple estas condiciones es de 7, lo que supone el 58,3\% del total del grupo.

De estos 7, en cuanto a etiología 5 son de afectación bilateral y 2 individuos sufrieron un ACV de afectación predominante derecha. Haciendo la distinción por sexos, 6 son varones y 1 únicamente es mujer y en cuanto a la antigüedad 3 son recientes y 4 son antiguos.

Esquemáticamente

\begin{tabular}{|c|c|c||c|c|c||c|c|c|}
\hline Antigüedad & $\mathbf{N}$ & $\%$ & Etiología & $\mathbf{N}$ & $\%$ & Sexo & $\mathbf{N}$ & $\%$ \\
\hline Reciente & 3 & 42,9 & ACV derecho & 2 & 28,6 & Masculino & 6 & 85,7 \\
\hline Antiguo & 4 & 57,1 & $\begin{array}{c}\text { Otras } \\
\text { etiologías }\end{array}$ & 5 & 71,4 & Femenino & 1 & 14,3 \\
\hline \hline Total & 7 & 100 & Total & 7 & 100 & Total & 7 & 100 \\
\hline
\end{tabular}

Tabla 26: Clasificación de los individuos por antigüedad, sexo y etiología. HC derecho. Grupo 1

A continuación se muestran los resultados medios obtenidos para cada una de las pruebas goniométricas medidas en el hombro; esto es FLEXIÓN, EXTENSIÓN, ABDUCCIÓN, ROTACIÓN INTERNA Y EXTERNA del conjunto de los individuos con afectación izquierda en cada uno de los 3 tiempos de medición. 
RESULTADOS

\begin{tabular}{|c|c|c|c|}
\hline Movimiento & N & Media & S \\
\hline ABD inicial hombro izquierdo & 7 & 96,43 & 37,718 \\
\hline ABD intermedia hombro izquierdo & 7 & 118,29 & 33,165 \\
\hline ABD final hombro izquierdo & 7 & 124,86 & 22,124 \\
\hline EXT inicial hombro izquierdo & 7 & 35,71 & 12,724 \\
\hline EXT intermedia hombro izquierdo & 7 & 42,86 & 6,986 \\
\hline EXT final hombro izquierdo & 7 & 37,00 & 12,410 \\
\hline FLEX inicial hombro izquierdo & 7 & 127,14 & 31,472 \\
\hline FLEX intermedia hombro izquierdo & 7 & 136,00 & 20,008 \\
\hline FLEX final hombro izquierdo & 7 & 143,57 & 9,449 \\
\hline ROTE inicial hombro izquierdo & 7 & 47,14 & 9,512 \\
\hline ROTE intermedia hombro izquierdo & 7 & 54,57 & 15,021 \\
\hline ROTE final hombro izquierdo & 7 & 74,29 & 5,345 \\
\hline ROTI inicial hombro izquierdo & 7 & 41,43 & 20,354 \\
\hline ROTI intermedia hombro izquierdo & 7 & 56,43 & 17,491 \\
\hline ROTI final hombro izquierdo & 7 & 54,43 & 24,952 \\
\hline
\end{tabular}

Tabla 27: Media, N y S de cada uno de los movimientos estudiados para los individuos del grupo 1 afectados del HC izquierdo

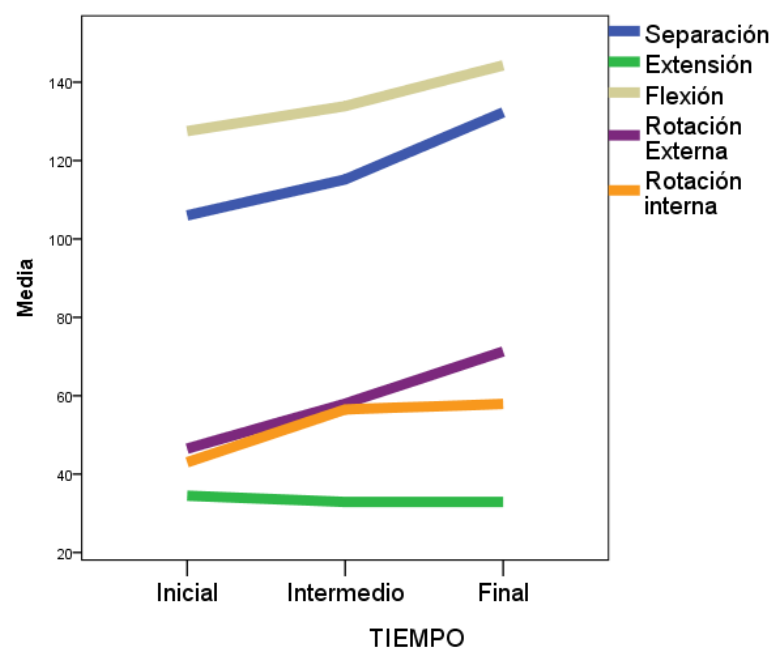

Figura 31: Individuos afectados del HC derecho. Grupo 1 


\section{RESULTADOS}

Donde se observa cómo se produce un aumento gradual de los valores de separación de hombro, flexión y rotación externa. Por el contrario la extensión de hombro se estanca e incluso tiende a retroceder. La rotación interna aumenta mucho su valor en el primer periodo del tratamiento pero posteriormente se estanca en este conjunto de individuos.

Se procederá ahora a estudiar qué ocurre en este grupo de afectación predominante del hemicuerpo derecho en el caso de distinguir a los individuos según su etiología (ACV derecho u otras) así como por sexo o instauración antigua o reciente del DCA. 


\subsection{RESULTADOS DEL BALANCE ARTICULAR SE- GÚN ETIOLOGÍA}

Hay un 28,6\% del total del grupo con un ACV derecho (2 sujetos) y un 71,4\% que pertenecen a otras etiologías de afectación bilateral (5 individuos).
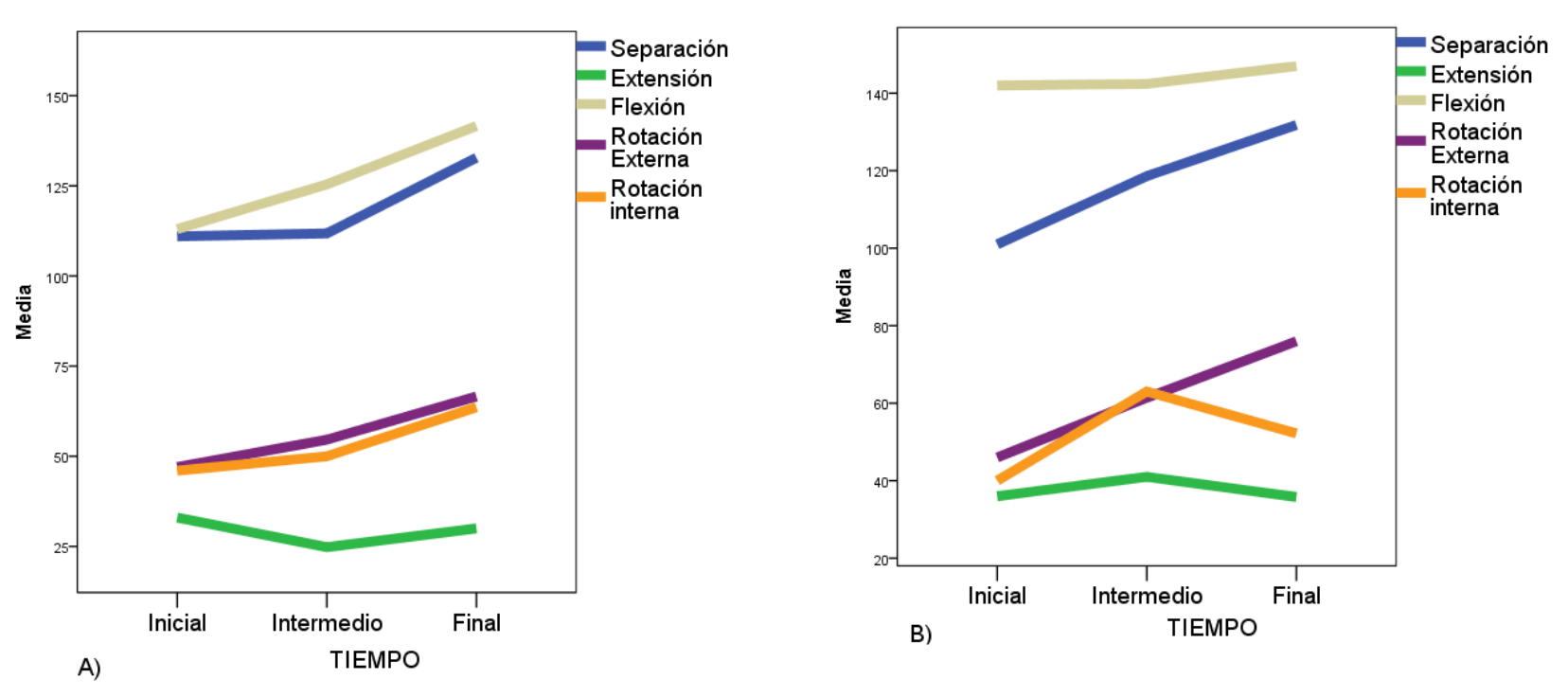

Figura 32: Individuos afectados del HC derecho. Grupo 1

A) Etiología ACV

B) Otras etiologías de afectación bilateral

Teniendo en cuenta la etiología del DCA se observa que aquellos que sufrieron un ACV derecho incrementan su valor en todas las pruebas goniométricas a excepción de la extensión de hombro que tiende a disminuir al principio para posteriormente mantenerse constante. La separación de hombro derecho aumenta fundamentalmente en el segundo periodo del estudio.

Respecto al resto de etiologías la separación de hombro y la rotación externa aumentan notablemente; sin embargo la rotación interna, que en un principio aumenta su valor, tiende finalmente a disminuir. La flexión de hombro y la extensión del mismo se mantienen más o menos constantes a lo largo del tiempo para este grupo de individuos. 


\subsection{RESULTADOS DEL BALANCE ARTICULAR SE- GÚN SEXO}

El 86,7 \% (6 sujetos) son varones mientras que hay una única mujer en este grupo que supone el 14,7\% del total de afectados del hemicuerpo derecho.

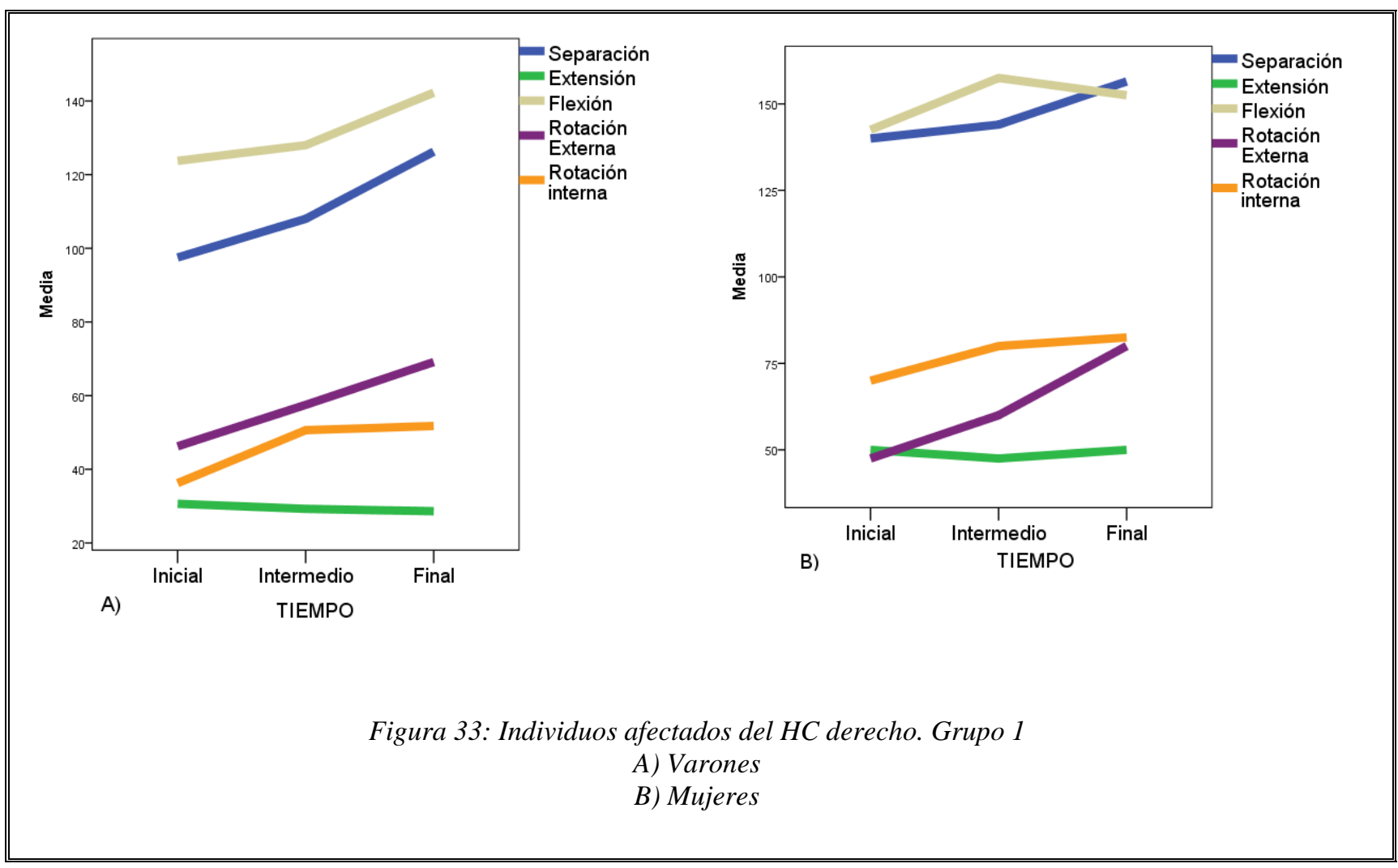

En los hombres todos los valores se incrementan a excepción de la extensión de hombro que tiende ligeramente a disminuir. En el caso de las mujeres, tan sólo existe un único caso para analizar por lo que resulta complicado extrapolar los datos al total de la muestra. 


\subsection{RESULTADOS DEL BALANCE ARTICULAR POR ANTIGÜEDAD}

Hay un 42,9 \% (3 individuos) de individuos con afectación reciente y un 57,1\% (4 individuos) de afectación antigua.

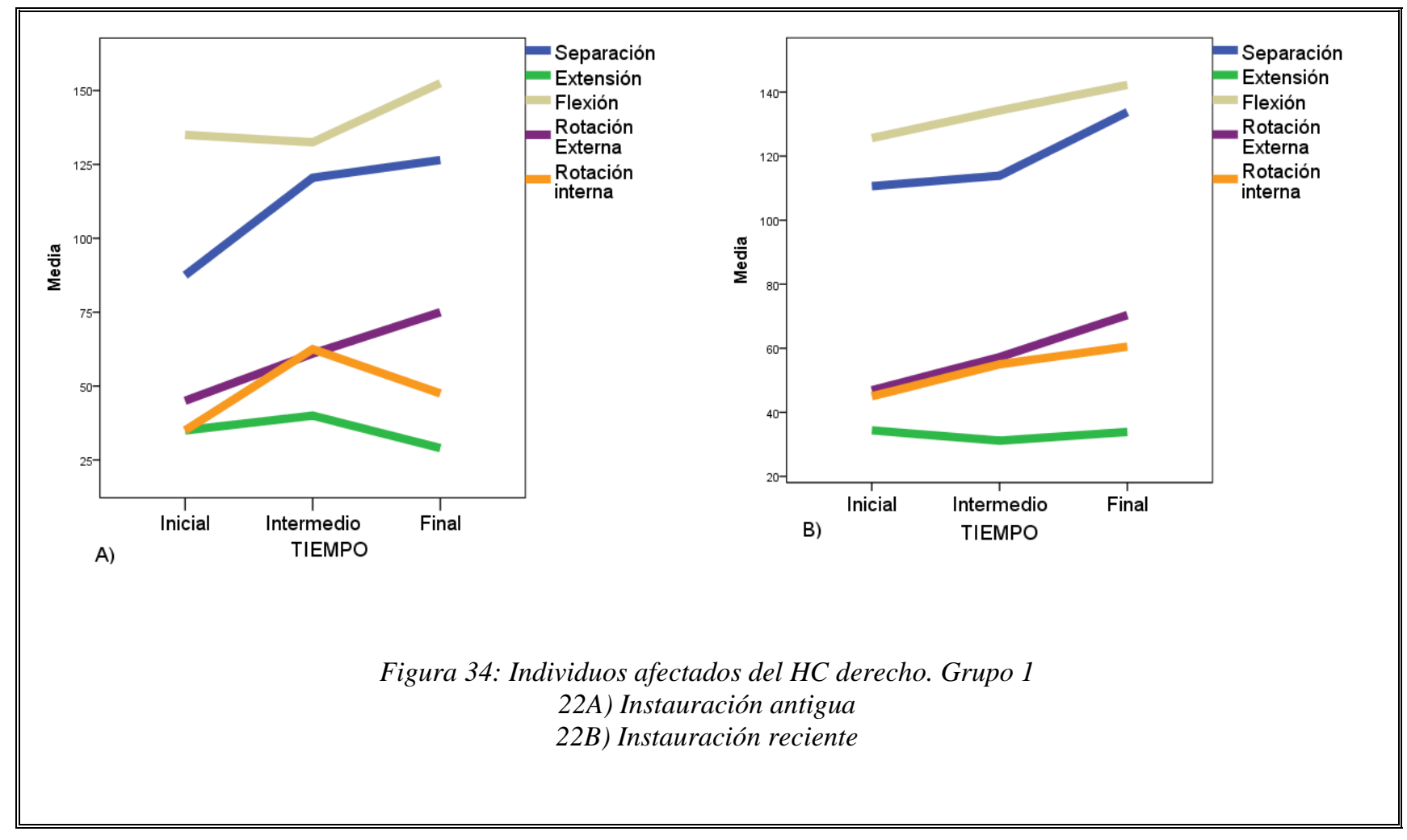

Los individuos de afectación reciente aumentan el valor en todas las pruebas goniométricas a excepción de la extensión de hombro que tiende a mantenerse igual. Sin embargo, aquellos con instauración antigua disminuyen su valor entre la medición intermedia y la final en la rotación interna, la extensión de hombro (de manera ligera). 


\section{RESULTADOS GONIOMETRÍA HEMICUERPO DE- RECHO GRUPO 2}

El total de individuos afectados en el grupo 2 del hemicuerpo derecho es de 29. De éstos, 14 (48,3\%) son hombres y 14 son mujeres $(51,3 \%)$.

En cuanto a la etiología, el 58,6\% presentaron un ACV de afectación derecha y el 41,4 $\%$ restante Otras etiologías de afectación bilateral.

Respecto a la antigüedad en la fecha de aparición del DCA, el 55,2 \% son de aparición reciente (menos de 2 años) y el 44,8 \% restante de instauración antigua.

Esquemáticamente podemos representarlo en la siguiente tabla:

\begin{tabular}{|c|c|c||c|c|c||c|c|c|}
\hline Antigüedad & $\mathbf{N}$ & $\%$ & Etiología & $\mathbf{N}$ & $\%$ & Sexo & $\mathbf{N}$ & $\%$ \\
\hline Reciente & 16 & 55,2 & $\begin{array}{c}\text { ACV } \\
\text { derecho }\end{array}$ & 17 & 58,6 & Masculino & 14 & 48,3 \\
\hline Antiguo & 13 & 44,8 & $\begin{array}{c}\text { Otras } \\
\text { etiologías }\end{array}$ & 12 & 41,4 & Femenino & 15 & 51,7 \\
\hline \hline Total & 29 & 100,0 & & 29 & 100,0 & & 29 & 100,0 \\
\hline
\end{tabular}

Tabla 28: Clasificación de los individuos por antigüedad, sexo y etiología. HC izq. Grupo 2

Los resultados de los individuos del grupo 2 afectados del hemicuerpo izquierdo en su conjunto son los siguientes, en los 3 tiempos de medición, para cada una de mediciones tomadas. 


\begin{tabular}{|c|c|c|c|}
\hline Movimiento & N & Media & S \\
\hline ABD inicial hombro izquierdo & 29 & 79,66 & 28,028 \\
\hline ABD intermedia hombro izquierdo & 29 & 82,34 & 27,073 \\
\hline ABD final hombro izquierdo & 29 & 91,38 & 32,383 \\
\hline EXT inicial hombro izquierdo & 29 & 14,83 & 10,563 \\
\hline EXT intermedia hombro izquierdo & 29 & 20,28 & 11,955 \\
\hline EXT final hombro izquierdo & 29 & 27,48 & 12,557 \\
\hline FLEX inicial hombro izquierdo & 29 & 84,48 & 35,816 \\
\hline FLEX intermedia hombro izquierdo & 29 & 90,03 & 32,543 \\
\hline FLEX final hombro izquierdo & 29 & 97,72 & 38,947 \\
\hline ROTE inicial hombro izquierdo & 29 & 40,34 & 16,952 \\
\hline ROTE intermedia hombro izquierdo & 29 & 47,28 & 13,641 \\
\hline ROTE final hombro izquierdo & 29 & 56,03 & 18,249 \\
\hline ROTI inicial hombro izquierdo & 29 & 29,14 & 15,182 \\
\hline ROTI intermedia hombro izquierdo & 29 & 34,66 & 14,256 \\
\hline ROTI final hombro izquierdo & 29 & 42,03 & 14,934 \\
\hline
\end{tabular}

Tabla 29: Clasificación de los individuos por antigüedad, sexo y etiología. HC derecho. Grupo 1

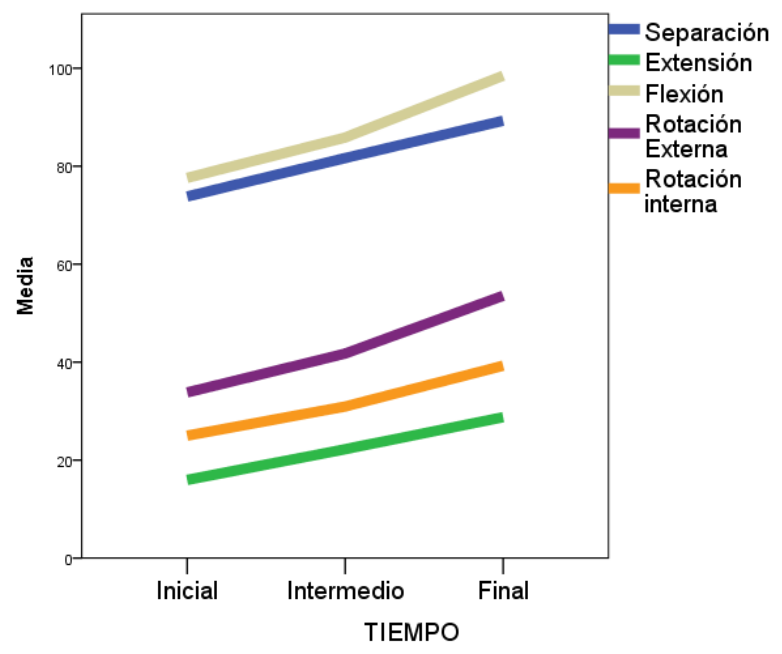

Figura 35: Individuos afectados del HC derecho. Grupo 2

Donde se observa cómo a lo largo del tiempo, todos los valores registrados aumentan en el hemicuerpo derecho para los individuos afectados en este grupo 2 .

Haciendo distinciones en cuanto a la etiología, el sexo o la antigüedad en la aparición del DCA, se observa lo siguiente: 


\subsection{RESULTADOS DEL BALANCE ARTICULAR SE- GÚN ETIOLOGÍA}

Hay en este grupo 17 individuos con ACV derecho y 12 sujetos con otras etiologías.
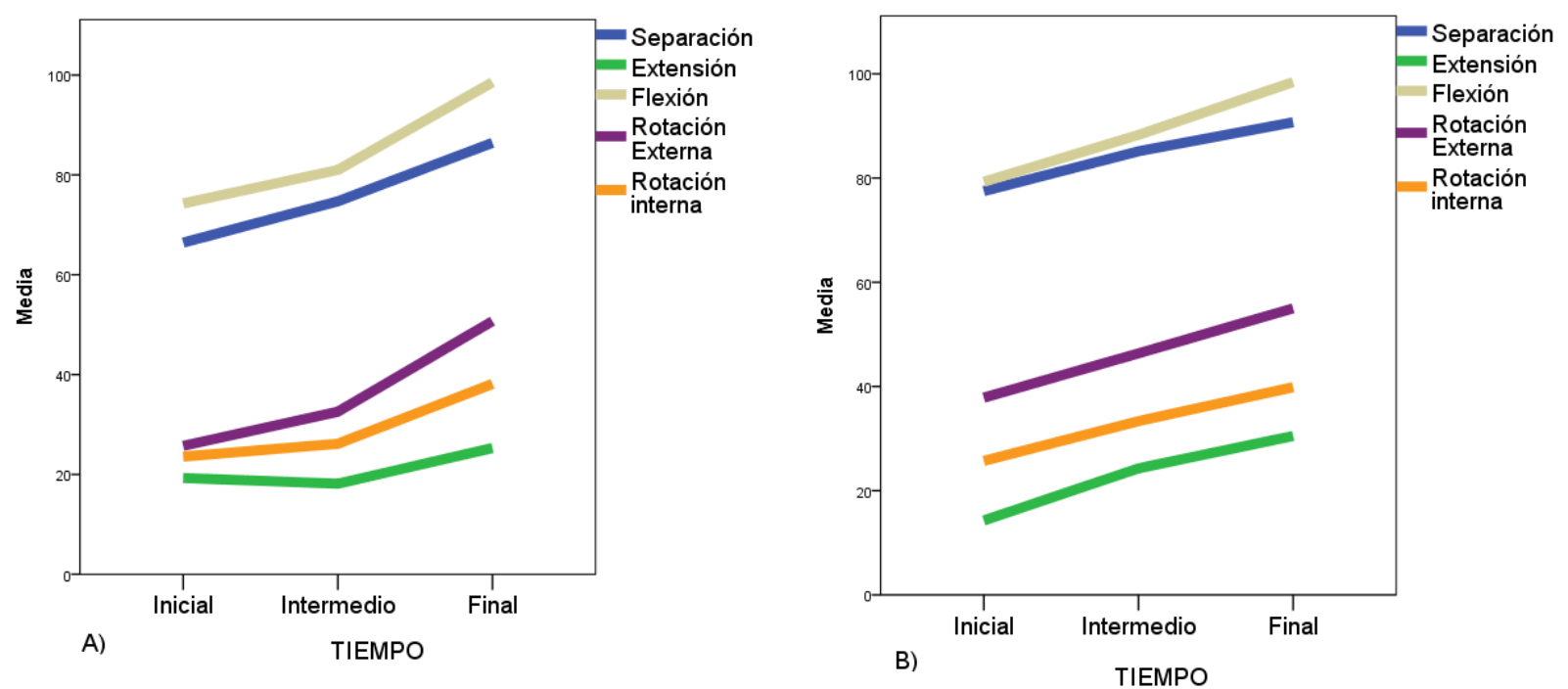

Figura 36: Individuos afectados del HC derecho. Grupo 2

A) Etiología ACV

B) Otras etiologías de afectación bilateral

Donde observamos que el incremento en los valores de la flexión y la rotación externa de hombro, es más evidente entre el tiempo medio del estudio y el final del mismo para los individuos con ACV derecho, mientras que en los que presentan otras etiologías el incremento es constante. Por su parte, la extensión de hombro decrece en un principio en los que presentan ACV derecho pero finalmente crece ligeramente. El resto de valores aumentan en ambos grupos etiológicos. 


\subsection{RESULTADOS DEL BALANCE ARTICULAR SE- GÚN SEXO}

En este grupo hay 14 individuos varones y 15 mujeres

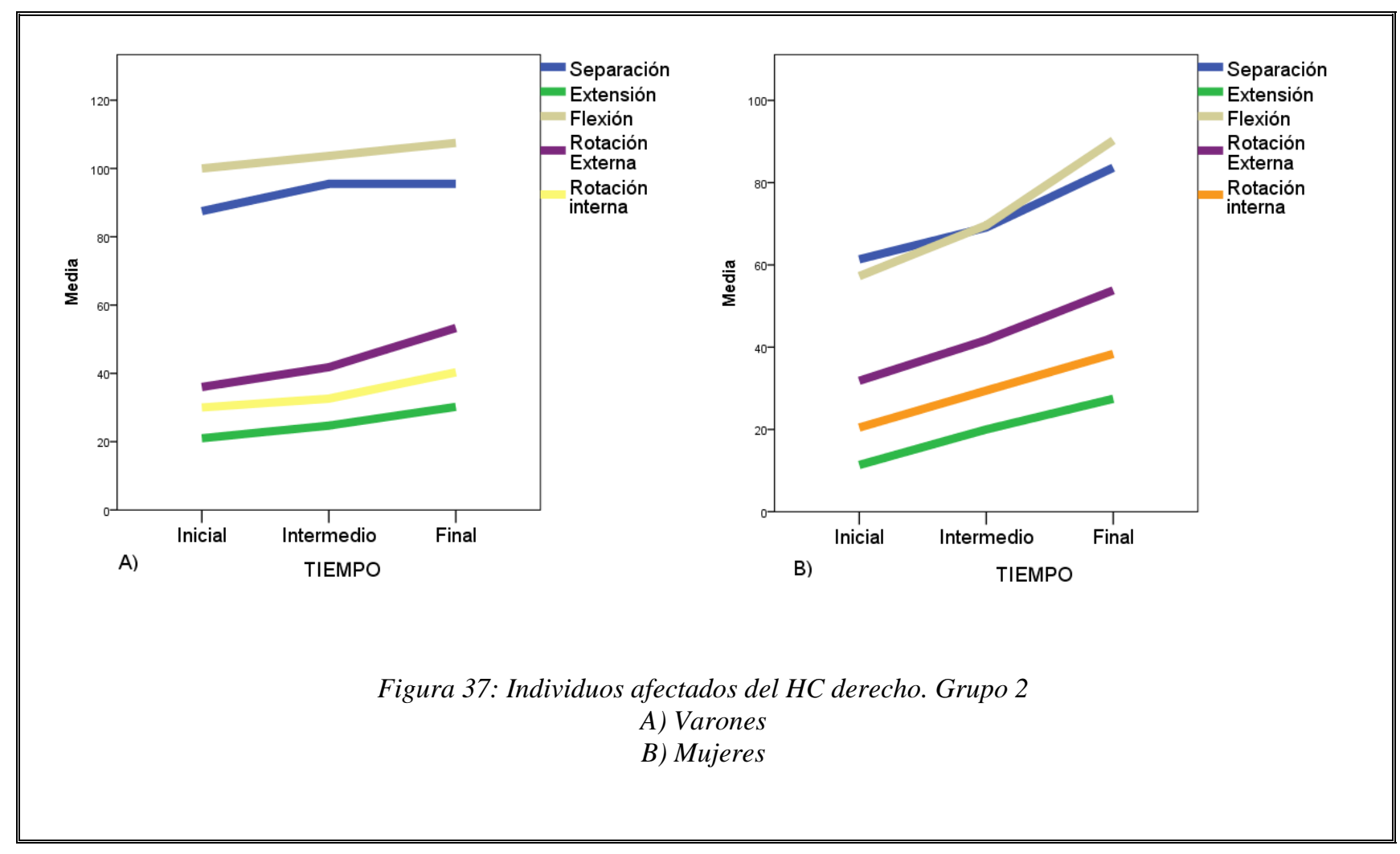

La flexión de hombro es mucho mayor en los varones al inicio, si bien es cierto, que se mantiene más o menos constante en todo el tratamiento. En las mujeres aumenta significativamente su valor, más incluso entre la mitad del tratamiento y el tiempo final. La separación de hombro tiende a estabilizarse en los varones y en las mujeres aumenta en todo el periodo, más incluso entre la mitad y el final del estudio. El resto de valores aumentan para ambos grupos (varones y mujeres), siendo el valor de la extensión el que menos se ve incrementado. 


\subsection{RESULTADOS DEL BALANCE ARTICULAR SE- GÚN ANTIGÜEDAD}

Por antigüedad; 16 individuos sufrieron el DCA de manera reciente y 13 en un periodo antiguo.

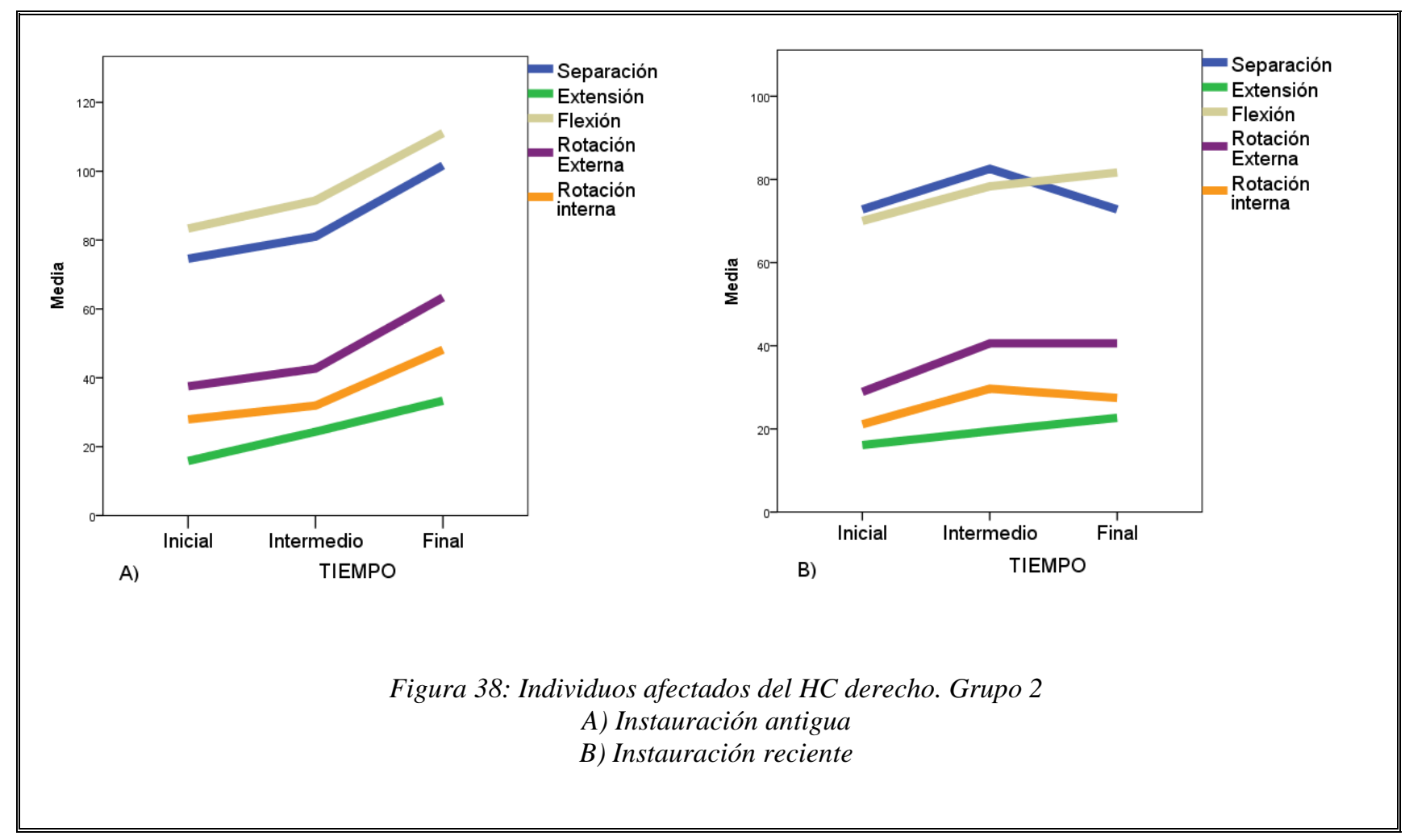

Los individuos con afectación antigua aumentan en todas las mediciones a lo largo del tiempo, y salvo en la extensión cuyo aumento es gradual, el resto aumenta significativamente entre el tiempo medio y el final del estudio. Por el contrario los individuos de afectación reciente disminuyen entre el tiempo medio y el final en separación de hombro y se estabilizan en el valor de la rotación interna y externa. El aumento en flexión de hombro es mucho menos significativo. La extensión de hombro aumenta de manera ligera para este colectivo. 


\section{CATEGORIZACIÓN DE LOS INDIVIDUOS AFECTA- DOS DEL HEMICUERPO DERECHO. GRUPOS 1 Y 2.}

A continuación se describe qué ocurre con los individuos en función de las categorías descritas anteriormente (mucho peor, peor, igual, mejor y mucho mejor) en cada una de las mediciones goniométricas al igual que se hizo con los individuos afectados del hemicuerpo izquierdo.

Para ello se construye la tabla 53 recogida en el ANEXO V. Los resultados obtenidos describen lo siguiente:

En la abducción (tabla 53-A), los individuos del primer grupo se sitúan en los niveles más altos de la clasificación mientras que en el segundo, aunque el estrato más colmado es el mejor hay individuos en todas las categorías.

La extensión (tabla 53-B) en el primer grupo alberga a la mayoría de los individuos en la categoría igual; no habiendo individuos en las categorías extremas. En el segundo grupo la mayoría de los sujetos se encontraban en los estratos igual y mejor sin embargo hubo individuos en todas las categorías.

En cuanto a la flexión (tabla 53-C) el grupo 1 no alberga individuos en las categoría inferior (mucho peor) y el segundo grupo contiene individuos en todos los estratos, siendo el más abundante en cuanto a número de sujetos el de mejor.

Respecto a la rotación externa (tabla 53-D) los individuos se sitúan en los estadíos más altos en el primer grupo; no habiendo sujetos en los dos niveles inferiores. La mayoría de ellos se encontraron mejor en este grupo. En cuanto al grupo 2, hubo individuos en todas las categorías siendo la predominante la cuarta.

En cuanto a la rotación interna (tabla 53-E) el grupo 1 tiene individuos en todas las categorías al igual que el grupo 2, donde los estratos donde más sujetos se registraron fueron los de igual y mejor.

Estas mismas categorías se pueden describir atendiendo, una vez más al sexo o la antigüedad del DCA. Así, podemos observar de manera gráfica que al establecer la diferencia entre la medición goniométrica final y la inicial (DIF_TOT) para el hemicuerpo derecho los individuos se encuentran agrupados de la siguiente manera:

VER ANEXO V, figuras 73-82. 
En el hemicuerpo derecho observamos que:

En la abducción los varones del grupo 1 (figura 68-A) se encuentran todos en niveles altos de la clasificación (igual, mejor, mucho mejor) mientras que en el segundo grupo se encuentran repartidos entre las diferentes categorías. Por su parte las mujeres del segundo grupo se encuentran fundamentalmente mejor y ninguna se encuentra en la categoría mucho peor. (figura 68-B).

Respecto a la antigüiedad del DCA los individuos del grupo 1 de afectación reciente (figura 69-A) se encuentran todos en los estratos altos de la clasificación y los de afectación antigua también, fundamentalmente en la categoría mucho mejor. En cuanto al segundo grupo, aquellos sujetos con afectación reciente se encuentran fundamentalmente en las categorías igual y mejor, aunque hay sujetos en todas las categorías. Los de aparición antigua se encuentran en esencia mejor y ninguno se encuentra mucho peor. (figura 69-B).

En cuanto a la extensión, los varones del grupo primero (figura 70-A) se encontraban fundamentalmente en el tercer grupo pero ninguno alcanzó la máxima categoría. Los del segundo grupo (figura 70-B) albergaron en su mayoría los grupos igual y mejor, pero tampoco alcanzaron el máximo nivel. Por su parte las mujeres de este segundo grupo (figura 70-B) estuvieron en esencia mejor y sí que llegaron a alcanzar la máxima categoría propuesta.

Teniendo en cuenta la antigüedad del DCA, los individuos del primer grupo con afectación reciente, se encontraron en los grupos igual y mejor mientras que los de afectación antigua se encontraron en esencia igual (figura 7-A). En el segundo grupo, los individuos de afectación reciente se encontraron igual en su mayoría, pero hubo sujetos en todas las categorías, mientras que aquellos que sufrieron el episodio con anterioridad, se encontraron en esencia mejor y todos ellos estuvieron situados en las categorías superiores (tercera a quinta). (figura 71-B).

En flexión, los varones del primer grupo (figura 72-A) están sobretodo mucho mejor y ninguno se encuentra mucho peor, mientras que los del segundo grupo (fi2ura 72-B) se reparten en todos los niveles. Las mujeres del segundo grupo (figura 77-B) están esencialmente mejor aunque se reparten entre todos los niveles a excepción de la categoría peor.

En cuanto a la antigüedad del DCA, los individuos del primer grupo de afectación reciente (figura 73-A) se encuentran situados en las categorías de peor y mejor, mientras que los de instauración más antigua se encuentran en esencia mucho mejor. En el segundo grupo, (figura 73-B) los individuos de afectación reciente se encuentran en todas las categorías, siendo la más poblada la de mejor y aquellos con instauración antigua presentan el mismo patrón. 
Si observamos los resultados en cuanto a la medida de la rotación externa; los varones del primer grupo (figura 74-A) se sitúan en los tres niveles más altos de la tabla estando la mayoría en la categoría de mejor o cuarto nivel. Los del segundo grupo (figura 74-B) se sitúan en todos los niveles pero la mayoría lo hacen en las categorías de igual y mejor. Las mujeres de este grupo se sitúan también en todos los niveles y lo hacen fundamentalmente en el cuarto. (figura 74-B)

En cuanto a la antigüedad en la aparición del DCA, los individuos del primer grupo (figura 75-A) cuya aparición es reciente, se encuentran en valores que oscilan entre igual y mucho mejor, mientras que los de afectación antigua se encuentran todos mejor. Los individuos del segundo grupo con afectación reciente (figura 75-B) se sitúan en todos los niveles siendo los más poblados el nivel tercero y el cuarto. Aquellos con afectación antigua de este segundo grupo también se sitúan en todos los niveles de la clasificación, siendo el nivel predominante el cuarto o mejor.

Y respecto a la rotación interna, en el caso de los varones del primer grupo (figura 76-A), los individuos se han situado en todos los niveles de la clasificación y el más poblado ha sido el cuarto o mejor, mientras que en el segundo grupo no se situó ningún individuo en las categorías de los extremos (figura 76-B). En cuanto a las mujeres de este segundo grupo, se situaron en todos los niveles de medición y el más representativo fue el cuarto.

En cuanto a la antigüedad de aparición del episodio, en el primer grupo, los individuos de afectación reciente del episodio se reparten entre los niveles establecidos en la clasificación, y al no ser un gran número de sujetos, no se establece una tendencia. Los individuos de afectación tardía se reparten también entre los diferentes estratos de la clasificación, habiendo una mayor concentración de sujetos en el estrato cuarto o mejor. (figura 77-A).

En el segundo grupo, los individuos de afectación reciente se sitúan en todas las categorías, siendo las más pobladas la tercera y la cuarta, mientras que los de afectación tardía no se encontraron en la categoría mucho peor. (figura 77-B). 


\section{RESULTADOS PARA EL ÍNDICE DE BARTHEL}

El índice de Barthel, medidor del grado de dependencia del individuo, se registró al inicio del tratamiento, en la mitad del mismo y al finalizar.

Este cuestionario es uno de los más difundidos a nivel mundial para determinar el grado de autonomía de un individuo. Consta como hemos visto de 10 categorías a evaluar en las que se recogen aspectos de la vida diaria: comer, bañarse, vestirse, arreglarse, control de las deposiciones, control de la micción, uso del retrete, trasladarse, deambular, subir escalones. En cada una de estas subcategorías se puntúa entre el 0 o máxima dependencia y puntuaciones que aumentan de cinco en cinco puntos en función del grado de autonomía del paciente.

La puntuación total será de un máximo de 100 puntos si el paciente realiza todas las actividades de manera autónoma.

Una vez establecida la puntuación de cada individuo (entre el 0 y el 100 en intervalos de 5 puntos) se procede a catalogar a éste en la siguiente escala:

- 0-20 puntos: dependencia total

- 21-60 puntos: dependencia severa

- 61-90 puntos: dependencia moderada

- 91-99 puntos: dependencia escasa

- 100: independencia

Es interesante conocer cuál es el nivel de dependencia de los individuos de este grupo en cada una de las mediciones tomadas.

Así, estudiaremos qué ocurre con los individuos del grupo 1 y del grupo 2 en cada uno de los tiempos de medición.

Haciendo una media de los resultados obtenidos por los individuos en cada uno de los tres tiempos de medición se observa lo siguiente 


\begin{tabular}{|c|c|c|c|}
\cline { 2 - 4 } \multicolumn{1}{c|}{} & \multicolumn{3}{c|}{ Puntuación media IB } \\
\cline { 2 - 4 } \multicolumn{1}{c|}{} & Inicial & Intermedio & Final \\
\hline Grupo 1 & 67,08 & $76,67(+9,59)$ & $85,00(+8.33)$ \\
\hline Grupo 2 & 38,61 & $39,86(+1.55)$ & $61,25(+21.39)$ \\
\hline Diferencia Puntuaciones & 28.47 & 36,81 & 23,25 \\
\hline
\end{tabular}

Tabla 30: Puntuaciones medias obtenidas en el IB. Grupos 1 y 2

Donde observamos que la media inicial del IB en el primer grupo es mayor que en el segundo en los tres tiempos de medición, sin embargo la diferencia de puntuaciones entre el primer y el segundo grupo se hace menos evidente en la segunda mitad del estudio.

El grupo 1 aumenta de manera progresiva su puntuación en el IB mientras que el segundo durante la primera parte del estudio (4,5 meses iniciales) apenas 1,5 puntos su puntuación media en la escala. Entre la segunda y la tercera valoración el grupo 2 ha aumentado en 21,39 puntos medios mientras que el primer grupo aumenta únicamente 8,33 puntos en este periodo, si bien es cierto que su puntuación final es 23,25 puntos mayor.

De manera gráfica

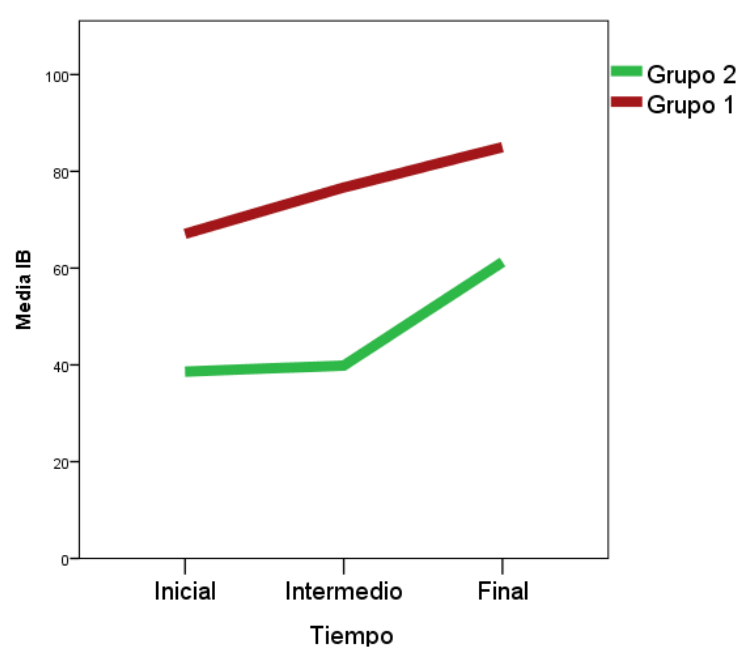

Figura 39: Puntuaciones medias IB. Grupos 1 y 2 


\section{RESULTADOS}

Si procedemos a establecer a los individuos por categorías, se obtienen los siguientes resultados:

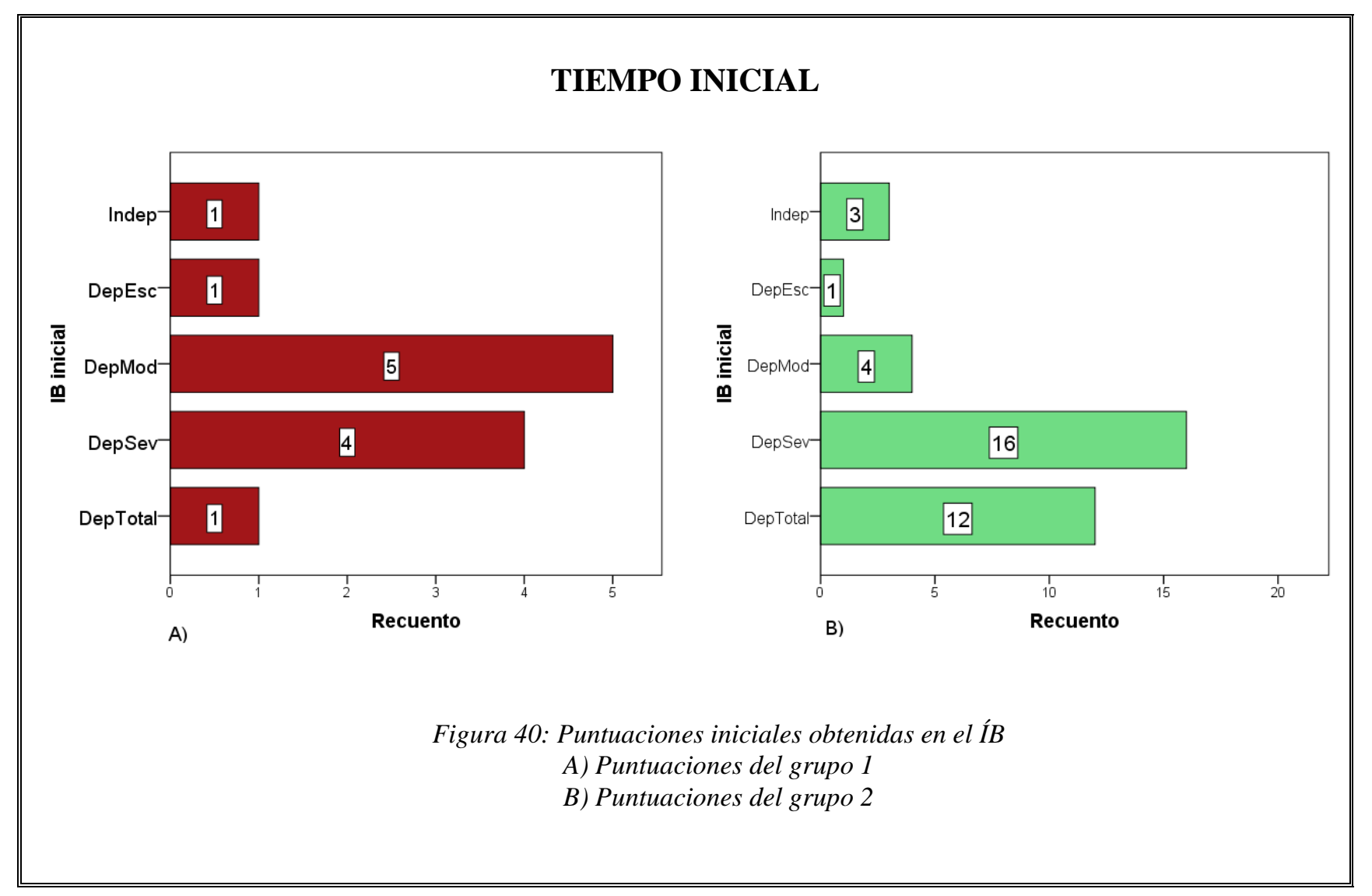

\begin{tabular}{|c||c|c||c|c|}
\hline \multicolumn{1}{|c||}{} & \multicolumn{2}{c||}{ GRUPO 1 } & \multicolumn{2}{c|}{ GRUPO 2 } \\
\cline { 2 - 5 } & Recuento & Porcentaje & Recuento & Porcentaje \\
\hline Dependencia Total & 1 & 8,3 & 12 & 33,3 \\
\hline Dependencia severa & 4 & 33,3 & 16 & 44,4 \\
\hline Dependencia Moderada & 5 & 41,7 & 4 & 11,1 \\
\hline Dependencia escasa & 1 & 8,3 & 1 & 2,8 \\
\hline Independencia & 1 & 8,3 & 3 & 8,3 \\
\hline Total & 12 & 100,0 & 36 & 100,0 \\
\hline
\end{tabular}

Tabla 31: recuento de individuos en cada nivel de independencia del ÍB en la valoración inicial. Grupos 1 y 2

Así vemos que el máximo porcentaje de individuos se sitúa en el grupo 1, en la categoría de dependencia moderada y ,sin embargo, en el grupo 2, las categorías de dependencia total y dependencia severa, sitúan más de la mitad de los sujetos. 


\section{TIEMPO INTERMEDIO}
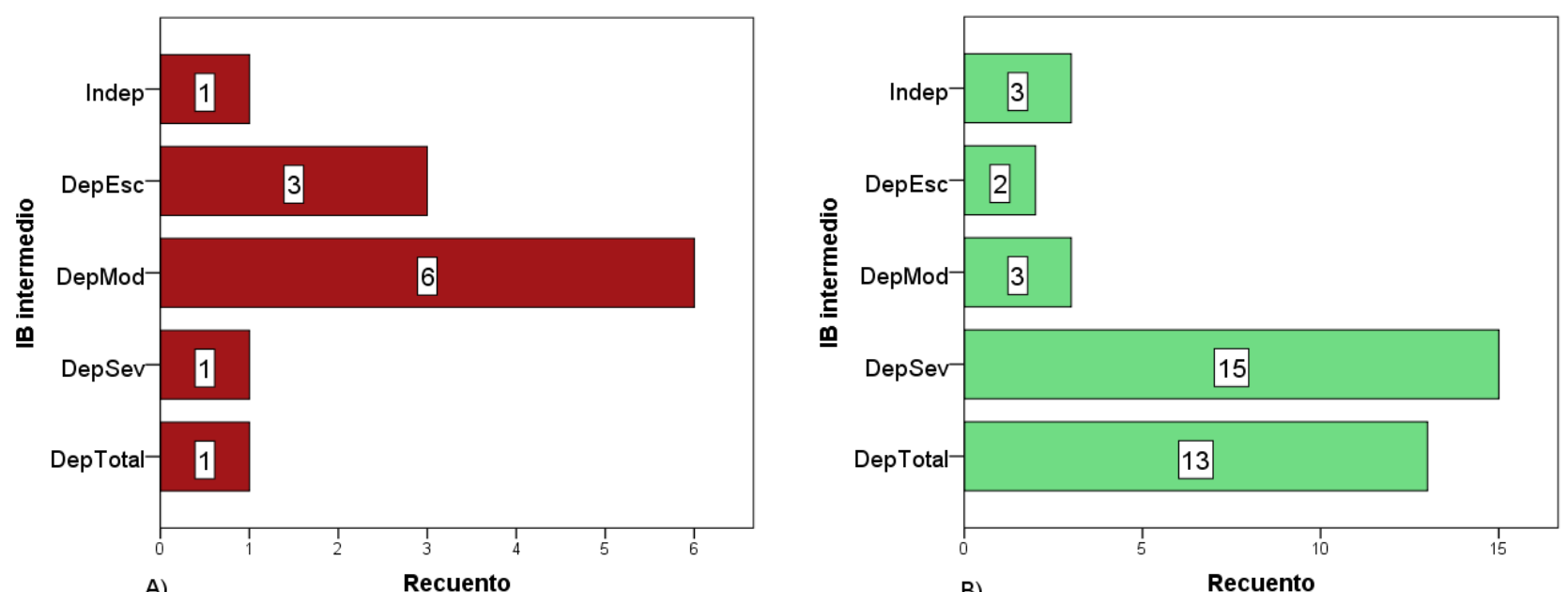

Figura 41: Puntuaciones intermedias obtenidas en el ÍB

A) Puntuaciones del grupo 1

B) Puntuaciones del grupo 2

\begin{tabular}{|c||c|c||c|c|}
\hline \multicolumn{1}{|c||}{} & \multicolumn{2}{c||}{ GRUPO 1 } & \multicolumn{2}{c|}{ GRUPO 2 } \\
\cline { 2 - 5 } & Recuento & Porcentaje & Recuento & Porcentaje \\
\hline Dependencia Total & 1 & 8,3 & 13 & 36,1 \\
\hline Dependencia severa & 1 & 8,3 & 15 & 41,7 \\
\hline Dependencia Moderada & 6 & 50,0 & 3 & 8,3 \\
\hline Dependencia escasa & 3 & 25,0 & 2 & 5,6 \\
\hline Independencia & 1 & 8,3 & 3 & 8,3 \\
\hline \hline Total & 12 & 100,0 & 36 & 100,0 \\
\hline
\end{tabular}

Tabla 32: recuento de individuos en cada nivel de independencia del ÍB en la valoración intermedia. Grupos 1 y 2 


\section{RESULTADOS}

En el tiempo intermedio la mitad de los sujetos del primer grupo se encontraban en niveles de dependencia moderada y el $25 \%$ en niveles de dependencia escasa. Sin embargo, el grupo 2 mantenía a más de la mitad de sus miembros en niveles de dependencia total y severa. Tan sólo un 5,6 \% de sus miembros se encontraban en niveles de dependencia escasa. En ambos grupos, tan sólo el 8,3 \% se encontraban en niveles de independencia.

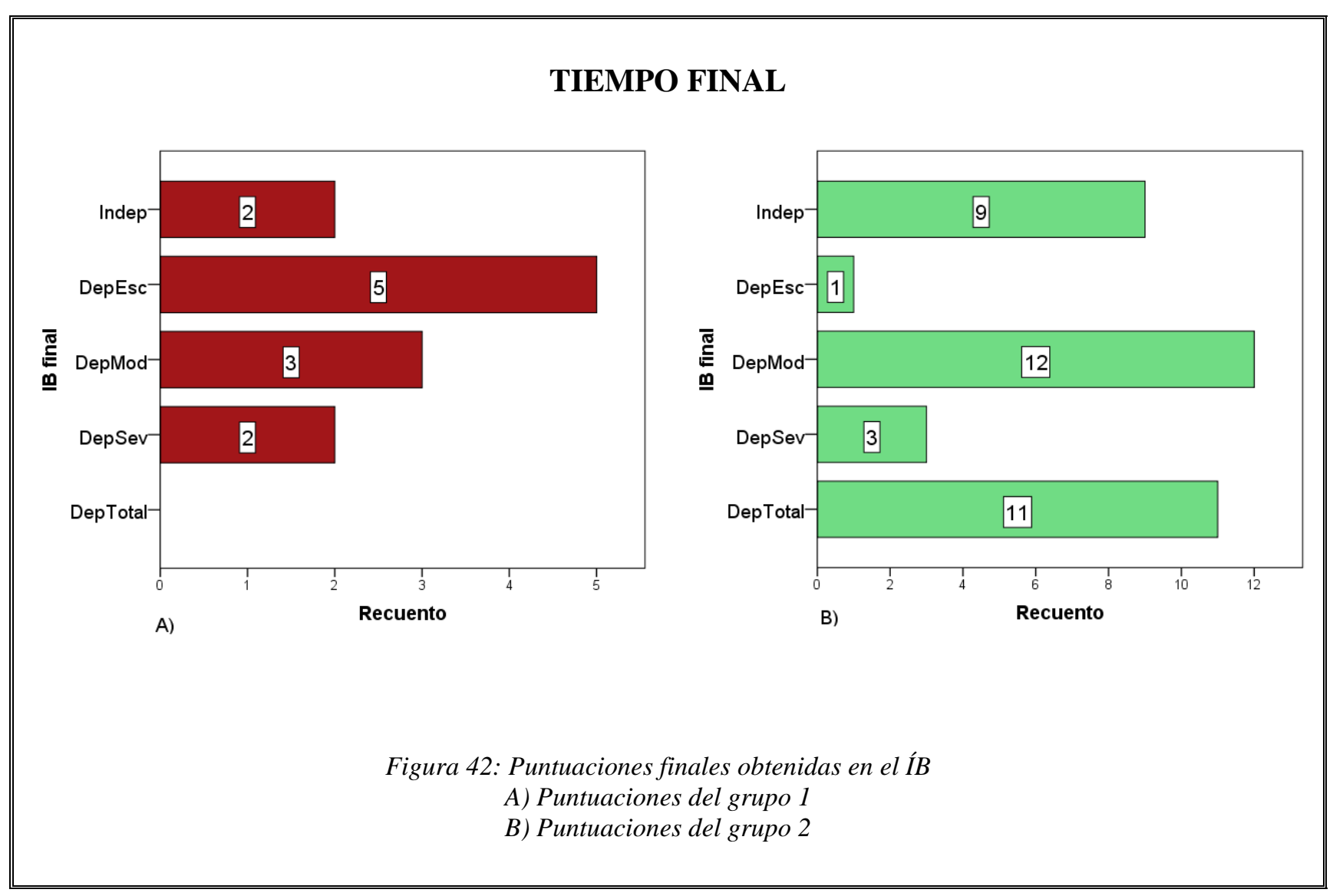

\begin{tabular}{|c||c|c||c|c|}
\hline \multicolumn{1}{|c||}{} & \multicolumn{2}{c||}{ GRUPO 1 } & \multicolumn{2}{c|}{ GRUPO 2 } \\
\hline & Recuento & Porcentaje & Recuento & Porcentaje \\
\hline Dependencia Total & & & 11 & 30,6 \\
\hline Dependencia severa & 2 & 16,7 & 3 & 8,3 \\
\hline Dependencia Moderada & 3 & 25,0 & 12 & 33,3 \\
\hline Dependencia escasa & 5 & 41,7 & 1 & 2,8 \\
\hline Independencia & 2 & 16,7 & 9 & 25,0 \\
\hline \hline Total & 12 & 100,0 & 36 & 100,0 \\
\hline
\end{tabular}

Tabla 33: recuento de individuos en cada nivel de independencia del ÍB en la valoración final. Grupos 1 y 2 
Al final del tiempo de estudio, en el grupo 1 (el tratado con terapia Vojta) presentaba a la mayoría de sus miembros en niveles de dependencia escasa $(41,7 \%$ de sus miembros). Así mismo, ninguno de sus componentes se encontraba en niveles de dependencia total y el 16,7 \% de los miembros alcanzaba los niveles máximos de independencia.

En el segundo grupo, el porcentaje de dependencia total de los individuos era del 30,6 \% y un tercio de sus miembros se encontraban en niveles de dependencia moderada $(33,3 \%)$, mientras que en el primer grupo tan sólo eran el $25 \%$ del total de los componentes.

La dependencia escasa tan sólo la alcanzó el 2,8 \% de sus miembros. La máxima independencia la alcanzó el $25 \%$ de sus miembros. 


\section{RESULTADOS PARA LA MEDIDA DE LA INDEPEN- DENCIA FUNCIONAL MOTORA}

El otro cuestionario empleado en el estudio para determinar el grado de dependencia de los sujetos fue la MEDIDA DE LA INDEPENDENCIA FUNCIONAL. En él se ofrecen una serie de ítems relacionados con las ABVD que se puntúan en función de si el sujeto puede o no hacerlas con autonomía. Cuanta mayor autonomía presente en su realización, mayor puntuación presentará en la actividad y al contrario.

Este cuestionario es uno de los más difundidos a nivel mundial para determinar el grado de dependencia de un individuo. Consta como se explicó anteriormente de 4 categorías motoras a evaluar con diversos subítems que recogen aspectos de la vida diaria: alimentación, que recoge 7 subítems; control de esfínteres, que recoge 2; movilidad, que recoge 3 y ambulación, que recoge 2. En cada una de estas subcategorías se puntúa entre el 1 o máxima dependencia y puntuaciones que aumentan hasta el 7 o independencia absoluta.

La puntuación mínima de este FIM motor es de 11 puntos y la máxima de 91.

A continuación se recoge gráficamente cómo evolucionaron los sujetos respecto a la vertiente motora de este cuestionario. 
MEDIDA DE LA INDEPENDENCIA FUNCIONAL MOTORA (MIFm)
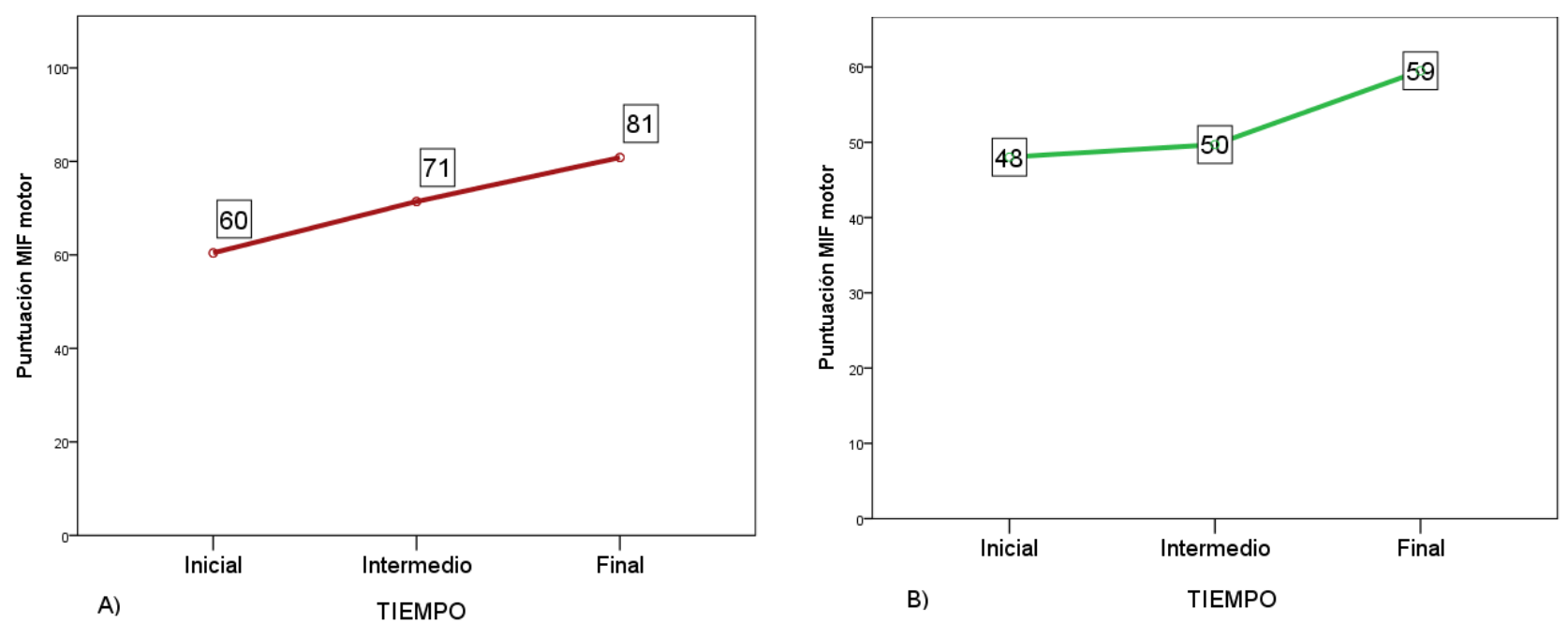

B)

TIEMPO

Figura 43: Puntuaciones obtenidas en la escala MIF subescala motora

A) Individuos del grupo 1

B) Individuos del grupo 2

Donde se observa que en el primer grupo las medias en los tres tiempos son siempre superiores a las del segundo grupo y además éstas siempre van en aumento.

En el grupo 2 entre la medición inicial y la intermedia apenas aumenta la puntuación total de la MIFm (2 puntos de diferencia entre la medición media y la inicial) y sin embargo en la medición intermedia y la final los sujetos aumentan 9 puntos en la escala.

El aumento entre el tiempo inicial y el medio así como entre el medio y el final del primer grupo es mayor que el que se produce en el segundo grupo. 


\section{RESULTADOS PARA EL CUESTIONARIO SF-36}

El cuestionario SF-36 se empleó en su versión $1.4^{130.134 .135}$ y los resultados fueron los siguientes:

Se estudiará el cambio en la percepción de la salud que tiene cada individuo de sí mismo al inicio del tratamiento y al finalizar el mismo.

Para ello se han recogido los datos en cada una de las categorías del cuestionario que derivan de las respuestas dadas a las 36 preguntas del mismo. Las diferentes categorías son: función física, rol físico, dolor, salud general, vitalidad, función emocional, rol emocional, salud mental y transición de la salud así como la puntuación total en el cuestionario que obtuvo cada individuo.

Previo a la obtención de los datos numéricos que se muestran a continuación, fue necesario la reconversión de las puntuaciones crudas de la escala en las puntuaciones estandarizadas, tal y como se detalla en el manual del cuestionario ${ }^{130.135}$. 


\begin{tabular}{|c|c|c|c|c|c|c|c|c||c|}
\hline \multicolumn{10}{|c|}{ A) PUNTUACIÓN INICIAL SF-36 } \\
\hline FF & FR & DL & SG & VT & FE & RE & SM & TS & Total \\
\hline 45 & 50 & 67,5 & 40 & 35 & 77,5 & 100 & 60 & 75 & \\
\hline 5 & 0 & 32,5 & 25 & 20 & 80 & 0 & 44 & 75 & 31,27 \\
\hline 70 & 50 & 100 & 45 & 50 & 100 & 100 & 80 & 50 & 71,66 \\
\hline 45 & 50 & 100 & 20 & 50 & 42,5 & 0 & 56 & 50 & 45,94 \\
\hline 25 & 50 & 90 & 40 & 55 & 12,5 & 33,33 & 68 & 50 & 47,09 \\
\hline 30 & 0 & 90 & 30 & 30 & 65 & 33,3 & 40 & 75 & 73,7 \\
\hline 5 & 0 & 90 & 40 & 30 & 12,5 & 100 & 44 & 75 & 44,05 \\
\hline 30 & 0 & 45 & 40 & 35 & 45 & 33,3 & 28 & 50 & 34,03 \\
\hline 45 & 0 & 77,5 & 20 & 35 & 42,5 & 33,33 & 52 & 75 & 42,25 \\
\hline 11 & 0 & 10 & 20 & 15 & 50 & 0 & 40 & 50 & 21,66 \\
\hline 55 & 25 & 90 & 45 & 60 & 35 & 0 & 44 & 75 & 47,66 \\
\hline 85 & 0 & 67,5 & 60 & 65 & 55 & 66,66 & 72 & 10.0 & 63,46 \\
\hline
\end{tabular}

FF: función físical RF: rol físico/ dl: dolor/ SG: salud general/ VT: vitalidad/ FE: función emocional/ RE: rol emocional/ TS: transición de la salud

\begin{tabular}{|c|c|c|c|c|c|c|c|c||c|}
\hline \multicolumn{10}{|c|}{ B) PUNTUACIÓN FINAL SF-36 } \\
\hline FF & FR & DL & SG & VT & FE & RE & SM & TS & Total \\
\hline 45 & 50 & 67,5 & 40 & 35 & 77,5 & 100 & 60 & 75 & 61,11 \\
\hline 5 & 0 & 32,5 & 25 & 20 & 80 & 0 & 44 & 75 & 31,27 \\
\hline 70 & 50 & 100 & 45 & 50 & 100 & 100 & 80 & 50 & 71,66 \\
\hline 45 & 50 & 100 & 20 & 50 & 42,5 & 0 & 56 & 50 & 45,94 \\
\hline 25 & 50 & 90 & 40 & 55 & 12,5 & 33,33 & 68 & 50 & 47,09 \\
\hline 30 & 0 & 90 & 30 & 30 & 65 & 33,3 & 40 & 75 & 73,7 \\
\hline 5 & 0 & 90 & 40 & 30 & 12,5 & 100 & 44 & 75 & 44,05 \\
\hline 30 & 0 & 45 & 40 & 35 & 45 & 33,3 & 28 & 50 & 34,03 \\
\hline 45 & 0 & 77,5 & 20 & 35 & 42,5 & 33,33 & 52 & 75 & 42,25 \\
\hline 11 & 0 & 10 & 20 & 15 & 50 & 0 & 40 & 50 & 21,66 \\
\hline 55 & 25 & 90 & 45 & 60 & 35 & 0 & 44 & 75 & 47,66 \\
\hline 85 & 0 & 67,5 & 60 & 65 & 55 & 66,66 & 72 & 10.0 & 63,46 \\
\hline
\end{tabular}

Tabla 34: resultados en el cuestionario sf-36. Grupo 1. A) resultados iniciales. B) resultados finales 


\begin{tabular}{|c|c|c|c|c|c|c|c|c|c|}
\hline \multicolumn{10}{|c|}{ A) PUNTUACIÓN INICIAL SF-36 } \\
\hline FF & $\mathbf{F R}$ & $\mathbf{D L}$ & SG & VT & FE & $\mathbf{R E}$ & SM & TS & Total \\
\hline 35 & 0 & 67,5 & 35 & 30 & 22,5 & 0 & 75 & 25 & 31,88 \\
\hline 30 & 0 & 32,5 & 25 & 10 & 12,5 & 0 & 44 & 75 & 25,44 \\
\hline 0 & 0 & 22,5 & 15 & 15 & 10 & 0 & 60 & 0 & 13,61 \\
\hline 35 & 0 & 80 & 20 & 25 & 42,5 & 0 & 56 & 50 & 34,27 \\
\hline 45 & 0 & 87,5 & 50 & 65 & 55 & 0 & 64 & 50 & 46,27 \\
\hline 0 & 0 & 10 & 35 & 15 & 22,5 & 0 & 44 & 50 & 19,61 \\
\hline 0 & 0 & 22,5 & 25 & 30 & 30 & 0 & 36 & 0 & 15,94 \\
\hline 0 & 0 & 67,5 & 10 & 25 & 0 & 0 & 44 & 25 & 19,05 \\
\hline 5 & 0 & 100 & 40 & 45 & 55 & 0 & 72 & 50 & 40,77 \\
\hline 80 & 75 & 90 & 60 & 70 & 55 & 33,33 & 68 & 50 & 64,59 \\
\hline 0 & 0 & 90 & 25 & 15 & 22,5 & 0 & 80 & 25 & 28,61 \\
\hline 35 & 0 & 90 & 45 & 50 & 22,5 & 33,33 & 64 & 75 & 46,09 \\
\hline 0 & 0 & 100 & 20 & 20 & 12,5 & 0 & 44 & 50 & 27,38 \\
\hline 0 & 0 & 22,5 & 0 & 10 & 10 & 0 & 16 & 0 & 6,5 \\
\hline 50 & 0 & 100 & 55 & 70 & 55 & 0 & 64 & 75 & 52,11 \\
\hline 30 & 75 & 77,5 & 85 & 70 & 80 & 100 & 68 & 75 & 73,78 \\
\hline 0 & 0 & 35 & 35 & 30 & 55 & 0 & 52 & 25 & 25,77 \\
\hline 0 & 0 & 22,5 & 45 & 20 & 42,5 & 0 & 28 & 25 & 20,33 \\
\hline 45 & 0 & 45 & 50 & 50 & 30 & 0 & 52 & 50 & 35,77 \\
\hline 10 & 0 & 32,5 & 30 & 45 & 22,5 & 0 & 40 & 25 & 22,77 \\
\hline 5 & 0 & 45 & 10 & 50 & 35 & 0 & 40 & 25 & 23,33 \\
\hline 0 & 0 & 45 & 10 & 5 & 22,5 & 33,33 & 32 & 0 & 16,42 \\
\hline 0 & 0 & 22,5 & 25 & 25 & 30 & 0 & 40 & 25 & 0 \\
\hline 30 & 0 & 77,5 & 30 & 55 & 67,5 & 0 & 64 & 75 & 30 \\
\hline 10 & 0 & 57,5 & 20 & 30 & 22,5 & 0 & 56 & 50 & 10 \\
\hline 0 & 0 & 57,5 & 25 & 25 & 35 & 0 & 64 & 50 & 0 \\
\hline 0 & 0 & 55 & 5 & 15 & 0 & 0 & 32 & 50 & 0 \\
\hline 0 & 0 & 65 & 25 & 15 & 0 & 0 & 32 & 25 & 0 \\
\hline 10 & 0 & 77,5 & 30 & 65 & 55 & 0 & 60 & 50 & 38,61 \\
\hline 0 & 0 & 45 & 25 & 25 & 22,5 & 0 & 68 & 50 & 26,16 \\
\hline 5 & 0 & 45 & 30 & 70 & 80 & 0 & 56 & 50 & 37,33 \\
\hline 10 & 0 & 52,5 & 20 & 25 & 22,5 & 0 & 60 & 75 & 29,44 \\
\hline 35 & 75 & 45 & 50 & 50 & 67,5 & 33,33 & 76 & 75 & 56,31 \\
\hline 5 & 0 & 65 & 35 & 45 & 55 & 0 & 60 & 50 & 35 \\
\hline 5 & 50 & 90 & 65 & 80 & 90 & 100 & 88 & 50 & 68,66 \\
\hline 30 & 75 & 100 & 50 & 75 & 77,5 & 66,66 & 76 & 75 & 69,46 \\
\hline 0 & 0 & 52,5 & 10 & 10 & 10 & 0 & 25 & 0 & 11,83 \\
\hline
\end{tabular}

FF: función físical RF: rol físico/DL: dolor/ SG: salud general/ VT: vitalidad/ FE: función emocional/ RE: rol emocional/ TS: transición de la salud 


\begin{tabular}{|c|c|c|c|c|c|c|c|c|c|}
\hline \multicolumn{10}{|c|}{ B) PUNTUACIÓN FINAL SF-36 } \\
\hline FF & FR & $\overline{D L}$ & SG & VT & FE & RE & SM & TS & Total \\
\hline 45 & 0 & 100 & 35 & 70 & 67.5 & 100 & 80 & 75 & 67.61 \\
\hline 20 & 25 & 90 & 50 & 70 & 77.5 & 100 & 92 & 75 & 66.61 \\
\hline 0 & 0 & 20 & 20 & 20 & 30 & 0 & 24 & 26 & 15.44 \\
\hline 60 & 100 & 52.5 & 50 & 60 & 77.5 & 100 & 64 & 50 & 68.22 \\
\hline 30 & 75 & 100 & 45 & 55 & 65 & 100 & 80 & 50 & 66.66 \\
\hline 70 & 75 & 90 & 40 & 70 & 67.5 & 100 & 68 & 75 & 72.83 \\
\hline 0 & 0 & 35 & 15 & 30 & 30 & 0 & 40 & 25 & 19.44 \\
\hline 25 & 25 & 100 & 30 & 75 & 77.5 & 33.33 & 72 & 75 & 56.98 \\
\hline 0 & 0 & 22.5 & 5 & 10 & 10 & 0 & 28 & 0 & 8.388 \\
\hline 95 & 100 & 90 & 80 & 80 & 62.5 & 100 & 88 & 75 & 85.61 \\
\hline 45 & 100 & 100 & 75 & 70 & 60 & 100 & 60 & 100 & 78.88 \\
\hline 33 & 0 & 80 & 25 & 35 & 55 & 0 & 52 & 50 & 33 \\
\hline 0 & 0 & 45 & 30 & 50 & 42.5 & 0 & 52 & 0 & 24.38 \\
\hline 0 & 0 & 35 & 25 & 20 & 25 & 0 & 36 & 50 & 21.22 \\
\hline 60 & 50 & 100 & 65 & 85 & 100 & 100 & 76 & 50 & 76.22 \\
\hline 65 & 100 & 100 & 65 & 90 & 100 & 100 & 88 & 75 & 87 \\
\hline 95 & 100 & 100 & 50 & 75 & 90 & 100 & 80 & 75 & 85 \\
\hline 45 & 50 & 100 & 40 & 55 & 67.5 & 100 & 64 & 75 & 66.27 \\
\hline 0 & 0 & 67.5 & 15 & 20 & 65 & 0 & 44 & 25 & 26.27 \\
\hline 30 & 100 & 100 & 35 & 90 & 90 & 100 & 88 & 75 & 78.66 \\
\hline 30 & 0 & 100 & 35 & 60 & 90 & 100 & 60 & 75 & 61.11 \\
\hline 0 & 0 & 45 & 15 & 15 & 50 & 0 & 16 & 0 & 15.66 \\
\hline 0 & 0 & 35 & 45 & 20 & 55 & 0 & 32 & 50 & 26.33 \\
\hline 0 & 0 & 55 & 30 & 25 & 42.5 & 0 & 52 & 50 & 28.27 \\
\hline 85 & 100 & 100 & 50 & 90 & 100 & 100 & 96 & 100 & 91.22 \\
\hline 0 & 0 & 45 & 20 & 45 & 52.5 & 10 & 68 & 25 & 28.38 \\
\hline 15 & 50 & 100 & 45 & 80 & 87.5 & 100 & 84 & 50 & 67.94 \\
\hline 0 & 0 & 35 & 5 & 20 & 35 & 0 & 44 & 0 & 15.44 \\
\hline 5 & 0 & 100 & 35 & 60 & 67.5 & 0 & 56 & 50 & 41.5 \\
\hline 20 & 50 & 90 & 35 & 70 & 100 & 100 & 84 & 75 & 69.33 \\
\hline 60 & 100 & 100 & 60 & 70 & 100 & 100 & 68 & 75 & 81.44 \\
\hline 0 & 0 & 65 & 25 & 45 & 67.5 & 0 & 56 & 25 & 31.5 \\
\hline 50 & 100 & 100 & 55 & 85 & 90 & 100 & 88 & 50 & 79.77 \\
\hline 55 & 75 & 100 & 80 & 90 & 100 & 100 & 96 & 75 & 85.66 \\
\hline 75 & 100 & 100 & 70 & 90 & 100 & 100 & 100 & 75 & 90 \\
\hline 100 & 100 & 90 & 65 & 85 & 100 & 100 & 88 & 50 & 86.44 \\
\hline 0 & 0 & 35 & 15 & 15 & 10 & 0 & 24 & 25 & 13.77 \\
\hline
\end{tabular}

Tabla 35: resultados en el cuestionario sf-36. Grupo 2. A) Resultados iniciales. B) Resultados finales 


\section{RESULTADOS}

Teniendo en cuenta las tablas anteriores se han trazado las medias para cada categoría así como la media de la puntuación total en cada uno de los grupos, tanto en el inicio del tratamiento como al finalizar éste, 9 meses después.

Así, el incremento en la puntuación total en el grupo 1 o grupo que realizó la terapia Vojta fue de 34,83 puntos mientras que en el grupo 2 fue de 22,63.

\begin{tabular}{|c|c|c|c|c|c|}
\hline \multicolumn{2}{|c|}{ SF-36 } & \multicolumn{2}{c|}{ Tiempo inicial } & \multicolumn{2}{c|}{ Tiempo final } \\
\hline \hline Categoría & Grupo & Media & s & Media & S \\
\hline \multirow{2}{*}{ FF } & 1 & 37.5 & 25,09 & 73,3 & 12,12 \\
\cline { 2 - 6 } & 2 & 14,17 & 19,65 & 23,91 & 32,87 \\
\hline \multirow{2}{*}{ RF } & 1 & 18,760 & 24,13 & 100,0 & 0,00 \\
\cline { 2 - 6 } & 2 & 9,72 & 24,84 & 43,76 & 44,47 \\
\cline { 2 - 6 } & 1 & 71,66 & 28,71 & 90,0 & 17,15 \\
\hline \multirow{3}{*}{ SG } & 2 & 58,40 & 26,51 & 76,18 & 28,91 \\
\cline { 2 - 6 } & 1 & 35,42 & 12,51 & 52,9 & 18,02 \\
\hline \multirow{3}{*}{ VT } & 1 & 31,26 & 18,26 & 40,42 & 20,65 \\
\cline { 2 - 6 } & 2 & 40,000 & 15,81 & 78,50 & 9,28 \\
\cline { 2 - 6 } & 1 & 36,81 & 22,37 & 57,22 & 26,84 \\
\hline \multirow{2}{*}{ RE } & 2 & 31,46 & 26,21 & 83,17 & 19,70 \\
\cline { 2 - 6 } & 1 & 41,68 & 24,88 & 68,12 & 26,98 \\
\hline \multirow{2}{*}{ SM } & 2 & 10,19 & 40,51 & 100,00 & 0,00 \\
\cline { 2 - 6 } & 2 & 52,33 & 15,21 & 59,54 & 48.87 \\
\hline \multirow{2}{*}{ TS } & 1 & 53,78 & 17,27 & 75,67 & 15,20 \\
\cline { 2 - 6 } & 2 & 66,67 & 16,28 & 89,59 & 23,44 \\
\hline \multirow{2}{*}{ TOTAL } & 1 & 41,67 & 23,91 & 52,81 & 27,86 \\
\cline { 2 - 6 } & 2 & 32,53 & 16,09 & 83,49 & 7,23 \\
\hline
\end{tabular}

Tabla 36 Puntuaciones medias iniciales y finales para el SF-36. Grupos 1 y 2 
A partir de los resultados descritos anteriormente se plantean los análisis estadísticos siguientes.

\section{ANÁLISIS DEL RESULTADO GONIOMÉTRICO DE LOS INDIVIDUOS AFECTADOS DEL HEMICUERPO IZQUIERDO}

Tras observar cómo se comportan los individuos afectados del hemicuerpo izquierdo procederemos a contrastar los resultados de aquellos que pertenecen al grupo 1 frente a los que pertenecen al segundo grupo.

Como se dijo anteriormente, el grupo 1 o de tratamiento con terapia Vojta tiene 10 individuos con estas características mientras que el grupo 2, o de tratamiento con FNP, cuenta con 19 sujetos afectados del hemicuerpo izquierdo.

Se realizará para ello un contraste entre los dos grupos mediante la $T$ de Student para la igualdad de medias en la que los resultados son los siguientes:

\begin{tabular}{|c|c|c|c|c|}
\hline movimiento & tiempo de medición & $t$ & pvalor & Significativo \\
\hline ABD & inicial & $-1,585$ & 0,130 & NS \\
\hline ABD & intermedio & $-2,291$ & 0,033 & * \\
\hline ABD & final & $-2,860$ & 0,009 & $\star$ \\
\hline EXT & inicial & $-1,678$ & 0,109 & NS \\
\hline EXT & intermedio & $-1,948$ & 0,066 & NS \\
\hline EXT & final & $-2,538$ & 0,022 & * \\
\hline FLEX & inicial & $-2,887$ & 0,010 & ** \\
\hline FLEX & intermedio & $-3,919$ & 0,001 & *** \\
\hline FLEX & final & $-3,906$ & 0,001 & 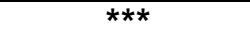 \\
\hline ROTE & inicial & $-1,001$ & 0,329 & NS \\
\hline ROTE & intermedio & $-2,255$ & 0,041 & * \\
\hline ROTE & final & $-3,477$ & 0,002 & ** \\
\hline ROTI & inicial & $-2,366$ & 0,025 & * \\
\hline ROTI & intermedio & $-4,381$ & 0,001 & $\star \star \star$ \\
\hline ROTI & final & $-4,666$ & 0,000 & $\star \star \star$ \\
\hline
\end{tabular}

ABD: abducción; EXT: extensión; FLEX: flexión; ROTE: rotación externa; ROTI: rotación interna; NS: No Significativo; *: Probablemente signficativo; ${ }^{* * / * * *}$ Altamente significativo.

Tabla 37: T de Student en individuos afectados del HC izquierdo

Así, según esta tabla al inicio tan sólo había diferencias significativas $(\mathrm{p}<0.05)$ entre los individuos de un grupo y el otro en los movimientos de flexión (FLEXI_1) y rotación interna (ROTII_1) del hombro izquierdo. En la mitad del tratamiento, las diferencias significativas fueron entre los movimientos de abducción, flexión, rotación externa y rotación interna respecto al movimiento del hombro izquierdo. Al finalizar el tratamiento, se encontraron diferencias significativas entre los individuos de un grupo y el otro afectados del hemicuerpo izquierdo. 


\subsection{COMPARACIÓN DE RESULTADOS ENTRE INDI- VIDUOS DEL GRUPO 1 SEGÚN LA ETIOLOGÍA DEL DCA}

Como se ha demostrado en el apartado anterior, sí hay diferencias estadísticamente significativas entre los individuos sometidos a tratamiento Vojta y los que realizaron otro tipo de fisioterapia.

Nos planteamos entonces si, dentro de la terapia Vojta, y dados sus buenos resultados existen diferencias significativas en el balance articular de hombro final entre los individuos que sufrieron un ACV y los que sufrieron otras etiologías.

Para ello se analizarán los resultados de los individuos afectados del hemicuerpo izquierdo, en los que hubo 5 sujetos con etiología ACV y 5 con otras etiologías.

Se procede a realizar un contraste de hipótesis mediante la $U$ de Mann Whitney ${ }^{190}$

\begin{tabular}{|c|c|c|}
\hline \multicolumn{3}{|c|}{ Prueba U de Mann Whitney para muestras independientes } \\
\hline \multicolumn{1}{|c|}{$\mathrm{H}_{0}$ La distribución de la medición goniométrica es siempre la misma en las distin- } \\
& tas etiologías de $D C A$ \\
\hline Categoría & Valor & Significativo \\
\hline FLEX final & 0,310 & NS \\
\hline EXT final & 0,690 & NS \\
\hline ABD final & 0,548 & NS \\
\hline ROTE final & 0,421 & NS \\
\hline ROTI final & 0,548 & NS \\
\hline
\end{tabular}

Tabla 38: Prueba U de Mann Whitney en individuos del grupo 1 afectados del hemicuerpo derecho

Por tanto según estos resultados, independientemente de la etiología del DCA, el tratamiento Vojta ofrece resultados similares a todos los pacientes. 


\section{ANÁLISIS DE RESULTADOS PARA EL ÍNDICE DE BARTHEL}

Una vez descritos los resultados obtenidos en el IB se plantea si las diferencias entre uno y otro grupo son significativas.

Para ello se realizan las siguientes pruebas.

\subsection{COMPARACIÓN DE LOS RESULTADOS DEL IB. GRUPOS 1 Y 2.}

En el grupo 1 hubo 12 sujetos y en el grupo 2 hubo 36.

Recordaremos que la puntuación media para el IB fue la siguiente en la valoración intermedia y final.

\begin{tabular}{|c|c|c|c|}
\hline IB & Grupo & media & S \\
\hline intermedio & 1 & 76,67 & 22,995 \\
\hline & 2 & 39,86 & 33,583 \\
\hline final & 1 & 85,00 & 16,376 \\
\hline & 2 & 61,25 & 39,846 \\
\hline
\end{tabular}

Tabla 39: Puntuaciones medias para el IB. Grupos 1 y 2

Haciendo una Prueba T para la igualdad de medias en muestras independientes vemos que los resultados medios presentan el siguiente $\mathrm{p}$ valor:

\begin{tabular}{|c|c|c|}
\hline IB & P valor & Significativo \\
\hline intermedio & 0,000 & ${ }^{\star \star \star}$ \\
\hline final & 0,006 & ${ }^{\star \star}$ \\
\hline
\end{tabular}

Tabla 40: Prueba T para el IB, grupos 1 y 2

Donde se observa que al comparar los resultados del IB en la mitad del tratamiento y al final del mismo, el resultado es estadísticamente significativo. 


\subsection{COMPARACIÓN DEL RESULTADO DEL IB INI- CIAL Y FINAL \\ - En el grupo 1}

En el grupo 1 al realizar la prueba T para la igualdad de medias en muestras relacionadas ${ }^{189.190}$ se obtuvo un valor t de $-3,206$ y un p valor de 0,008 (*).

- En el grupo 2

En el grupo 2 al realizar la prueba $\mathrm{T}$ para la igualdad de muestras relacionadas se obtuvo un valor de $\mathrm{t}$ de $-3,416$ un p valor de $0,002(*)$.

Luego podemos decir que las diferencias entre el IB inicial y final en ambos grupos, siendo estos estudiados de manera independiente, fueron significativas.

\section{ANÁLISIS DE RESULTADOS PARA LA MIF}

Al igual que se hizo con el IB, una vez descritos los resultados obtenidos para la MIF en su vertiente motora, se plantea si las diferencias entre uno y otro grupo son significativas.

Para ello se realizan las siguientes pruebas: 


\subsection{COMPARACIÓN DE LOS RESULTADOS DE LA MIF MOTORA. GRUPOS 1 Y 2.}

En el grupo 1 hubo 12 sujetos y en el grupo 2 hubo 36.

Recordaremos que la media de las mediciones intermedias y finales para la MIF motora fue la siguiente

\begin{tabular}{|c|c|c|c|}
\hline MIFm & Grupo & Media & S \\
\hline intermedio & 1 & 71,42 & 14,106 \\
\hline & 2 & 49,69 & 26,152 \\
\hline final & 1 & 80,83 & 11,854 \\
\hline & 2 & 59,50 & 29,761 \\
\hline
\end{tabular}

Tabla 41: Puntuaciones medias para el IB. Grupos 1 y 2

Haciendo una Prueba T para la igualdad ${ }^{189.190}$ de medias en muestras independientes vemos que los resultados medios presentan el siguiente $\mathrm{p}$ valor:

\begin{tabular}{|c|c|c|c|}
\hline MIFm & t & P valor & Significativo \\
\hline intermedio & $-2,734$ & 0,009 & ${ }^{*}$ \\
\hline final & $-2,406$ & 0,020 & ${ }^{*}$ \\
\hline
\end{tabular}

Tabla 42: Prueba T para el IB, grupos 1 y 2

Donde se observa que en la valoración intermedia la diferencia entre la puntuación en esta escala de uno y otro grupo sí es estadísticamente significativa.

\subsection{COMPARACIÓN DEL RESULTADO DE LA MIF MOTORA INICIAL Y FINAL}

- En el grupo 1

En el grupo 1 al realizar la prueba $\mathrm{T}$ para la igualdad de medias en muestras relacionadas ${ }^{189.190}$ se obtuvo un valor t de $-4,146$ y un $\mathrm{p}$ valor de $0,002(* *)$.

- $\quad$ En el grupo 2

En el grupo 2 la t fue de $-2,866$ y el p valor fue de 0,007 (**).

En ambos grupos al comparar el resultado final con el inicial la mejoría es estadísticamente significativa. 


\section{CORRELACIÓN ENTRE SUBÍTEMS DEL IB Y LA MIF}

La fuerte correlación existente entre las puntuaciones obtenidas en la MIF y el IB se ha puesto de manifiesto en múltiples estudios ${ }^{191.192 .193}$, y en el nuestro, la relación entre ellas evaluada mediante el coeficiente de correlación de Spearman también lo fue. Para ello se han tomado los valores finales obtenidos en el IB y en la MIF y se han relacionado mediante el coeficiente de correlación de Spearman ${ }^{190}$.

Además, quisimos obtener la correlación entre dos ítems concretos que, a consideración de los investigadores, eran los más relevantes en la patología que se estaba estudiando. Así, en pacientes adultos con DCA y déficit de movilidad de hombro se analizó la correlación entre el ítem alimentación recogido en la MIF y el ítem comer que establece el IB.

\begin{tabular}{|c|c|c|}
\cline { 2 - 3 } \multicolumn{1}{c|}{} & $\boldsymbol{\rho}$ & Significación \\
\hline FIM/IB final & 0,948 & ${ }^{\star \star \star}$ \\
\hline Alimentación/Comer & 0,943 & ${ }^{\star \star \star}$ \\
\hline
\end{tabular}

Tabla 43: Coeficiente de correlación de Spearman entre MIF/IB y los ítems alimentación (MIF)/co$\operatorname{mer}(I B)$

Viendo además, que entre estos dos ítems, el nivel de correlación es altamente significativo.

Haciendo una representación gráfica de la puntuación del final del IB frente a la puntuación final de la MIF se obtiene la siguiente gráfica:

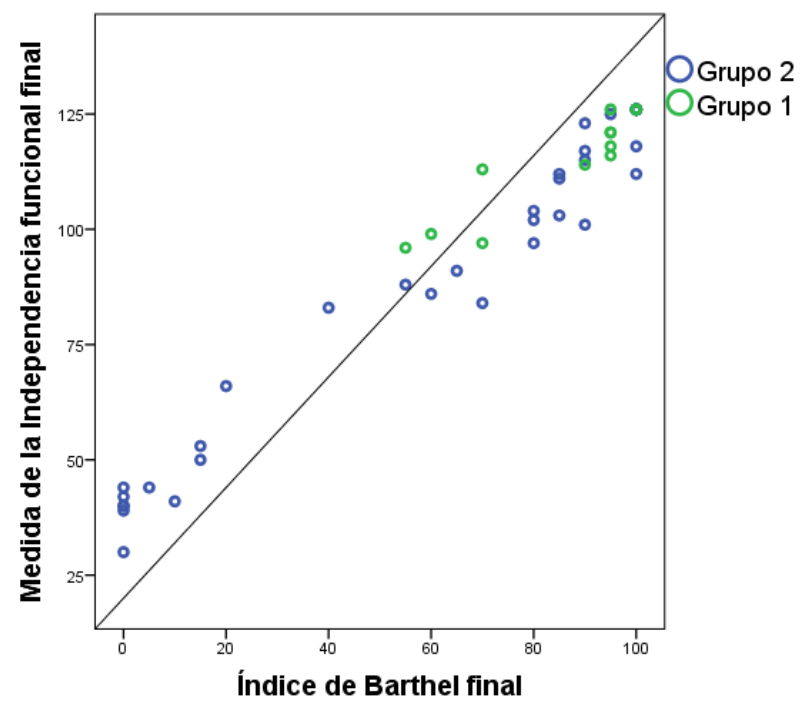

Figura 44: Diagrama de dispersión que muestra la regresión existente entre el IB y la MIF 


\section{ANÁLISIS DEL CUESTIONARIO SF-36}

Se procederá a estudiar ahora si la puntuación final obtenida en el cuestionario de salud SF-36 en su versión 1.4 es estadísticamente significativa al comparar el grupo 1 con el grupo 2.

Por otro lado, se intentará averiguar si entre cada grupo, existen diferencias significativas entre la puntuación media inicial y final de los individuos.

\subsection{EN EL GRUPO 1}

Al realizar una prueba $\mathrm{T}$ para muestras apareadas el valor $\mathrm{t}$ fue de $-7,093 \mathrm{y}$ el $\mathrm{p}$ valor fue de 0,000

\subsection{EN EL GRUPO 2}

$\mathrm{Al}$ realizar una prueba $\mathrm{T}$ para muestras apareadas el valor $\mathrm{t}$ fue de $-5,642 \mathrm{y}$ el $\mathrm{p}$ valor fue de 0,000 .

Por tanto en ambos grupos, la diferencia de puntuaciones en el cuestionario de percepción de la salud es estadísticamente significativa.

\subsection{ANÁLISIS DEL GRUPO 1 FRENTE AL GRUPO 2}

Se procede a comparar el las puntuaciones iniciales y finales de cada uno de los dos grupos. Para ello se realiza una prueba $\mathrm{T}$ para la igualdad de medias en muestras independientes.

En la puntuación inicial el valor de $\mathrm{t}$ fue de $-2,953 \mathrm{y}$ el $\mathrm{p}$ valor es de 0,008

En la puntuación final el valor t fue de $-3,448$ y el p valor de 0,001

Por tanto ambos resultados son estadísticamente significativos, lo que nos lleva a decir que existen diferencias importantes entre el estado de percepción de la salud en cada uno de los grupos ya al inicio del tratamiento, pero que al final del mismo estas diferencias son aún mayores, puesto que el $\mathrm{p}$ valor disminuye. 


\subsection{ANÁLISIS MULTIVARIANTE}

Se ha llevado a cabo un Análisis de Correspondencias Múltiples (Gifi A. $1990)^{194}$, sobre los datos generados a partir de las respuestas al cuestionario SF36 de los pacientes afectados de DCA, tras someterse dichos pacientes a tratamiento fisioterapéutico a lo largo de 9 meses.

Dicho análisis se ha realizado con el fin de estudiar, de forma global para el conjunto de los pacientes, la autopercepción del estado de salud tras el tratamiento, ya que una de nuestras hipótesis de trabajo era que los individuos presentaban una diferente percepción de su salud tras el tratamiento efectuado. Adicionalmente el análisis también ha sido utilizado para conocer si el instrumento SF36 podría servir, a través de la información de los ítems que contempla este cuestionario de calidad de vida relacionada con la salud, para obtener una tipología de la percepción de la salud de los pacientes (o diferenciación y clasificación de los mismos) en base a sus características personales y/o al tratamiento fisioterapéutico recibido.

El capítulo de Material y Métodos (apartado 7.1) recoge de manera sintética las técnicas estadísticas empleadas. El Análisis de Correspondencias Múltiples (ACM o HOMALS), se ha realizado utilizando el módulo programado por el grupo de investigación DTSS (Data Theory Scaling System group) perteneciente a la Universidad holandesa de Leiden, y que en su versión 1.1 se encuentra implementado en el programa SPSS $22^{199}$.

Para el análisis multivariante, el punto de partida ha sido la matriz de datos generada a partir de las respuestas dadas al cuestionario SF-36 por los 48 pacientes que constituyen nuestra muestra. En dicha matriz, las filas se corresponden con los 48 individuos y las columnas se corresponden con las 36 variables consideradas. El ACM se realizó por tanto a partir de la siguiente matriz de datos:

\begin{tabular}{|c|c|c|c|c|c|c|}
\hline & SF1 & SF2 & $\ldots$ & SF17 & $\ldots$ & SF36 \\
\hline Paciente 1 & $\begin{array}{c}\text { Muy } \\
\text { buena }\end{array}$ & $\begin{array}{c}\text { Mucho } \\
\text { mejor }\end{array}$ & $\ldots$ & No & $\ldots$ & $\begin{array}{c}\text { Bastante } \\
\text { falsa }\end{array}$ \\
\hline Paciente 2 & Buena & $\begin{array}{l}\text { Algo } \\
\text { mejor }\end{array}$ & $\ldots$ & No & $\ldots$ & No lo sé \\
\hline . & . & . & . & & & . \\
\hline . & . & . & & & & . \\
\hline Paciente 23 & Mala & Igual & $\ldots$ & No & $\ldots$ & $\begin{array}{c}\text { Bastante } \\
\text { cierta }\end{array}$ \\
\hline - & . & 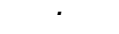 & & & & \\
\hline - & . & . & & . & & . \\
\hline Paciente 48 & Regular & $\begin{array}{c}\text { Mucho } \\
\text { mejor }\end{array}$ & $\ldots$ & Si & $\ldots$ & No lo sé \\
\hline
\end{tabular}

Figura 45: Representación esquematizada de la matriz de datos 
La solución multivariante seleccionada y que a continuación desarrollamos, es la que contempla la existencia de 2 variables latentes, pues estudios multivariantes realizados en muestras americanas y europeas, demostraron que las 8 escalas del cuestionario SF-36 definen 2 componentes principales de salud, la componente física y la mental (Vilagut, G. Et al , 2005). Esta solución bidimensional (desde un problema generado en un espacio de 36 dimensiones), presenta un porcentaje de varianza explicada, o inercia global, del 90\%; es decir, en la que prácticamente toda la variación de los datos queda recogida en el plano factorial generado por estas dos dimensiones y en el que la primera dimensión recoge un 66,4\% de la inercia, mientras que el 23,6\% es recogida por la segunda, tal y como se muestra en la siguiente tabla:

Resumen del modelo

\begin{tabular}{|c|c|c|c|}
\hline \multirow{2}{*}{ Dimensión } & Alfa de & \multicolumn{2}{|c|}{ Varianza contabilizada para } \\
\cline { 3 - 4 } & Cronbach & Total (autovalor) & Inercia \\
\hline 1 & & 23,899 &, 664 \\
2 & & 8,511 &, 236 \\
& 0,97 & 32,409 &, 900 \\
\hline
\end{tabular}

Tabla 44: Resumen del modelo

El coeficiente Alfa de Cronbach, que presenta un valor de 0,97 (prácticamente 1), pone de manifiesto que la reducción multivariante de la matriz de datos de nuestros pacientes tiene pleno sentido, pues este coeficiente (además de poner de manifiesto la gran fiabilidad de la escala de medida del instrumento SF36), es una media ponderada de las correlaciones entre las preguntas o ítems -variables-, lo que explica que pueda realizarse una reducción de la dimensionalidad de la matriz de datos global en tan sólo 2 dimensiones, y recoger un porcentaje de varianza explicada del $90 \%$.

Del análisis realizado se obtienen las medidas de discriminación, como se observa en la tabla de medidas discriminantes. El ACM obtiene, a partir del análisis, una medida de discriminación para cada variable, que puede considerarse la varianza de la variable cuantificada en esa dimensión (con un valor máximo de 1 cuando no existen datos faltantes), y por ello, las medidas de discriminación que sean grandes deben interpretarse como un alto grado de discriminación entre las categorías de una variable a lo largo esa dimensión, al contrario de lo que debe hacerse con las medidas de discriminación pequeñas.

La tabla con las medidas de discriminación (tabla 46) muestra cómo la primera dimensión presenta altas varianzas en relación con prácticamente la totalidad de las variables (preguntas o ítems) analizadas. Este resultado resulta congruente con lo que cabría esperar de un instrumento absolutamente validado y reproducido -el SF36-; 


\section{RESULTADOS}

dado que todas las preguntas han sido diseñadas para medir el estado de salud autopercibido, y que los pacientes presentan daño cerebral, parece consistente entender que esta primera dimensión recoge el factor físico fundamentalmente.

\begin{tabular}{|c|c|c|}
\multicolumn{1}{|c|}{ Medidas } & \multicolumn{2}{c|}{ Discriminantes } \\
\cline { 2 - 3 } & \multicolumn{2}{|c|}{ Dimensión } \\
\hline & $\mathbf{1}$ & 2 \\
\hline SF1 &, 860 &, 305 \\
\hline SF2 &, 766 &, 139 \\
\hline SF3 &, 508 &, 289 \\
\hline SF4 &, 739 &, 349 \\
\hline SF5 &, 905 &, 165 \\
\hline SF7 &, 894 &, 301 \\
\hline SF8 &, 529 &, 308 \\
\hline SF9 &, 693 &, 362 \\
\hline SF10 &, 709 &, 227 \\
\hline SF11 &, 786 &, 345 \\
\hline SF12 &, 842 &, 363 \\
\hline SF13 &, 625 &, 044 \\
\hline SF14 &, 631 &, 073 \\
\hline SF15 &, 756 &, 010 \\
\hline SF16 &, 864 &, 030 \\
\hline SF17 &, 843 &, 011 \\
\hline SF18 &, 799 &, 000 \\
\hline SF19 &, 758 &, 024 \\
\hline SF20 &, 419 &, 435 \\
\hline SF21 &, 731 &, 149 \\
\hline SF22 &, 750 &, 053 \\
\hline SF23 &, 671 &, 425 \\
\hline SF24 &, 424 &, 265 \\
\hline SF25 &, 767 &, 474 \\
\hline SF26 &, 643 &, 331 \\
\hline SF27 &, 428 &, 147 \\
\hline SF28 &, 674 &, 344 \\
\hline SF29 &, 810 &, 438 \\
\hline SF30 &, 679 &, 228 \\
\hline SF31 &, 613 &, 284 \\
\hline SF32 &, 687 &, 369 \\
\hline SF34 &, 341 &, 238 \\
\hline SF36 &, 377 &, 236 \\
\hline & $, 36,385$ &, 284 \\
\hline & & \\
\hline &, 210 \\
\hline
\end{tabular}

Tabla 45: Medidas de discriminación 
La segunda dimensión de la solución, sin embargo, presenta medidas de discriminación más modestas que indican un grado de discriminación menor entre las categorías de dichas variables en la dimensión, con la excepción del ítem 20 (escala Función Social), además de las preguntas del cuestionario 25 y 23. Existen por otra parte algunos ítems del cuestionario (33, 34 y 36, escala Salud General) cuya varianza cuantificada es pequeña y similar en ambas dimensiones (el grado de discriminación entre las categorías de dichas variable en las 2 dimensiones es pequeño), lo que quizás podría indicar su menor idoneidad en el análisis particular de nuestra muestra de pacientes, y por tanto en la problemática abordada, aunque esto requeriría de estudios ulteriores para confirmarse.

La representación gráfica de las medidas de discriminación en el Diagrama de Dispersión generado por las 2 dimensiones obtenidas, permite clarificar aún más, cómo cada dimensión de la solución recoge mayor o menor información (varianza) de cada uno de los ítems del SF36, y representa tanto el factor físico como mentas, como se puede observar en la siguiente figura:

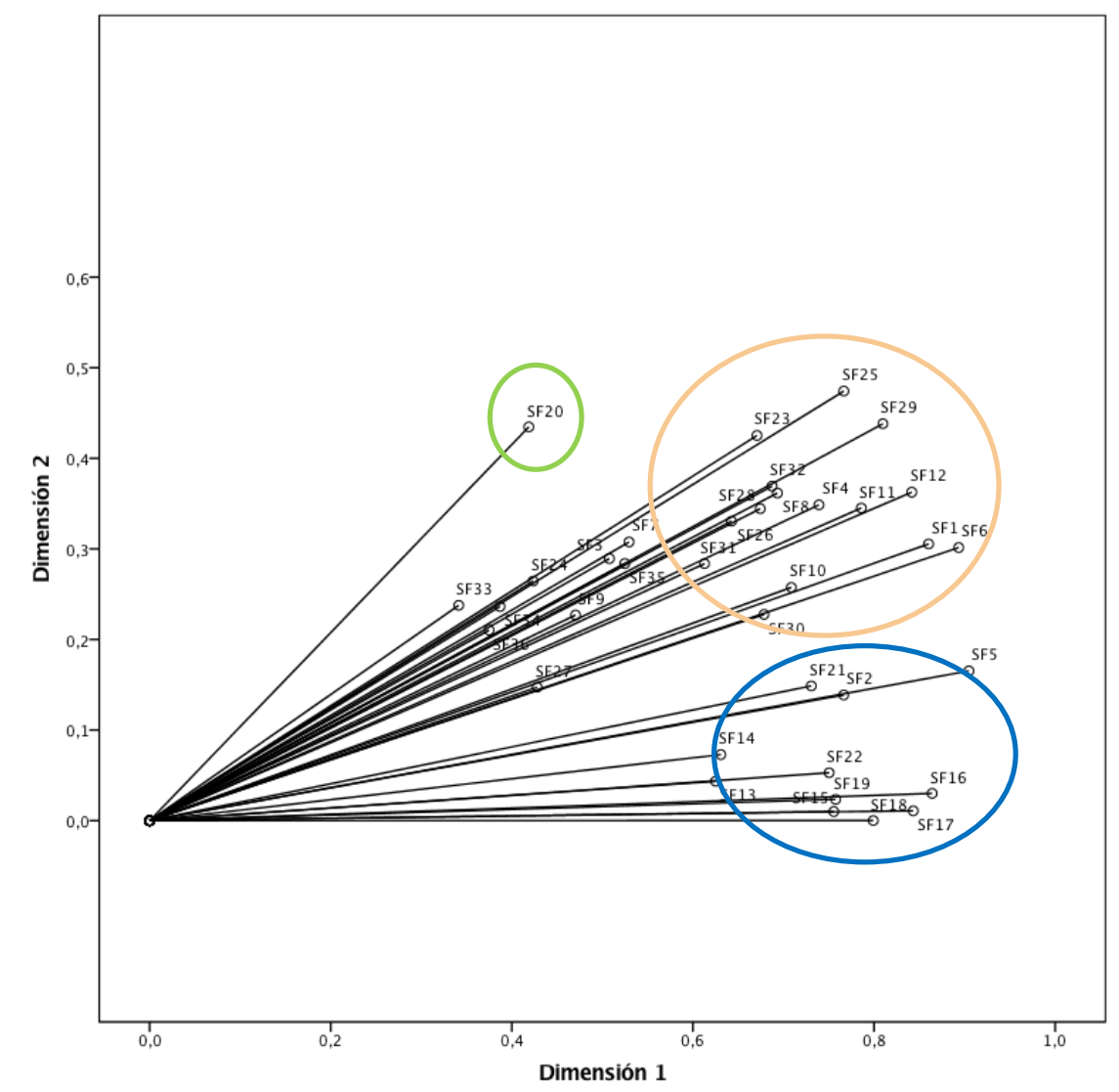

Figura 46: Representación de las Medidas de Discriminación en el plano factorial, que muestra el grado de discriminación entre las categorías de los ítems por cada una de las 2 dimensiones 


\section{RESULTADOS}

En la figura se observa cómo determinadas preguntas contribuyen en esencia a la dimensión 1 (rodeadas con un círculo azul) mientras que otras, aún con medidas de discriminación también elevadas en la primera dimensión, contribuyen también a explicar la dimensión 2 (ítems rodeados en naranja). Mención especial merece la pregunta SF 20 por ser el único ítem del cuestionario que presenta su mayor discriminación en la dimensión 2, dicha variable aparece rodeada en el gráfico mediante un círculo verde. El resto de las variables son aquellas cuya varianza cuantificada en ambas dimensiones es pequeña (y similar), como ya vimos con anterioridad

La representación de los pacientes en el plano factorial determinado por la solución en dos dimensiones del ACM, se muestra en la siguiente figura:

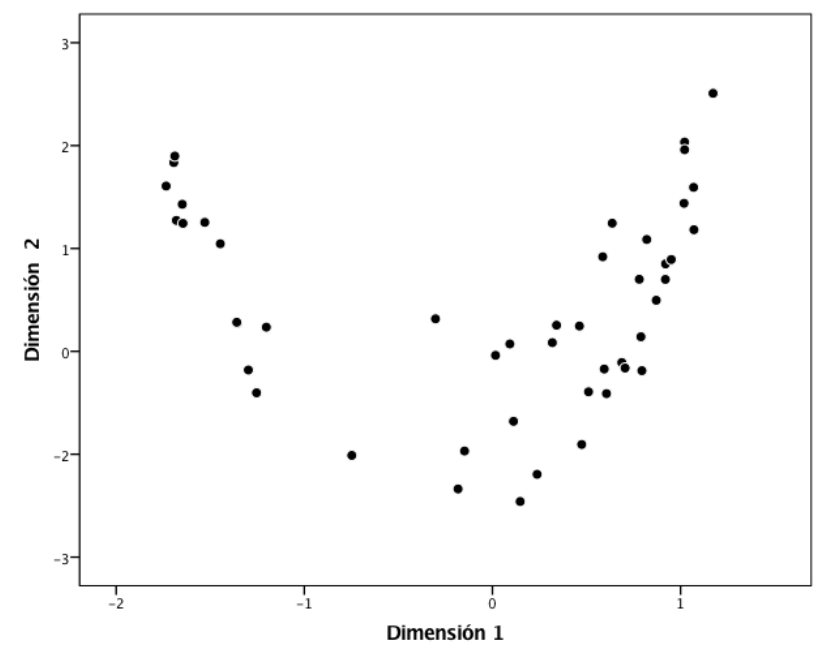

Figura 47: Primer plano factorial de la solución del ACM en la que aparecen representados los pacientes 


\section{RESULTADOS}

La nube de puntos correspondientes a los pacientes ( $\mathrm{u}$ objetos, en la terminología Gifi, adoptada por el SPSS), no se presenta homogénea, si bien tampoco pueden observarse agrupaciones nítidas de los mismos, enumerados por su identificador en el siguiente gráfico.

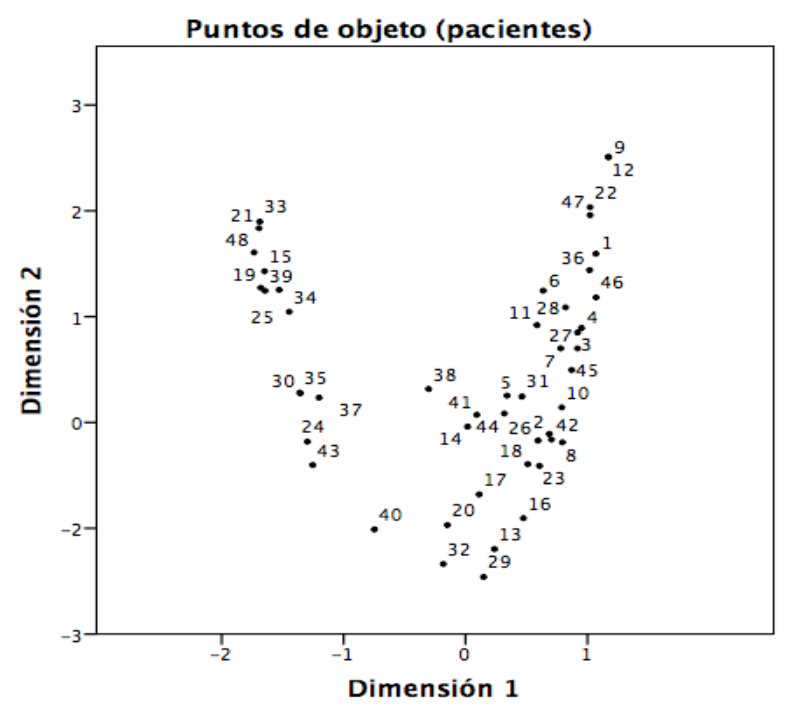

Figura 48: Enumeración de los Pacientes en el primer plano factorial del ACM

Los pacientes se distribuyen prácticamente en todo el plano factorial, por lo que para poder dar interpretación a estos resultados, recurriremos a las preguntas del cuestionario respecto de la dimensionalidad de la solución, así como a las características propias de los pacientes, tales como edad, sexo, patología, tratamiento recibido, etc., características todas ellas implícitas en la solución, y realizar de este modo una discriminación entre individuos, si acaso una tipología de los pacientes. Las limitaciones determinadas por la muestra utilizada y el tamaño de la misma, dificultarán sin embargo esta labor. 


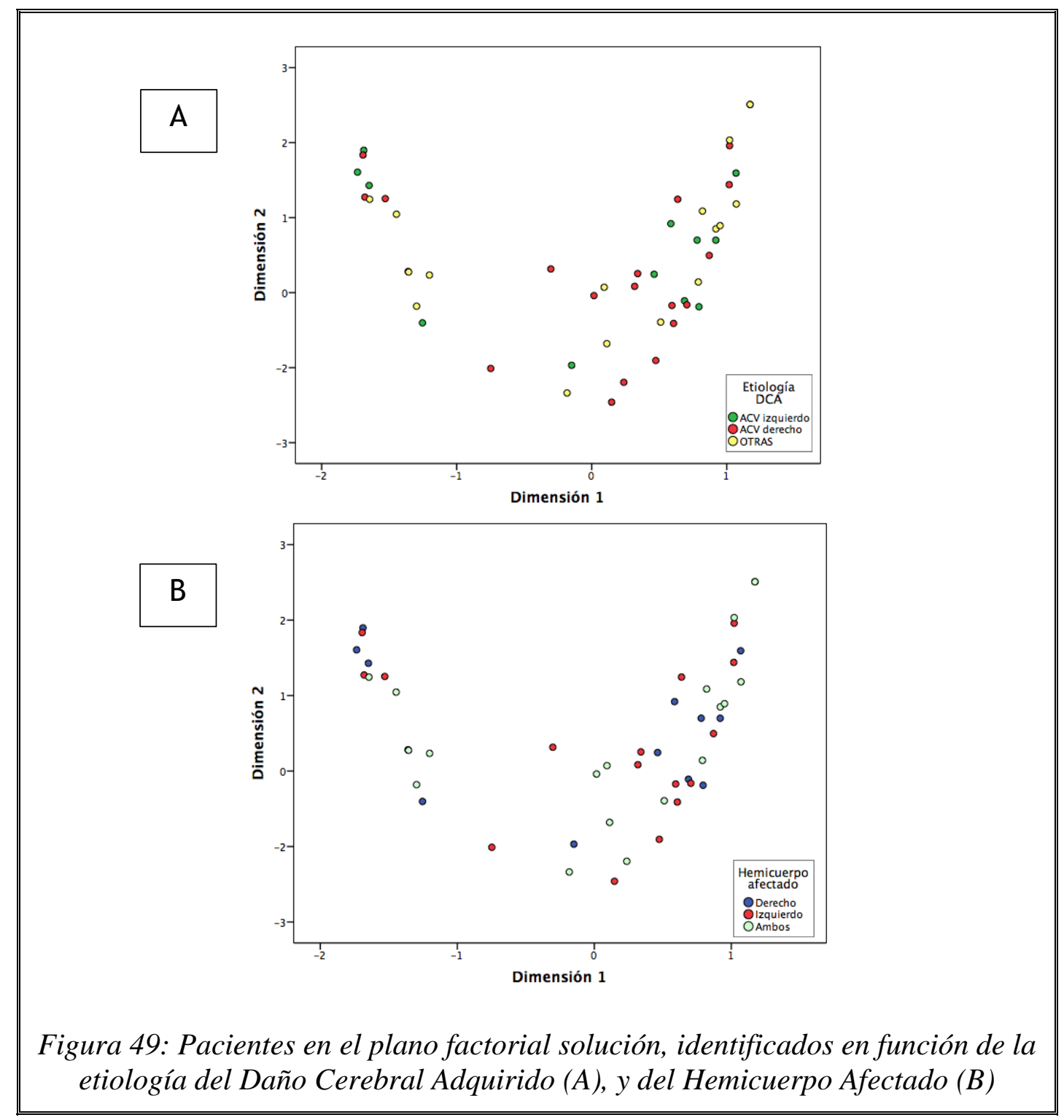

En las figuras anteriores, se observa que el posicionamiento de los pacientes en el plano factorial en relación a su respuesta al cuestionario SF36, parece no estar relacionado directamente con características tales con la etiología del daño cerebral adquirido, o el hemicuerpo afectado, pues los pacientes con categorías diferentes ara ambas características aparecen mezclados a lo largo de la nube de puntos. Como tampoco parecen estar relacionadas con variables tales como el sexo (aunque la mayor parte de los varones se posicionan a la derecha del gráfico), o la antigüedad del daño cerebral, tal y como se muestra en a continuación: 


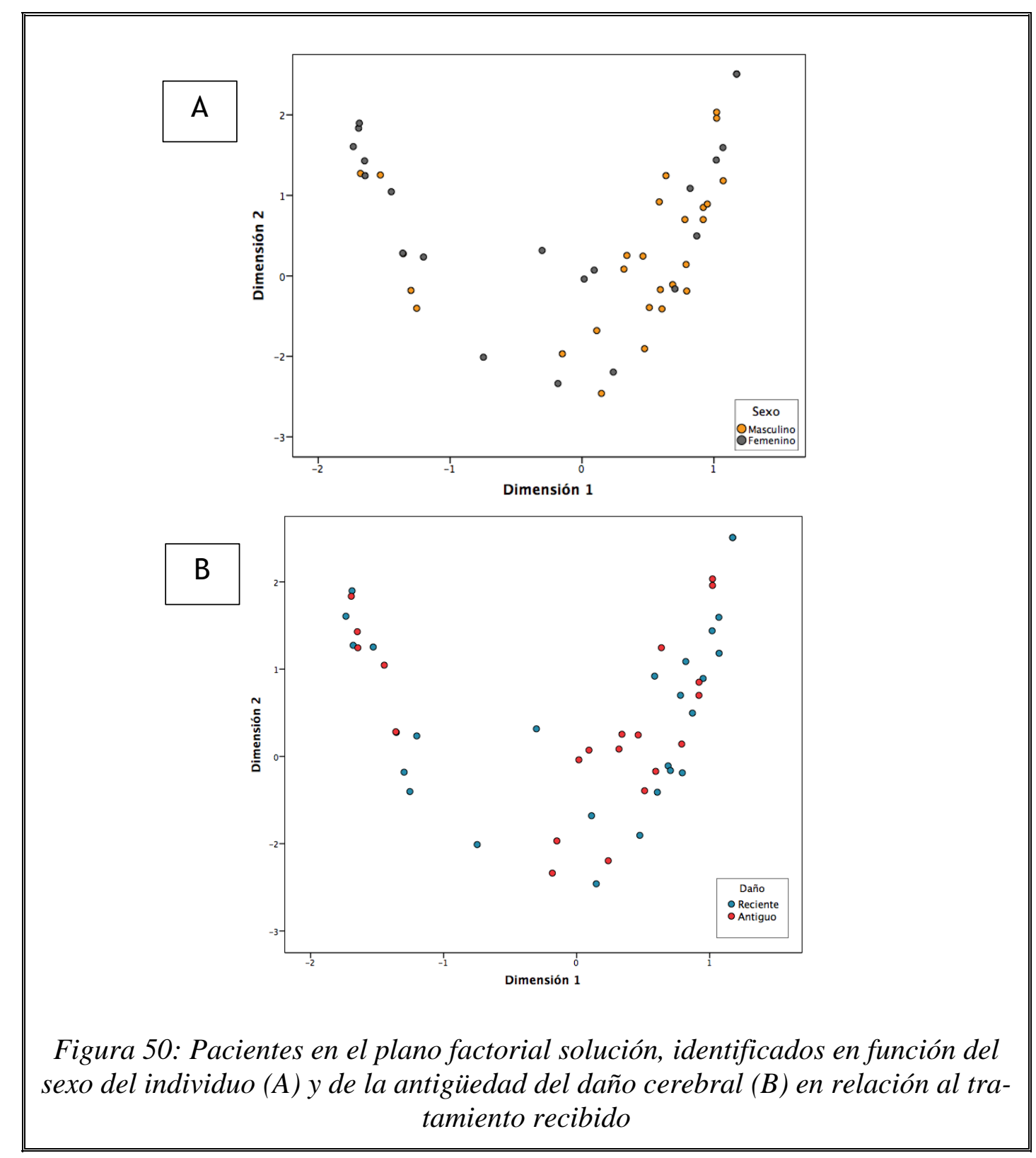

Sin duda una posible explicación a que las nubes de puntos presenten las categorías de las variables no diferenciadas por grupos sea la heterogeneidad de los individuos en relación a las variables consideradas, así como al pequeño tamaño de la muestra analizada, que sugiere la realización de estudios posteriores en los que estos aspectos sean tenidos en cuenta, lo que permitiría la consecución de inferencias más precisas.

Curiosamente, donde si observamos un distinto posicionamiento de los pacientes en el plano factorial solución, es en relación al tratamiento recibido. Como se observa en la siguiente figura, todos los pacientes que recibieron el Tratamiento Vojta aparecen, en relación a su respuesta al cuestionario SF36 que se muestra en dicho plano factorial, en el lado superior derecho de la nube de puntos, y si bien se encuentran 


\section{RESULTADOS}

mezclados con algunos pacientes que recibieron el otro tratamiento de Fisioterapia, están separados de la mayor parte de estos, que se posicionan en el lado inferior y/o izquierdo del plano.

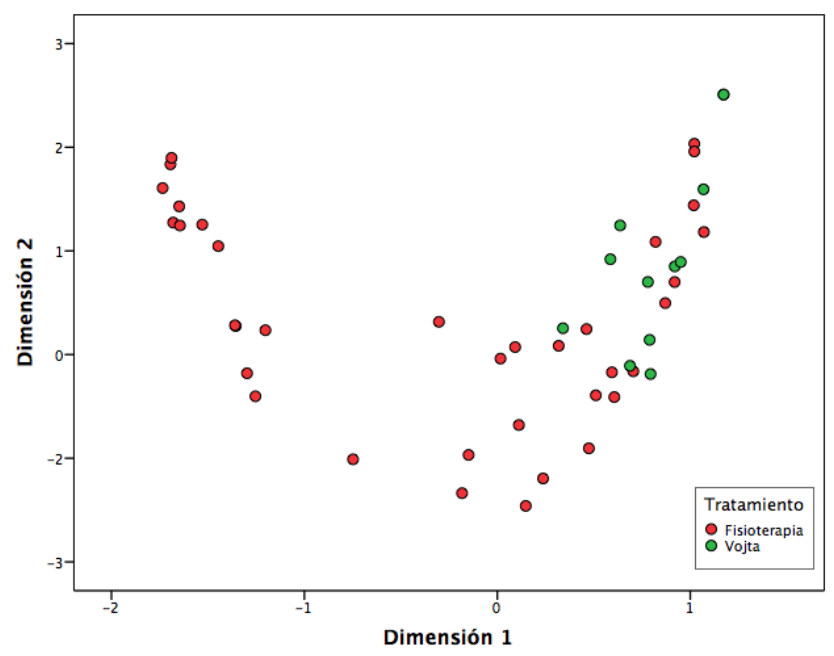

Figura 51: Pacientes en el plano factorial solución identificados en función del Tratamiento recibido.

La explicación a este posicionamiento debemos buscarlo en el mismo plano factorial de dimensión reducida determinado por las dos variables latentes obtenidas en el análisis de correspondencias múltiples. En primer lugar, estudiando las medidas de discriminación de las categorías de los ítems del SF-36 respecto de la dimensión 1, que es en la que se observan diferencias de los pacientes en relación al tratamiento recibido (figura 51).

Además, representando en dicho plano solución otras variables estudiadas y descritas en este estudio (variables suplementarias como son la etiología del DCA, el sexo de los individuos, la antigüedad de aparición o el tratamiento), podemos intentar conocer la importancia que dichas tienen en relación a las dimensiones obtenidas. Esta representación se muestra en la figura siguiente. 


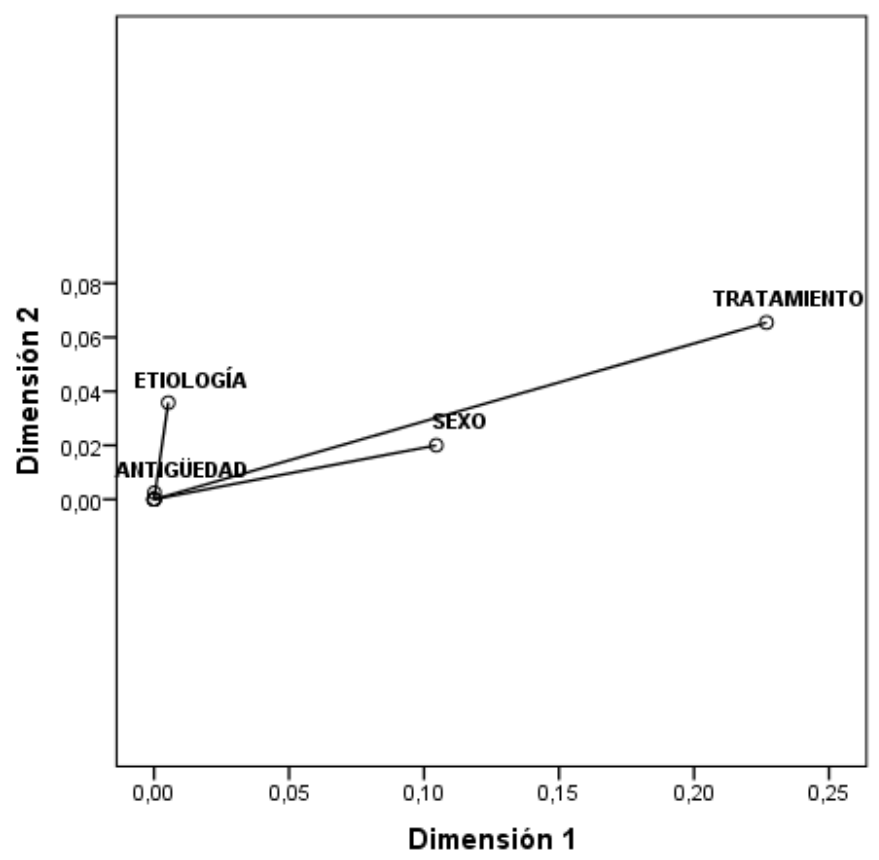

Figura 52: Posicionamiento de las variables Etiología del Daño, Antigüedad de aparición del mismo, Sexo de los pacientes y Tratamiento en el plano de dimensión reducida creado a través del SF-36

Se observa en dicha figura que la variable Tratamiento se encuentra muy relacionada con la primera dimensión, manifestando de este modo que dicha dimensión recoge en gran medida esta información; esta podría ser una explicación por la cual todos los pacientes tratados con el Tratamiento Vojta aparecen en el lado superior derecho de la nube de puntos del plano factorial. Aunque el Sexo también presenta un comportamiento ligado a esta primera componente, sin embargo su implicación es de menor valor. Por otro lado la Etiología del DCA se encuentra relacionada con ambas dimensiones, lo que explicaría la mezcla de los tipos de pacientes en relación a este aspecto; en cuanto a la Antigüedad de aparición, tiene menor importancia en relación a cualquiera de las dimensiones obtenidas.

Adicionalmente, otra forma de explicar el posicionamiento de los individuos, es representando en el plano factorial solución configurado por las dos variables latentes obtenidas tras el ACM, cada una de las variables que recogen la puntuación de las escalas en las que se divide el cuestionario SF-36, tal y como se muestra a continuación. 


\section{RESULTADOS}

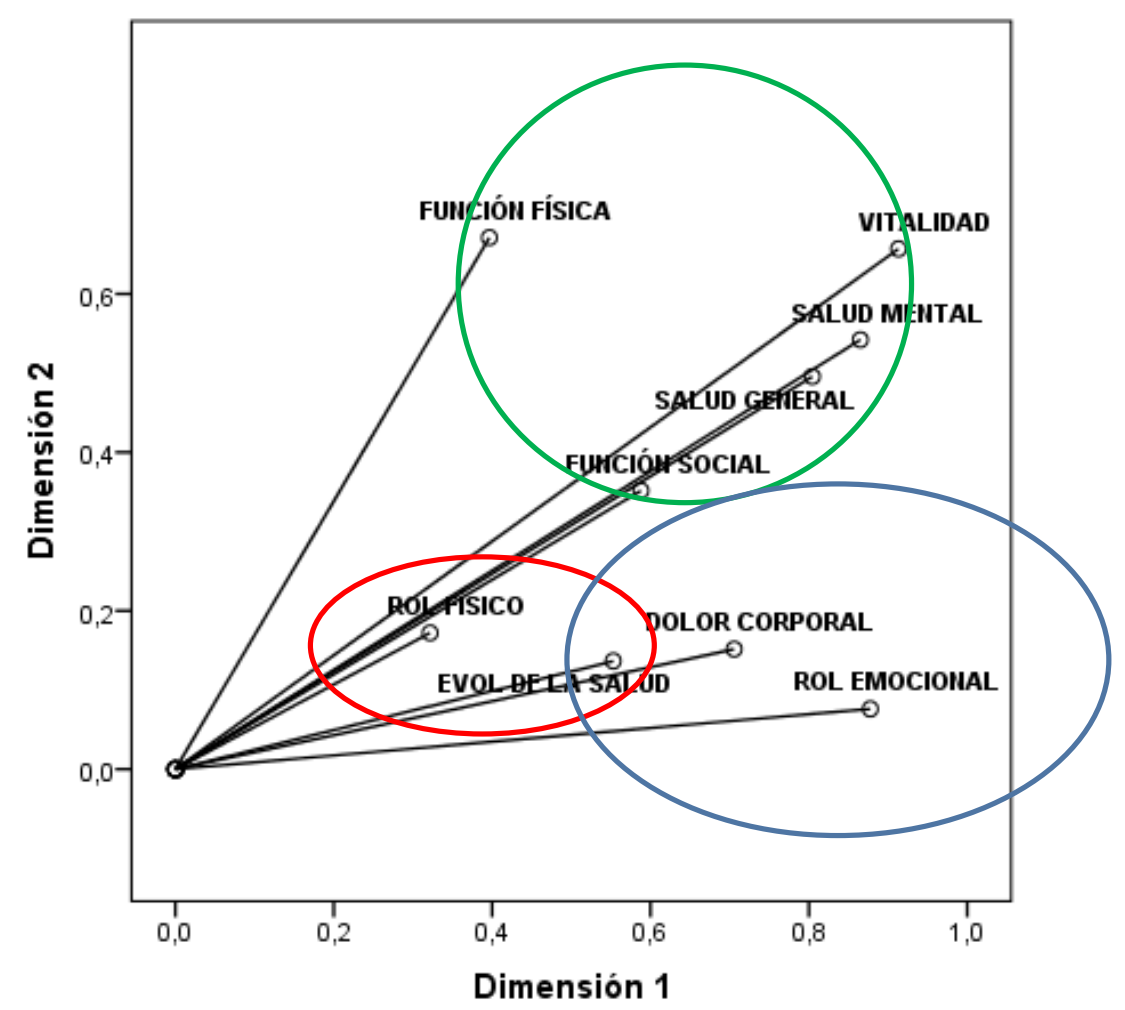

Figura 53: Posicionamiento de las subescalas del SF-36 en el plano de dimensión reducida obtenido a través de las respuestas de los pacientes sobre su salud autopercibida

Así en dicha representación se observa, curiosamente, que los aspectos físicos, (rodeados en rojo), se encuentran implicados en menor medida con las dimensiones del plano, lo cual merece sin duda una reflexión y mayor análisis. Otros aspectos que evalúan el cuestionario como la salud mental, la vitalidad, el estado de salud general y la función social muestran su importancia en relación con ambas dimensiones (rodeadas en verde). El resto de escalas del SF-36 como son dolor corporal, evolución declarada de la salud y rol emocional (rodeadas en azul), quedan recogidas en esencia por la primera dimensión, siendo la evolución de la salud el aspecto menos importante de estos.

Este resultado presenta un gran interés, pues si bien estas variables no han participado en el estudio y por tanto no han condicionado su resultado, es posible sin embargo posicionarlas en el mismo, considerándolas como variables suplementarias. Y es de gran interés el resultado, pues la puntuación de estas variables es calculada a partir de las respuestas del cuestionario SF36, y sin embargo su representación gráfica es absolutamente consistente con la teoría subyacente, y con el posicionamiento de los pacientes en el plano factorial, como tendremos ocasión de comprobar a continuación. 


\section{RESULTADOS}
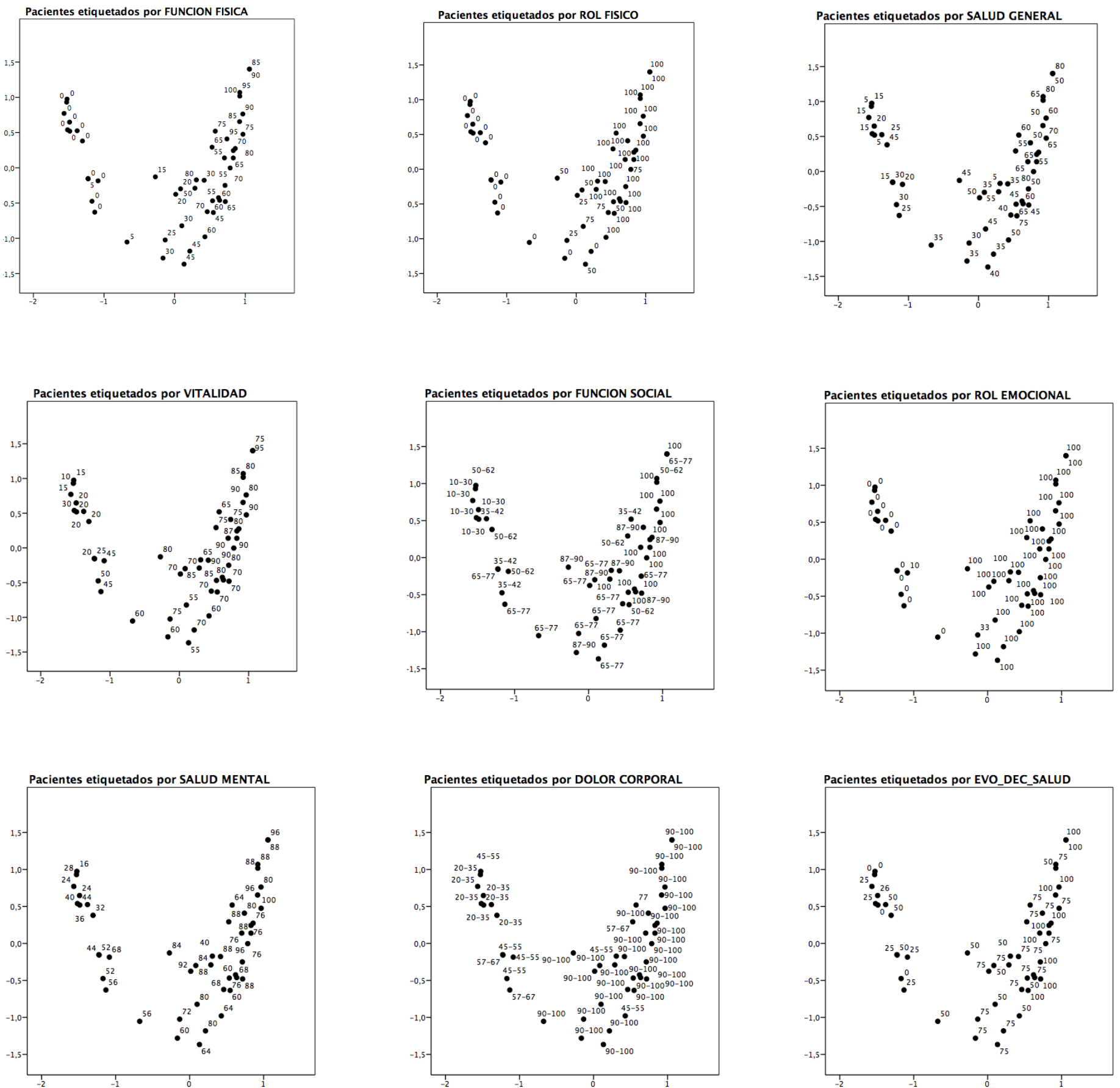

Figura 54: Pacientes etiquetados según las categorías de las escalas del SF-36 


\section{RESULTADOS}

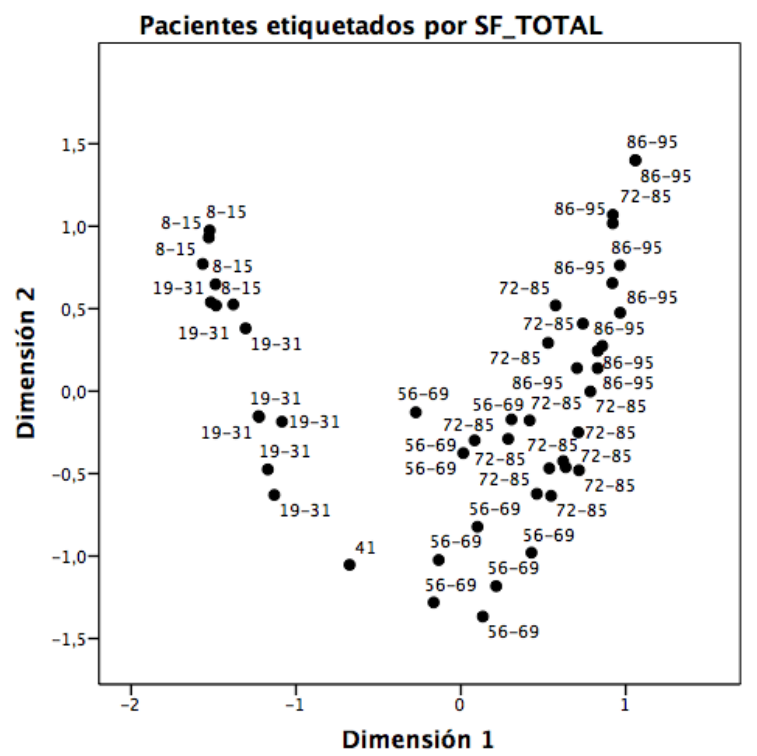

Figura 55: Pacientes etiquetados según la puntuación total obtenida en el SF-36

A raíz de los resultados gráficos obtenidos y presentados previamente, se observa la existencia de un gradiente de percepción de la salud, que en relación a todas las escalas estudiadas, se presenta desde el extremo superior izquierda hasta el extremo superior derecha, describiendo la trayectoria que se muestra en la siguiente figura: 


\section{RESULTADOS}
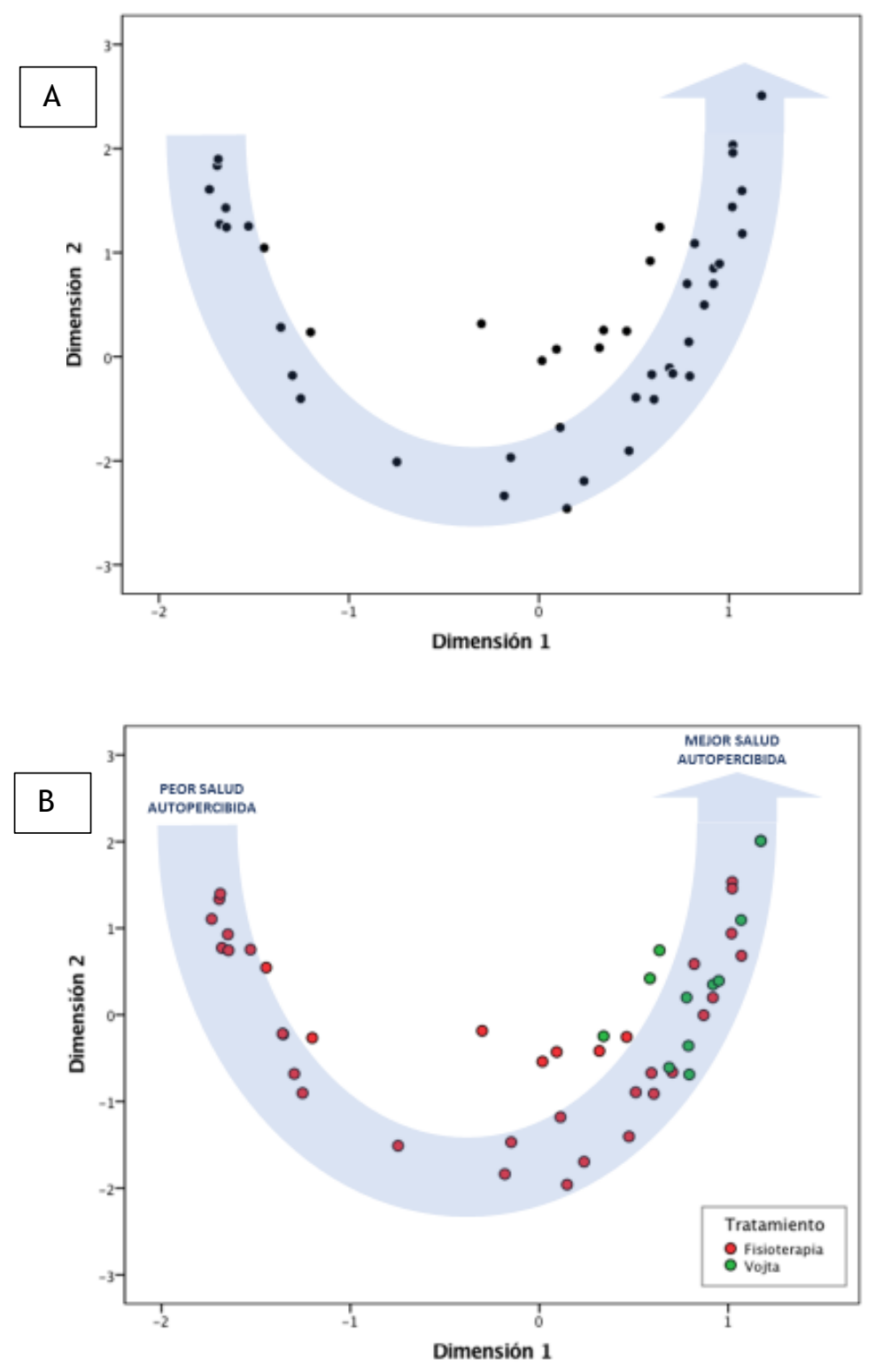

Figura 56: Gradiente de percepción de la salud observado en las escalas del SF-36

A) Conjunto íntegro de los pacientes con DCA

B) Pacientes etiquetados según el tratamiento recibido

Esta sería una evidencia adicional que indicaría que el Tratamiento Vojta presenta resultados esperanzadores en el tratamiento de pacientes con Daño Cerebral Adquirido; puesto que tras nueve meses de intervención obtienen mejores puntuaciones en el nivel de salud autopercibida. 


\section{DISCUSIÓN}

\section{EL DCA: REVISIÓN DE LA LITERATURA 1.1. ANÁLISIS SOCIODEMOGRÁFICO DE LA MUES- TRA}

El Daño Cerebral Adquirido es una entidad clínica con alta prevalencia en la población ${ }^{143.144}$. Sólo en nuestro país, de acuerdo con el informe que realizado por FEDACE (Federación Española de DCA) con la colaboración del Real Patronato sobre Discapacidad durante el año 2015; en España viven 420.000 personas con Daño Cerebral Adquirido. El 78\% de los casos tuvieron su origen en un ictus y el 22\% restante en traumatismos craneoencefálicos y otras causas. Cada año se dan 104.071 nuevos casos de Daño Cerebral Adquirido: 99.284 por accidentes cerebrovasculares, 4.937 por TCEs y 481 por anoxias.

Haciendo una clasificación etaria, el 65,03 \% de las personas con DCA son mayores de 65 años, dato que se relaciona con la alta incidencia del ictus en un colectivo en el que la mayor parte del mismo (el 52\%) son mujeres ${ }^{143}$.

De acuerdo con estos datos, el DCA es una entidad clínica frecuente en la sociedad actual. Se ha considerado importante por tanto desarrollar un estudio que quizás pueda aportar posibilidades terapéuticas que ayuden al tratamiento de la misma.

Contrastando los resultados sociodemográficos obtenidos por FEDACE con los del presente estudio, se observa que, efectivamente, en ambos casos la etiología predominante en el DCA es el ACV. En nuestro trabajo concretamente el 66,7\% de los varones y el $65 \%$ de las mujeres presentaron esta etiología. Además, la segunda causa más frecuente (aunque mucho menos relevante que el ictus) fueron tanto en el informe de la federación española de DCA como en nuestro estudio los TCE. Recordaremos que de acuerdo a nuestros resultados el 13,3\% de los hombres y el 15\% de las mujeres desarrollaron un DCA postTCE, siendo ésta la segunda causa más frecuente de aparición.

En cuanto a la frecuencia de aparición por sexos, en el presente estudio el $60 \%$ de los participantes fueron hombres y el $40 \%$ mujeres, lo que difiere con el predominio de aparición del DCA en mujeres, según los datos anteriormente descritos. 


\section{DISCUSIÓN}

Esquemáticamente:

\begin{tabular}{|c|c|c|c|}
\hline Prevalencia & Informe FEDACE & \multicolumn{2}{|c|}{ Nuestra experiencia } \\
\cline { 3 - 4 } & & hombres & mujeres \\
\hline 10 ACV & $78 \%$ & $66,7 \%$ & $65 \%$ \\
\hline 20 TCE y otros & $22 \%$ & $33,3 \%$ & $35 \%$ \\
\hline
\end{tabular}

Tabla 46: Comparación de la etiología del DCA según el informe de FEDACE y nuestra experiencia

\begin{tabular}{|c|c|c|}
\hline Prevalencia & Informe FEDACE & Nuestra experiencia \\
\hline Hombres & $48 \%$ & $60 \%$ \\
\hline Mujeres & $52 \%$ & $40 \%$ \\
\hline
\end{tabular}

Tabla 47: Comparación de la prevalencia del DCA por sexos según el informe de FEDACE y nuestra experiencia

\subsection{LA SUBLUXACIÓN GLENOHUMERAL: CAUSA DE RIGIDEZ DE HOMBRO}

Han sido muchos los autores que han intentado explicar las causas de la subluxación glenohumeral y de la rigidez de hombro asociada.

La subluxación glenohumeral sucede cuando se compromete la integridad mecánica de la articulación gleno-humeral causando una diferencia palpable entre el acromion y la cabeza del húmero ${ }^{177}$.

La articulación gleno-humeral es multiaxial y tiene un rango de movimiento que supera el de otras articulaciones como el codo o la rodilla. Para lograr esta movilidad, la articulación gleno-humeral compensa su baja estabilidad ósea con estabilidad muscular ${ }^{177}$ de esta forma la afectación del funcionamiento normal de la musculatura, como ocurre después de un ictus con afectación motora, condiciona un riesgo potencial para la subluxación.

De manera habitual, durante el período inicial tras un ictus, el brazo hemipléjico se encuentra flácido o hipotónico. Por ello, la musculatura del hombro ya no puede mantener la cabeza del húmero en la fosa glenoidea y hay un alto riesgo de subluxación del hombro. Durante este período la extremidad afecta debe estar bien apoyada ya que el propio peso del brazo puede ser suficiente para dar lugar a la subluxación del hombro. La adopción de posturas incorrectas en decúbito (cama), realizar trasferencias, la falta de apoyo mientras el paciente se encuentra en bipedestación, etc. facilitan la subluxación articular. 
Creutzfeldt CJ et al, (2012) ${ }^{159}$. realizaron una revisión sistemática a cerca de lo publicado en relación con el DCA. Las referencias para esta revisión se identificaron a través de las búsquedas de PubMed en inglés, español y alemán con el término de búsqueda stroke combinado con los términos respectivos dolor central, dolor de hombro hemipléjico, rigidez, espasticidad, fatiga, incontinencia, ataques posteriores al accidente cerebrovascular, disfunción sexual, trastornos del sueño, respiración, depresión, ansiedad y emocionalismo. La búsqueda se limitó en un principio para revisar artículos, guías de práctica clínica y ensayos controlados aleatorios, así como los publicados después de 1995, también se tuvieron en cuenta los artículos que recogían en sus propios archivos.

En lo que concierne a nuestro estudio, nos centraremos únicamente en la parte relacionada con el hombro. En este metaanálisis se determinó que la rigidez de hombro generalmente se desarrolla semanas o pocos meses después del accidente cerebrovascular ${ }^{160}$. La prevalencia de esta secuela aumenta con el grado de deterioro motor situándose en el $83 \%$ en sujetos con baja función motora, siendo el resultado de déficits sensoriales y motores, subluxación articular y rango de movimiento pasivo limitado $^{160}$.

Los tratamientos propuestos para vencer la rigidez, el dolor y la espasticidad en este caso fueron la terapia física con movimientos pasivos y el fortalecimiento de la cintura escapular ${ }^{161}$, pero no hay evidencia disponible de que la intervención reduzca el dolor o mejore la Resonancia Magnética (RM) en el hombro hemipléjico ${ }^{160}$. El tratamiento con inyección intramuscular de toxina botulínica tipo A, las inyecciones de esteroides intraarticulares y la estimulación eléctrica neuromuscular sugieren una buena recuperación funcional con la mayoría de los pacientes mejorados e incluso sin dolor a los 6 meses $^{162.163 .164}$.

\subsection{GHS Y DOLOR DE HOMBRO ASOCIADO}

Las investigaciones clínicas realizadas hasta el momento son controvertidas según la revisión realizada por Murie-Fernández et al. ${ }^{177}$.

Unas apoyan ${ }^{180}$ y otras refutan ${ }^{181}$ la existencia de una asociación entre la subluxación y GHS. Los tamaños muestrales pequeños y las diferencias en los métodos de evaluación han obstaculizado los estudios en esta área ${ }^{182}$.

La subluxación del hombro se asocia con dolor ${ }^{183}$. Sin embargo, no todos los pacientes hemipléjicos con subluxación experimentan dolor en el hombro y la idea de que esta subluxación es una causa de dolor en el hombro hemipléjico sigue siendo controvertida $^{182,183}$. Cailliet ${ }^{179}$ añadió que en la etapa flácida, la escápula asume una posición inferior y de rotación, ya que el músculo serrato está paralizado y la parte superior del músculo trapecio ya no sujeta la escápula. Así, la combinación de la flacidez de la musculatura de apoyo y la baja posición de la escápula predisponen a la subluxación de la cabeza del húmero en sentido inferior respecto a la fosa glenoidea. 


\section{DISCUSIÓN}

Sin embargo, Prevost et al ${ }^{166}$ concluye que la posición de la escápula no es un factor importante en la aparición de la subluxación inferior en hemiplejía y Price et al. ${ }^{169}$ observaron que la subluxación en pacientes con infarto cerebral no tenía relación con la posición de reposo escapular.

A la vista de nuestros resultados debemos decir que, según los criterios de inclusión empleados, no es necesario tener un dolor inicial para tener patología de movimiento restrictivo en la articulación glenohumeral, puesto que los pacientes que participaron en el estudio, en el momento inicial no presentaban dolor en el complejo articular del hombro.

En los estudios mencionados en el apartado 1.2.1, la población de referencia es únicamente la que ha sufrido $\mathrm{ACV}$, sin embargo en nuestro trabajo incluimos diversas etiologías de DCA. No obstante, no debemos olvidar que el ACV constituye la causa más frecuente de DCA en adultos a nivel mundial y en España ${ }^{143.144}$, hecho que concuerda con la etiología del DCA predominante en nuestro trabajo.

Cabe mencionar también que los pacientes de nuestro estudio se encontraban en periodo de rehabilitación, habiendo superado la fase aguda del episodio de DCA. 


\section{LA METODOLOGÍA VOJTA COMO TRATAMIENTO DEL HOMBRO AFECTADO POR CAUSA NEUROLÓ- GICA}

La terapia Vojta se ha empleado en numerosas ocasiones como tratamiento de afectaciones de origen neurológico ${ }^{24.25 .158}$.

En el caso de lesiones de afectación de miembro superior, merece una mención especial el estudio de Perales López "Efecto de la terapia de locomoción refleja combinada con el tratamiento de fisioterapia en lesión medular" 158 en el que se indica que en el caso de un paciente afectado de lesión medular, tras 6 meses de tratamiento, se consigue aumentar el balance articular de hombros en abducción de $43^{\circ}$ en el hombro derecho a $127^{\circ}$ y en el izquierdo de 81 a $118^{\circ}$, estando situado el paciente durante la medición en sedestación. En el ÍB ${ }^{108.109 .111 .111}$ sus resultados fueron de 0 a 35 puntos; lo que significa que el paciente pasó de un nivel de dependencia total (puntuación 0 en el IB) a una puntuación de 35 equivalente a un nivel de dependencia severa.

\begin{tabular}{|c|c|c|c|c|}
\cline { 2 - 5 } \multicolumn{1}{c|}{} & \multicolumn{2}{c|}{ Perales López } & \multicolumn{2}{c|}{ Nuestra experiencia: Tratamiento } \\
Vojta
\end{tabular}

Tabla 48. Comparación de los resultados de Perales López con los obtenidos en nuestro estudio en el grupo 1

Comparando este resultado con el que se obtiene de la valoración articular y del IB de los individuos del grupo 1 (sometidos a terapia con metodología Vojta) se observa que:

En nuestro caso, los pacientes sometidos a terapia Vojta partían de una puntuación media de 67.08 puntos al inicio del tratamiento (dependencia moderada) y a los 9 meses su puntuación total fue de 85.00 puntos (dependencia escasa), siendo el incremento total de 17.92 puntos.

A la vista de la tabla anterior podemos decir que nuestros pacientes afectados del hemicuerpo derecho presentan un rango articular en abducción de hombro mayor que el paciente del estudio presentado por Perales, si bien es cierto que partían de un mejor balance articular inicial. En cuanto a los individuos afectados del hemicuerpo izquierdo de nuestro estudio, alcanzan valores muy similares en la separación de hombro final, aunque los de nuestro estudio partían de mejores condiciones. 


\section{LA FNP COMO TRATAMIENTO DEL HOMBRO AFECTADO POR CAUSA NEUROLÓGICA}

En el estudio de Álvarez $M F^{186}$ titulado "Evaluación y Tratamiento De síndrome de hombro doloroso en hemiplejía” se muestra la evolución del balance articular pasivo de hombro en pacientes que sufrieron un ACV tras un tratamiento de 8 semanas con fisioterapia neurológica en Mar de Plata, Argentina, basado en la FNP.

Los resultados en el miembro superior afecto que presentaron los pacientes, gráficamente, fueron:

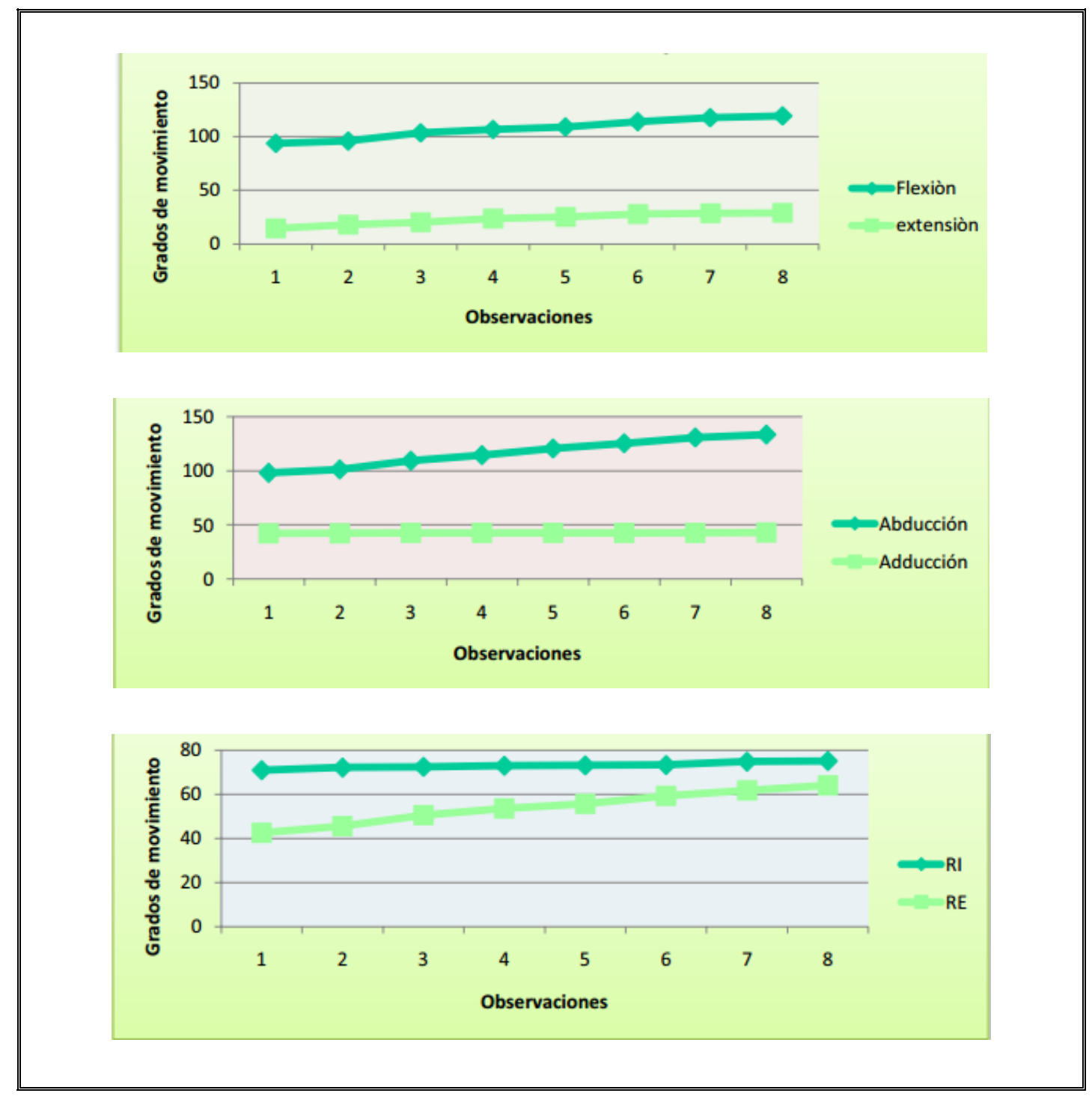

Figura 57: Resultados de Álvarez MF en el tratamiento del miembr superior afecto por causa neurológica ${ }^{186}$ 
Mientras que los nuestros presentaron una puntuación media inicial y final que se recoge en la siguiente tabla:

\begin{tabular}{|c|c|c||c|c|c|}
\hline \multicolumn{5}{|c|}{ Grupo 2 } \\
\hline \multicolumn{5}{|c|}{ Codo afectado } \\
\cline { 1 - 1 } Derecho & \multirow{2}{*}{ Izquierdo } & \multirow{2}{*}{ Comparativa } \\
\cline { 1 - 1 } \multicolumn{2}{|c|}{ Valor goniometría } & & Valor goniometría & \\
\hline ABD_1 & 79,66 & menor & ABD_1 & 78,84 & menor \\
\hline ABD_3 & 91,38 & menor & ABD_3 & 83,53 & menor \\
\hline FLEX_1 & 84,48 & menor & FLEX_1 & 74,58 & menor \\
\hline FLEX_3 & 97,72 & menor & FLEX_3 & 86,32 & menor \\
\hline EXT_1 & 14,83 & igual & EXT_1 & 17,63 & igual \\
\hline EXT_3 & 27,48 & igual & EXT_3 & 23,16 & igual \\
\hline ROTE_1 & 40,34 & igual & ROTE_1 & 35 & menor \\
\hline ROTE_3 & 56,03 & menor & ROTE_3 & 51,32 & menor \\
\hline ROTI_1 & 29,14 & menor & ROTI_1 & 20,79 & menor \\
\hline ROTI_3 & 42,03 & menor & ROTI_3 & 35,32 & menor \\
\hline
\end{tabular}

$A B D$ 1: separación inicial; $A B D \_3:$ separación final; FLEX_1: flexión inicial; FLEX_3: flexión final; EXT_1: extensión inicial; EXT_3: extensión final; ROTE_1: rotación externa 1; ROTE_3: rotación externa final; ROTI_1: rotación interna 1; ROTI_3: rotación interna final

Tabla 49: comparación del estudio de Álvarez $M F^{186}$ con nuestra experiencia en el grupo 2

Comparando los resultados del estudio mostrado con los que hemos obtenido en nuestro caso, podemos decir lo siguiente.

Ante la misma terapia de FNP los pacientes del grupo 2 de nuestro estudio, a pesar de estar en tratamiento durante 9 meses, alcanzan valores finales muy inferiores en la goniometría de hombro para la prueba de abducción (tanto en el hemicuerpo derecho como en el izquierdo) y en la valoración de la flexión de hombro.

Nuestros resultados también son menores para los valores de rotación externa e interna si los comparamos con el estudio anterior, tanto en individuos afectados del hemicuerpo izquierdo como derecho.

Sin embargo los resultados en extensión de Álvarez $M F$ son muy similares a los obtenidos en nuestro estudio: no se observa un gran aumento del valor total y el resultado final es similar, estando los nuestros durante 9 meses en tratamiento y los anteriores tan sólo 8 semanas.

No obstante habría que determinar qué protocolo exacto de FNP se ha seguido en el estudio de Álvarez MF así como el grado de interacción con otras terapias.

Comparando los resultados del estudio en Mar de Plata con los que hemos obtenido de los individuos sometidos a tratamiento con terapia Vojta. 


\begin{tabular}{|c|c|c|c|c|c|}
\hline \multicolumn{6}{|c|}{ Grupo 1} \\
\hline \multicolumn{6}{|c|}{ Lado afectado } \\
\hline \multicolumn{2}{|c|}{ Derecho } & \multirow{2}{*}{$\begin{array}{l}\text { Compara- } \\
\text { tiva }\end{array}$} & \multirow{2}{*}{\multicolumn{2}{|c|}{$\begin{array}{c}\text { Izquierdo } \\
\text { Valor goniometría }\end{array}$}} & \multirow[t]{2}{*}{ Comparativa } \\
\hline Valor gol & metría & & & & \\
\hline ABD_1 & 96,43 & igual & ABD_1 & 98 & igual \\
\hline ABD_3 & 124,86 & menor & ABD_3 & 117,40 & menor \\
\hline FLEX_1 & 127,14 & mayor & FLEX_1 & 117 & mayor \\
\hline FLEX_3 & 143,57 & mayor & FLEX_3 & 131,8 & mayor \\
\hline EXT_1 & 35,71 & menor & EXT_1 & 27,60 & menor \\
\hline EXT_3 & 37 & igual & EXT_3 & 34,50 & igual \\
\hline ROTE_1 & 47,14 & Igual & ROTE_1 & 42 & igual \\
\hline ROTE_3 & 74,29 & mayor & ROTE_3 & 71,90 & mayor \\
\hline ROTI_1 & 41,43 & menor & ROTI_1 & 37,50 & menor \\
\hline ROTI_3 & 54,43 & menor & ROTI_3 & 64,70 & menor \\
\hline
\end{tabular}

$A B D$ 1: separación inicial; $A B D$ 3: separación final; FLEX 1: flexión inicial; FLEX 3: flexión final; EXT_1: extensión inicial; EXT_3: extensión final; ROTE_1: rotación externa 1; ROTE_3: rotación externa final; ROTI_1: rotación interna 1; ROTI_3: rotación interna final Tabla 50: comparación del estudio de Álvarez $M F^{186}$ con nuestra experiencia en el grupo 1

Comparando los individuos del grupo 1 de nuestro trabajo con los del estudio anterior vemos que, al igual que ocurría con el grupo 2; la extensión final es similar en todos los casos, aumentando poco su valor total, que en condiciones normales según Kapandji ${ }^{8}$ podría tomar valores de $50^{\circ}$. A pesar de que en este caso los individuos del grupo Vojta de nuestro estudio partían de una extensión menor, tanto aquellos afectados del hemicuerpo derecho como del izquierdo.

Sin embargo la abducción, a pesar de ser similar al inicio, en 9 meses no consigue aumentar tanto como lo hace en los individuos del estudio anterior en tan sólo 8 semanas. Por su parte la flexión aumenta más en los sujetos de nuestro estudio, si bien es cierto que se partía de un valor inicial más elevado.

Interesante es conocer el dato de la rotación externa, cuyos valores iniciales son similares en ambos casos (grupo Vojta de nuestro estudio e investigación de Álvarez $M F$.) pero sin embargo alcanza valores más altos en los individuos sometidos a terapia Vojta.

La rotación interna es menor al inicio en ambos hemicuerpos en los sujetos del grupo 1 de nuestro estudio y lo es también a los 9 meses de tratamiento.

En este punto es importante recordar que en nuestro trabajo los individuos que se sometieron al tratamiento con FNP afectados del hemicuerpo izquierdo cuya etiología del DCA fue un ACV (figura 25A) o de hemicuerpo derecho (figura 33A) presentan una ganancia menor en el rango articular que los individuos con etiología similar que se sometieron al tratamiento Vojta (figuras $21^{\mathrm{a}}$ y $29^{\mathrm{a}}$ )<. 


\section{IB/MIF PRONÓSTICO ${ }^{187}$}

Algunos autores ${ }^{188}$ consideran un mal pronóstico funcional los valores iniciales de Barthel $<20$ y de FIM <40 en pacientes con afectación neurológica.

En nuestro caso el valor inicial en el IB en el grupo 1 fue de 67,08 mientras que en el grupo 2 fue de 38,21 por lo que los sujetos de nuestro estudio no estaban considerados como de mal pronóstico.

Este mismo grupo de investigación ${ }^{188}$ propone correlacionar la puntuación en el IB con el grado de dependencia/independencia para las AVBD (entendiéndose que el individuo independiente es aquel que obtiene 85 o más puntos en el IB) utilizando el Barthel inicial frente al grado de dependencia previa al ACV.

\begin{tabular}{|l|l|l|l|}
\hline \multicolumn{2}{|l|}{ IB $<20$} & IB $>20$ \\
\hline Independencia previa & $77 \%$ & Independencia previa & $96 \%$ \\
\hline
\end{tabular}

Tabla 51: relación entre el IB y el nivel de independencia previo

Según los resultados de nuestro trabajo, el IB inicial fue superior a 20 en ambos grupos,

Es decir, de acuerdo con este trabajo, alrededor del $96 \%$ de los sujetos de nuestro estudio tendrían independencia previa al DCA. (Es decir, un IB superior a 95 puntos).

\section{RESULTADOS GONIOMÉTRICOS OBTENIDOS CON LA TERAPIA VOJTA ${ }^{4.24}$}

De acuerdo a los principios de la terapia Vojta ${ }^{4}$, la locomoción refleja origina una serie de relaciones musculares en el hombro (activación de determinados músculos) que hacen que se produzcan los movimientos en la cintura escapular. Dichos movimientos ocurren de manera distinta en el lado facial y en el lado nucal, dependiendo de hacia dónde esté orientada la cabeza del individuo.

En la reptación refleja el hombro es la articulación más importante sobre la que se desarrolla todo el mecanismo de la $\mathrm{RR}^{24}$.

En el brazo facial junto con la cintura escapular se produce la función de apoyo para el tronco. Así la cintura escapular es enderezada sobre ese hombro en sentido axial (antigravitatorio). En primer lugar se produce una adducción de la escápula y un centramiento de la articulación del hombro con rotación externa, abducción y flexión de hombro. El punto fijo en este momento es la columna vertebral a través de los músculos trapecio medio y romboides. El movimiento se produce únicamente hasta que se constituye el apoyo sobre el codo. 


\section{DISCUSIÓN}

La cabeza y el tronco son impulsados hacia delante sobre el hombro en dirección al brazo facial, en sentido lateral y craneal.

Particularizando en cada uno de los músculos implicados, podemos decir lo siguiente:

- Los músculos redondo menor, supraespinoso e infraespinoso se implican en la rotación externa para colocar al húmero en un movimiento fásico.

- El pectoral mayor, como músculo aproximador y rotador interno hace la aducción del húmero hasta que se forma apoyo.

- El dorsal ancho, el deltoides (fibras posteriores) y la porción larga del tríceps braquial hacen la extensión de hombro para formar el punto de apoyo.

- El braquial anterior y el bíceps braquial se encuentran en oposición al tríceps. La resultante es que el codo no se flexiona ni se extiende si la posición de partida es superior a los $90^{\circ}$ de flexión de codo. Por eso el ángulo en la posición de partida (que son $45^{\circ}$ ) es determinante.

Todos ellos, en movimiento fásico, hacen lo posible por mover el epicóndilo medial hasta que éste se puede mover, cuando el movimiento alcanza el máximo posible cambian su punto fijo y se orientan hacia el codo.

Una vez que el codo se encuentra en equilibrio y en el hombro no se va a producir más movimiento los puntos de apoyo se dirigen al codo.

- La escápula ahora va hacia lateral y craneal y la glenoides se pone sobre la cabeza del húmero, el bíceps y el tríceps en sinergia tiran hacia el codo en una función enderezadora.

- Los rotadores externos también contribuyen al movimiento de la escápula porque tienen apoyo en el codo y tiran de su inserción escapular. No pueden ir a rotación interna porque están activados en el húmero hacia la rotación externa.

- El pectoral mayor ya no puede dirigir su contracción hacia la adducción ni rotación interna porque el punto fijo se dirige a rotación externa. La tendencia es a aproximar el tronco al punto fijo en el hombro. Sin embargo no puede hacerlo porque están activos en contra el trapecio inferior y los músculos que orientan las apófisis espinosas hacia el punto de apoyo. La escápula se constituye como una estructura intermedia entre la columna vertebral y el codo.

- El romboides hace de punto fijo en la escápula y tracciona de las espinosas hacia el punto de apoyo.

- El dorsal ancho sostiene el tronco en el eje transversal. Su función es la de extender y rotar internamente pero con el brazo como punto de apoyo tira de las espinosas hacia el apoyo (codo) y de la pelvis hacia craneal. El dorsal ancho sostiene el tronco en el eje transversal hacia rotación interna y extensión pero con el codo como punto fijo de apoyo tirará de las espinosas hacia el apoyo y de la pelvis hacia craneal.

- El serrato anterior toma punto fijo en la escápula y tira del tórax hacia craneal y aproxima las costillas hacia la escápula. 
- El bíceps y el tríceps del lado facial toman como punto fijo el codo para movilizar girar la escápula sobre la cabeza humeral (en sentido lateral, ventral y craneal).

- El deltoides del lado facial dirige también su contracción hacia el codo, elevando así el ángulo inferior de la escápula.

El punto de apoyo de todo el proceso es el codo. Cuando se produce el apoyo en el codo, se observa el antebrazo en pronación con desviación radial de muñeca, flexión dorsal de muñeca, abducción de los metacarpianos, dedos en flexión y abducción con oposición del pulgar. El antebrazo y la mano quedan en descarga.

Los rotadores internos y externos de hombro equilibran su fuerza de tal manera que la posición patológica del brazo en rotación interna no se provoca tan fácilmente debido a que mediante la RR no prevalece la potencia de los rotadores internos.

En el brazo nucal la respuesta esperada sin embargo es la de avance. Se produce por tanto la adducción de la escápula (el ángulo inferior de la misma va hacia la abducción); se flexiona el hombro y se producen la abducción y rotación externa.

En el codo se produce una semiflexión, el antebrazo supina y la muñeca va a flexión dorsal con desviación radial y separación de los metas.

Tras conocer estas activaciones musculares, se plantea lógico correlacionar las respuestas esperadas con la terapia de la locomoción refleja, con los resultados obtenidos en nuestro estudio.

Se observa que los músculos rotadores de hombro (internos y externos) se activan en gran medida como centradores de la cabeza humeral en el brazo facial y hacen que el balance articular de hombro para estos movimientos aumente.

La abducción y la flexión, a pesar de obtenerse en la primera valores inferiores que en la segunda, en términos generales en nuestro estudio, (recordemos que este movimiento es más sencillo fisiológicamente puesto que no precisa de báscula externa escapular ${ }^{8}$ ), aumenta en los sujetos sometidos a terapia Vojta, debido a la activación del deltoides en este mismo brazo así como al movimiento de avance en el brazo nucal.

Sin embargo, la extensión de hombro apenas se modifica a lo largo del tiempo de tratamiento en los pacientes del grupo 1 de nuestro estudio, y ello puede ser debido a que el tríceps está funcionando como punto fijo en el codo del brazo facial, en equilibrio con el bíceps braquial y que en el brazo nucal lo que se produce es un movimiento de avance. 


\section{DISCUSIÓN}

\section{LIMITACIONES DEL ESTUDIO}

Al comparar las puntuaciones en el cuestionario SF-36 inicial entre los grupos se obtuvieron diferencias significativas; lo que nos lleva a decir que la percepción de la salud en ambos conjuntos era diferente ya en la valoración inicial, y no se puede determinar con exactitud qué porcentaje de la mejoría puede atribuirse al tratamiento.

Las limitaciones en cuanto al tamaño muestral: distinto número de sujetos en cada grupo, grupos de estudio con escaso número de miembros; así como las diferencias existentes en las condiciones previas de cada uno, hacen que sea necesario proponer nuevas líneas de investigación en este campo, homogeneizando los grupos y mejorando los tamaños muestrales. 


\section{CONCLUSIONES}

1. El estado general de salud dentro del estudio de calidad de vida aumentó tras 9 meses de tratamiento en ambos grupos. Siendo mayor la mejoría en el grupo tratado con terapia Vojta

2. En un colectivo heterogéneo como son los pacientes con Daño Cerebral Adquirido el cuestionario de salud autopercibida por el paciente SF-36 funciona, puesto que en cada una de las escalas que lo componen se describe un patrón constante de percepción de la salud. Sin embargo existen diferencias entre ellas puesto que en un análisis multivariante de dicho cuestionario no todas las escalas se significan en igual proporción.

3. La correlación entre el índice de Barthel y la Medida de la Independencia Funcional obtenida al finalizar el estudio fue fuerte. Además, algunos subítems que definen capacidades funcionales similares: alimentación (IB), comer (MIF) correlacionan de una forma elevada.

4. El IB y la MIF son escalas y miden la discapacidad, útiles para valorar los cambios que se han producido y que expresan la mejoría funcional del grupo de terapia con Vojta respecto al grupo que recibió únicamente FNP.

5. El rango articular de hombro aumenta con la fisioterapia aplicada, siendo mayor el conseguido en los pacientes sometidos a terapia Vojta y FNP respecto a los que sólo realizaron FNP. Dicha mejoría es más evidente en los movimientos de flexión y rotación interna.

6. La mejoría observada en los individuos que realizan terapia Vojta es independiente de la etiología de su DCA.

7. Los resultados han de ser tomados con cautela dado que los grupos sometidos a tratamiento no eran homogéneos al inicio del estudio; observándose esto en los 3 cuestionarios utilizados, lo que condiciona la atribución de cambios por el tratamiento. 


\section{CONCLUSIONES}

8. Es necesario continuar en esta línea de investigación con tamaños muestrales mayores y homogeneizando los grupos. 


\section{ANEXO 1}

\section{FORMULARIO DE REGISTRO DE PACIENTES Y ESCALAS DE VA- LORACIÓN}




\section{ANEXOS}

FICHA DE EVALUACIÓN

NC

Apellidos:

Nombre:

\begin{tabular}{|l|l|c|c|}
\hline Edad & Sexo & \multicolumn{2}{|c|}{ Institucionalizado } \\
\hline & & SI & NO \\
\hline
\end{tabular}

Diagnóstico Médico:

\begin{tabular}{|l|l|l|}
\hline \multirow{2}{*}{} & \multicolumn{2}{|c|}{ Rango articular pasivo sin dolor } \\
\cline { 2 - 4 } & T & \multicolumn{1}{|c|}{ IZQUIERDO } \\
\hline Al inicio & TERECHO & F \\
& R & T \\
\hline A los 4 meses & F & R \\
& T & T \\
& R & R \\
\hline A los 9 meses & F & F \\
& T & T \\
& R & R \\
\hline
\end{tabular}

\begin{tabular}{|l|l|l|l|}
\hline Puntuaciones & IB & MIF motor & MIF cognitivo \\
\hline Al inicio & & & \\
\hline A los 4 meses & & & \\
\hline A los 9 meses & & & \\
\hline
\end{tabular}

OBSERVACIONES

NC: número control 


\section{CUESTIONARIO SF-36}

Por favor conteste las siguientes preguntas.

Algunas preguntas pueden parecerse a otras pero cada una es diferente. Tómese el tiempo necesario para leer cada pregunta, y marque con una la casilla que mejor describa su respuesta.

1. En general, usted diría que su salud es:

$1 \square$ Excelente

$2 \square$ Muy buena

$3 \square$ Buena

$4 \square$ Regular

$5 \square$ Mala

2. ¿Cómo diría que es su salud actual, comparada con la de hace un año?

$1 \square$ Mucho mejor ahora que hace un año

$2 \square$ Algo mejor ahora que hace un año

$3 \square$ Más o menos igual que hace un año

$4 \square$ Algo peor ahora que hace un año

$5 \square$ Mucho peor ahora que hace un año

\section{LAS SIGUIENTES PREGUNTAS SE REFIEREN A ACTIVIDADES O COSAS QUE USTED PODRÍA HACER EN UN DÍA NORMAL}

3. Su salud actual, ¿le limita para hacer esfuerzos intensos, tales como correr, levantar objetos pesados, o participar en deportes agotadores?

$1 \square$ Sí, me limita mucho

$2 \square$ Sí, me limita un poco

$3 \square$ No, no me limita nada

4. Su salud actual, ¿le limita para hacer esfuerzos moderados, como mover una mesa, pasar la aspiradora, jugar a los bolos o caminar más de una hora?

$1 \square$ Sí, me limita mucho

$2 \square$ Sí, me limita un poco

$3 \square$ No, no me limita nada

5. Su salud actual, ¿le limita para coger o llevar la bolsa de la compra?

$1 \square$ Sí, me limita mucho

$2 \square$ Sí, me limita un poco

$3 \square$ No, no me limita nada. 


\section{ANEXOS}

6. Su salud actual, ¿le limita para subir varios pisos por la escalera?

$1 \square$ Sí, me limita mucho

$2 \square$ Sí, me limita un poco

$3 \square$ No, no me limita nada

7. Su salud actual, ¿le limita para subir un solo piso por la escalera?

$1 \square$ Sí, me limita mucho

$2 \square$ Sí, me limita un poco

$3 \square$ No, no me limita nada

8. Su salud actual, ¿le limita para agacharse o arrodillarse?

$1 \square$ Sí, me limita mucho

$2 \square$ Sí, me limita un poco

$3 \square$ No, no me limita nada

9. Su salud actual, ¿le limita para caminar un kilómetro o más?

$1 \square$ Sí, me limita mucho

$2 \square$ Sí, me limita un poco

$3 \square$ No, no me limita nada

10. Su salud actual, ¿le limita para caminar una sola manzana (unos 100 metros)?

$1 \square$ Sí, me limita mucho

$2 \square$ Sí, me limita un poco

$3 \square$ No, no me limita nada

11. Su salud actual, ¿le limita para caminar varias manzanas (varios centenares de metros)?

$1 \square$ Sí, me limita mucho

$2 \square$ Sí, me limita un poco

$3 \square$ No, no me limita nada

12. Su salud actual, ¿le limita para bañarse o vestirse por sí mismo?

$1 \square$ Sí, me limita mucho

$2 \square$ Sí, me limita un poco

$3 \square$ No, no me limita nada 
LAS SIGUIENTES PREGUNTAS SE REFIEREN A PROBLEMAS EN SU TRABAJO O EN SUS ACTIVIDADES COTIDIANAS

13. Durante las 4 últimas semanas, ¿tuvo que reducir el tiempo dedicado al trabajo o a sus actividades cotidianas, a causa de su salud física?

$\square$ Sí

$\square$ No

14. Durante las 4 últimas semanas, ¿hizo menos de lo que hubiera querido hacer, a causa de su salud física?

$\square$ Sí

No

15. Durante las 4 últimas semanas, ¿tuvo que dejar de hacer algunas tareas en su trabajo o en sus actividades cotidianas, a causa de su salud física?

$\square$ Sí

No

16. Durante las 4 últimas semanas, ¿tuvo dificultad para hacer su trabajo o sus actividades cotidianas (por ejemplo, le costó más de lo normal), a causa de su salud física?

$\square$ Sí

$\square$ No

17. Durante las 4 últimas semanas, ¿tuvo que reducir el tiempo dedicado al trabajo o a sus actividades cotidianas, a causa de algún problema emocional (como estar triste, deprimido, o nervioso?

$1 \square$ Sí

$2 \square$ No

18. Durante las 4 últimas semanas, ¿hizo menos de lo que hubiera querido hacer, a causa de algún problema emocional (como estar triste, deprimido, o nervioso)?

$1 \square$ Sí

$2 \square$ No

19. Durante las 4 últimas semanas, ¿no hizo su trabajo o sus actividades cotidianas tan cuidadosamente como de costumbre, a causa de algún problema emocional (como estar triste, deprimido, o nervioso)?

$1 \square$ Sí

$2 \square$ No 


\section{ANEXOS}

20. Durante las 4 últimas semanas, ¿hasta qué punto su salud física o los problemas emocionales han dificultado sus actividades sociales habituales con la familia, los amigos, los vecinos u otras personas?

$1 \square$ Nada

$2 \square$ Un poco

$3 \square$ Regular

$4 \square$ Bastante

$5 \square$ Mucho

21. ¿Tuvo dolor en alguna parte del cuerpo durante las 4 últimas semanas?

$1 \square$ No, ninguno

$2 \square$ Sí, muy poco

$3 \square$ Sí, un poco

$4 \square$ Sí, moderado

$5 \square$ Sí, mucho

$6 \square$ Sí, muchísimo

22. Durante las 4 últimas semanas, ¿hasta qué punto el dolor le ha dificultado su trabajo habitual (incluido el trabajo fuera de casa y las tareas domésticas)?

$1 \square$ Nada

$2 \square$ Un poco

$3 \square$ Regular

$4 \square$ Bastante

$5 \square$ Mucho

23. Durante las 4 últimas semanas, ¿cuánto tiempo se sintió lleno de vitalidad?

$1 \square$ Siempre

$2 \square$ Casi siempre

$3 \square$ Muchas veces

$4 \square$ Algunas veces

$5 \square$ Sólo alguna vez

$6 \square$ Nunca

24. Durante las 4 últimas semanas, ¿cuánto tiempo estuvo muy nervioso?

$1 \square$ Siempre

$2 \square$ Casi siempre

$3 \square$ Muchas veces

$4 \square$ Algunas veces

$5 \square$ Sólo alguna vez

$6 \square$ Nunca 
25. Durante las 4 últimas semanas, ¿cuánto tiempo se sintió tan bajo de moral que nada podía animarle?
$1 \square$ Siempre
$2 \square$ Casi siempre
$3 \square$ Muchas veces
$4 \square$ Algunas veces
$5 \square$ Sólo alguna vez
$6 \square$ Nunca

26. Durante las 4 últimas semanas, ¿cuánto tiempo se sintió calmado y tranquilo?

$1 \square$ Siempre

$2 \square$ Casi siempre

$3 \square$ Muchas veces

$4 \square$ Algunas veces

$5 \square$ Sólo alguna vez

$6 \square$ Nunca

27. Durante las 4 últimas semanas, ¿cuánto tiempo tuvo mucha energía?

$1 \square$ Siempre

$2 \square$ Casi siempre

$3 \square$ Muchas veces

$4 \square$ Algunas veces

$5 \square$ Sólo alguna vez

$6 \square$ Nunca

28. Durante las 4 últimas semanas, ¿cuánto tiempo se sintió desanimado y deprimido?

$1 \square$ Siempre

$2 \square$ Casi siempre

$3 \square$ Muchas veces

$4 \square$ Algunas veces

$5 \square$ Sólo alguna vez

$6 \square$ Nunca

29. Durante las 4 últimas semanas, ¿cuánto tiempo se sintió lleno de agotado?

$1 \square$ Siempre

$2 \square$ Casi siempre

$3 \square$ Muchas veces

$4 \square$ Algunas veces

$5 \square$ Sólo alguna vez

$6 \square$ Nunca 


\section{ANEXOS}

30. Durante las 4 últimas semanas, ¿cuánto tiempo se sintió lleno de feliz?

$1 \square$ Siempre

$2 \square$ Casi siempre

$3 \square$ Muchas veces

$4 \square$ Algunas veces

$5 \square$ Sólo alguna vez

$6 \square$ Nunca

31. Durante las 4 últimas semanas, ¿cuánto tiempo se sintió cansado?

$1 \square$ Siempre

$2 \square$ Casi siempre

$3 \square$ Muchas veces

$4 \square$ Algunas veces

$5 \square$ Sólo alguna vez

$6 \square$ Nunca

32. Durante las 4 últimas semanas, ¿con qué frecuencia la salud física o los problemas emocionales le han dificultado sus actividades sociales (como visitar a los amigos o familiares)?

$1 \square$ Siempre

$2 \square$ Casi siempre

$3 \square$ Algunas veces

$4 \square$ Sólo alguna vez

$5 \square$ Nunca

Por favor diga si le parece CIERTA o FALSA cada una de las siguientes frases

33. Creo que me pongo enfermo más fácilmente que otras personas.

$1 \square$ Totalmente cierta

$2 \square$ Bastante cierta

$3 \square$ No lo sé

$4 \square$ Bastante falsa

$5 \square$ Totalmente falsa

34. Estoy tan sano como cualquiera.

$1 \square$ Totalmente cierta

$2 \square$ Bastante cierta

$3 \square$ No lo sé

$4 \square$ Bastante falsa

$5 \square$ Totalmente falsa 
35. Mi salud es excelente.

$1 \square$ Totalmente cierta

$2 \square$ Bastante cierta

$3 \square$ No lo sé

$4 \square$ Bastante falsa

$5 \square$ Totalmente falsa

36. Creo que mi salud va a empeorar.

$1 \square$ Totalmente cierta

$2 \square$ Bastante cierta

$3 \square$ No lo sé

37. $4 \square$ Bastante falsa

38. $5 \square$ Totalmente falsa

39. 


\section{ANEXOS}

\section{ÍNDICE DE BARTHEL}

\begin{tabular}{|l|l|}
\hline P & Actividad: Comer \\
\hline $\mathbf{1 0}$ & $\begin{array}{l}\text { Independiente Capaz de utilizar cualquier instrumento necesario, capaz de desmenuzar la } \\
\text { comida, extender la mantequilla, usar condimentos, etc., por sí solo. Come en un tiempo } \\
\text { razonable. La comida puede ser cocinada y servida por otra persona }\end{array}$ \\
\hline $\mathbf{5}$ & $\begin{array}{l}\text { Necesita ayuda: Para cortar la carne o el pan, extender la mantequilla, etc., pero es capaz } \\
\text { de comer solo }\end{array}$ \\
\hline $\mathbf{0}$ & Dependiente. Necesita ser alimentado por otra persona \\
\hline
\end{tabular}

\begin{tabular}{|l|l|}
\hline $\mathbf{P}$ & Actividad: Lavarse - bañarse \\
\hline $\mathbf{5}$ & $\begin{array}{l}\text { Independiente: Capaz de lavarse entero, puede ser usando la ducha, la bañera o permane- } \\
\text { ciendo de pie y aplicando la esponja sobre todo el cuerpo. Incluye entrar y salir del baño. } \\
\text { Puede realizarlo todo sin estar una persona presente }\end{array}$ \\
\hline $\mathbf{0}$ & Dependiente Necesita alguna ayuda o supervisión \\
\hline
\end{tabular}

\begin{tabular}{|l|l|}
\hline P & Actividad: Vestirse \\
\hline $\mathbf{1 0}$ & $\begin{array}{l}\text { Independiente: Capaz de poner y quitarse la ropa, atarse los zapatos, abrocharse los boto- } \\
\text { nes y colocarse otros complementos que precisa (por ejemplo braguero, corsé, etc.) sin } \\
\text { ayuda) }\end{array}$ \\
\hline $\mathbf{5}$ & Necesita ayuda Pero realiza solo al menos la mitad de las tareas en un tiempo razonable \\
\hline $\mathbf{0}$ & Dependiente \\
\hline
\end{tabular}

\begin{tabular}{|l|l|}
\hline $\mathbf{P}$ & Actividad: Arreglarse \\
\hline $\mathbf{5}$ & $\begin{array}{l}\text { Independiente. Realiza todas las actividades personales sin ninguna ayuda. Incluye la- } \\
\text { varse cara y manos, peinarse, maquillarse, afeitarse y lavarse los dientes. Los comple- } \\
\text { mentos necesarios para ello pueden ser provistos por otra persona }\end{array}$ \\
\hline $\mathbf{0}$ & Dependiente. Necesita alguna ayuda \\
\hline
\end{tabular}

\begin{tabular}{|l|l|}
\hline $\mathbf{P}$ & Actividad: Deposición \\
\hline $\mathbf{1 0}$ & $\begin{array}{l}\text { Continente Ningún episodio de incontinencia. Si necesita enema o supositorios es capaz } \\
\text { de administrárselos por sí solo }\end{array}$ \\
\hline $\mathbf{5}$ & $\begin{array}{l}\text { Accidente ocasional Menos de una vez por semana o necesita ayuda para enemas o su- } \\
\text { positorios }\end{array}$ \\
\hline $\mathbf{0}$ & Incontinente Incluye administración de enemas o supositorios por otro \\
\hline
\end{tabular}




\begin{tabular}{|l|l|}
\hline $\mathbf{P}$ & Actividad: Micción(valórese la semana previa) \\
\hline $\mathbf{1 0}$ & Continencia normal, o es capaz de cuidarse de la sonda si tiene una puesta \\
\hline $\mathbf{5}$ & $\begin{array}{l}\text { Un episodio diario como máximo de incontinencia, o necesita ayuda para cuidar de la } \\
\text { sonda }\end{array}$ \\
\hline $\mathbf{0}$ & Incontinencia \\
\hline
\end{tabular}

\begin{tabular}{|l|l|}
\hline $\mathbf{P}$ & Actividad: Usar el retrete \\
\hline $\mathbf{1 0}$ & Independiente para ir al cuarto de aseo, quitarse y ponerse la ropa... \\
\hline $\mathbf{5}$ & Necesita ayuda para ir al retrete, pero se limpia solo \\
\hline $\mathbf{0}$ & Dependiente \\
\hline
\end{tabular}

\begin{tabular}{|l|l|}
\hline P & Actividad: Trasladarse \\
\hline $\mathbf{1 5}$ & Independiente para ir del sillón a la cama \\
\hline $\mathbf{1 0}$ & Mínima ayuda física o supervisión para hacerlo \\
\hline $\mathbf{5}$ & Necesita gran ayuda, pero es capaz de mantenerse sentado solo \\
\hline $\mathbf{0}$ & Dependiente \\
\hline
\end{tabular}

\begin{tabular}{|l|l|}
\hline $\mathbf{P}$ & Actividad: Deambular \\
\hline $\mathbf{1 5}$ & Independiente, camina solo 50 metros \\
\hline $\mathbf{1 0}$ & Necesita ayuda física o supervisión para caminar 50 metros \\
\hline $\mathbf{5}$ & Independiente en silla de ruedas sin ayuda \\
\hline $\mathbf{0}$ & Dependiente \\
\hline
\end{tabular}

\begin{tabular}{|l|l|}
\hline P & Actividad: Escalones \\
\hline $\mathbf{1 0}$ & Independiente para bajar y subir escaleras \\
\hline $\mathbf{5}$ & Necesita ayuda física o supervisión para hacerlo \\
\hline $\mathbf{0}$ & Dependiente \\
\hline
\end{tabular}

\section{$\mathbf{P}=$ Puntuación}

0-20 dependencia total

21-60 dependencia severa

61-90 dependencia moderada

91-99 dependencia escasa

100 independencia

Máx.puntuación 100 (90 si va en silla de ruedas) 


\section{MEDIDA DE LA INDEPENDENCIA FUNCIONAL}

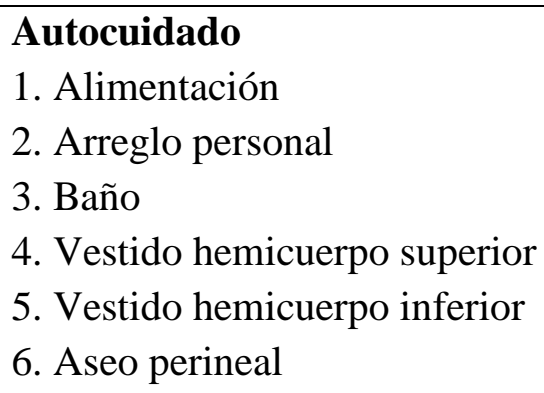

1. Alimentación

2. Arreglo personal

3. Baño

4. Vestido hemicuerpo superior

5. Vestido hemicuerpo inferior

6. Aseo perineal

\section{Control de esfínteres}

7. Control de la vejiga

8. Control del intestino

\section{Movilidad}

9. Traslado de la cama a silla o silla de ruedas

10. Traslado en baño

11. Traslado en bañera o ducha

\section{Ambulación}

12. Caminar/desplazarse en silla de ruedas

13. Subir y bajar escaleras

\section{Comunicación}

14. Comprensión

15. Expresión

\section{Conocimiento social}

16. Interacción social

17. Solución de problemas

18. Memoria

TOTAL 126 puntos 
PUNTUACIÓN: Grado de dependencia Nivel de funcionalidad

Sin ayuda

7 Independencia completa

6 Independencia modificada

Dependencia modificada

5 Supervisión

4 Asistencia mínima (mayor del 75\% de independencia)

3 Asistencia moderada (mayor del 50\% de independencia)

Dependencia completa

2 Asistencia máxima (mayor del $25 \%$ de independencia)

1 Asistencia total (menor del 25\% de independencia) 


\section{ANEXOS}

\section{ESCALA DE LA ESPASTICIDAD DE ASHWORTH}

\begin{tabular}{|l|l|}
\hline 0 & No incremento de tono, normal \\
\hline 1 & $\begin{array}{l}\text { Ligero incremento en tono, con resistencia mínima } \\
\text { durante parte del movimiento articular }\end{array}$ \\
\hline 2 & Incremento moderado de tono a lo largo del movimiento articular \\
\hline 3 & Incremento marcado, difícil de completar el arco de movimiento \\
\hline 4 & Contractura fija \\
\hline
\end{tabular}




\section{ANEXO 2 \\ CONSENTIMIENTO INFORMADO}




\section{ANEXOS}

\section{MODELO DE CONSENTIMIENTO INFORMADO DEL PACIENTE O CO-}

\section{LABORADOR}

\section{Impreso CBE-A1}

Yo ${ }^{1}$

DNI/Pasaporte,

He leído la hoja informativa que me ha sido entregada ${ }^{2}$

He tenido oportunidad de efectuar preguntas sobre el estudio.

He recibido respuestas satisfactorias.

He recibido suficiente información en relación con el estudio.

He hablado con el Dr./Investigador: José Ignacio Calvo Arenillas

Entiendo que la participación es voluntaria.

Entiendo que puedo abandonar el estudio:

-Cuando lo desee.

- Sin que tenga que dar explicaciones.

- Sin que ello afecte a MIS cuidados médicos.

También he sido informado de forma clara, precisa y suficiente de los siguientes extremos que afectan a los datos personales que se contienen en este consentimiento y en la ficha o expediente que se abra para la investigación:

-Estos datos serán tratados y custodiados con respeto a mi intimidad y a la vigente normativa de protección de datos.

-Sobre estos datos me asisten los derechos de acceso, rectificación, cancelación y oposición que podré ejercitar mediante solicitud ante el investigador responsable en la dirección de contacto que figura en este documento. 
•Estos datos no podrán ser cedidos sin mi consentimiento expreso y no lo otorgo en este acto.

Doy mi consentimiento sólo para la extracción necesaria en la investigación de la que se me ha informado y para que sean utilizadas las muestras (fluidos, tejidos, etc...) exclusivamente en ella, sin posibilidad de compartir o ceder éstas, en todo o en parte, a ningún otro investigador, grupo o centro distinto del responsable de esta investigación o para cualquier otro fin.

Declaro que he leído y conozco el contenido del presente documento, comprendo los compromisos que asumo y los acepto expresamente. $\mathrm{Y}$, por ello, firmo este consentimiento informado de forma voluntaria para MANIFESTAR MI DESEO DE PARTICIPAR EN ESTE ESTUDIO DE INVESTIGACIÓN SOBRE - COMPARACIÓN DE LA EFICACIA DE DOS MÉTODOS FISIOTERAPÉUTICOS EN PERSONAS CON DAÑO CEREBRAL ADQUIRIDO, hasta que decida lo contrario. Al firmar este consentimiento no renuncio a ninguno de mis derechos. Recibiré una copia de este consentimiento para guardarlo y poder consultarlo en el futuro.

Nombre del paciente o sujeto colaborador:

\section{DNI/Pasaporte}

Firma:

Fecha:

Nombre del investigador: José Ignacio Calvo Arenillas

DNI 07427423X

Firma:

Identificación del Grupo/Instituto//Centro/Otros, responsable de la investigación, cuando no se trate de proyectos individuales:

Universidad de Salamanca 


\section{ANEXOS}

Fecha: 01/10/2014

Dirección de contacto del Investigador y/o del Grupo.... responsables de la investigación y del tratamiento de los datos:

E.U. Enfermería y Fisioterapia. Calle Donantes de Sangre s/n 37003 Salamanca Área de fisioterapia 923294500 (Ext 3167)

NOTAS

${ }^{1}$ Indicar el nombre completo

2 Incorporar de forma inseparable o al dorso de éste documento. 


\section{LEA ESTA HOJA DETENIDAMENTE}

Objetivo del estudio: Se le ha invitado a participar en un estudio que tiene como objetivo principal comparar la eficacia de dos métodos fisioterapéuticos en personas don daño cerebral adquirido.

Beneficios del estudio: Los beneficios esperados de este estudio son mejorar la movilidad del complejo articular del hombro de manera bilateral; además permitirá en un futuro a otros pacientes como usted beneficiarse de este tipo de tratamiento.

Procedimientos del estudio: En caso de aceptar participar en el estudio se le pasaran una serie cuestionarios y test de evaluación. Estos test no les causaran daño alguno y no se acompañan de ningún riesgo. El estudio tendrá una duración de 9 meses y los cuestionarios se repetirán al inicio del estudio, a la mitad del mismo y al finalizar.

Riesgos asociados al estudio: No existen riesgos añadidos a su enfermedad por participar en el estudio.

\section{Aclaraciones:}

- No recibirá ninguna consecuencia desfavorable en caso de no participar en la investigación.

- Si decida participar, podrá retirarse en el momento que desee.

- No tendrá que hacer gasto alguno durante la intervención.

- No recibirá pago por su participación.

- La información personal de cada paciente será mantenida en estricta confidencialidad por el grupo de investigadores. 


\section{ANEXOS}

\section{MODELO DE CONSENTIMIENTO INFORMADO PARA LA TOMA DE FOTOGRAFÍAS DE LAS SESIONES DE FISIOTERAPIA}

Este documento intenta explicarle todas las cuestiones relativas a la utilización que se reaizará de sus datos de participación a través de la toma de imágenes en las sesiones de fisioterapia. Léalo atentamente y consulte con el/la terapeuta todas las dudas que se le planteen.

\section{INFORMACIÓN ACERCA DE LA TOMA DE IMÁGENES EN LAS SESIONES}

Desde el área de fisioterapia de la Universidad de Salamanca se lleva a cabo la toma de imágenes en esta sesión con fines formativos y de investigación para los/las terapeutas que realizan su labor en este centro. Las imágenes se utilizarán exclusivamente como soporte visual de la tesis doctoral de Dña Ana Domínguez García, investigadora de este mismo centro.

\section{USO Y CONFIDENCIALIDAD DE LOS DATOS}

Los datos que se obtengan de su participación serán utilizados únicamente con fines de formación e investigación y solamente por parte del equipo de terapeutas que forman parte de este proyecto de tesis doctoral, guardándose siempre sus datos personales en un lugar seguro de tal manera que ninguna persona ajena pueda acceder a esta información y atendiendo a un estricto cumplimiento de la Ley Orgánica 15/1999 sobre la Protección de Datos de Carácter Personal. En ningún caso se harán públicos sus datos personales, siempre garantizando la plena confidencialidad de los mismos y el riguroso cumplimiento del secreto profesional en el uso y manejo de la información y el material obtenidos.

\section{REVOCACIÓN DEL CONSENTIMIENTO}

Si, en el caso de decidir participar y consentir la colaboración inicialmente, en algún momento de la intervención usted desea dejar de participar en la grabación de las sesiones, rogamos que nos lo comunique y a partir de ese momento se dejarán de utilizar las imágenes con fines de formación e investigación

\section{DECLARACIÓN DE CONSENTIMIENTO}

Yo, Don/Dña. he leído el documento de consentimiento informado que me ha sido entregado, he comprendido las explicaciones en él facilitadas acerca de la toma de imágenes en las sesiones de fisioterapia y he podido resolver todas las dudas y preguntas que he planteado al respecto. También comprendo que, en cualquier momento y sin necesidad de dar ninguna explicación, puedo revocar el consentimiento que ahora presento. También he sido informado/a de que mis datos personales serán protegidos y serán utilizados únicamente con fines de formación y desarrollo profesional para el equipo de terapeutas del centro. Tomando todo ello en consideración y en tales condiciones, CONSIENTO participar en la grabación de las sesiones y que los datos que se deriven de mi participación sean utilizados para cubrir los objetivos especificados en el documento. En ........................., a ..... de de 20..... Firmado: Don/Dña. (El/la usuario/a) 
ANEXOS

\section{ANEXO 3}

INFORME FAVORABLE DEL COMITÉ DE BIOÉTICA DE LA UNIVERSIDAD DE SALAMANCA 


\section{ANEXOS}

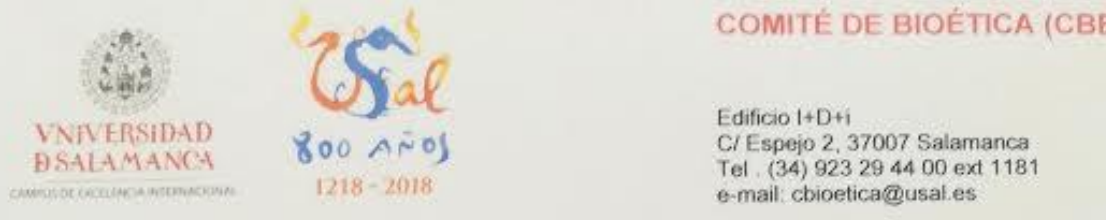

El Comité de Bioética de la Universidad de Salamanca, en su reunión ordinaria del dia 4 de octubre de 2016, ha considerado las circunstancias que concurren en el proyecto de investigación titulado "Comparación de la eficacia de dos métodos fisioterapéuticos en personas con daño cerebral adquirido", que tiene como investigador principal al Dr. José Ignacio Calvo Arenillas.

A la vista de la documentación presentada, este Comité ha acordado informar favorablemente el proyecto de investigación, ya que cumple los requisitos éticos requeridos para su ejecución.

Y para que así conste lo firmo en Salamanca a 7 de octubre de 2016
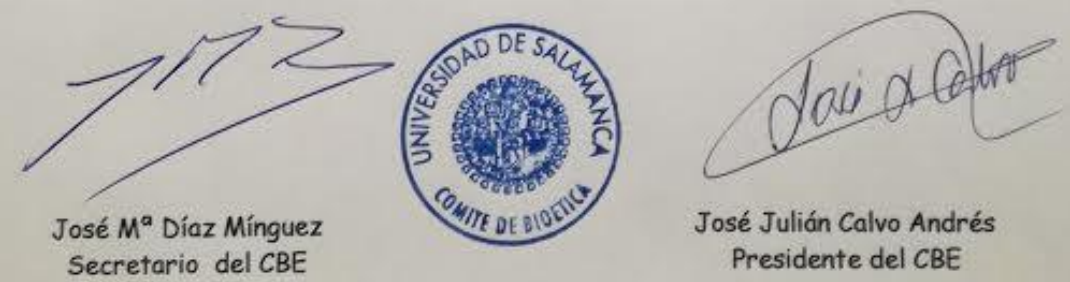

RBGISTRO UNICO UNIVBRSIDAD DB SALAMANCD 


\section{ANEXO 4}

\section{CATEGORIZACIÓN DE LOS INDIVIDUOS AFECTA- DOS DEL HEMICUERPO IZQUIERDO. GRUPOS 1 Y 2.}

\begin{tabular}{|c|c|c|}
\hline A) & \multicolumn{2}{|c|}{ Abducción } \\
\hline Categoría & Grupo 1 & Grupo 2 \\
\hline & Frecuencia & Frecuencia \\
\hline $\begin{array}{l}\text { Mucho } \\
\left.\text { peor (1 }{ }^{\circ}\right)\end{array}$ & 0 & 1 \\
\hline Peor $\left(2^{\circ}\right)$ & 1 & 5 \\
\hline Igual (3) & 3 & 6 \\
\hline Mejor $\left(4^{\circ}\right)$ & 4 & 5 \\
\hline $\begin{array}{c}\text { Mucho } \\
\text { mejor (5) }\end{array}$ & 3 & 2 \\
\hline
\end{tabular}

\begin{tabular}{|c|c|c|}
\hline B) & \multicolumn{2}{|c|}{ Extensión } \\
\hline Categoría & Grupo 1 & Grupo 2 \\
\hline & Frecuencia & Frecuencia \\
\hline $\begin{array}{l}\text { Mucho } \\
\text { peor (1ㅇ) }\end{array}$ & 1 & 2 \\
\hline Peor $\left(2^{\circ}\right)$ & 2 & 3 \\
\hline Igual (3) & 4 & 8 \\
\hline Mejor $\left(4^{\circ}\right)$ & 4 & 6 \\
\hline $\begin{array}{c}\text { Mucho } \\
\text { mejor (5) }\end{array}$ & 0 & 0 \\
\hline
\end{tabular}

\begin{tabular}{|c|c|c|}
\hline C) & \multicolumn{2}{|c|}{ Flexión } \\
\hline Categoría & Grupo 1 & Grupo 2 \\
\hline & Frecuencia & Frecuencia \\
\hline $\begin{array}{l}\text { Mucho } \\
\text { peor (1ㅇ) }\end{array}$ & 1 & 1 \\
\hline Peor $\left(2^{\circ}\right)$ & 1 & 1 \\
\hline Igual (3) & 2 & 6 \\
\hline Mejor (4) & 4 & 10 \\
\hline $\begin{array}{c}\text { Mucho } \\
\text { mejor (5) }\end{array}$ & 3 & 1 \\
\hline
\end{tabular}

\begin{tabular}{|c|c|c|}
\hline D) & \multicolumn{2}{|c|}{ Rotación Externa } \\
\hline Categoría & Grupo 1 & Grupo 2 \\
\hline & Frecuencia & Frecuencia \\
\hline $\begin{array}{l}\text { Mucho } \\
\text { peor (1ํ) }\end{array}$ & 0 & 0 \\
\hline Peor $\left(2^{\circ}\right)$ & 1 & 2 \\
\hline Igual $\left(3^{\circ}\right)$ & 5 & 5 \\
\hline Mejor (4ㅇ) & 5 & 11 \\
\hline $\begin{array}{c}\text { Mucho } \\
\text { mejor (5) }\end{array}$ & 0 & 1 \\
\hline
\end{tabular}

\begin{tabular}{|c|c|c|}
\hline E) & \multicolumn{2}{|c|}{ Rotación Interna } \\
\hline Categoría & Grupo 1 & Grupo 2 \\
\hline & Frecuencia & Frecuencia \\
\hline $\begin{array}{l}\text { Mucho } \\
\text { peor (1ㅇ) }\end{array}$ & 0 & 0 \\
\hline Peor (2) & 0 & 1 \\
\hline Igual $\left(3^{\circ}\right)$ & 5 & 8 \\
\hline Mejor $\left(4^{\circ}\right)$ & 1 & 8 \\
\hline $\begin{array}{c}\text { Mucho } \\
\text { mejor (5) }\end{array}$ & 5 & 2 \\
\hline
\end{tabular}

Tabla 52: Categorización individuos grupos 1 y 2 hemicuerpo izquierdo 


\section{ANEXOS}

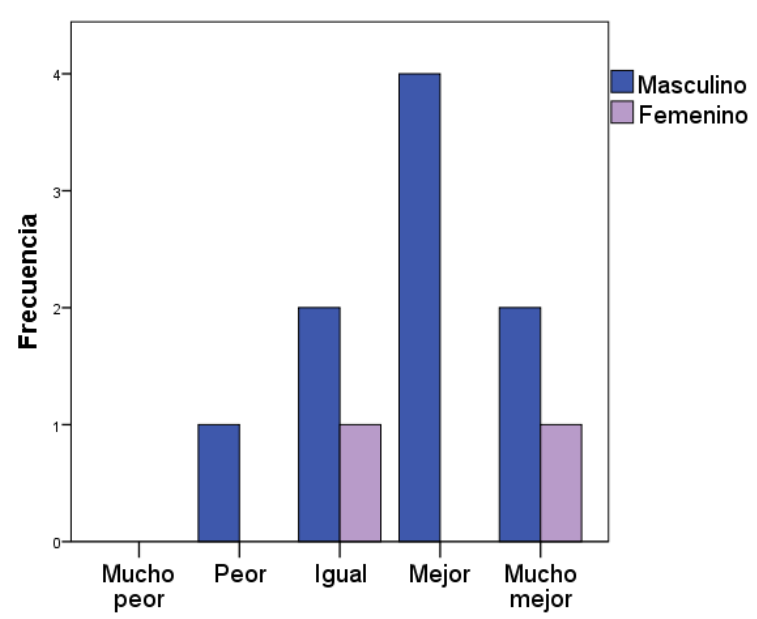

A)

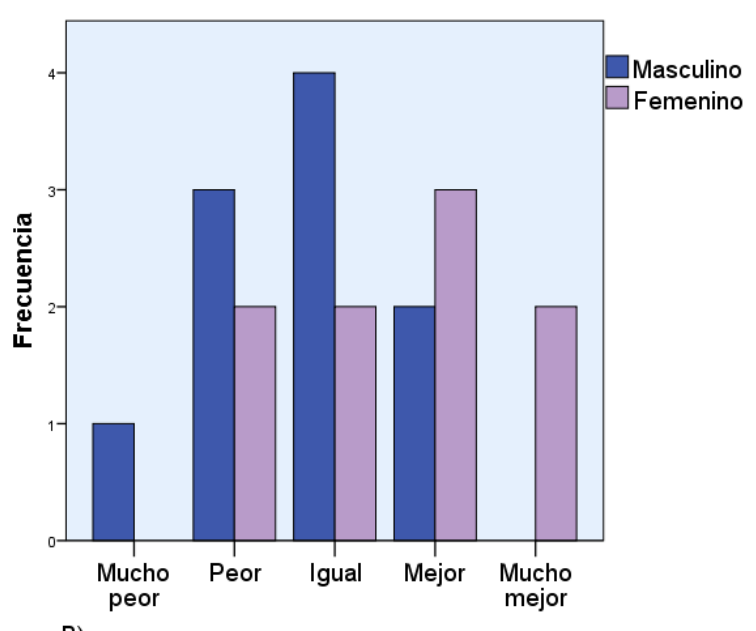

B)

Figura 58: Categorización de los individuos en función del sexo para la abducción

A) Grupo 1

B) Grupo 2

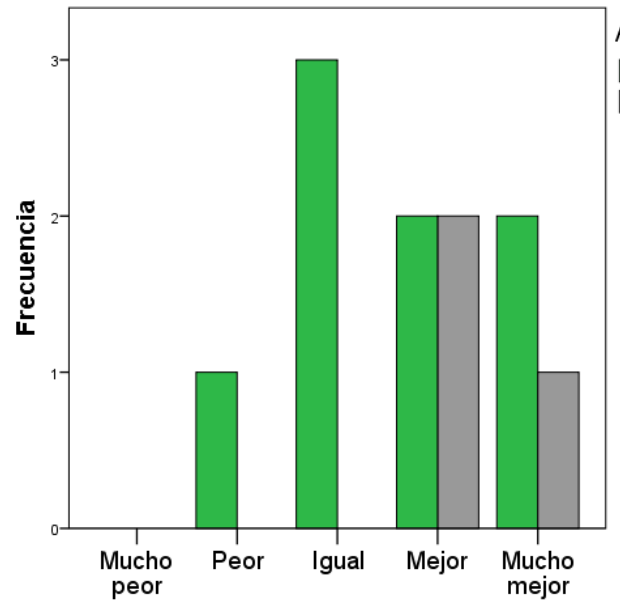

A)

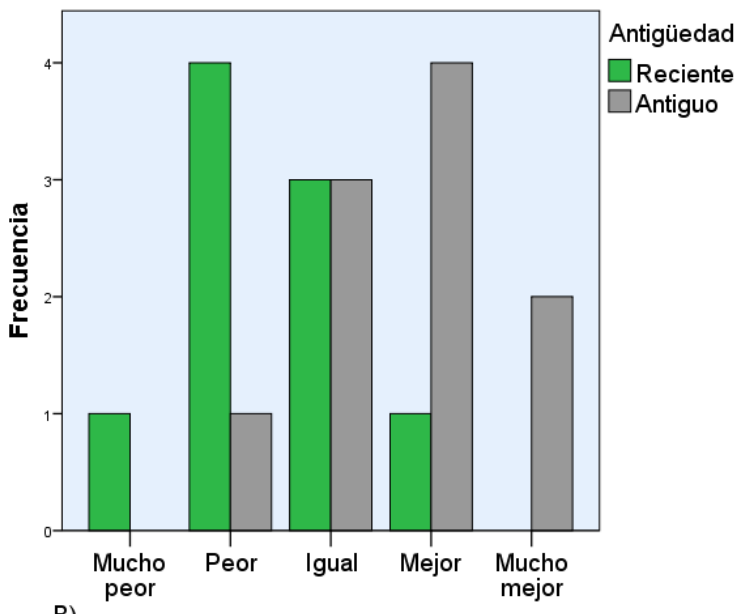

B)

Figura 59: Categorización de los individuos en función de la antigüedad de aparición para la abducción

$$
\begin{aligned}
& \text { A) Grupo } 1 \\
& \text { B) Grupo } 2
\end{aligned}
$$


ANEXOS
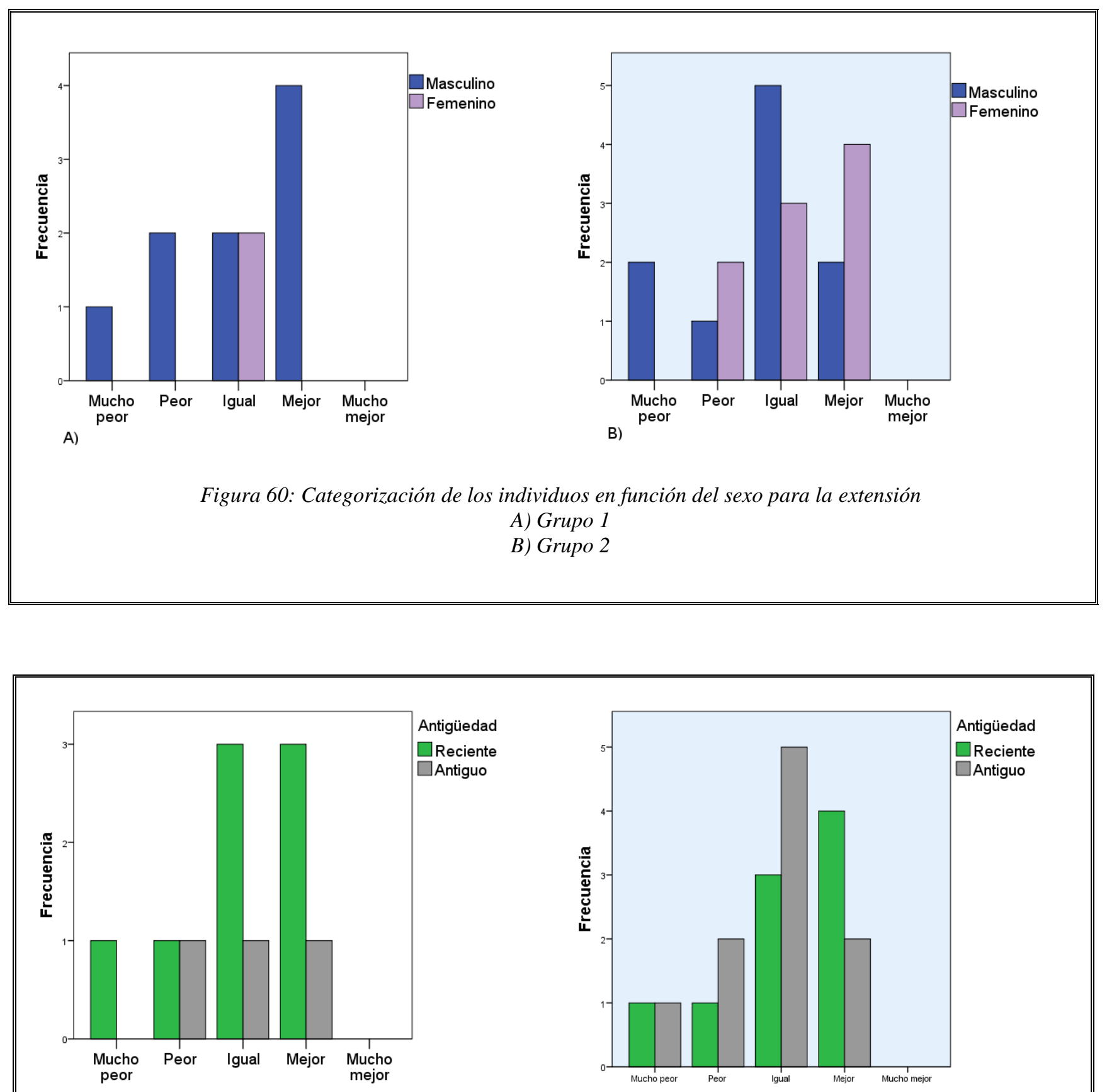

A)

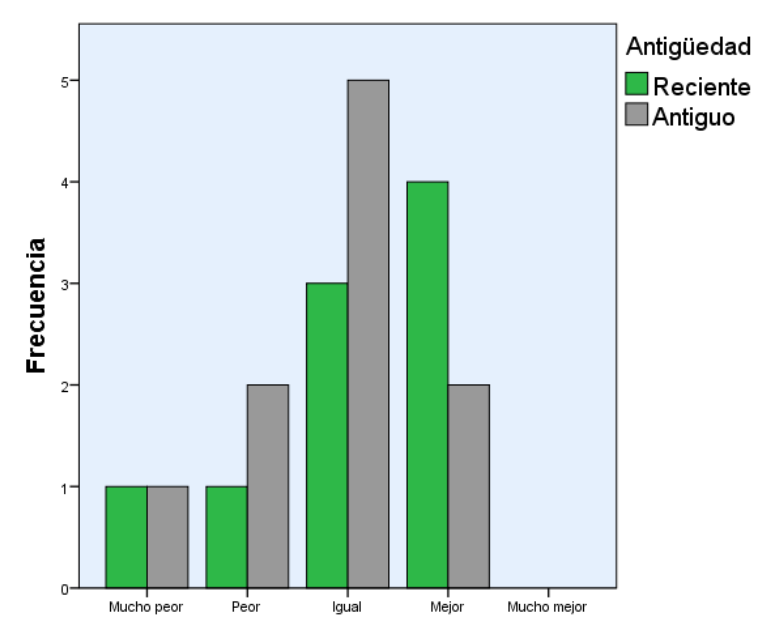

B)

Figura 61: Categorización de los individuos en función de la antigüedad de aparición para la extensión A) Grupo 1

B) Grupo 2 


\section{ANEXOS}
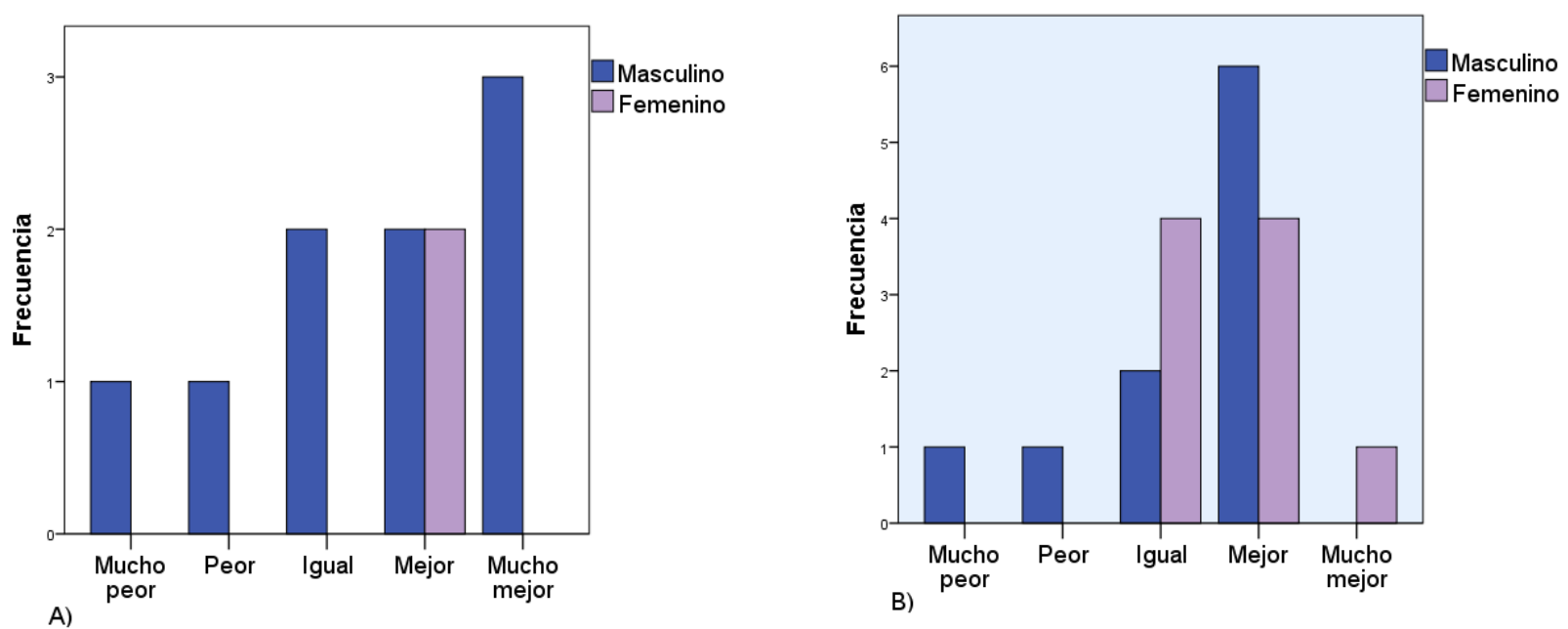

Figura 62: Categorización de los individuos en función del sexo para la flexión
A) Grupo 1

B) Grupo 2
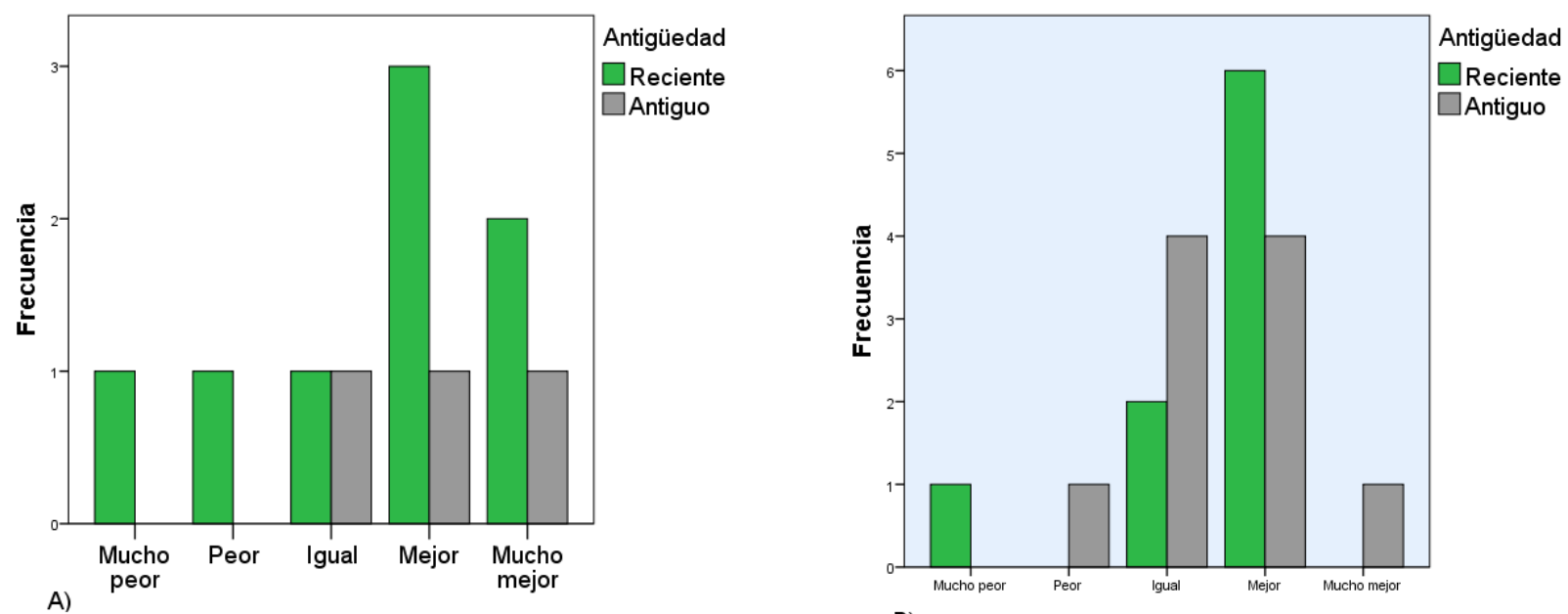

B)

Figura 63: Categorización de los individuos en función de la antigüedad de aparición para la flexión

A) Grupo 1

B) Grupo 2 
ANEXOS

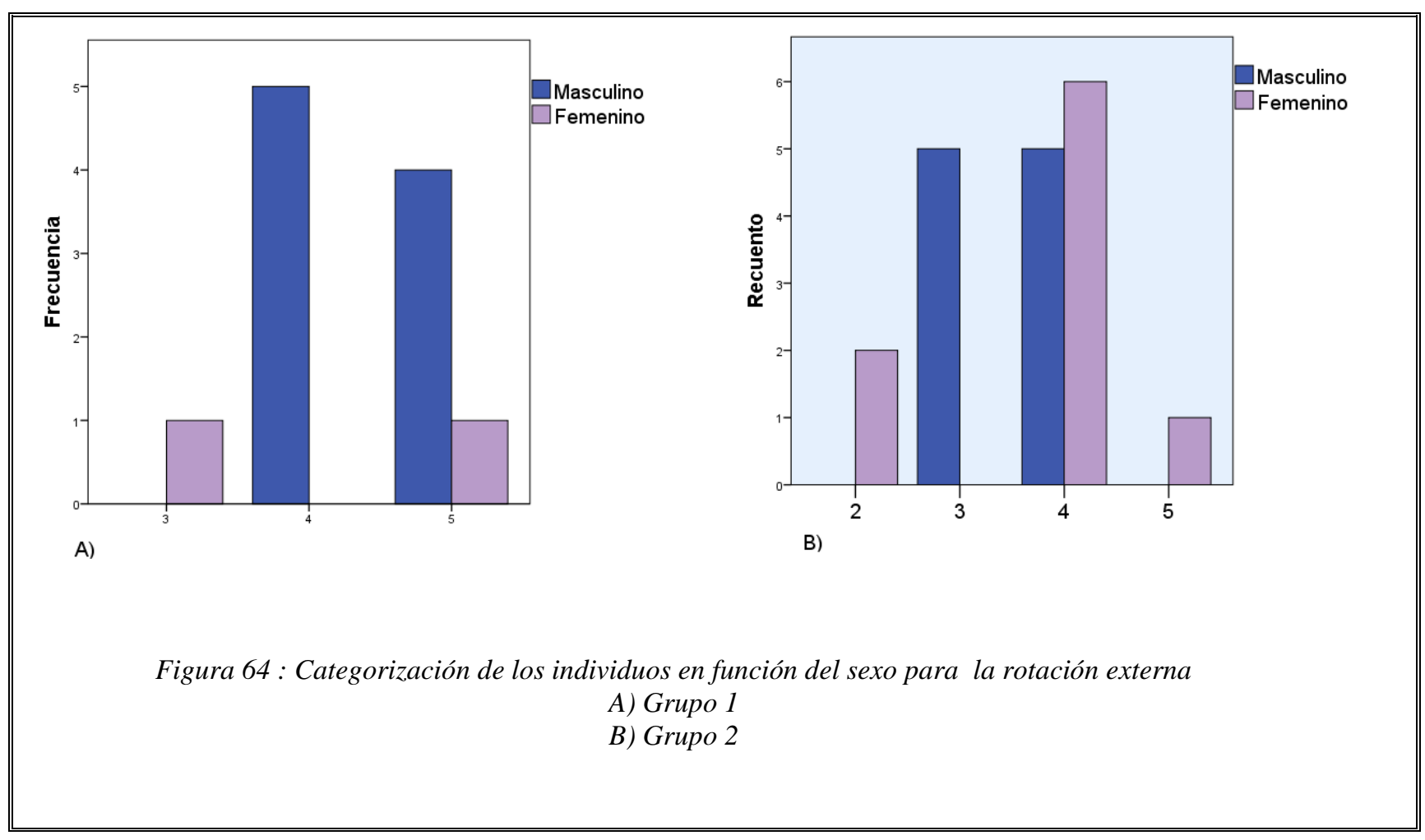

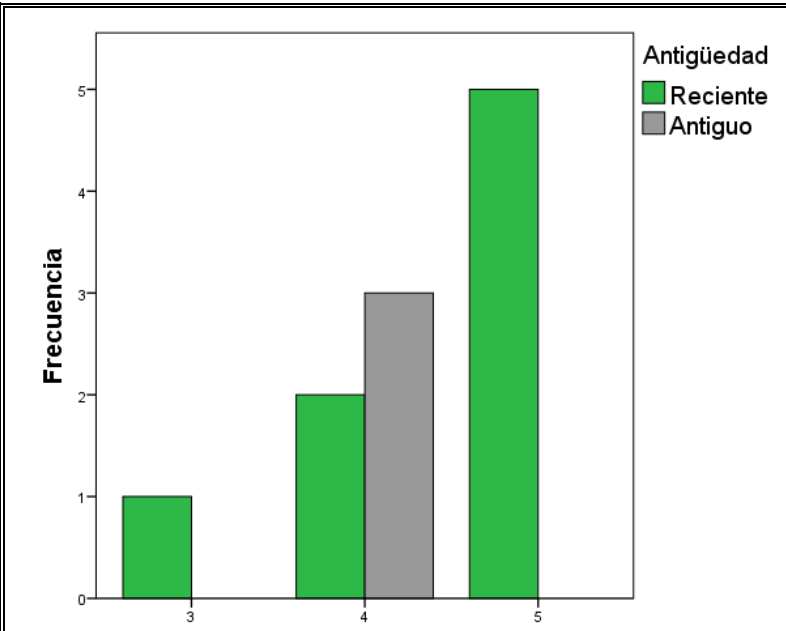

A)

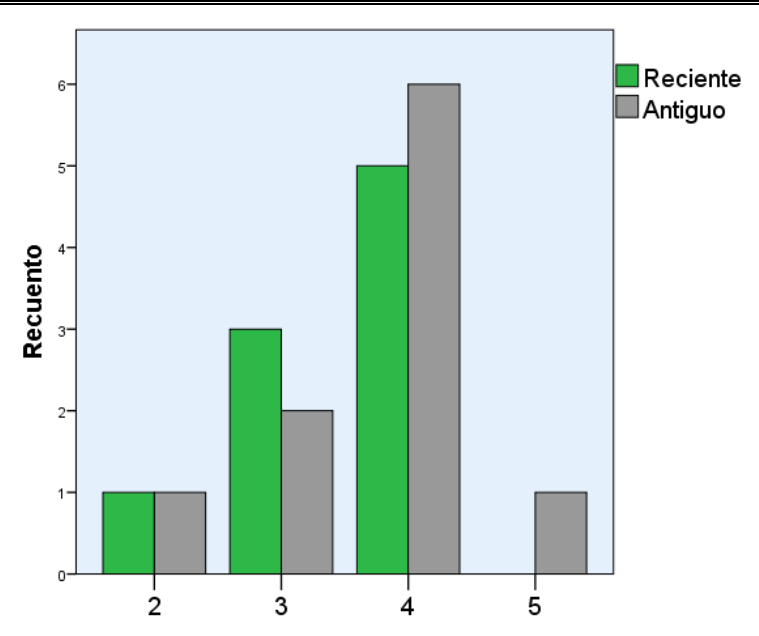

B)

Figura 65: Categorización de los individuos en función de la antigüedad de aparición para la rotación externa A) Grupo 1

B) Grupo 2 


\section{ANEXOS}

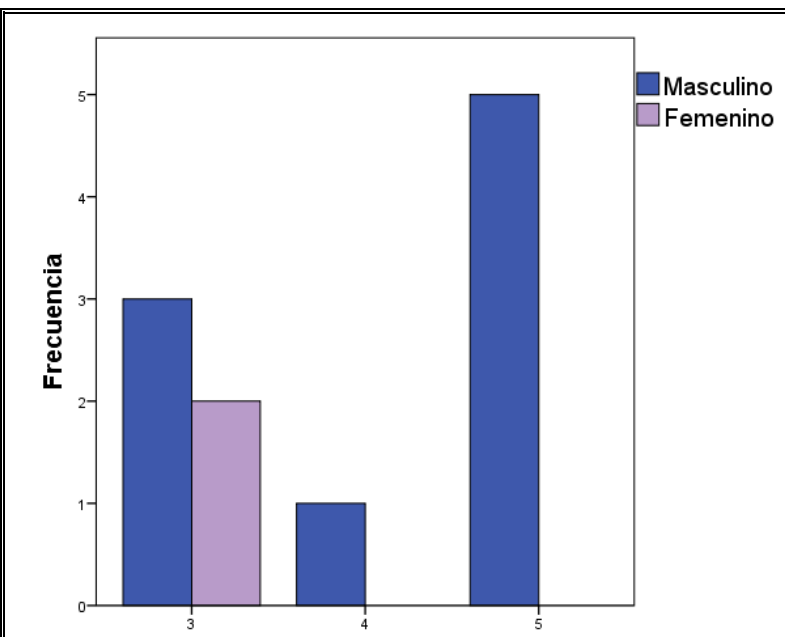

A)

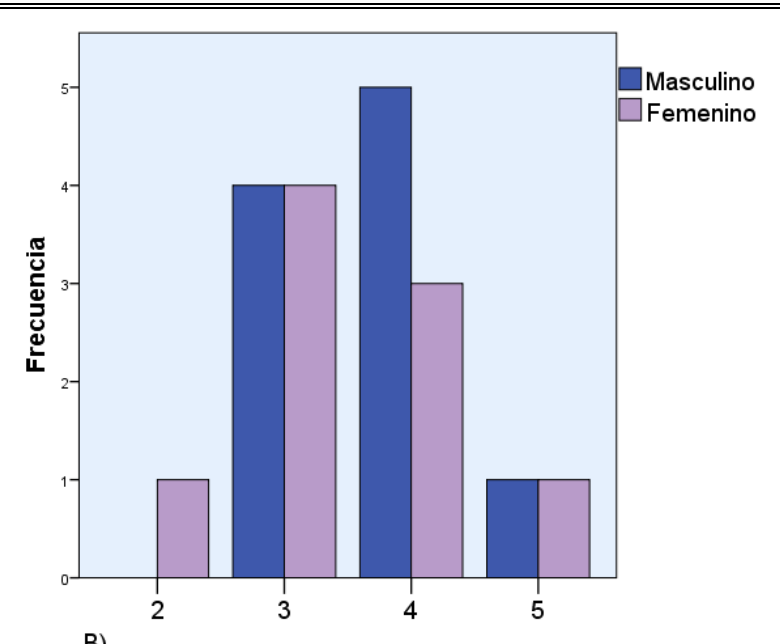

B)

Figura 66: Categorización de los individuos en función del sexo para la rotación interna A) Grupo 1

B) Grupo 2
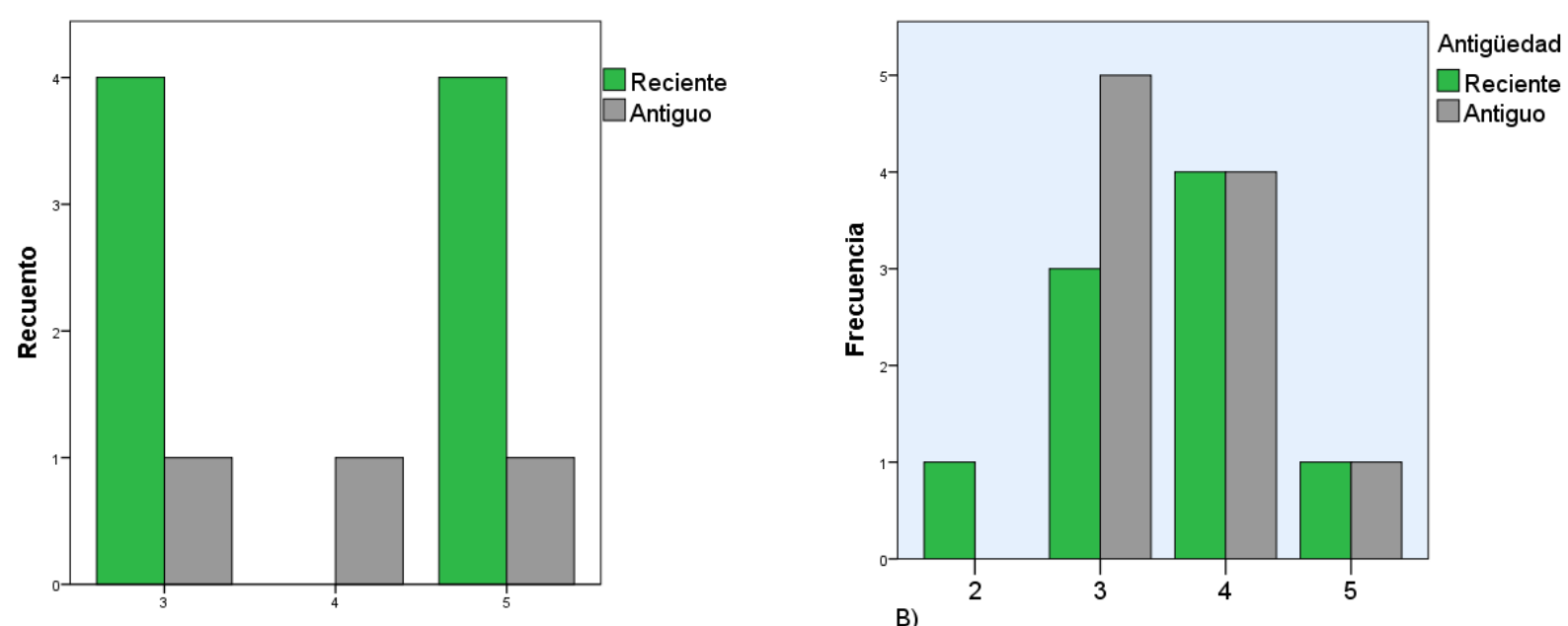

Figura 67: Categorización de los individuos en función de la antigüedad de aparición para la rotación interna A) Grupo 1

B) Grupo 2 


\section{ANEXO 5}

\section{CATEGORIZACIÓN DE LOS INDIVIDUOS AFEC- TADOS DEL HEMICUERPO DERECHO. GRUPOS 1 Y}

2.

\begin{tabular}{|c|c|c|c|c|c|c|c|}
\hline A) & \multicolumn{3}{|c|}{ Abducción } & \multicolumn{2}{|c|}{ B) } & \multicolumn{2}{|c|}{ Extensión } \\
\hline Categoría & Grupo 1 & \multicolumn{2}{|c|}{ Grupo 2} & \multicolumn{2}{|c|}{ Categoría } & & Grupo 2 \\
\hline & Frecuencia & \multicolumn{2}{|c|}{ Frecuencia } & \multirow{2}{*}{\multicolumn{2}{|c|}{$\begin{array}{l}\text { Mucho } \\
\text { peor (1ㅇ) }\end{array}$}} & & Frecuencia \\
\hline $\begin{array}{l}\text { Mucho } \\
\text { peor (1ㅇ) }\end{array}$ & 0 & \multicolumn{2}{|c|}{2} & & & & 1 \\
\hline Peor (2) & & \multicolumn{2}{|c|}{4} & \multicolumn{2}{|c|}{ Peor $\left(2^{\circ}\right)$} & & 2 \\
\hline Igual (3) & 2 & \multicolumn{2}{|c|}{7} & \multicolumn{2}{|c|}{ Igual (3ํ) } & & 10 \\
\hline Mejor (4) & 2 & \multicolumn{2}{|c|}{12} & \multicolumn{2}{|c|}{ Mejor (4) } & & 14 \\
\hline $\begin{array}{c}\text { Mucho } \\
\text { mejor (5ㅇ) }\end{array}$ & 3 & \multicolumn{2}{|c|}{4} & \multicolumn{2}{|c|}{$\begin{array}{c}\text { Mucho } \\
\text { mejor (5) }\end{array}$} & & 2 \\
\hline C) & \multicolumn{3}{|c|}{ Flexión } & \multicolumn{2}{|c|}{ D) } & \multicolumn{2}{|c|}{ Rotación Interna } \\
\hline \multirow[t]{2}{*}{ Categoría } & Grupo 1 & \multicolumn{2}{|c|}{ Grupo 2} & \multicolumn{2}{|c|}{ Categoría } & & Grupo 2 \\
\hline & Frecuencia & \multicolumn{2}{|c|}{ Frecuencia } & \multirow{2}{*}{\multicolumn{2}{|c|}{$\begin{array}{l}\text { Mucho } \\
\text { peor (1ํ) }\end{array}$}} & & Frecuencia \\
\hline $\begin{array}{l}\text { Mucho } \\
\text { peor (1ㅇ) }\end{array}$ & 0 & 5 & & & & & 2 \\
\hline Peor $\left(2^{\circ}\right)$ & 3 & 1 & & & $r\left(2^{\circ}\right)$ & & 2 \\
\hline Igual (3ํ) & 0 & 5 & & & $1\left(3^{\circ}\right)$ & & 8 \\
\hline Mejor (4ㅇ) & 1 & 1 & & & $r\left(4^{\circ}\right)$ & & 13 \\
\hline $\begin{array}{c}\text { Mucho } \\
\text { mejor (5) }\end{array}$ & 3 & 6 & & & $\begin{array}{l}\text { cho } \\
\text { r (5) }\end{array}$ & & 4 \\
\hline & & E) & & $\mathrm{ac}$ & nterna & & \\
\hline & & Categoría & & & Grup & & \\
\hline & & & & & Frecue & & \\
\hline & & $\begin{array}{l}\text { Mucho } \\
\text { peor (1ㅇ) }\end{array}$ & & & 1 & & \\
\hline & & Peor (2) & & & 4 & & \\
\hline & & Igual (3을 & & & 9 & & \\
\hline & & Mejor (4ㅇ) & & & 12 & & \\
\hline & & $\begin{array}{l}\text { Mucho } \\
\text { mejor (5) }\end{array}$ & & & 3 & & \\
\hline
\end{tabular}

Tabla 53: Categorización individuos grupos 1 y 2 hemicuerpo derecho 


\section{ANEXOS}

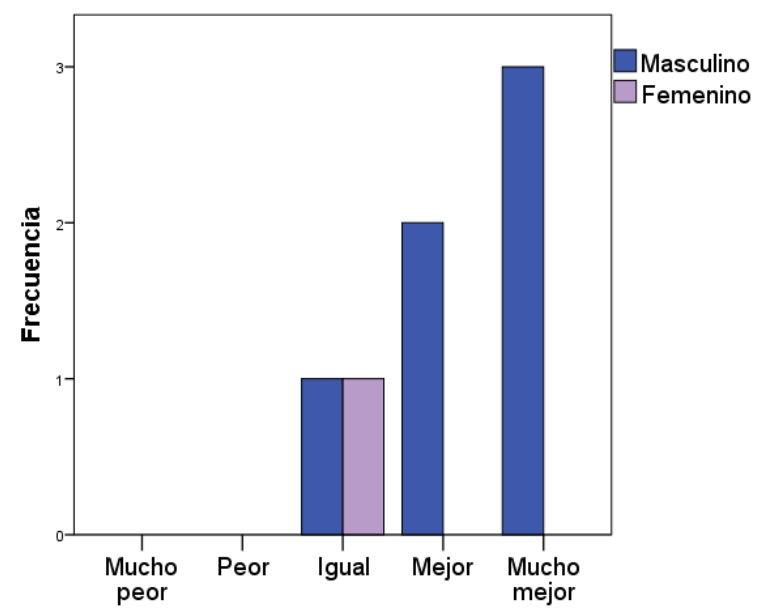

A)

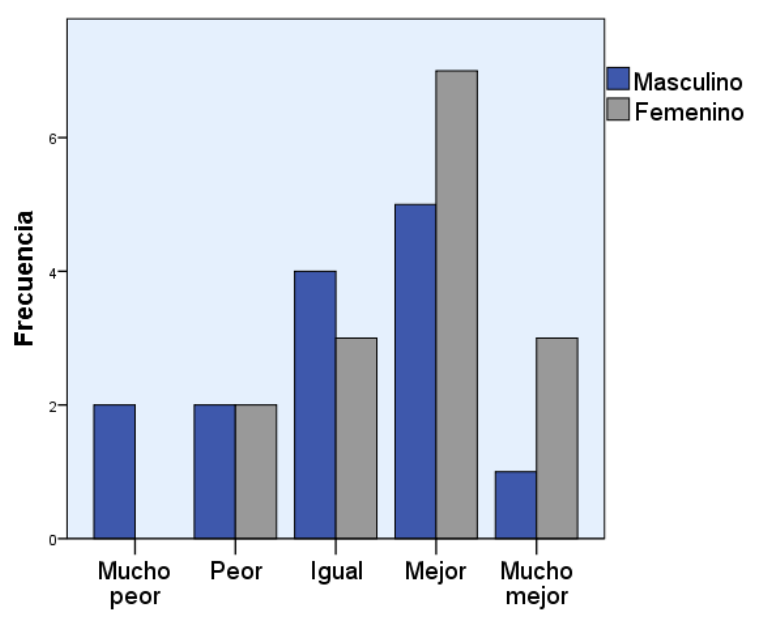

B)

Figura 68: Categorización de los individuos en función del sexo para la abducción

A) Grupo 1

B) Grupo 2
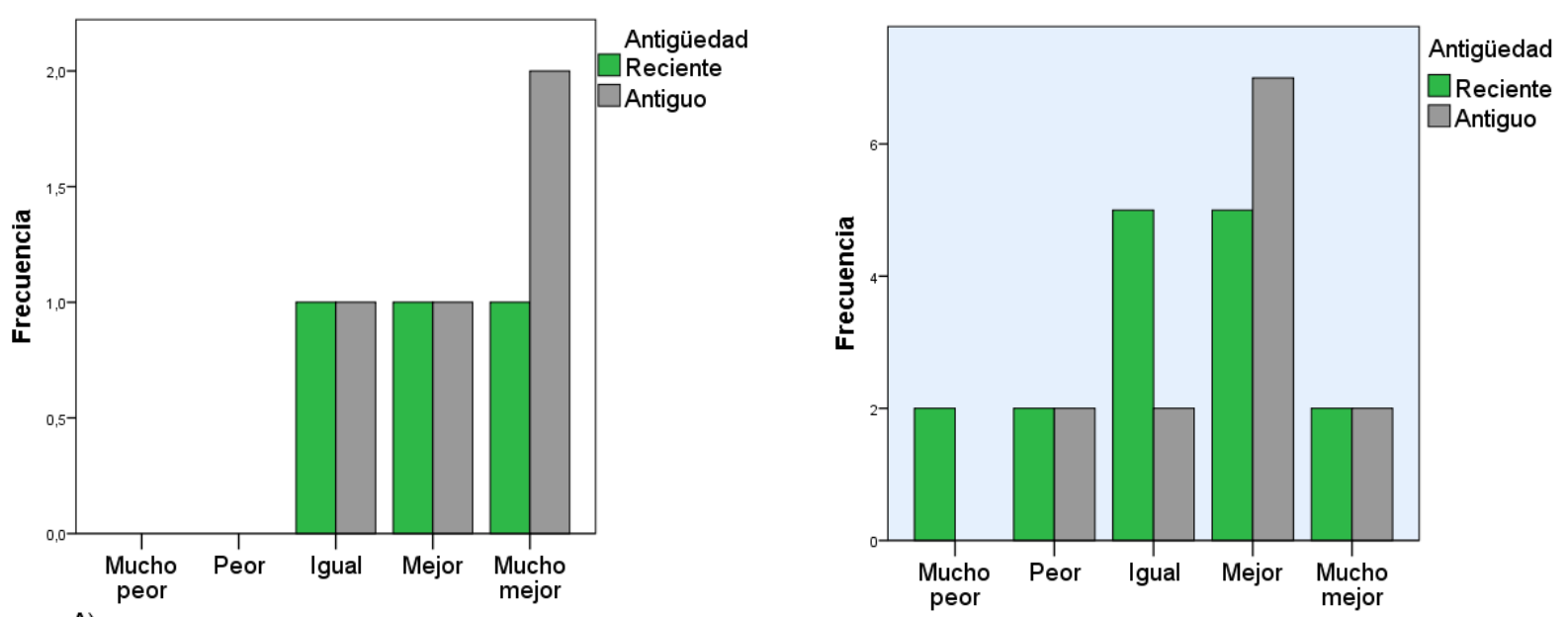

B)

Figura 69: Categorización de los individuos en función de la antigüedad de aparición para la abducción

A) Grupo 1

B) Grupo 2 
ANEXOS
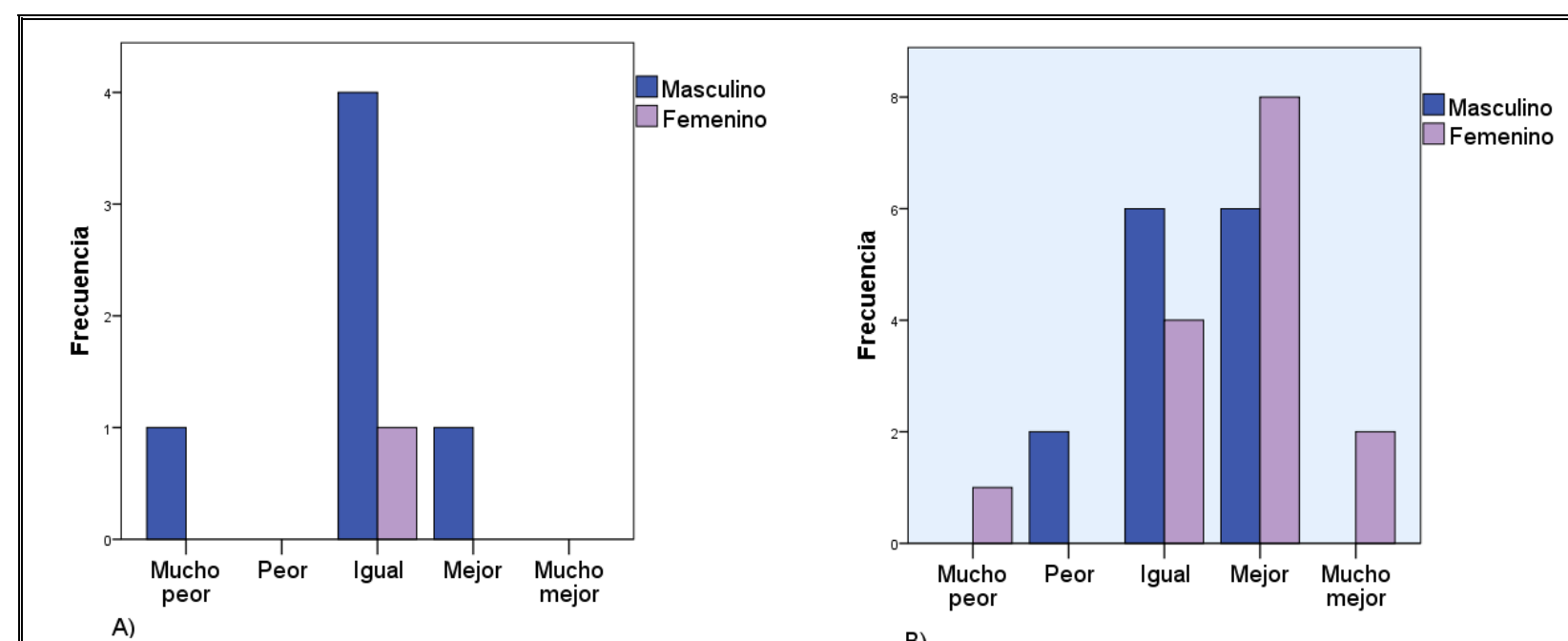

B)

Figura 70: Categorización de los individuos en función del sexo para la extensión

A) Grupo 1

B) Grupo 2
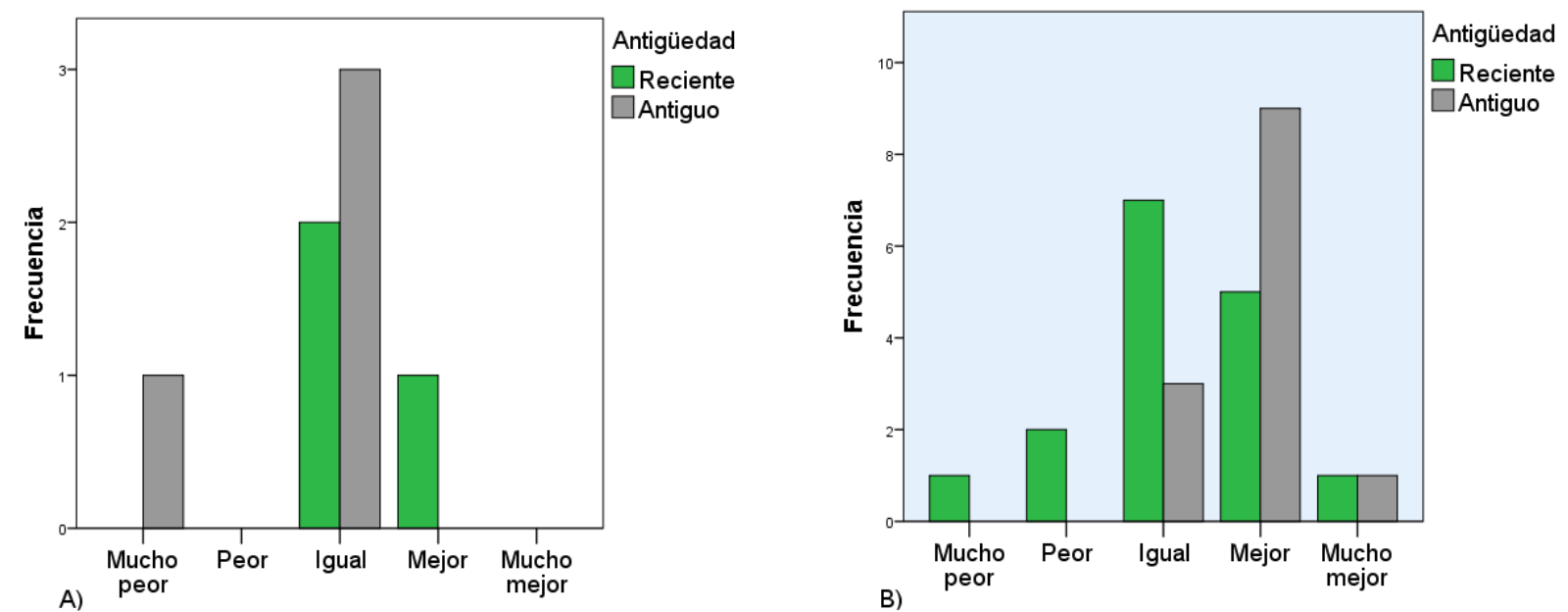

Figura 71: Categorización de los individuos en función de la antigüedad de aparición para la extensión A) Grupo 1 


\section{ANEXOS}
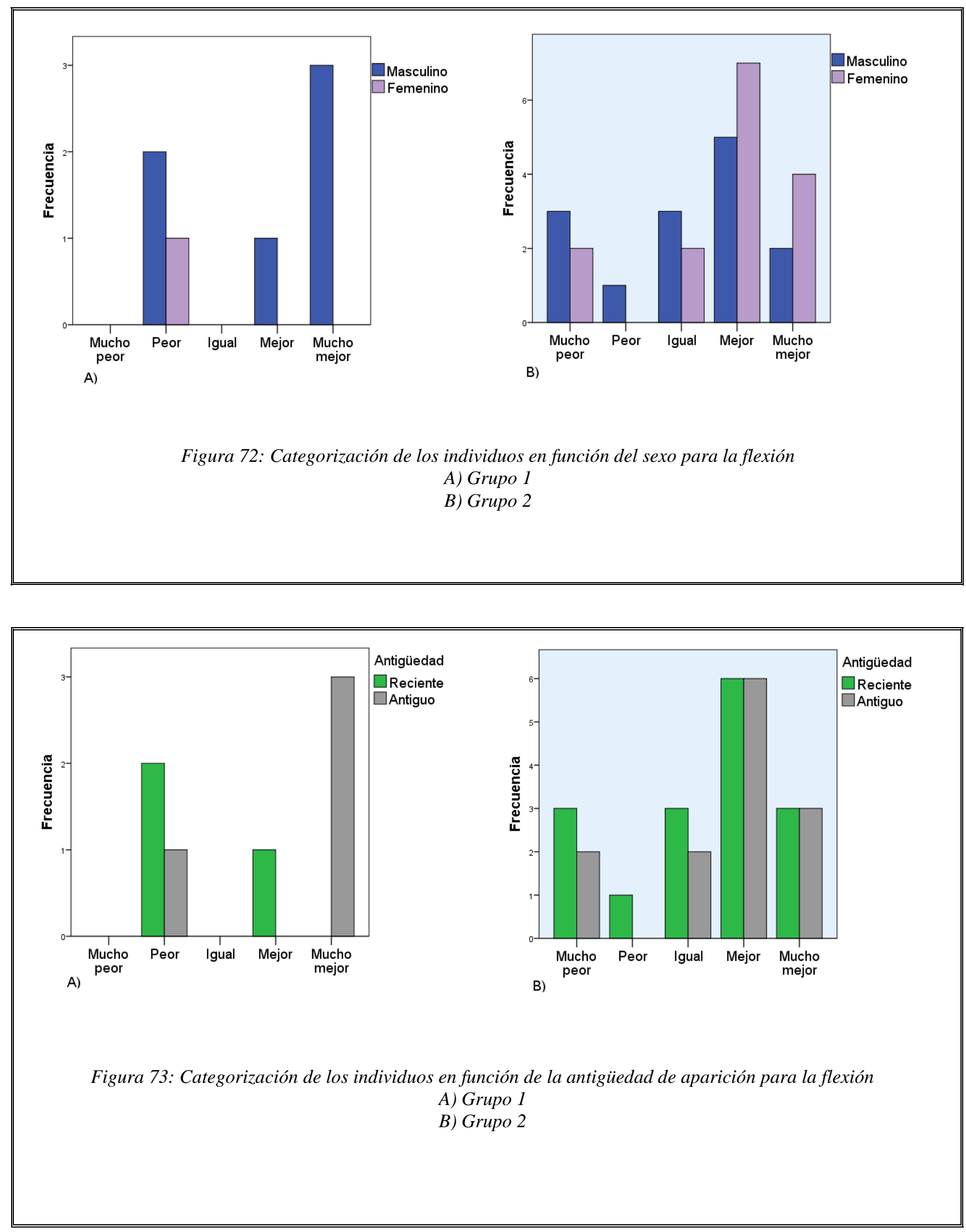

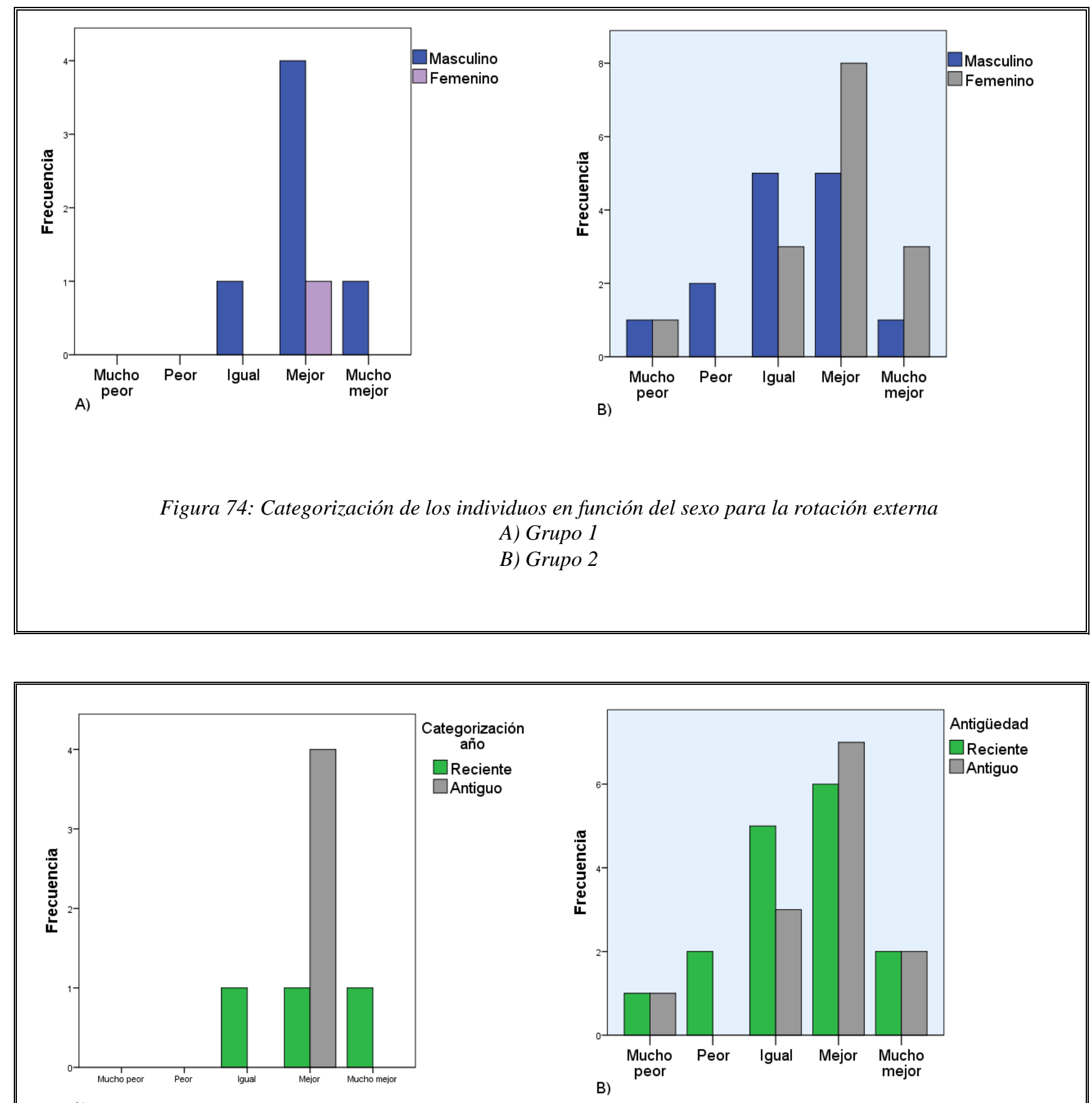

A)

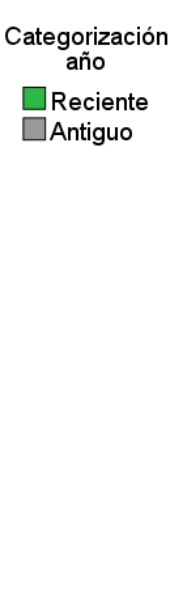

A) Grupo 1

Figura 75: Categorización de los individuos en función de la antigüedad de aparición para la rotación externa A) Grupo 1 


\section{ANEXOS}
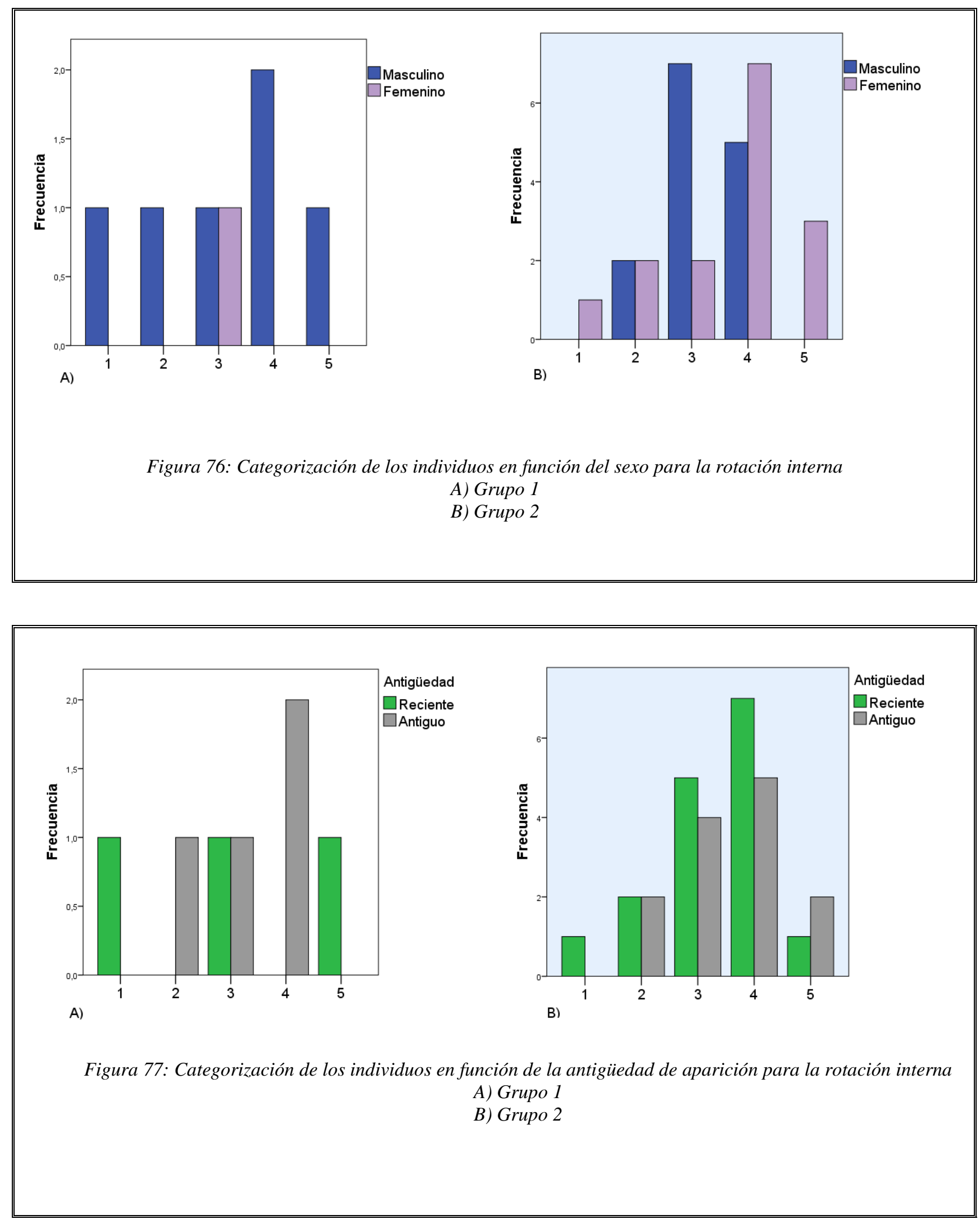


\section{BIBLIOGRAFÍA}

1. Stokes M, Stack E. Fisioterapia en la rehabilitación neurológica. Ámsterdam ; Barcelona: Elsevier, D.L.; 2013. 426 p.

2. Bisbe Gutiérrez M, Santoyo C, Segarra Vincenç T. Fisioterapia en neurología : procedimientos para restablecer la capacidad funcional. Buenos Aires: Editorial Médica Panamericana; 2012. 223 p.

3. Párraga Bermejo JL. Cuidados al paciente con alteraciones neurológicas. Madrid: Difusión Avances de Enfermería; 2011. 379 p.

4. Václav V, Annegret P. El principio Vojta. In Barcelona: Springer; 1995. (I, II, III).

5. Bobath. Evaluación de los patrones motores para el examen inicial, la planificación del tratamiento y el progreso. In: Hemiplegia del adulto: Evaluación y tratamiento. 3rd ed. Buenos Aires: Panamericana; 1993. p. 192.

6. Clasificación internacional del Funcionamiento, la Discapacidad y de la Salud [Internet]. Available from:http://sid.usal.es/idocs/F8/8.4.1-3428/8.4.13428.pdf

7. Juan García FJ [Coord]. Evaluación Clínica y Tratamiento de la Espasticidad. Buenos Aires ; Madrid [etc.]: Editorial Médica Panamericana, D.L.; 2009. 187 p.il.

8. Kapandji I .Fisiología articular: esquemas comentados de mecánica humana. Hombro, codo, pronosupinación, muñeca, mano. 6th ed. Madrid: Editorial Médica Panamericana; 2006.

9. Fundamentos de la terapia Vojta [Internet]. Available from: http://www.vojta.com/es/principio-vojta/terapia-vojta/fundamentos

10. Pérez Ares J, Sainz De Murieta Rodeyro J, Varas de la Fuente AB. Fisioterapia del complejo articular del hombro: evaluación y tratamiento de los tejidos blandos. Barcelona: Masson, imp.; 2004. 280 p. 


\section{BIBLIOGRAFÍA}

11. Amoza S. Fisiopatología y tratamiento. En: Castillo Sánchez J, Jiménez Martín I, et al, editores. Reeducación funcional tras un ictus. Barcelona: Elsevier España; 2015. 273 p. : il.

12. Gabbe BJ, Cameron Peter A, Finche CF. The status of the Gasgow Coma Scale. Emergency Medicine 2003; 15: 353-360.

13. Leonavicius R, Adomaitiene V. Features of sleep disturbances in multiple sclerosis patients. Psychiatria Danubina. 2014 Sep 26;3:249-55.

14. Bravo Amaro M [et al.]. Manual de cardiología para enfermeras. In Vigo: [s.n.]; 2006. p. 365 p.il.

15. Test de Wriht [Internet]. Available from: http://www.fisaude.com/videos/fisioterapia-profesional/tests-compresion-en-desfiladeros-cervicobraquiales/testde-wriht.html

16. Test de Adson [Internet]. Available from: http://www.fisaude.com/videos/fisioterapia-profesional/tests-compresion-en-desfiladeros-cervicobraquiales/test-de-adson.html.

17. Special Tests for Thoracic Outlet Syndrome [Internet]. Available from: https://www.youtube.com/watch?v=YN1jdnWJ2iY.

18. Exploración de hombro - Maniobras Manguito Rotador [Internet]. Avaible from: https://www.youtube.com/watch?v=WO7B6mELyq0

19. De Toro J. Exploración del hombro [Internet]. Available from: https://www.youtube.com/watch?v=PfpI_FKBQoc

20. Exploracion del hombro:3.Maniobra de Hawkins Kennedy [Internet]. Available from: https://www.youtube.com/watch?v=85qFFfTGOEs.

21. Pastor Gómez I. El daño cerebral sobrevenido: un abordaje transdisciplinar dentro de los servicios sociales. Acquired Brain Damage: A Transdisciplinary Social Services Source: /. Intervencion Psicosocial PsychosocialIntervention. 2008; 17(3):237-44.

22. López de Arróyabe Castillo E, Calvete Zumalde E. Daño cerebral adquirido: percepción del familiar de las secuelas y su malestar psicológico. Acquired brain injury: Family perceptions of the sequels and their psychological distress. Clínica y Salud. 2013 Mar;24, Issue 1(1):27-35. 
23. Lezak MD. Brain Damage is a family affair. Journal of Clinical and Experimental. Neuropsychology 1988. 1(10):111-23.

24. Perales López L, Pérez Gorricho A, Varela E. Efecto de la terapia Vojta en la rehabilitación de la marcha en dos pacientes adultos con daño cerebral adquirido en fase tardía. Fisioterapia. 2009;31:151-62

25. Loáiciga Espeleta C. La terapia Vojta como herramienta de tratamiento de las alteraciones neuromotoras en la marcha de niños y adultos. [Salamanca (España)]: Universidad de Salamanca; 2014.

26. Martínez Marín M, Moreno Hernández F, Ruiz Pérez LM. Control y aprendizaje motor. Madrid: Síntesis D.L.; 1999.

27. Barbany J. Fisiología del ejercicio físico y el entrenamiento. 2nd ed. Badalona: Paidotribo; 2006. 192 p.

28. Díaz López D. Terapia celular en el sistema nervioso central: recuperación estructural y funcional en un modelo murino de muerte neuronal selectiva. [Salamanca (España)]: Universidad de Salamanca; 2011.

29. Altman J. Are new neuronsformed in the brains of adult mammals? Science. 1962;(135) 1127-8.

30. Altman J, Bayer SA. Prenatal development of the cerebellar system in the rat. II. Cytogenesis and histogenesis of the inferior olive, pontine gray, and the precerebellar reticular nuclei. View issue TOC. May 1978.179(1). 49-75

31. Altman J. Autoradiographic and histological studies of postnatal neurogenesis. IV. Cell proliferation and migration in the anterior forebrain, with special reference to persisting neurogenesis in the olfactory bulb. Journal of comparative Neurology. 137:433-57.

32. Altman J. Autoradiographic and histological evidence of postnatal hippocampal neurogenesis in rats. Journal of comparative Neurology. 1964; 319-35.

33. Lledo P, Alonso M, Grubb M. Adult neurogenesis and functional plasticity. Natural Reviews of Neuroscience. 7:179-93.

34. Lois C, García Verdugo J, Álvarez Buylla A. Chainmigration of neuronal precursors. Science. 271:978-81. 


\section{BIBLIOGRAFÍA}

35. González Granero S, Capilla V, Lezameta M, García Verdugo J. Aspectos comparados de la neurogénesis y migración tangencial al bulbo olfatorio. La olfacción en España. 2006; 155-70.

36. Polonio López B, Romero Ayuso M. Terapia ocupacional aplicada al daño cerebral adquirido. Buenos Aires, Madrid [etc.]: Editorial Médica Panamericana, D.L.; 2010. 509 p.

37. Latarjet M, Ruiz liard A. Configuración interna y sistematización de la médula espinal. In: Anatomía Humana. Madrid: Ed. Médica Panamericana; 2004. p. 252-61.

38. Castellanos Ballesteros JJ. Sistema motor. Vía Piramidal. In: Lecciones de neuroanatomía. Sevilla: Universidad de Sevilla; 1999. p. 259-62.

39. Lawrence D, Kuypers H. The functional organization of the motor system in the monkey. I. The effects of bilateral piramidal lesions. Brain. 1968 Mar;1(91):1-14.

40. Lemon R, Landau W, Lawrence D, Tutssel D. Revisited: copies of the original filmed material from their classic papers in Brain. Brain. 2012 Jul;(135):22905.

41. Proteau L, Elliott D. Vision and motor control. Amsterdam; New York: North-Holland: Elsevier; 1992. 478 p.

42. Sherrington CS. Flexion-reflex of the limb, crossed extension-reflex, and réflex stepping and standing. The Journal of Physiology. 1910; 40:28-121.

43. Sherrington CS.Strychnine and réflex inhibition of skeletal muscle. The Journal of Physiology. 1907; 36:185-204.

44. Sherrington CS. Observations on the scratch reflex in the spinal dog. The Journal of Physiology. 1906; 34:1-50.

45. .Shumway-Cook A, Wollacott MH. Motor Control: Theory and practical applications. Baltimore: Lippincott Williams and Wilkins; 2000.

46. Gesell. Developmental pediatrics. Journal of Pediatrics. 1947; 30:188-94.

47. McGraw M. Neuromuscular maturation of the human infant. New York: Hafner; 1945. 
48. Schmidt RA, Lee TD. Motor control and learning: a behavioural emphasis. Champaign: Human Kinetics; 2005.

49. Smith J, Smith R, Zernicke Hay M. Locomotion in exercised and non exercised catscordotomized at two or twelve weeks of age. Experimental Neurology. 1982; 16:394-413.

50. Aruin A, Bernstein N. The biomechanical foundations of a safe labour environment: Bernstein'svision in 1930. Engine Control. 2002;3-18.

51. Rossignol IS, Barbeau H. New approaches to locomotor rehabilitation in spinal cord injury. Annals of Neurology. 1995;37:555-6.

52. Bernstein N. The coordination and regulation of movement. London: Pergamon. 1967;

53. Edelman GM, Sporns O. Solving Bernstein's problem: a proposal for the development of coordinated movement by selection. Child Development 1993. 64:960-81.

54. Lamb Robertson MC, Gillespie WJ, Gillespie LD, Cumming RG, Rowe BH. Interventions for preventing falls in elderly people. Cochrane Data base Syst Rev. 2003; 4.

55. Abernethy, B., Kippers, V., Hanrahan, S. J., Pandy, M. G., McManus, A. M., \& Mackinnon, L. (1996). The Biophysical Foundations of Human Muvement, Human Kinetties. Australia: The University of Queensland.

56. Feller, J. A., Webster, K. E. Proprioception and Anterior Cruciate Ligament Reconstruction. The Anterior Cruciate Ligament: Reconstructon and Basic Science. 1st edition. Philadelphia: Saunders. Elsevier. 2008.

57. Strap M. Functionalneuroanatomy of implicitlearning: associative, motor, and habit. RevNeurol. 2007;44:234-42.

58. Magill RA. Motor learning and control: concepts and applications. McGrawHill. 2007.

59. Schmidt RA, Wrisberg CA. Motor Learning and Performance: A Problem-based Learning Approach. Human Kinetics. Champaign; 2004.

60. Molina-Rueda F, Perez-Cruz S. Reflections on physiotherapy: motor learning, how to learnourpatients. Issues of physiotherapy. 2010;39:211-8. 


\section{BIBLIOGRAFÍA}

61. Gibson JJ. Theecologicalapproach to visual perception. Boston: Houghton Mifflin; 1979.

62. Greene PH. Why is it easy to control your arms. J MotBehav. 1982;260-86

63. León-Carrión J. Artificial neural networks and Luria neuro psychological theory. Spanish Journal of Neuropsychology. 2002;4:168-78.

64. Baron RJ. The brain computer. London: Lawrence Erlbaum; 1987.

65. Mc Clelland JL, Rumelhart JL. DCs memory and representation of general and specific information. The Quarterly journal of experimental psychology. 1996(114):159-88.

66. Morris RGM, et al. Elements of a neurobiological theory of the hippocampus: the role of acivity-dependent synaptic plasticity in the memory. Philosophical Transactions of the Royal Society of Lond- Serie B. 2003; 358:773-86.

67. Blake D., Byl N., Merzenich M. Representation of the hand in the cerebral cortex. Behavioral Brain Research. 2002; 135:179-84.

68. Kandel E. Psychotherapy and the single synapse: the impact of psychiatrict hought on neurobiological research. op.cit.

69. Kandel E. The molecular biology of memory storage: a dialogue between genes and synapses. Science. 2001;294:1030-8.

70. Cheung V., Spielman R. Thegenetics of variation in gene expression. Nature GeneticsS upplement. 2002;32:522-5.

71. Mafistretti P, Ansermet F. El oso polar y la ballena. Apuestas de la plasticidad. In: A cada cual su cerebro Plasticidad neuronal e inconsciente. Katz editores. Argentina, España; 2006. p. 237.

72. Sánchez de Muniain P. El largo camino hacia la normalidad. In: Detección de la parálisis cerebral infantil en el primer año de vida Temario. Madrid: Servicios empresariales. S.L; p. 99-144.

73. Delval J. El estudio del desarrollo humano. In: El desarrollo humano. 8th ed. Madrid: Siglo XXI de España Editores; 2008. p. 23-51.

74. Coriat LF. Maduración psicomotriz en el primer año del niño. Editorial Hemisur; 1974. $170 \mathrm{p}$. 
75. Bobath B. Introducción. In: Desarrollo motor en distintos tipos de parálisis cerebral. 6th ed. Argentina: Editorial médica panamericana S.A; 1987. p. 11-2.

76. Bobath B. Base neurofisiológica para el tratamiento de la parálisis cerebral. 2nd ed. Madrid: Editorial médica panamericana S.A; 1982. 133 p.

77. Covos Álvarez P. ¿Qué le ocurre a mi hijo? Delimitación de conceptos. In: El desarrollo psicomotor y sus alteraciones. 1st ed. Madrid: Ediciones Pirámide; 2007. p. 13-40.

78. Arroyo Riaño M., Espinosa Jorge J. Parálisis cerebral. In: Rehabilitación infantil. Madrid: Editorial médica panamericana S.L; 2012. p. 137-52.

79. Tractos Extrapiramidales; Sistema Extrapiramidal [Internet]. Available from: http://www.lookfordiagnosis.com/mesh_info.php?term=Tractos+Extrapira$\underline{\text { midales\&lang=2 }}$

80. Esteban Hernández J, San Román Montero JM. Bloque I. Epidemiología y Fisiopatología de la cardiopatía isquémica. In: Factores de riesgo en la Cardiopatía isquémica. 28 may. 2010. Madrid: Librería-Editorial Dykinson, 28 may. 2010 - 280 páginas; p. 13-72.

81. Fernández Pardal MM, Bonardo P. Enfermedad cerebrovascular isquémica. In: Neurología. Argentina: Ed. Médica Panamericana; 2010. p. 39-68.

82. Davies P. Pasos a seguir. 2ªed. Argentina: Ed. Médica Panamericana; 2003. $544 \mathrm{p}$.

83. Morales F., Capablo JLB, Modrego PJ., Ara JRB, Pina MA. Prevalence of Multiple Sclerosis in the Sanitary District of Calatayud, Northern Spain: Is Spain a Zone of High Risk for this Disease? Neuroepidemiology. 1998;17(September-October):258-64

84. Benton J, Wengel S, Burke W. Depression in Parkinson'sDisease: An Update. In: Parkinson disease and Non motor Dysfunction. 2nd ed. Humana Press; p. 3-128.

85. Micheli FE. Enfermedad de Parkinson y trastornos relacionados. Madrid: Ed. Médica Panamericana; 2006. 628 p.

86. Rodríguez Murillo M. Traumatismo craneoencefálico del niño y adolescente. México: Univ. J. Autónoma de Tabasco; 2007. 102 p. 


\section{BIBLIOGRAFÍA}

87. Pacheco Rodríguez A, Serrano Moraza A. Manejo prehospitalario del síndrome coronario agudo. In: Manual de emergencia médica prehospitalaria. Arán Ediciones; 2001. p. 107-20.

88. Anton Adams H. Medicina Interna. In: Medicina de Urgencias. Ed. Médica Panamericana; 2008. p. 4-13.

89. Martin Jadraque L. Cardiopatía Isquémica. Angina de pecho. Infarto de miocardio. 2nd ed. Madrid: Ediciones Norma; 1988. 731 p.

90. Martínez Gil J, Martínez Cañadas J, Fuster Antón I. Lesiones en el hombro y fisioterapia. Madrid: Arán ediciones; 2006. 243 p.

91. Kaltenborn F. Fisioterapia manual extremidades. 10th ed. Madrid, Buenos Aires etc: McGraw Hill- Interamericana; 2001. 293 p.

92. Quesnot A, Chanussot J. Hombro. In: Rehabilitación del miembro superior. 1st ed. Madrid, Buenos Aires, Bogotá etc: Editorial Médica panamericana; 2010. p. 392.

93. Bohannon R, Melissa S. Interrater Reliability of a Modified Ashworth Scale of Muscle Spasticity. Physical Therapy February. 1987;67(2):206-7.

94. Sloan R., Sinclair E, Thompson J, Taylor S, Pentland B. Inter-raterreliability of the modified Ashworth Scale for spasticity in hemiplegicpatients. International Journal of rehabilitationresearch. 1992;15:158-61.

95. Pandyan A, Price I, Barnes P, Johnson R. A biomechanical investigation into the validity of the modified Ashworth Scale as a measure of elbow spasticity. Clinical Rehabilitation. 2003 Mar;17(3):290-4.

96. Fisk J, Pontefract A, Ritvo P, Archibald C, Murray T. The impact of fatigue on patients with multiple sclerosis. The Canadian Journal of Neurological Sciences (Le JournalCanadien des Sciences Neurologique). 1994;21(1):9-14.

97. Barthel, Mahoney FI. Functional evaluation: The Barthel Index. Maryland State Medical Journal. 1965;14:61-5-

98. Granger CV. Atención de la salud. Evaluación funcional del paciente crónico. In: Krusen: Medicina física y rehabilitación. 4th ed. Madrid: Editorial médica Panamericana; 1993. p. 281-94. 
99. Carr JH, Shepherd RB. Fisioterapia en los trastornos cerebrales: guía clínica. Editorial Médica Panamericana.; 1985.

100.Collen F, Wade D, et al. Mobility after stroke: reliability of measures of impairment and disability. Disability\&Rehabilitation. 12(1):6-9.

101.Podsiadlo D, Richardson S. Thetimed "Up \&Go": a test of basic functional mobility for frai lelderly people. Journal of de American Geriatrics Society. $1991 \mathrm{Feb} ; 39(2): 142-8$.

102.Ware JE, Snow KK, Kosinski M, Gandek B. SF-36 Health Survey: manual and interpretation guide. New England Medical Center. Boston. 1993;

103.Harwood RH, Dickinson E, Ebrahin S. The London Handicap Scale: a new out come measure for chronic disease. Qual Health Care. 1994;3:11-6.

104.Alonso Babarro A, González Barón M. Medidas de capacidad funcional. In: Valoración clínica en el paciente con cáncer. Buenos Aires, Madrid etc: Ed. Médica Panamericana; 2006. p. 1-16.

105.Casado Martín D. Problemática de la dependencia. In: Efectos y abordajes de la dependencia: un análisis económico. Barcelona (España): Elsevier España; 2007. p. $1-59$.

106. Wylie C, White B. A measure of disability. Archives of Environmental Health. 1964;8:834-9.

107.Wylie C. Measuring end results of rehabilitation of patients with stroke. Public Health Reports. 1967;82:893-8

108. Mahoney F, Barthel D. Functional evaluation: the Barthel Index. Md Med J. $1965 ; 14: 61-5$.

109.Loewen S, Anderson B. Reliability of theModified Motor Assessment scale and the Barthel Index. Physical Therapy. 1988;68:1077-81.

110.Collin C, Davis S, Horne V, Wade D. Reliability of the Barthel ADL Index. International Journal Rehabilitation Research. 1987;10:356-7.

111.Granger C, Albrecht G, Hamilton B. Outcome of comprehensive medical rehabilitation: measurement by pulses Profile and the Barthel Index. Archives of Physical Medicine and Rehabilitation. 1979;60:145-54. 


\section{BIBLIOGRAFÍA}

112.Wellwood I, Denns M, Warlow C. A comparision of the Barthel Index and the OPCS disability instrument used to measure outcome after a cute stroke. Age ageing. 1995;24:54-7.

113.Wade D, Hewer R. Functional abilities after stroke: measurement, natural history and prognosis. Journal of Neurology, Neurosurgery, and Psychiatry. 1987;50:177-82.

114. Shah S, et al. Improving the sensitivity of the Barthel Index for stroke rehabilitation. Journal of clinical Epidemiology. 1989;42:703-9,

115.McGinnis G, Seward M, DeJong G, Scott Osberg M. Program evaluation of physical medicine and rehabilitation departments using self-report Barthel. Archives of Physical Medicine and Rehabilitation. 1986;67:123-5.

116.Baztán J, Pérez del Molino J, Alarcón T, San Cristóbal E, Manzarbeitia I. Índice de Barthel: Instrumento válido para la valoración funcional de pacientes con enfermedad cerebrovascular. Izquierdo G, editor. Revista Española de Geriatría y Gerontología. 1993;28:32-40.

117.Fortinsky R, Granger C, Seltzer G. The use of functional assessment in understanding home care needs. Medical Care. 1981;19:489-97.

118.Stone S, et al. The Barthel Index in clínical practice: use on a rehabilitation Ward for elderly people. Journal of the Royal College of Physicians of London. 1994;28:419-23.

119.Alarcón M, González Montalvo J, Bárcena Álvarez A, Sánchez del Corral Usaola F, Muñoz Cebrián C, Salgado Alba A. Características del "paciente geriátrico" al ingreso en la unidad de agudos de un servicio de geriatría. Revista Española de Geriatría y Gerontología. 1993;28:285-90.

120.Trust Study Group. Randomised, double-blind, placebo-controlled trial of nimodipine in acutes troke. Lancet. 1990;336:1205-9.

121.Cid Ruzafa J, Damián Moreno J. Valoración de la discapacidad física. El índice de Barthel. Revista Española de Salud Pública Madrid Mar/Abr. 1997;71(2).

122. Research Foundation State University of New York. Guide for use of the Uniform data set for Rehabilitation. [New York]: University of New York; 1991. 
123. Martín Rodríguez J. Medida de la independencia funcional. Coslada (Madrid): Hospital Monográfico Asepeyo.

124.Baldry Currents J, Coats T. The timing of disability mesurements following injury. Injury. 2000;31:93-8.

125.Baldry Currents J. Evaluation of disability and hándicap following injury. Injury. 2000;31:99-106.

126.Daving Y, Andren E, Nordholm L, Grimby G. Reliability of an interview approach to the Functional Independence Measure. Clinical Rehabilitation. 2001;15:301-10.

127.Van der Putten J, Hobart J, Freeman J, Thompson A. Measuring change in disability after in patient rehabilitation: comparison of the responsiveness of the Barthel index and the Functional Independence Measure. Journal of Neurology, Neurosurgery, and Psychiatry. 1999;66:480-4.

128.Pollak N, Rheault W, Stoecker J. Reliability and validity of the FIM for persons aged 80 years and a above from a multilevel continuing care retirement community. Archives of Physical Medicine and Rehabilitation. 1996;77:105661.

129.Grimby G, Gudjonsson G, Rodhe M, Sunnerhagen K, Sundh V, Ostensson M. The functional Independence measure in Sweden: experience for outcome measurement in rehabilitation medicine. Scandinavian Journal of Rehabilitation Medicine. 1996;28:51-62.

130.Villagut G, Valderas JM, Ferrer M, Garín A, López García D, Alonso A. Interpretación de los cuestionarios de salud SF-36 y SF-12 en España: componentes físico y mental. Medicina Clínica. 130(19):740-1.

131.Ware J, Sherbourne C. The MOS 36-item short-form health survey (SF-36) Conceptual frame work and ítem selection. Medical Care. 1992;30:473-83.

132.Ware J. SF-36 health survey update. Spine. 25:3130-9.

133.Ware JJ, Snow K, Kosinski M, Gandek B. SF-36 Health Survey: manual and interpretation guide. Boston: New England Medical Center. 1993. 


\section{BIBLIOGRAFÍA}

134.Alonso J, Prieto L, Ferrer M, Vilagut G, Broquetas J, Roca J. Testing the measurement properties of the Spanish version of the SF-36 Health Survey among male patients with chronic obstructive pulmonary disease. Quality of Life in COPD Study Group. Journal of Clinical Epidemiology. 1998;51:108794.

135.Failde I, Ramos I. Validity and reliability of the SF-36 Health Survey Questionnaire in patients with coronary artery disease. Journal Clinical Epidemiology. 2000;53:359-65.

136.Buckup K, Johannes B. Pruebas clínicas para patología ósea, articular y muscular. Exploraciones, signos y síntomas. 5th ed. Elsevier; 2012.

137.Nara I. Ejercicios básicos fisioterapéuticos en accidentes cerebrovasculares. In: Manual de fisioterapia en accidentes cerebrovasculares. 1st ed. Madrid: Ibersaf Editores; 2003. p. 73-7.

138. Adler S., Beckers D, Buck M. La Facilitación Neuromuscular Propioceptiva en la práctica. Guía ilustrada. 2nd ed. Argentina, Colombia, España etc: Editorial médica panamericana; 2002.

139.Viel E. El método Kabat: facilitación neuromuscular propioceptiva. 1st ed. Barcelona: Masson; 1994. 158 p.

140. Kisner C, Colby LA. Amplitud del movimiento. Movilidad. In: Ejercicio terapéutico. Fundamentos y técnicas. 1st ed. Barcelona: Editorial Paidotribo; 2005.

141.Available from: http://fisioterapiauax.pbworks.com/f/Vojta(3).pdf.

142. Machuca Murga F, León-Carrión J, Barroso y Martín JM. Eficacia de la rehabilitación neuropsicológica de inicio tardío en la recuperación funcional de pacientes con daño cerebral traumático. Revista Española de Neuropsicología. 2006;8(3-4):81-103.

143.Available from: https://fedace.org/epidemiologia_dano_cerebral.html.

144.Available from: http://www.asdace.org/index.php/que-es-el-dca

145.Available from: http://pilerite.com/posicion-anatomica

146.Wanklyn P. The painful hemiplegic shoulder: Pathogenesis, diagnosis and management. Reviews in Clinical Gerontology. 1994;4:245-51. 
147.Cano de la Cuerda R, Molero- Sánchez A, Carratalá-Tejada M, AlguacilDiego I., Molina-Rueda F, Miangolarra-Page J., et al. Theories and control models and motor learning: clinical applications in neuro-rehabilitation. Neurología. 2015;30(1):32-41

148. Sánchez Fernández R, Conejero Casares JA, Canto Elías F. Medición del balance articular. Sistema SFTR. Barcelona. España: Elsevier Doyma; 2014. 97 p.

149.Hernando Rosado A, Useros Olmo AI. Métodos fisioterápicos aplicados a pacientes adultos con daño cerebral adquirido. Revista de la Facultad de Ciencias de la Salud [Internet]. 2008 Jun;6(Universidad Alfonso X el Sabio). Available from: $\quad$ http://www.uax.es/publicaciones/archivos/CCSREV08_001.pdf

150.Amelivia Rodríguez M.A. Tratamiento rehabilitador de los traumatismos craneoencefálicos en la fase aguda. Revista Rehabilitación. 2002;36(6):321-6

151.García Díez E. Fisioterapy of the spasticity: technicals and methods. Fisioterapia. 2004;26(1):25-35.

152.Brunnstrom S. Movement Therapy in Hemiplegia. Londres: Harper\&Row. 1970.

153.Bobath B. Adult Hemiplegia: evaluation and treatment. Oxford: ButterworthHeinemann. 1990.

154.Flórez García MT. Intervenciones para mejorar la función motora en el paciente con ictus. Rehabilitación. 2000;34(6):423-37.

155.Carr J, Shepherd R. A motor relearning programme for stroke. Rockville: Aspen System. 1987.

156.Carr J, Shepherd R. Neurological Rehabilitation: optimizing motor performance. Oxford: Butterworth Heinemann. 1998.

157. Objective Range of Motion Measurement of all Joints. Instruction in Application of the Bi-level Inclinometer [Internet]. ISOMED; July 24. Available from: www.isomed.us 


\section{BIBLIOGRAFÍA}

158.Perales López L, García Heras A, Delgado I, Lara Romero M. Efecto de la terapia de locomoción refleja combinada con el tratamiento de fisioterapia en lesión medular. Presentación de un caso Effects of reflex locomotion therapy in addition to physiotherapy spinal cord injuries. A case report. Fisioterapia. 2011;33(3):126-30.

159. Creutzfeldt CJ, Holloway RG, Walker M. Journal of General Internal Medicine [Internet]. 2012;27(7):853-60. Available from:http://doi.org/10.1007/s11606-011-1966-4

160.Lingren I, Jönsson AC, Norrving B, Lindgren A. Shoulder pain after stroke: a prospective population-based study. Stroke. 2007 Feb;38(2):343-8.

161.Van Peppen RP, Kwakkel G, Wood-Dauphinee S, Hendriks HJ, Van der Wees PJ, Dekker J. Clinical Rehabilitation. 2004 Dec;18(8):833-62.

162. Singh JA, Fitzgerald PM. Botulinum toxin for shoulder pain. Cochrane Database Syst Rev. 2010 Sep 8;(9):CD008271.

163.Koog TH, Jin SS, Yoon K, Min BI. Interventions for hemiplegic shoulder pain: systematic review of randomised controlled trials. Disability Rehabilitation. 2010;32(4):282-91.

164.Gamble GE, Barberan E, Laasch HU, Bowsher D, Tyrrell PJ, Jones AK. Poststroke shoulder pain: a prospective study of the association and risk factors in 152 patients from a consecutive cohort of 205 patients presenting with stroke. European Journal of Pain. 2002;6(6):467-74.

165.Basmajian JV, Bazant FJ. Factors preventing downward dislocation in the adducted shoulder joint. Journal of Bone and Joint Surgery. 1959;41:1182-6.

166.Prevost R, Arsenault AB, Dutil E, Drovin G. Rotation of the scapula and shoulder subluxation in hemiplegia. Archives of Physical Medicine and Rehabilitation. 1987;68:786-90.

167.Ikai T, Yonemoto K, Miyano S, Talejara T. Interval change of the shoulder subluxation in hemiplegic patients. The Japanese Journal of Rehabilitation Medicine. 1992;29:569-75.

168.Culham EG, Noce RR, Bagg SD. Shoulder complex position and glenohumeral subluxation in hemiplegia. Archives of Physical Medicine and Rehabilitation. 1995;76:857-64. 
169.Price CI, Rodgers H, Franklin P, Curless RH, Johnson GR. Glenohumeral subluxation, scapula resting position, and scapula rotation after stroke: a noninvasive evaluation. Archives of Physical Medicine and Rehabilitation. 2001;82:955-60.

170.Zorowitz RD. Recovery patterns of shoulder subluxationafter stroke: a sixmonth follow-up study. Top Stroke Rehabilitation. 2001;8:1-9.

171.Chang JJ, Tsau JC, Lin YT. Predictors of shoulder subluxationin stroke patients. Kaohsiung Journal of Medical Sciences. 1995;11:250-6.

172.Daviet JC, Salle JY, Borie MJ, Munoz M, Rebeyrotte I, Dudognon P. Clinical factors associate with shoulder subluxation in stroke patients. Annales de Réadaptation et de Médecine Physique. 2002;45:505-9.

173.Teasell RW. The painful hemiplegic shoulder. Archives of Physical Medicine and Rehabilitation State Art Rev. 1998;12:489-500.

174.Griffin JW. Hemiplegic shoulder pain. Physical Therapy Journal. 1986;66:1884-93.

175.Hanukah A, Sashimi H, Ohkawa T. Arthrographic findings in hemiplegic shoulders. Archives of Physical Medicine and Rehabilitation. 1984;65:706-11.

176. AncliVe J. Shoulder pain in hemiplegia: incidence and influence on movement and recovery of function. Proceedings 3rd International Physiotherapy Congress. 1990;187-92.

177. Murie-Fernández M, Carmona Iraguia M, Gnanakumarb V, Meyerc M, Foleyc $\mathrm{N}$, Teasell R. Hombro doloroso hemipléjico en pacientes con ictus: causas y manejo. Neurología. 2012;27(4):234-44.

178. Matteo P, Luca N, Lucio A R. Glenohumeral subluxation in hemiplegia: An overview. Journal of Rehabilitation Research \& Development. 2005 JulAug;42(4):557-68. 


\section{BIBLIOGRAFÍA}

179.Cailliet R. The shoulder in hemiplegia. 3rd ed. Philadelphia(PA): FA Davis Company; 1980. 78-86. p.

180.Roy CW, Sand M, Marshall S. The effect of shoulder pain on outcome of acute hemiplejia. Clinical Rehabilitation. 1995;9:21-7.

181.Zorowitz RD, Hughes MB, Idank D, Ikai T, Johnston MV. Shoulder pain and subluxation after stroke: correlation or coincidence? American Journal of Occupational Therapy. 1996;50:194-201.

182.Bender L, McKenna K. Hemiplegic shoulder pain: defining the problem and its management. Disability and Rehabilitation. 2001;44(23):698-705.

183.Moskowitz E. Complications in the rehabilitation of hemiplegic patients. Medical Clinics of North America. 1969;53:541-59.

184.Método Perfetti. [Internet]. Available from: http://www.centroperfetti.com/metodo-perfetti

185.Bassoe Gjelsvik S. The Bobath Concept in Adult Neurology. 2nd ed. New York: Thieme; 2016. 296 p.

186.Álvarez MF. Evaluación y Tratamiento De síndrome de hombro doloroso en hemiplejía Autor: Álvarez, María Fernanda Tutor: Lic. Pirillo, Claudia Año: 2011 [Internet]. [Buenos Aires, Argentina]: Universidad Fasta; 2011. Available

from:http://redi.ufasta.edu.ar:8080/xmlui/bitstream/handle/123456789/543/20 $\underline{11 \_ \text {K } 010 . p d f ? \text { sequence }=1}$

187.Arias Cuadrado Á. Rehabilitation of the stroke: evaluation, prognosis and treatment. Galicia Clínica. 2009;70(3):25-40.

188.Sánchez Blanco. Predictive Model of functional independence in stroke patients admitted to a rehabilitation programme. Clinical Rehabilitation. 1999;13:464-75.

189.Glantz SA. Bioestadística. 6th ed. México; Madrid [etc.]: McGraw Hill; 2006. $520 \mathrm{p}$.

190.Tomás Sábado J. Fundamentos de bioestadística y análisis de datos para enfermería. 1st ed. Barcelona: Universitat Autònoma de Barcelona, Servei de Publicacions; 2009. 146 p. 
191.Mirallas Martínez JA, Real Collado MC. ¿Índice de Barthel o Medida de Independencia Funcional? 2003;37(3):152-7.

192.Harpreet S, Lipson D, Foley N, Salter K, Bhogal S, Pohani G, et al. A comparison of the Barthel Index and the Functional Independence Measure as outcome measures in stroke rehabilitation: patterns of disability scale usage in clinical trials. Original articles. International Journal of Rehabilitation Research. 2005 Jun;28(2):135-9.

193.I-P Hsueh, J-H Lin, J-S Jeng, C-L Hsieh. Comparison of the psychometric characteristics of the functional independence measure, 5 item Barthel index, and 10 item Barthel index in patients with stroke. Journal of neurology neurosurgery and psychiatry. 2002;73:188-90.

194.Gifi, A. Nonlinear Multivartiate Análisis. Chichester: Whiley; 1990.

195.De Leeuw J, Van Rijckervorsel J. HOMALS and PRINCALS- Some generalizations of principal components analysis. In: Data Análisis and Informatics. Ámsterdam: North Holland: Diday et al. (eds); 1980. p. 231-42.

196.Heiser W.J, Meulman J.J. Homogeneity analysis: Exploring the distribution of variables and their nonlinear relationships. In: Correspondence analisys in the social sciences: Recent developments and applications. Nueva Cork. Academia Pres: M. Greenacre y J. Blasius, (Eds); p. 179-209.

197.IBM SPSS Statistics for Windows (version 22.0). Armonk, NY: IBM Corp, 2013.

198.Tomalá Robles J. Evaluación de la Calidad y Nivel de Satisfacción de los Servicios Básicos en la parroquia Letamendi de la ciudad de Guayaquil [Tesis de grado]. [Escuela Superior Politécnica del litoral]: Instituto de ciencias matemáticas; 2002.

199.Headquarters, 233 S. Wacker Drive. 11th floor. Chicago, Illinois 60606.

200.López García E, Banegasa JR, Pérez Regadera AG, Guitiérrez Fisaca JL, Alonso J, Rodríguez Artalejo F. Population-based reference values for the Spanish version of the SF-36 Health Survey in the elderly. Medicina Cínica. Abril 23;120(15):568-73. 